\title{
Understanding and Supporting 'Families with Complex Needs'
}

Edited by

Nathan Hughes and

Carolina Munoz-Guzman

Printed Edition of the Special Issue Published in Social Sciences 
Nathan Hughes and Carolina Munoz-Guzman (Eds.)

\section{Understanding and Supporting 'Families with Complex Needs'}


This book is a reprint of the Special Issue that appeared in the online, open access journal, Social Sciences (ISSN 2076-0760) in 2015 (available at:

http://www.mdpi.com/journal/socsci/special_issues/families).

\section{Guest Editors}

Nathan Hughes

School of Social Policy, The University of Birmingham, UK

Melbourne School of Government, The University of Melbourne, Australia

Centre for Adolescent Health, Murdoch Childrens Research Institute, Australia

Carolina Munoz-Guzman

School of Social Work, Universidad Católica de Chile, Chile

Editorial Office

MDPI AG

Klybeckstrasse 64

Basel, Switzerland

Publisher

Shu-Kun Lin

Assistant Editor

Siyang Liu

\section{Edition 2016}

MDPI $\bullet$ Basel $\bullet$ Beijing $\bullet$ Wuhan $\bullet$ Barcelona

ISBN 978-3-03842-159-7 (Hbk)

ISBN 978-3-03842-160-3 (PDF)

(C) 2016 by the authors; licensee MDPI, Basel, Switzerland. All articles in this volume are Open Access distributed under the Creative Commons Attribution License (CC BY), which allows users to download, copy and build upon published articles even for commercial purposes, as long as the author and publisher are properly credited, which ensures maximum dissemination and a wider impact of our publications. However, the dissemination and distribution of physical copies of this book as a whole is restricted to MDPI, Basel, Switzerland. 


\section{Table of Contents}

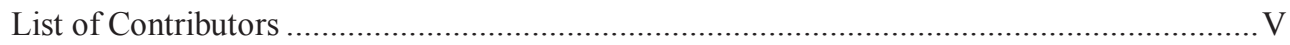

About the Guest Editors.............................................................................................. VII

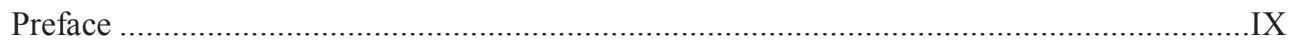

\section{Nathan Hughes and Carolina Munoz-Guzman}

Understanding and Supporting "Families with Complex Needs": An Editorial

Reprinted from: Soc. Sci. 2015, 4(4), 1335-1339

http://www.mdpi.com/2076-0760/4/4/1335 .XI

Rubina Jhadray, Gráinne Fadden, Martin Atchison, Paula Conneely, Julia Danks, Alison Lee and Chris Mansell

Applying the Behavioural Family Therapy Model in Complex Family Situations

Reprinted from: Soc. Sci. 2015, 4(2), 459-468

http://www.mdpi.com/2076-0760/4/2/459 1

\section{Maria Tsekoura}

"Providing a Roof That Allows One to Dream of a Better Life": A Case Study of Working with Families in Extreme Poverty

Reprinted from: Soc. Sci. 2015, 4(2), 260-275

http://www.mdpi.com/2076-0760/4/2/260

\section{Rayen Cornejo Torres and Ariel Rosales Ubeda}

Objective Structures and Symbolic Violence in the Immigrant Family and School

Relationships: Study of Two Cases in Chile

Reprinted from: Soc. Sci. 2015, 4(4), 1243-1268

http://www.mdpi.com/2076-0760/4/4/1243

\section{Elena Cabiati}

The Need for Participative Interventions in Child Protection: Perspectives from Nuevo León State

Reprinted from: Soc. Sci. 2015, 4(2), 393-420

http://www.mdpi.com/2076-0760/4/2/393 .... 
Carolina Muñoz-Guzmán, Candice Fischer, Enrique Chia and Catherine LaBrenz

Child Welfare in Chile: Learning from International Experiences to

Improve Family Interventions

Reprinted from: Soc. Sci. 2015, 4(1), 219-238

http://www.mdpi.com/2076-0760/4/1/219 .84

\section{Ahmet Gümüscü, Lennart Nygren and Evelyn Khoo}

Bringing the Family Back in: On Role Assignment and Clientification in the

Swedish Social Services

Reprinted from: Soc. Sci. 2015, 4(1), 117-133

http://www.mdpi.com/2076-0760/4/1/117 105

\section{Rolv Lyngstad}

Different Welfare System-Same Values? How Social Work Educators in Norway, Chile and Argentina Comprehend Core Social Work and Social Policy Issues

Reprinted from: Soc. Sci. 2015, 4(1), 239-259

http://www.mdpi.com/2076-0760/4/1/239

\section{Eva K. Robertson}

"Como Arrancar una Planta": Women's Reflections about Influences of Im/Migration on Their Everyday Lives and Health in Mexico

Reprinted from: Soc. Sci. 2015, 4(2), 294-312

http://www.mdpi.com/2076-0760/4/2/294

\section{Natalia Hanley and Leah Ruppanner}

Understanding the Effects of Crime on Women: Fear and Well-Being in the Context of Diverse Relationships

Reprinted from: Soc. Sci. 2015, 4(2), 276-293

http://www.mdpi.com/2076-0760/4/2/276

\section{Cristina González}

Social Policies in Contemporary Latin America: Families and Poverty in the

Social Protection Systems

Reprinted from: Soc. Sci. 2015, 4(1), 134-147

http://www.mdpi.com/2076-0760/4/1/134 


\section{List of Contributors}

Martin Atchison: The Meriden Family Programme, Birmingham and Solihull Mental Health Foundation Trust, Tall Trees, The Uffculme Centre, Birmingham B13 8QY, UK.

Elena Cabiati: Department of Sociology, Catholic University of Milan, Largo A. Gemelli 1, Milano 20123, Italy.

Enrique Chia: School of Psychology, Pontificia Universidad Católica de Chile, Avda, Vicuña Mackenna 4860 Macul, Santiago 781000, Chile.

Paula Conneely: The Meriden Family Programme, Birmingham and Solihull Mental Health Foundation Trust, Tall Trees, The Uffculme Centre, Birmingham B13 8QY, UK.

Rayen Cornejo Torres: School of Social Work, Pontificia Universidad Católica de Chile, Santiago 781000, Chile.

Julia Danks: The Meriden Family Programme, Birmingham and Solihull Mental Health Foundation Trust, Tall Trees, The Uffculme Centre, Birmingham B13 8QY, UK.

Gráinne Fadden: The Meriden Family Programme, Birmingham and Solihull Mental Health Foundation Trust, Tall Trees, The Uffculme Centre, Birmingham B13 8QY, UK.

Candice Fischer: School of Psychology, Pontificia Universidad Católica de Chile, Avda, Vicuña Mackenna 4860 Macul, Santiago 781000, Chile.

Cristina González: Escuela de Trabajo Social, Universidad Nacional de Córdoba, Avenida Valparaíso s/n, Ciudad Universitaria, Córdoba 5000, Argentina.

Ahmet Gümüscü: Department of Social Work, Umeå University, Umeå SE-90187, Sweden.

Natalia Hanley: Department of Criminology, University of Melbourne, 300 Grattan Street, Melbourne VIC 3003, Australia.

Nathan Hughes: School of Social Policy, The University of Birmingham, UK; Melbourne School of Government, The University of Melbourne, Australia; Centre for Adolescent Health, Murdoch Childrens Research Institute, Australia.

Rubina Jhadray: The Meriden Family Programme, Birmingham and Solihull Mental Health Foundation Trust, Tall Trees, The Uffculme Centre, Birmingham B13 8QY, UK.

Evelyn Khoo: Department of Social Work, Umeå University, Umeå SE-90187, Sweden.

Catherine LaBrenz: Fundación Hogar Esperanza, Avenida Trinidad Oriente 3400 La Florida, Región Metropolitana, Santiago 4170000, Chile.

Alison Lee: The Meriden Family Programme, Birmingham and Solihull Mental Health Foundation Trust, Tall Trees, The Uffculme Centre, Birmingham B13 8QY, UK.

Rolv Lyngstad: Faculty of Social Sciences, University of Nordland, Bodø N-8027, Norway.

Chris Mansell: The Meriden Family Programme, Birmingham and Solihull Mental Health Foundation Trust, Tall Trees, The Uffculme Centre, Birmingham B13 8QY, UK.

Carolina Muñoz-Guzmán: School of Social Work, Pontificia Universidad Católica de Chile, Avda, Vicuña Mackenna 4860 Macul, Santiago 781000, Chile

Lennart Nygren: Department of Social Work, Umeå University, Umeå SE-90187, Sweden.

Eva K. Robertson: Faculty of Professional Studies, University of Nordland, Bodø NO-8049, Norway. 
Ariel Rosales Ubeda: School of Social Work, Pontificia Universidad Católica de Chile, Santiago 781000, Chile.

Leah Ruppanner: Department of Sociology, University of Melbourne, 300 Grattan Street, Melbourne VIC 3003, Australia.

Maria Tsekoura: School of Social Work, Pontificia Universidad Católica de Chile, Avda, Vicuña Mackenna 4860 Macul, Santiago 781000, Chile. 


\section{About the Guest Editors}
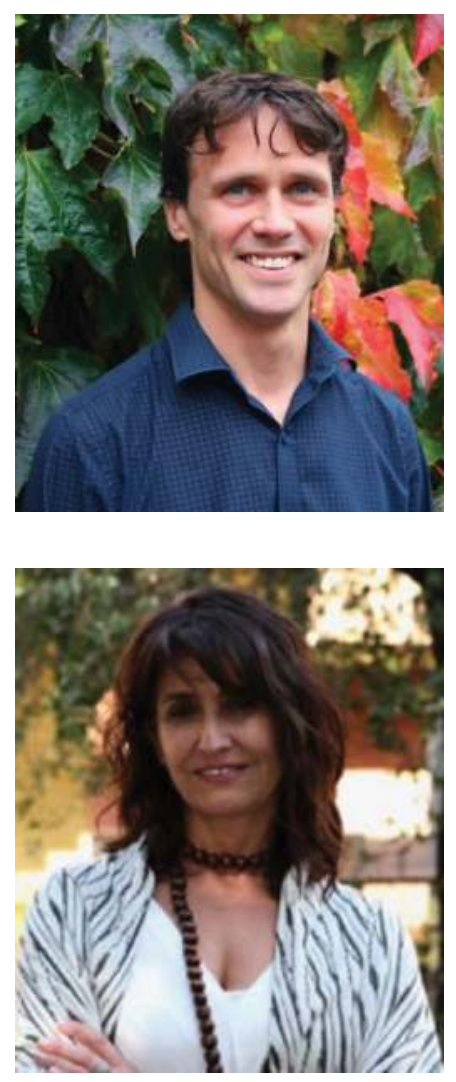

Nathan Hughes is Senior Lecturer in Social Policy and Social Work at the University of Birmingham, and Honorary Senior Research Fellow at the University of Melbourne and the Murdoch Childrens Research Institute. Nathan was coordinator of the European Commissionfunded international research exchange programme, 'Understanding and supporting families with complex needs'. Engaging research teams in seven universities across six countries in Europe and Latin America, the project explored family-focused policies and practices across social care, education and health.

Carolina Muñoz-Guzman is Associate Professor in the School of Social Work at the Pontificia Universidad Católica de Chile. Carolina graduated as MSW from Boston College US, and PhD in Social Policy from the Institute of Applied Social Sciences, University of Birmingham in UK. Currently, she is the Director of the School of Social Work at the Pontificia Universidad Católica de Chile. Her research focuses on children and families, especially social policy for these groups. She also studies social work education, and lately has been involved in projects related to family perceptions about risk and disasters. 



\section{Preface}

Family forms are many and varied, reflecting a myriad of understandings and influencing factors. In any given cultural context, normative notions of family structure, such as the 'nuclear family', may not therefore reflect the reality of family life, experiences and functions, as described and articulated by families themselves; particularly those from minority or marginalized communities. Despite this complexity and perpetual change, the importance of family for the experience of both interdependence and individual support and well-being remains constant. This is particularly the case for 'families with complex needs', who experience both a 'breadth' of 'interrelated or interconnected' needs and a 'depth' of 'profound, severe, serious or intense needs' (Rankin and Regan, 2004), and are therefore most reliant on services and support. This might include families affected by mental health needs, disability, caring responsibilities, migration and asylum seeking, criminal behavior, drug and alcohol misuse, and so on.

The increasing complexity of family life, alongside the continued important and complex role played by family in supporting members with particular needs, poses a range of challenges for services seeking to engage with families, particularly those with complex needs. For family-focused services to deliver effectively, the complexity of family roles, functions, and compositions therefore need to be examined and understood. Failure to recognize the structure, role and function of various family relationships may lead to ineffective service provision or a resistance to engage in support by the family. Nonetheless, there is significant evidence that existing policy and service provision finds 'thinking family' both challenging and controversial.

Contributions to this text consider how 'families with complex needs' form and experience contemporary life, and how such understandings might inform policy and practice responses, including through examination of models and approaches to family-based policy and service provision. Drawing on fieldwork and analyses in a wide variety of countries and contexts, there is a particular emphasis on Latin America.

Nathan Hughes and Carolina Munoz-Guzman

Guest Editors 



\section{Understanding and Supporting "Families with Complex Needs": An Editorial}

\section{Nathan Hughes and Carolina Munoz-Guzman}

Reprinted from Soc. Sci. Cite as: Hughes, N.; Munoz-Guzman, C. Understanding and Supporting "Families with Complex Needs": An Editorial. Soc. Sci. 2015, 4, 1335-1339.

Family forms are many and varied, reflecting a myriad of understandings and influencing factors. In any given cultural context, normative notions of family structure, such as the "nuclear family", may not therefore reflect the reality of family life, experiences and functions, as described and articulated by families themselves; particularly those from minority or marginalized communities [1]. Despite this complexity and perpetual change, the importance of family for the experience of both interdependence and individual support and well-being remains constant. This is particularly the case for "families with complex needs", who experience both a "breadth" of "interrelated or interconnected" needs and a "depth" of "profound, severe, serious or intense needs" [2], and are therefore most reliant on services and support. This might include families affected by mental health needs, disability, caring responsibilities, migration, asylum seeking, crime, drug and alcohol misuse, and so on.

The increasing complexity of family life, alongside the continued important and complex role played by family in supporting members with particular needs, poses a range of challenges for services seeking to engage with families, particularly those with complex needs. For family-focused services to deliver effectively, the complexity of family roles, functions, and compositions therefore need to be examined and understood. Failure to recognize the structure, role and function of various family relationships may lead to ineffective service provision or a resistance to engage in support by the family. However, in sharp contrast to this complexity and fluidity of experience, Murray and Barnes [3] argue that "family" is a taken-for-granted and narrowly defined concept within policy documentation in the UK, and highlight the importance of "exploring normative assumptions about family" that inform policy discourses, aims and objectives. Similarly Jelin [4] argues welfare policies across Latin America are anchored in an implicit model of family that is far from users' daily reality.

Clearly the way in which the needs of the family are constructed and responded to by policy and practice may affect relationships with families as "service users". Of specific concern is the core tension within debates concerning the support of families regarding the right to private family life and the public interest in family intervention. The identification of a small number of families as being in need of intervention provides opportunities to consider how to deliver support; however such an approach is also "demarcating a particular group of families (loosely defined) as having complex needs best met through identification as a public concern", which may be "a source of resistance" to engagement in services ([5], p. 12). 
Given this challenging context it is unsurprising that there is significant evidence that existing policy and service provision finds "thinking family" both challenging and controversial, with clear implications for professional knowledge and frameworks, training, practices, and the design and delivery of interventions. This special issue seeks to support attempts to address this challenging context by providing critical reflections on policy, services and interventions, and professional practices, and by offering accounts of the "lived experience" of families subject to such policies and practices and/or defined as experiencing "complex needs".

In order to do so effectively, the collection of papers is deliberately broad in its coverage of substantive policy and practice areas and specific family needs, including those related to mental health, child protection, foster care, migration, crime victimisation, and poverty. What's more, papers on specific topics offer reflections that are readily transferable to other policy areas.

Similarly the collection of papers is deliberately international in its coverage, and comparative in its analysis. Articles draw on research and policy and practice examples from Mexico, Chile, Argentina, Norway, Sweden, Italy and the UK. This reflects the participation of many of the authors in a recent international researcher exchange scheme, funded by the European Commission Seventh Framework Programme. Entitled "Understanding and supporting families with complex needs", the scheme sought to enhance understandings of family-focused approaches in social care, education, and health by enabling collaboration between eight research groups across Europe and Latin America in a series of case studies. More information can be found on the scheme's webpage [6].

Previous research has identified a typology of family-focused services that includes: those that work with the family to support the service user; those that address the needs of family members so as to enable them to support a primary service user within the family; and an emerging category of "whole family approaches" that uniquely emphasize shared needs, strengths or risk factors that could not be dealt with through a focus on family members as individuals [7]. It is this latter category that is of greatest interest in supporting "families with complex needs". Morris et al. [5] suggest some momentum towards "whole family approaches" in relation to a number of service user groups and contexts. However, whilst there is emerging evidence that such approaches may be effective in engaging families with complex needs, they are often tentative and yet to be evaluated [5]. This is echoed by Mauras [8] who argues that, in Latin American countries, there is still a strong tendency of developing diverse policies oriented towards individuals, instead of towards the family as a whole.

Papers in this collection offer some useful reflections on such approaches. Jhadray et al. [9] provide an account of a whole family approach currently being trialled in the UK to support families affected by mental health difficulties. In particular, the paper offers useful reflections on the processes of implementation. Similarly Tsekoura [10] offers a case study of a voluntary sector youth organisation supporting families living in "extreme poverty" in Chile and Mexico. In describing the strengths-based, holistic support provided, the article offers important reflections for policy and practice more generally. In particular approaches to empowerment 
through the fostering of "family agency" are directly transferable to support for families experiencing a range of complex difficulties.

Other papers offer critical reflections on models of intervention and professional practices that do not readily or effectively engage with the family when meeting the needs of a single primary service provider. Cornejo Torres and Rosales Ubeda [11] explore the difficulties facing immigrant families in Chile in engaging with schools. They describe conflict caused by the school's inability to address cultural differences, leading to poor social integration. Cabiati [12] is highly critical of the lack of meaningful participation of family members in the child protection system in Mexico. In sharp contrast to the practices described by Tsekoura, Cabiati describes a child-centred approach that denies agency to parents, ensuring "asymmetric power relations" between parents and professionals. The likely limitations of such an approach are presented. Similarly Munoz Guzman and colleagues [13] reflect on approaches to "alternative care" in Chile, Italy and Sweden, including how the potentially competing rights of the child and of the parent might both be guaranteed and assimilated.

The challenges in working with families with complex needs are also reflected in papers examining professional perspectives. Gumuscu and colleagues [14] present the practices and perspectives of social work professionals within five varied sectors of social services in Sweden, highlighting varied constructions of the family as "expert", "client" or "non-client", and the implications these constructions have for practices and service user experience. The reflections of service providers are mirrored by those of social work educators in Lyngstad's [15] analysis of values and understandings in relation to complex and controversial issues related to support of families with complex needs.

There remains insufficient research into the everyday lived experiences of families with multiple difficulties, and particularly more marginalized families. Morris and Featherstone [16] argued that this "absence of conceptual and empirical understandings of family practices, coupled with the contradictory drivers for policy and practice, can only result in confusion for families at the point of engagement with services, and piecemeal underdeveloped outcomes". This is mirrored in the Latin American context [17]. Of key concern here is the extent to which different family practices (such as extended family support, parenting methods, child rearing within or across households, and so on) are understood and whether (or not) some approaches may be in danger of problematising specific families without engaging with differences as sources of strength or resilience.

Several of the papers in this collection address this theme by considering how "families with complex needs" form and experience contemporary life in the context of the everyday challenges they face. This in turn supports reflections on how such understandings might inform policy and practice responses. For example, Robertson [18] provides an insightful account of the "everyday lives and health" of migrant women in Mexico, detailing the exercise of agency both in the decision to migrate and in the subsequent attempts of mothers to ensure the welfare and well-being of their children.

Indeed, gender is a recurring theme of the special issue. Most notably Hanley and Ruppanner [19] consider the experiences of women in a range of national contexts regarding fear of crime, comparing the influence of various forms of family structure on fear and 
well-being. Issues of gender also emerge as key themes in other papers, including in relation to child protection services [12] and education [11].

Gender is also a key theme within Gonzalez's [20] reflections on assumptions regarding the role of women in the nuclear family that are at the heart of social policy construction within a neo-liberal context. Such an analysis demonstrates how normative notions of family, and the influence this has on expectations regarding women, are particularly pertinent to the role of mothers within families with complex needs. Interestingly, however, the role of neo-liberalism is shaping the views of social work educators and professionals is argued by Lyngstad [15] to be limited. The relative roles of policy contexts and professional practices in shaping the experience of families with complex needs in accessing services therefore offers a further theme for reflection.

\section{Author Contributions}

Nathan Hughes completed the first draft of this article. Carolina Munoz-Guzman completed the second draft.

\section{Conflicts of Interest}

The authors declare no conflict of interest.

\section{References}

1. Fiona Williams. Rethinking Families. London: Calouste Gulbenkian Foundation, 2004.

2. Jennifer Rankin, and Sue Regan. Meeting Complex Needs: The Future of Social Care. London: Turning Points/Institute of Public Policy Research, 2004.

3. Lesley Murray, and Marian Barnes. "Have Families Been Rethought? Ethic of Care, Family and 'Whole Family' Approaches.” Social Policy \& Society 9 (2010): 533-44.

4. Elizabeth Jelin. Las Familias Latinoamericanas en el Marco de las Transformaciones Globales: Hacia una Nueva Agenda de Políticas Públicas. Santiago: CEPAL, 2005.

5. Kate Morris, Nathan Hughes, Harriet Clarke, Jerry Tew, Paul Mason, Sarah Galvani, Ann Lewis, Lucy Loveless, Saul Becker, and Gale Burford. Think Family: A Literature Review of Whole Family Approaches. London: Cabinet Office, 2008.

6. University of Birmingham. "Understanding and Supporting Families with Complex Needs (2010-2014).” Available online: http://www.birmingham.ac.uk/research/activity/ social-policy/families-policy-practice/research/supporting-families.aspx (accessed on 31 August 2015).

7. Nathan Hughes. "Models and Approaches in Family-Focused Policy and Practice." Social Policy \& Society 9 (2010): 545-55.

8. Marta Maurás Pérez. La familia y las Políticas Públicas: Hacia una "Sociedad de Redes". Santiago: CEPAL, 2005. 
9. Rubina Jhadray, Gráinne Fadden, Martin Atchison, Paula Conneely, Julia Danks, Alison Lee, and Chris Mansell. "Applying the Behavioural Family Therapy Model in Complex Family Situations.” Social Sciences 4 (2015): 459-68.

10. Maria Tsekoura. "'Providing a Roof That Allows one to Dream of a Better Life': A Case Study of Working with Families in Extreme Poverty." Social Sciences 4 (2015): 260-75.

11. Rayen Cornejo Torres, and Ariel Rosales Ubeda. "Objective Structures and Symbolic Violence in the Immigrant Family and School Relationships: Study of Two Cases in Chile." Social Sciences 4 (2015): 1243-68.

12. Elena Cabiati. "The Need for Participative Interventions in Child Protection: Perspectives from Nuevo León State.” Social Sciences 4 (2015): 393-420.

13. Carolina Muñoz-Guzmán, Candice Fischer, Enrique Chia, and Catherine LaBrenz. "Child Welfare in Chile: Learning from International Experiences to Improve Family Interventions." Social Sciences 4 (2015): 219-38.

14. Ahmet Gümüscü, Lennart Nygren, and Evelyn Khoo. "Bringing the Family Back in: On Role Assignment and Clientification in the Swedish Social Services." Social Sciences 4 (2015): 117-33.

15. Rolv Lyngstad. "Different Welfare System — Same Values? How Social Work Educators in Norway, Chile and Argentina Comprehend Core Social Work and Social Policy Issues." Social Sciences 4 (2015): 239-59.

16. Kate Morris, and Brid Featherstone. "Investing in Children, Regulating Parents, Thinking Family: A Decade of Tensions and Contradictions." Social Policy \& Society 9 (2010): 557-66.

17. Regina Mioto, Martha Silva Campos, and Telma Cristiane Sasso de Lima. "Quem Cobre as Insuficiências das Políticas Públicas? Contribuição ao Debate Sobre o Papel da Família na Provisão de Bem-Estar Social.” Revista de Políticas Públicas 10 (2006): 165-83.

18. Eva K. Robertson. “'Como Arrancar Una Planta': Women's Reflections about Influences of Im/Migration on Their Everyday Lives and Health in Mexico." Social Sciences 4 (2015): 294-312.

19. Natalia Hanley, and Leah Ruppanner. "Understanding the Effects of Crime on Women: Fear and Well-Being in the Context of Diverse Relationships.” Social Sciences 4 (2015): 276-93.

20. Cristina González. "Social Policies in Contemporary Latin America: Families and Poverty in the Social Protection Systems." Social Sciences 4 (2015): 134-47. 



\title{
Applying the Behavioural Family Therapy Model in Complex Family Situations
}

\author{
Rubina Jhadray, Gráinne Fadden, Martin Atchison, Paula Conneely, Julia Danks, Alison Lee \\ and Chris Mansell
}

\begin{abstract}
Behavioural Family Therapy (BFT) is a skills based intervention that aims to support families where a member is experiencing a mental health problem. The Meriden Family Programme has extensive experience in supporting families who have complex needs. The programme delivers training in the approach and works with families with the aim of providing information, education and reducing stress within the family environment. Training has recently taken place within various mental health services to equip staff with the skills to work collaboratively with families and to understand and support their needs.
\end{abstract}

Reprinted from Soc. Sci. Cite as: Jhadray, R.; Fadden, G.; Atchison, M.; Conneely, P.; Danks, J.; Lee, A.; Mansell, C. Applying the Behavioural Family Therapy Model in Complex Family Situations. Soc. Sci. 2015, 4, 459-468.

\section{Introduction}

The Meriden Family Programme has been delivering training in Behavioural Family Therapy (BFT) and working with families since 1998. The programme has delivered training locally, nationally and internationally as there is a widespread need for training in the area of family interventions [1]. The aim of the programme is to ensure that families have access to family sensitive services and evidence based interventions. The programme uses a cascade training system, in which individuals are trained in BFT and then go on to train as trainers and supervisors. This allows them to deliver BFT courses and supervise others within their own organisations and services. To date there are over 5000 people trained in BFT worldwide and just over 400 trainers and supervisors. The Meriden Programme offers ongoing supervision to organisations that are delivering family work to ensure that implementation within their services is supported. The programme offers an array of specialist training packages which are available to professionals, family members and service users.

When someone has a mental health problem, it does not only affect them individually but has an effect on the whole family: their daily lives, physical health and relationships [2]. The family is there as a support network for the individual and can be an integral part of the care and recovery process. The family can be seen as experts on their family member's disorder and the difficulties that they are facing, and so they can be a valuable source of support if services work collaboratively with them. Families may experience high levels of stress, burden and may be up against issues such as confidentiality when trying to be a part of the care that their loved one is receiving [3]. They may need information and skills to help them understand and cope better with the disorder and what their family is experiencing. 
BFT is an approach aimed at supporting the family and the individual. It is a practical, skills based intervention that typically involves sharing information with the service user and their family about the service user's mental health issues, experience and treatment. The intervention consists of a number of components including engagement, assessment, formulation and early warning signs work in which the family develops a clear "staying well" plan. Each family member is also encouraged to set realistic and achievable personal goals for themselves. BFT promotes positive communication, problem solving skills and stress management within the family. When families are under pressure, whether it be because of a mental health issue, substance misuse or other reasons, communication can often deteriorate or become minimal. BFT aims to promote positive communication within families through skills training, and looks at skills such as "expressing pleasant feelings" and "active listening"; with the aim of creating a more supportive and stress-free environment for everyone involved. This type of evidence based family approach has been shown to reduce relapse rates, stress and hospitalisation, therefore improving the quality of life for individuals suffering from mental health difficulties and their families [4,5].

Family interventions have been shown to be effective where individuals are suffering from Schizophrenia and Psychosis [4,6,7] and Bipolar Disorder [8,9]. The Meriden Programme team has worked with families who are experiencing a range of difficulties and who may have complex needs.

The implementation of family interventions in clinical practice has been recommended by health guidelines and policies in the UK [10] and in the PORT Guidelines in the United States [11] encouraging professionals to take into account the needs of the family and to offer education and support. There has also recently been evidence showing the cost-effectiveness of family interventions highlighting the benefits for services as well as for families [12].

There are needs of families that are similar despite which service or specialism their family member is receiving care from. However, there may be some variation in their need for support and information depending on the nature of the problem and on what they are offered by services. It is important for professionals working in different settings to be aware and equipped to help families and keep them involved. This requirement impacts on the training provided to different services and the need to tailor it to the requirements of the team. With this is mind, we have recently delivered training on an eating disorders unit, a mother and baby unit, within early intervention services and conducted a family work pilot project on an acute inpatient unit. BFT has also been utilised with families whose relatives are in secure settings. The detail of some of these is outlined below and highlights how family work can be beneficial in understanding and supporting families with complex needs in mental health services.

\section{Case Examples of Supporting Families with Complex Needs}

\subsection{BFT in a Mother and Baby Unit}

A pilot project looking at the implementation of a brief family intervention within a Mother and Baby unit was recently conducted. The unit was looking to involve families further within the care of service users. A brief intervention consisting of components of the BFT model including assessment, information sharing, recognising early warning signs and developing a staying well plan and 
problem solving was delivered to all staff on the unit. The training lasted a day and was repeated to ensure that all staff were able to attend. All sessions with the family were designed to last 20 minutes in order to increase the chance of ward staff being able to commit to this amount of time. The families were then interviewed using a short post intervention questionnaire looking at the impact of being involved in the service user's care in this way. The training team included a carer who had received the full BFT intervention along with his family who shared with the staff very clearly, how each of the components had been helpful to them as a family unit. As part of the training, for each component, staff were given time to practice the skills that they were learning. They had guided practice on delivering the sessions to families and received feedback from their peers and trainers in what they each did well and how they might do some things differently. Supervision sessions have been set up to support the staff beyond the training.

The staff on the mother and baby unit already have systems in place for working with partners, but working with the brief family intervention meant identifying a wider network of support. This initially created an increased workload as more people were offered individual meetings. What had been designed as 20 minute sessions were turning into 1.5-2 hour meetings as the staff familiarised themselves with the questions and also the process of engaging people using this particular method of assessment. It was identified through supervision that some staff, although highly motivated and enthusiastic to use the approach were anxious about delivering some of the components and have avoided doing so.

The delivery of the components and the engagement of the mothers and their families can be seen as key for the intervention to have maximum benefit. There could be potential difficulties in the initial engagement of mothers both as parents and people recovering from mental health problems. The focus on including families can be seen as important in meeting the needs of a mother suffering from a mental disorder [13]. However staff members also need to appreciate that some aspects of family relationships may be challenging. Some family relationships can be seen as potential stressors and can have a negative effect on the esteem and confidence of mothers [14]. So in situations such as these, the discussion of how engaging in the intervention can improve relationships and what the benefits of the intervention could be for the mother and the relationships she has with family members may be helpful. Discussions around ways in which the mother and family members may be able to communicate their needs and views better may take place in an attempt to overcome hesitancy towards family work. Another potential barrier to engagement may be side-effects of medication. It has been seen that medication can have a negative impact on a mothers' ability to engage with her children [15] this could further have an effect on relationships with family members and their ability to engage with services. This should be considered when delivering family work and discussed sensitively and appropriately.

A complexity that frequently occurs in the process of engaging mothers in services is the fear of losing their children to authorities [15] which could make them reluctant to disclose their difficulties, as the child or children are seen as central to their lives and motherhood as a fulfilling and rewarding part of their lives. In the UK, babies of $48 \%$ of mothers with schizophrenia discharged from mother and baby units were under some form of supervision by social services after discharge [16]. So, this complexity of both suffering from a mental illness and being a 
caregiver may give rise to difficulties in engagement as there may not be an openness in sharing difficulties, experiences of coping and identifying extra support needs.

The mother may also encounter difficult relationships with family members or partners when there is judgment towards her or a lack of understanding of the mothers' experiences [17]. This could lead to reluctance to engage with the intervention as the mother may feel that her behavior may be evaluated in some way. The information sharing component of the BFT model addresses this and attempts to increase the understanding of the experiences that the mother has been through, the mental health problem and the impact of this on the family members involved. Information sharing would also allow family members to share their experiences and relay what would be of further help to them. As there can be issues with engagement, staff training and supervision are imperative to the implementation of family work within a mother and baby unit. Professionals should be well-equipped with the skills and confidence to deliver the sessions and this can be enhanced and developed through regular supervision.

On completing the outlined intervention, family members and service users felt there were a number of benefits. Family members were more involved in the care of their relative whilst on the ward; they had a greater understanding of symptoms and what to look for and felt like they had permission to talk to each other in a different way. Family members knew who to contact if things were to start deteriorating and were grateful for being signposted to support services. The benefits to the services are that if families are supported during an admission and thoroughly prepared for discharge, they can build capacity and resources to manage situations better and rely less on services. If the family are given the skills to help them cope better themselves, use their own resources, have a plan of what to do and who to contact, they will build better relationships with the people in the service user's support system.

\subsection{BFT in an Eating Disorders Service}

The training for the staff from an eating disorders service took place over three half day sessions. These sessions were repeated so that all staff could get the opportunity to attend.

The first training session looked at the experience of having someone in the family who is unwell, before some discussion about the experiences of family members who came into contact with the eating disorders service. The issue of confidentiality was then explored, focussing on the specific issues with confidentiality that related to people with eating disorders. The second session was spent looking at the concept of the Triangle of Care [18], which led to discussion about how the team linked with families, and then moved on the idea of involving families in developing staying well plans, and the benefits of doing so. An example of a brief family assessment interview schedule was also discussed. The final session included input from a carer, and a carer support worker. The structured process of problem solving was demonstrated and discussion took place about how this could be used with families.

One of the reoccurring themes from the training was that confidentiality played a significant part in how relationships developed with families. Following the discussion around confidentiality, some clinicians reported that they were starting to have more proactive conversations with service users about the benefits of families being involved in some aspects of their care, rather than feeling 
that they had to concur with the statement from service users that they didn't want their family involved at all.

Confidentiality can affect relationships between service users and their families and between the family and mental health professionals. It has been recognised that carers and families need certain information around the difficulty and guidance on how to deal with their family members problems, to enable them to care more safely and effectively for them [19]. Service users have the right to decide how information about them is shared and this can be seen as key in building trust between them and services. Alternatively, it can be seen that involving the service user's family can enable the family to provide more effective support as they would be better informed and more sensitive to the issues affecting their family member. Also, the family would be instrumental in supporting the service user outside of hospital and in their daily lives.

When a person suffers from anorexia nervosa, this often becomes a core value within their lives [20-22]. This can affect relationships within the family, as values that were previously core to the service user (such as family relationships) become secondary to the eating disorder. This may cause issues as the family may not understand the value placed on anorexia nervosa by the service user and why, and this can lead to conflict. Encouragement from services to involve and share information with the family can help ease situations such as these and aid in the recovery of the service user.

Sufferers of eating disorders can put themselves at high risk both physically and psychologically. Decisions that they make regarding their treatment and care can impact on the level of risk and their recovery. It has been argued that decision making abilities of people can be compromised as a result of their difficulties and value systems [20-22]. As mentioned previously, the eating disorder becomes the central value in a person's life, thus the decisions that they take may not be in the best interests of their recovery. Working collaboratively by including families in the treatment and decision making process may be helpful in making more effective decisions, and help family members be more supportive and understanding, as they are included in the process.

The issue of confidentiality can make it difficult to involve carers, as professionals may be unclear on what information they can and cannot share, so this may lead to reluctance by staff to share information. Staff may also lack confidence in being assertive in sharing information. Clinicians may be mindful of the need to develop a relationship with the service user so may be cautious about when and how to introduce the idea of sharing information with the family. They can find the whole situation challenging when there is a lot of stress in the family situation. It can sometimes take time and a number of discussions before an agreement can be reached to involve the family. A collaborative, team approach in giving a consistent message about the importance of involving the family may be helpful in increasing confidence in staff.

Families understand the idea of confidentiality and can be worried about expressing concerns in case the service user is unhappy with this. Even if they are told by professionals that they can talk to staff, some family members may be reluctant to do so in case this upsets the service user. Discussions at supervision indicate that sometimes, if the service user is upset about a decision made by the team, the family will be informed by the service user about this. The family will then argue the case on the service user's behalf, without having any understanding about the reasons for 
the clinical decision. Encouraging the involvement of family members and sharing information with them, still allows for client-centered and sensitive care, and may not be detrimental to relationships between professionals and service users.

Although the service consistently carried out carers' assessments and shared general information about anorexia nervosa with families, there was some acknowledgement that there were opportunities to increase the involvement with families. If the team were to carry out an assessment of the family which included questions, for example about their understanding of the eating disorder, the team could be clearer about what information would be beneficial for the family. This in turn could have a positive impact on the service user. Empowering the service user to have discussions with their family about what they do that is helpful or unhelpful (as part of developing a staying well plan) was thought to be really helpful and a more focused way of getting families involved in a practical way that benefitted everyone.

Currently there is discussion about having a 'workbook' for families in contact with the inpatient service. Service users will work their way through an 18 page manual during an admission to help them work on their ways of coping with their eating disorder. There may be a much shorter version for families in the near future which will include a brief assessment of their perspective on the eating disorder, information, involvement in the development of a staying well plan, and an introduction to the process of problem solving.

\subsection{BFT and the Troubled Families Team}

In December 2011, the UK Government committed to investing additional funding to "turn around the lives of the 120,000 most troubled families in England" [23] and issued a clear statement in terms of what needed to change for these families: getting children into school, cutting crime and anti-social behaviour and putting adults on the path to work. As such, the Troubled Families programme was established to work in partnership with local authorities to help change these families' lives and address issues at a local level.

The team provides a single point of contact for families facing a range of multiple problems in their daily lives. The team has workers from a variety of agencies, including Community Housing, the local Council, Youth Offending Services and Police Services.

Working with up to 500 families facing complex and multiple issues, 50 of which will require intensive direct support, the underlying principles of the approach are to:

- holistically address the needs of the family as a whole

- $\quad$ build trust with families resisting help

- share information and intelligence to understand family histories

- use resources flexibly and provide needs based access to services

- build family capacity and resilience through intensive support

Following involvement in an initial away-day, the Meriden Programme was invited to deliver family work training to nine members of the eleven strong team. Given the nature of the team and its varied membership, it was felt that having a "shared model" for working with families in a consistent and structured way may be of benefit. 
The training was adapted slightly to meet the specific needs of the team and the complex nature of the families they work with. The most significant issue, initially, was that there was commonly no diagnosed mental health issue within the families supported by the team. However, team members generally felt there were significant levels of undiagnosed mental health issues and a high level of substance misuse. Supporting families where there are co-existing mental health issues and substance misuse can be challenging. Family interventions that consist of goal-setting, psychoeducation and communication and problem solving skills training can reduce the stress in families [24]. As a result, the training included "additional" sessions on common mental health issues, how stress affects us all, stress vulnerability, family stress and illness, mental health and cannabis use - together with the more traditional topics of the evidence for using BFT with families, information sharing, staying well planning, communication skills and problem solving.

The training was delivered over five days, two days one week and three the next. This allowed the team to process the learning, talk through as a team how the model might fit and to start talking to their families about working in this way. At the end of the training there was a real sense of optimism and hope that working more collaboratively, and in a more "proactive" way, would improve the outcomes for families.

During training it was noted that staff were motivated and enthusiastic with regard to changing their own practice - they were cautious as to how the families would receive the new intervention. The model had not been adapted to work with families experiencing complex problems such as these before, and there is a little research of the model being applied to families such as those in contact with the Troubled Families programme. In subsequent supervision sessions however, it emerged that a number of families (initially described as "abusive", "chaotic" and "constantly in crisis") welcomed the approach as a new and more positive way of dealing with their situation, helping with both family relationships and communication within the home.

The following is a report by one of the people who attended the training.

My experience of completing the Meriden Training in Behavioural Family Therapy was positive and insightful. I felt that the training was accommodated to our needs in terms of relating the approach accordingly to the client group which we would be delivering the work to. The trainers took into consideration the difficult circumstances and dynamics which we would have to face throughout delivery of the work, and helped us to understand how the approach would be appropriate and helpful for some of our families as well as how to demonstrate these points to families and engaging them with family work sessions.

I am in the process of delivering the sessions to two of my families, which has been challenging due to the additional difficulties which they present with, which often requires crisis intervention support. The main challenge which I have been faced with for delivering the work overall is maintaining the momentum of family work with the families in terms of reminding them why adhering to the sessions is important and will be effective in the long term in relation to the current pressing issues and demands that they present with. However, due to the approach not being rigid and somewhat 
adaptable according to the family's needs, it does enable us to take this into account when delivering the work. Families, although initially expressing reluctance to engage with family work have expressed enthusiasm, interest and reflection throughout the sessions. They have all identified the need for better communication and how this could help improve their functioning as a family and relationships within the family.

Receiving supervision from the trainers has been helpful, particularly for reflection purposes as to how our delivery of the work may impact the response from families about family work. The trainers have offered advice and strategies around how to manage the challenges which we face on delivering the approach to the particular families which we work with. Supervision also assists with maintaining our confidence in and adherence to the model as well as identifying and reflecting on what has worked well [25].

\section{Conclusions}

The examples above demonstrate the range of complex situations where family work can be applied. The Behavioural Family Therapy model is flexible and is adapted to the needs of the individual family, whatever the setting. There are a number of components to the approach as can be seen below:

- Establishment of a positive, respectful, collaborative relationship between family and clinician.

- Agreement that service user and key family members will meet together with clinician.

- Information sharing and an agreement about issues relating to confidentiality.

- Time and space for discussion of emotional issues and personal reactions to mental health problem and its management.

- Support for family members in the achievement of personal goals.

- Focus on management of practical day to day issues.

- Enhancement of family problem-solving skills.

- Agreement on relapse prevention strategies.

- Development of effective communications patterns.

- Agreement on the ongoing nature of the relationship between family and mental health services.

As can be seen from theses components, the focus on day to day issues and the collaborative nature of the approach means that experienced workers can deliver it in a meaningful way in different contexts, ensuring that the needs of service users and their families in that setting can be met. Despite the flexibility of the approach, there is a lack of evidence supporting the use of the model in complex family situations that are unrelated to mental health, such as poverty or social disadvantage. Components of the model, such as problem solving training, may be helpful, as this may help families work together to find solutions to help their situations and decrease stress within the family home. However, the effectiveness of the model in these contexts is yet to be investigated. Working with families also gives rise to issues such as confidentiality and how it can be utilized in a positive way as well as complexities in the engagement of families. 


\section{Author Contributions}

The Meriden Family Programme team applies the BFT model in different clinical settings. This article reflects the work of all members of the team.

\section{Conflicts of Interest}

The authors declare no conflict of interest.

\section{References}

1. Gráinne Fadden, and Rebecca Heelis. "The Meriden West Midlands Family Programme: Lessons learned over ten years.” Journal of Mental Health 20 (2011): 79-88.

2. Carers UK. Carers at Breaking Point. London: Carers UK, 2014.

3. Terence V. McCann, Dan I. Lubman, and Eileen Clark. "First-time primary caregivers' experience accessing first-episode psychosis services." Early Intervention in Psychiatry 5 (2011): 156-62.

4. Fiona Pharoah, Jair J. Mari, John Rathbone, and Winson Wong. "Family Intervention for Schizophrenia." Cochrane Database of Systematic Reviews 12 (2010): doi:10.1002/14651858. CD000088.pub3.

5. Mario Pfammatter, Ulrich M. Junghan, and Hans D. Brenner. "Efficacy of psychological therapy in schizophrenia: Conclusions from meta-analyses." Schizophrenia Bulletin 32 (2006): S64-80.

6. Lisa Dixon, Curtis Adams, and Alicia Lucksted. "Update on family psychoeducation for schizophrenia." Schizophrenia Bulletin 26 (2000): 5-20.

7. Gabi Pitschel-Walz, Stephen Leucht, Josef Bäuml, Werner Kissling, and Rolf R. Engel. "The effect of family interventions on relapse and rehospitalisation in Schizophrenia-A meta-analysis." Schizophrenia Bulletin 27 (2001): 73-92.

8. David J. Miklowitz, Michael W. Otto, Ellen Frank, Noreen A. Reilly-Harrington, Sachs R. Wisniewski, Jane N. Kogan, Gary S. Sachs, Michael E. Thase, Jayendra N. Calabrese, Lauren B. Marangell, et al. "Intensive psychosocial intervention enhances functioning in patients with bipolar depression: Results from a 9-month controlled trial." Archives of General Psychiatry 64 (2007): 1340-47.

9. David J. Miklowitz, Michael W. Otto, Ellen Frank, Noreen A. Reilly-Harrington, Stephen R. Wisniewski, Jane N. Kogan, Andrew A. Nierenberg, Joseph R. Calabrese, Lauren B. Marangell, Laszlo Gyulai, et al. "Psychosocial treatments for bipolar depression: A 1-year randomized trial from the Systematic Treatment Enhancement Program." Archives of General Psychiatry 64 (2007): 419-26.

10. National Institute for Health and Care Excellence. Psychosis and Schizophrenia in Adults: Treatment and Management. London: National Institute for Health and Care Excellence, 2014. 
11. Anthony F. Lehman, Julie Kreyenbuhl, Robert W. Buchanan, Faith B. Dickerson, Lisa B. Dixon, Richard Goldberg, Lisa D. Green-Paden, Wendy N. Tenhua, Daniela Boerescu, Cenk Tek, et al. "The Schizophrenia Patient Outcomes Research Team (PORT): Updated treatment recommendations." Schizophrenia Bulletin 30 (2004): 193-217.

12. Martin Knapp, Andrew D. McDaid, Valentina Lemmi, Paul McCrone, A-La Park, Michael Parsonage, Jed Boardman, and Geoff Shepherd. Investing in Recovery: Making the Business Case for Effective Interventions for People with Schizophrenia and Psychosis. London: Centre for Mental Health, The London School of Economics and Political Science, Rethink Mental Illness, 2014.

13. Barbara J. Friesen, Judith Katz-Leavy, and Joanne Nicholson. Supporting Parents with Mental Health Needs in Systems of Care. Washington: Technical Assistance Partnership for Child and Family Mental Health, 2011.

14. Dinali N. Perera, Liz Short, and Sabin Fernbacher. "'It's not that straightforward!': When family support is challenging for mothers living with mental illness." Psychiatric Rehabilitation Journal 37 (2014): 170-75.

15. Angeles Diaz-Caneja, and Sonia Johnson. "The views and experiences of severely mentally ill mothers-A qualitative study." Social Psychiatry and Psychiatric Epidemiology 39 (2004): 472-82.

16. Louis Howard, Nisha Shah, Margaret Salmon, and Louis Appleby. "Predictors of social services supervision of babies of mothers with mental illness after admission to a psychiatric mother and baby unit." Social Psychiatry and Psychiatric Epidemiology 38 (2003): 450-55.

17. Joanne Nicholson, Elaine M. Sweeney, and Jeffrey L. Geller. "Focus on women: Mothers with mental illness: II. Family relationships and the context of parenting." Psychiatirc Services 49 (1998): 643-49.

18. Alan Worthington, Paul Rooney, and Ruth Hannan. The Triangle of Care, Carers Included: A Guide to Best Practice in Mental Health Care in England. London: Carers Trust, 2013. Available online: http://static.carers.org/files/the-triangle-of-care-carers-included-final-6748.pdf (accessed on 1 December 2014).

19. Sidney Bloch, George I. Szmukler, Helen Herman, Ann Benson, and Silvana Colussa. "Counselling caregivers of relatives with schizophrenia: Themes, interventions, and caveats." Family Process 34 (1995): 413-25.

20. Jacinta Tan, Tony Hope, and Anne Stewart. "Competence to refuse treatment in anorexia nervosa." International Journal of Law and Psychiatry 26 (2003): 697-707.

21. Jacinta Tan, Tony Hope, and Anne Stewart. "Anorexia nervosa and personal identity: The accounts of patients and their parents." International Journal of Law and Psychiatry 26 (2003): $533-48$.

22. Jacinta Tan, Tony Hope, Anne Stewart, and Raymond Fitzpatrick. "Control and compulsory treatment in anorexia nervosa: The views of patients and parents." International Journal of Law and Psychiatry 26 (2003): 627-45.

23. Department for Communities and Local Government. Helping Troubled Families Turn Their Lives Around. London: Department for Communities and Local Government, 2014. 
24. Jennifer D. Gottlieb, Kim T. Mueser, and Shirley M. Glynn. "Family therapy for schizophrenia: Co-Occurring psychotic and substance use disorders." Journal of Clinical Psychology 68 (2012): 490-501.

25. Interviewee 1. Solihull, UK. Interview, 2014. 


\title{
"Providing a Roof That Allows One to Dream of a Better Life": A Case Study of Working with Families in Extreme Poverty
}

\section{Maria Tsekoura}

\begin{abstract}
This paper presents a case study of a youth organisation working with families in extreme poverty and lack of adequate housing in Chile and Mexico. It initially describes the considerable structural changes that relate to the emergence of the organisation, and then discusses how across context case study research that draws from the interpretivist interactionist tradition was employed. In the main body it presents interventions that aim to provide families with temporary accommodation, social support, education, micro-credit opportunities, and legal support. The paper aims to contribute to a discussion concerning wider insights to be gained from context-specific approaches in working with families. The article highlights the need for policy and practice that approaches families as complex, dynamic and context specific entities that are re-configured through their networks and interpersonal interactions, and are subject to particular plays of power relations. Furthermore, it argues for practice that fosters family agency that is based on recognition of strengths, emotional and cognitive aspects of decision making as well as nurturing of hope.
\end{abstract}

Reprinted from Soc. Sci. Cite as: Tsekoura, M. "Providing a Roof That Allows One to Dream of a Better Life": A Case Study of Working with Families in Extreme Poverty. Soc. Sci. 2015, 4, 260-275.

\section{Introduction}

A small settlement at the outskirts of Santiago was bustling with life on a Saturday morning in November 2013. It took a long bus-ride and a fifteen min walk from the nearest community to arrive there. The settlement was surrounded by hills on the one side and a small river-rubbish pit to the south. Thirty families were living there in basic housing, sharing electricity and water facilities. The one-room dwellings were made by wooden and plastic material, with earthen floors. Towards the centre of the settlement houses were made with more robust cement material and the alleys were less muddy and wide enough to fit a car. In most cases a number of generations cohabit together. Walking around the community, younger men are training their horses and a family is preparing bread in a wood-burning oven to sell in the nearby town with their vending bicycle. A number of volunteers arrive together in a car and scatter around the settlement, after a few minutes it becomes clear that they are looking for the families they work with and especially the children they are tutoring. Other volunteers are heading to the community centre where they will interact with pre-school children, while others are tutoring children in public as there is lack of space in the family house. On the way to the community centre of the settlement is an enclosure with animals, representing the support provided to a community member through micro-credit opportunities. The owner guides us around the enclosure with immense pride as this is the first opportunity she ever had to secure an income for her family. This activity within the settlement was initiated and supported by Techo. Techo was established in Chile in 1997 (initially known as Un Techo para 
Chile), as a non-profit, youth-run organisation, and draws its funding by individual donations, grants, and corporate support. Its mission is to work with communities and families in extreme poverty who live in "the most excluded slums of the continent". A focus on poverty reduction in the region of Latin America reflects both a global antipoverty consensus as it trickled down in the agenda of international organisations, national and subnational policy making bodies as well as the stark reality of poverty in the region exacerbated by the marketization of public life and globalisation. As poverty was a reality in the wider region of Latin America, the organisation had by 2013 expanded into 19 countries and attracts a large amount of young volunteers. The objectives of the organisation involve the promotion of community development within slums throughout the Latin American continent, fostering social awareness and action regarding poverty, as well as advocacy for the recognition of the human rights of the excluded families. The joint work in communities between families and volunteers is designed to evolve in three levels: insertion in the slums to assess the type and the extent of needed support; joint work to identify priority interventions such as house building, educational assistance for children, micro-credit projects, basic skills training, and small business projects; and implementation of long term interventions that aim to create sustainable development within communities.

This article will first locate the emergence of the organisation within rising alternatives in working against poverty within the Chilean and the broader Latin American context. Then it will continue by presenting the story narrated by the volunteers regarding how they work together with families to set goals and initiate action, in order to contribute to a discussion regarding the rationale underpinning policy and practice in working with marginalised families.

\section{Setting the Context: Emerging Alternatives in Addressing Poverty}

The aim of this brief first part is to highlight the connections between the context and the organisation itself. The emergence of the organisation can be understood within the considerable structural changes that have taken place in the Latin American context over the last decades, such as the growing importance of market oriented policies and the re-establishment of democracy. The project was established in 1997 in Chile as a youth-led organisation aiming to directly contribute to the elimination of poverty through provision of temporary housing and social support. As poverty was a reality in the wider region of Latin America, the organisation had by 2013 expanded into 19 countries and attracts a large amount of young volunteers. While poverty has traditionally been present in the Latin American region, social inequalities have been exacerbated after the introduction of economic policies which signalled a tendency for the dismantling of the welfare state, privatisation of the economy, and "concerted efforts to roll back existing guarantees to social protection in the name of a larger role for the market, families and communities" ([1], pp. 59-60).

Although declining the average rate of poverty in the Latin American region has remained above $40 \%$ throughout the 1990 s and the 2000 s, with $18.6 \%$ of poor people being indigents and living with less than a dollar per day between 2003 and 2005 [2]. Poverty in Chile reflected the above percentages in the 1980s and 1990s, while since the 2000s this rate has been decreasing due to state targeted poverty reduction projects [3], and an economy functioning on the basis of basic service provision and export-led growth [4]. However, inequalities remain high, and isolation and 
marginalisation remains a reality for parts of the popular sector [2,4-7]. For Jenson [2] the limits of the market oriented model and the failure of efforts to counteract them such as the economic adjustment policies opened up space for the emergence of a new set of converging policy objectives in the mid-1990s. These new principles consist of a social investment perspective which instead of proposing particular policies "describes a specific logic for fighting poverty" ([1], p. 60), and supports policy initiatives that promote learning for the creation of human capital. Within such a perspective work with families becomes child-centred and many Latin American countries start following strategies to deal with high levels of poverty that endorse social protection based on cash transfers to mothers, conditional to certain behaviours related to children's schooling, health and care of children [1,8,9]. For Fiszbein [10] there was a shift towards two separate and parallel systems of policies which involved on the one hand social insurance that reaches formal sector workers, and social assistance on the other hand that targets the very poor. Such policy shifts have succeeded in addressing some of the limitations of the "truncated" system [11], but still privilege the middle class while protection for the poor is scarcely resourced. Sections of the population, especially those working in the informal sector and those lacking adequate housing, have limited access to systems of social protection and depend upon support provided from nongovernmental organisations.

A second key development that describes the context within which the organisation has emerged relates to shifting expressions of citizenship and the transition to democracy. The 1990s marked Chile's transition to democracy, which allowed for a number of organisations (private and public institutions) to start addressing individually, and in partnership, the issues of poverty [5]. A number of organisations and partnerships focused on housing. Housing problems involved both inadequate housing such as poorly constructed buildings, improper material, and precarious conditions, as well as a lack of basic accommodation for segments of the population. According to Finn ([5], p. 187), discussions between public and private institutions aimed to "move beyond critique of state policy to development of concrete alternatives that focused on poor communities not as 'problems' but as units of solution".

For a number of commentators such efforts to work against social inequalities were restrained within the boundaries created by the new understandings of citizenship, prevalent in the region by the mid-1990s. Dagnino [12], for example, states that the legacy of neoliberal policies in Latin America was a re-conceptualisation of citizenship as individual participation in the labour market and a new understanding of families as responsible for creating their own opportunities in order to foster the wellbeing of their members. Commenting on the Chilean context in particular Rakodi [4] argues that the individualistic ethos of Chile's model of democracy, its liberalised economy, and spatial segmentation weakened collective organisation. Therefore, a previously active civil society against authoritarian rule has retreated to quietism. Similarly, the poor are powerless to "make any effective claims on the political system" ([4], p. 255). However undeniable those developments might be, a different type of commentary, offered by Bennet [13], allows us to approach the context and the particular organisation from different analytical angle. Bennett explores (albeit in a North American context) the impact of market oriented policies and globalisation on the possibilities and expressions of social action, especially among younger generations. Where others see passivity and decreased collective organisation he describes a shift towards more reflective and 
personalised forms of engagement whereby citizenship is exercised on the principles of self-actualisation, choice of lifestyle, and personal values. Bennett's emerging "personalised politics", far from being expressed through voting or engagement in party politics and unions, are evident in people's choices (especially young people's choices) to get involved in causes that they personally deem important, be it the environment, social justice, or poverty eradication. Therefore, the emergence and practice of this organisation is understood in this article as a reflection of a shift towards more personalised and action-focused politics among young people, facilitated also by a general acknowledgment in the region of poverty as social inequality, rather than as an inevitable result of economic development.

\section{Methodology}

The research employed an interpretative interactionist methodological approach [14] which seeks to make the connections between individual discourses and policy or material conditions. This approach combines an interpretive emphasis on individual meaning-making, and an interest in situating the significance of such meaning within specific contexts. Furthermore, its focus on critically interpreting the process under investigation and linking it with the purpose of the study, allows us to define the boundaries of what and where is to be studied, and what constitutes the units of analysis. This study aimed to explore meaning making processes within work with families in extreme poverty. More specifically, the research questions focused on: (a) What notions of family did the participants employ? (b) How was poverty and need conceptualized? (c) What "working with families" meant on a practical (daily-weekly) basis? (d) What was the aim of their action and how was this linked to their own social experience? and (e) How did decision making occur in terms of priorities and methods of work (different levels of planning and decision making)?

The boundaries of the cases and the choices of the units of analysis were established on the basis of the above purpose and research questions. Techo's work is representative of a prominent tendency in Latin America in the 1990s to develop housing related projects as a part of a process of reducing poverty. While the organisation started working in the Chilean context (as it has been described earlier in this article), its work has soon expanded to other Latin American countries. This was possible because of commonalities regarding the extent of poverty and cultural similarities, such as common language. This study includes instances of Techo's work from both the Chilean and the Mexican context. Using data from both countries allowed this study to gain more information about processes and spaces enabled by the same organisation in different contexts. Therefore, employment of across-context case studies was a strategy that aimed to conceptualise common characteristics regarding processes or events, and to simultaneously embed these common characteristics in the particular context and time in which they were developed ([15], p. 69); thus allowing the production of concrete and context-dependent knowledge [16]. The data was collected through participant observation, semi-structured interviews with 25 volunteers, and revision of relevant documentation (the organization's own publications and research, volunteer and staff interviews to newspapers/magazines, and websites) in Chile and Mexico. However, the study involved volunteers from a wider range of countries in the region (seven in total), who were living and working in these two countries when the interviews took place. 
Working with families to combat poverty has its own temporality formed by processes, agendas and strategies - described in the introduction of this article - that shaped the fields of possibilities for action against poverty. This temporal character is affected by macro power relations, which create cultural meanings in regard to the scope and resources of working with excluded families. The effects of such power became obvious in the language the participants used to represent themselves and their work. Thus, the aim of interpretation was to make the connections between these discourses and the individual/personal interpretations regarding how they chose to engage with their organization and work with the families. The process of interpretation involved grasping both the unity and the structuring elements of the processes present in participants' interpretations. The process of interpretation in interpretive interactionist research starts at a very early stage, when the phenomenon under investigation, research questions and instances are defined. Obtained data are extracted from their context and dissected into their constituent elements ("bracketing" stage). This involves approaching participants' interpretations as text to be coded and analyzed through keeping memos regarding emerging patterns, overlaps, and connections. The identified elements are reclassified and brought together into a totality ("constructing" stage) to explore how they relate to each other and to the issue of the investigation while at a final stage they are located back to the social world and in the context in which they occurred ("contextualising" stage) ([14], pp. 70-89).

The structuring elements or categories devised through this process (which encompassed the different dimensions of the accounts of the participants) referred to two general areas: (a) personal learning and values (personal commentary on social conditions) and the ability to work towards social change; and (b) perceptions of poverty, poor families and their capacity to act as social actors. The relationships between these different structuring elements in the data were teased out on the basis of the following questions: (a) How individual motivation to participate related to particular citizenship values as well as perceptions of the role of poverty in family lives; and (b) How such perceptions gave rise to particular approaches in getting involved with families and how these affected the quality of interactions. For example, the data was interrogated to explore how a perception of social change as "bringing hope back" related to "communication and decision making processes" when working with families; how perceptions of poverty as "inability to claim rights" related to descriptions of "family involvement in the implementation of projects"; or poverty as a "multidimensional process" related to "priority areas for intervention"; and finally how views of the organisation as "new and still in process of learning" talked about the ways in which "feedback from families" was negotiated.

In interpretive interactionism it is important that processes are interpreted through the stated actions and the language used by the research participants. This brings attention to key issues which fashion processes of interpretation such as the history, power, emotionality, and beliefs concerning the knowledge ([14], p. 49) not only of the participants, but of the researcher too. Micro-power relations affect each aspect of the research and manifest themselves not only in the world/reality/process that is studied, but also at the level of the researcher gaining access [17], as qualitative methods are both "material and interpretive practices" which "do not stand outside politics and cultural criticism" [14]. An interpretive emphasis on meanings and experience rejects the idea of a distanced, impartial, and "freed from personal history" researcher. In practice this 
means that while the researcher ensures objectivity and rigor when conducting the fieldwork and analyzing the data, at the same time he/she recognizes the need to respectfully communicate with the participants, in order to immerse in the ways they construct their activities and their meanings. The socio-historical identity of the researcher herself as "European", "female" and "academic" had to be negotiated and fears about the possibility of "evaluation by an external actor" had to be discussed. Therefore the presentation of this study reflects a conscious effort to balance both a constructive approach to the personal accounts of the participants that allows positive aspects of their work to arise, and at the same time to maintain a critical distance. Moreover, an interpretive emphasis on meanings and experience requires that the outcomes of policy initiatives or interventions are judged from the point of view of those most involved. Due to its time constraints this project focused mostly on the perspective of the young volunteers. While interaction with families occurred during participant observation the main body of the data consists of the accounts of volunteers. Thus, it cannot be argued that the results represent all involved actors, but they focus on those actors that intend to deliver a service.

\section{Assisting Families to Overcome Poverty}

In the interviews the volunteers described the initiation of interventions to occur when community leaders or members approaching the organisation asking for assistance either because they have heard about its work, or have witnessed it in neighbouring communities. At the first stage a group of young volunteers visits the community to map the circumstances and to assess the type of necessary interventions. This happens in collaboration with the community members who provide their input in regular meetings with the volunteers and by participating in assemblies (asambleas). In these meetings the volunteers initiate a dialogue with the community, present their work, and identify both their possibilities to support the community as well as the limitations of their intervention. During this process volunteers identify the strengths of the community, the extent of existing support from government agencies and other non-governmental organisations, their willingness and ability to be involved in future projects (for example high mobility between communities prevents interventions as it is not deemed to have a potential for long-term cooperation), and also existing infrastructure. Also in these meetings are identified members of the community who would be willing to assume leadership, and would act as a bridge between the life in the community and the volunteers that represent the organisation. Assemblies provide a base for the initiation of dialogue between the volunteers and the members of the community to identify areas of priority for intervention and improvement of the community life.

Meetings with the families take place after decisions are made as to who is to be assisted - according to the demands of resource management - in order to explain the rationale of the decision-making and to maintain a degree of cooperation with the families on a different level beyond the provision of transitional housing.

In line with an organisational principle to act on an urgent basis, the first stage of interventions involves the construction of transitional housing (semi-assembled wooden constructions that are assembled by the volunteers). The choice of families to receive the temporary housing occurs on the basis of a needs assessment regarding the quality of existing accommodation, income, type/existence 
of work, dependent members, lack of assistance from state agencies or other organizations. Needs are assessed by the volunteers through a questionnaire (adapted to the reality of each country), meetings with the families that wish to be assisted, and assessment of the material conditions of their existing housing.

There was no apparent focus in the interviews with the volunteers in both countries on interventions that privileged specific age groups. Furthermore, there was not a focus on children alone, nor on the role of the parents solely as carers. Indeed, the participants resisted describing particular forms or family structures for intervention, and referred to it as an extended network that supports its individual members. The process of support was rather seen as beneficial to all members of a family. While no families that express an interest are refused help, there was recognition that sometimes single parent families were prioritised as they met the financial criteria for assistance. Similarly, an increased number of children or vulnerable children increased families' eligibility for support on the basis of income criteria. Families were described in the accounts of the volunteers as being responsible to provide a safe environment for its members such as stability and secure routine. Adequate housing was deemed essential for accomplishing this mission. Only after having secured decent and safe accommodation were families seen as able to focus more effectively in securing the means to get out of poverty. Social exclusion, economic hardship, and poverty were cited as affecting the skills and the ability of the families to provide support for their members. The volunteers allowed some degree of control for their partners during the process by permitting them space to define their concept of family and to represent their reality of family life. In this way they recognised the particular factors that shaped the experience, and constrained the agency of families.

There was a focus on families as a space that needs to be assisted and sufficiently resourced in order to deal with the needs of its individual members. Discourses that either construct poor families as either responsible for their poverty or as undeserving, and dichotomies between "deserving versus undeserving poor" were notably absent in the volunteer accounts. An organisational commitment to empowering families and working in partnership was affirmed in the efforts, narrated by the volunteers in the interviews, to promote family participation in the second stage of the intervention: the process of construction of the transitional housing. Families were described as having clear responsibilities during the process of the actual construction to get involved though participation in the actual construction of their house, preparation of the land for the placement of the house, and preparation of food for those involved. Such participation, and a small contribution from the families to the cost of the house was seen by the volunteers as an opportunity for the families to demonstrate their commitment to the project and to this partnership. As one of the volunteers put it: "We aim at facilitating processes for all members of the community... (we aim) for this to be a participative space, where they are central actors...we don't want them to think this is something we are doing for them" [18] (Interviewee 6). In some instances, however, experience of abject poverty renders families unable to fulfil their side of the partnership, especially the responsibility regarding their financial contribution. In the accounts of volunteers from Mexico such barriers were overcome by allowing the families to contribute in any ways/means available to them: "now we have a sewing machine in the office that was given to us 
by a family when we built a house for them...last year our office was full of walnuts families had given us as a payment" (Interviewee 17). This practice draws on a long-term tradition in the Mexican society that involves the exchange of material goods or services in the place of monetary exchange (trueque). This was also possible due to the ability of the volunteers to secure the necessary resources (construction material and money) through cooperation with community and business donations in the context of social responsibility (corporate responsibility). Furthermore, this strategy allowed families with a form of agency that recognised the financial barrier to participation and enabled involvement in the project by building on existing strengths and assets.

There was a clear tendency among the volunteers interviewed to highlight that the organisation was currently undergoing a shift in its priorities and practices. In this new strategy housing is not the sole expression of interventions, but also the establishment of long-term partnership with communities and families. In concrete terms the principles of creating lasting cooperation with the community and implementing "social interventions" are materialised through educational support for children, micro-credit opportunities, support with legal issues and advocacy regarding the fulfilment of rights. Accordingly, the implementation of such interventions is achieved through the establishment of a common space in the community which acts as a point of meeting between community and volunteers, as well as a physical reminder of the commitment of the two parts to maintain cooperation. This shift towards more social interventions was discussed alongside the recognition that poverty is a multidimensional experience, and as such needs multiple responses. This stage of work was presented as having evolved when important conceptual shifts took place within the organisation as a direct consequence of engagement with the families and communities, demarcating thus a progressive understanding of poverty as a multidimensional phenomenon. In the volunteer accounts this is described as a process of adapting organisational processes. This adaptation followed a realisation of the multitude of the factors affecting the lives of the poorest sections of the population, and of the limits of emergency interventions in fighting poverty. Furthermore, families were approached as part of their communities and support involves mobilising all community members: "we work with the community as well to make it all a community process...members of the community or neighbours who want they participate and they say: 'this a first step in making this community a better place"" (Interviewee 8). Therefore, fostering family agency and change was presented to occur through a process of building on the existing relationships and strengths in the community.

The construction of houses and the long-term interventions were seen by the volunteers as a process of learning for both volunteers and families, and as a way to dismantle misconceptions that characterize both sides of divided societies. Regarding the volunteers, divisions expressed in semantic constructions such as "wealthy-deprived" or "rich-poor" are the base through which they are invited to appreciate the effects of poverty, the extent of social inequalities, and their own social position. This occurs through seminar work that takes place in parallel to the construction and the long term interventions, and aims to provide a conceptual frame to the work undertaken and to challenge misconceptions regarding the roots/effects of poverty. In these meetings the teachings of the prominent thinkers of popular education in the region-especially Freire-are used to demonstrate how problems are socially constructed and deeply rooted in the relations of 
power, inequality, and division within the socio-historical context of Latin America. The new volunteers are immersed by the more experienced volunteers in the principles and practice of popular education and community development, and are invited to think about how they can put them into practice in the particular contexts in which they work.

The volunteers approached the process of construction as educational also for those accepting the assistance in the sense that this experience enlarges their perspective of the possibility of a better life. This is seen to evolve in two ways: firstly by giving them the message that the rest of society cares for them, and secondly by showing them that poverty is not happening to them because they deserve it or are defective in some way in comparison to others. As one volunteers stated: "they see we are not that different and worthy for being well off...they see we are normal people" (Interviewee 4).

Therefore, the work of the volunteers was not only understood as building upon existing relationships within communities to deliver support for the families. Additionally, creating relationships between volunteers and families was seen as an essential part of the process, and of mutual benefit.

Discourses that hold families responsible for their misfortunes were approached as an outdated form of citizenship, characteristic of older generations. Volunteer work was framed as an effort to challenge such divisive language and understandings, described as pertinent in the Latin American context. Some volunteers engaged with such concepts in an effort to exhibit their understanding and empathy "the families have lost their hope...you have to bring hope back...you get angry sometimes...you get sad...you say: "why am I working with you?"...but that's their way to show their poverty...the drugs, the violence...to show they are not happy with their lives" (Interviewee 9).

The above comment echoes the narratives of liberation theology where hopelessness is directly linked to powerlessness [18]. Hope in anti-oppressive practice is to be restored through bringing together people who suffer similar forms of oppression and to help them to understand the roots of their oppression, re-discover confidence, and reclaim a sense of dignity. Similar narratives are evident when volunteers discuss the impact they wish to achieve within the communities. In many accounts the desired "impact" of working within communities was framed around families becoming more able to recognise their own strengths and capable of assessing their vulnerability. The language employed, both in the interviews and the volunteer meetings and workshops, resembled a form of Freiran popular education, where vulnerable families are seen as creators of change themselves through new knowledge, dialogue, analysis, and participatory methodologies [19]. This process of "autoreconocimiento" (self-recognition), as one volunteer called it, includes families and communities understanding who they are, the particular elements of their identity and how these exacerbate their vulnerability as to: "be motivated to do something and not see us as an organisation which does the work for them... and also (to generate) the empathy needed on a collective level" (Interviewee 7). Thus, processes within the community, described in the above stages, were seen by the volunteers as a way to break down the divisions between social classes in the Latin American context. They were seen as a form of popular education that highlights the importance of investing time in allowing people to reach their own analysis of their social reality through prioritizing "the process by which the poor come to understand that poverty and oppression is not 
their fault nor is it inevitable" ([20], p. 268). This educational process allows the families to understand the factors of their vulnerability, and enables the emergence of possibilities for a better life.

\section{Insights: Strengths and Complexities in Working with Families}

The examples and processes discussed, although initially designed as community rather than family interventions, bear important insights regarding work with families with complex needs.

The first set of insights relates to conceptualisations of family structures. Family was described in broad terms, and was understood as a group of interdependent individuals with shared needs and interests. While risk or problematic behaviour was recognised as part of the daily experience of families, the attention was placed on the socio-political inequalities that were perceived to impact directly on families' ability to support their members. Changes in family behaviour were expected not as direct result of the short-term intervention, but as the outcome of a long-standing process that empowers families to overcome structural inequalities. There were no proposed family structures or forms: by avoiding pre-determining family forms and by defining family structure and relationships the way its members understood them, the volunteers allowed flexibility for recognition of the complexity of daily family life. This generated space for establishing more meaningful partnership with the families and enhanced their ability to better address the issues arising within particular families. Thus, the volunteers in the narration of their practices allowed for the redefining of family as an enabling and contextual network.

This contradicts a wider policy shift towards more child-centred models of practice that has also become increasingly relevant within organisations and public bodies in the Latin American context. In this model support becomes conditional upon certain behaviours regarding children's health and education, it is delivered within nuclear family structures, and the role of parents (especially mothers) is constructed as one of caretakers $[1,8,9]$. This often can lead to a pathologising of families who are unable to handle risk, and increase their children's capabilities for the future [8,21-23]. It also has the potential to privilege professional or expert-led intervention, which strips family of the ability to make decisions regarding the wellbeing of its members. The approach to family identified within this study resemble what Hughes [24] (commenting on the UK context) calls "whole family approaches" in that it tends to conceptualise family widely, favours work with "naturally occurring family structures", and encourages multi-agency work for family empowerment. However, instead of a democratisation of decision making and a "relocation of rights and responsibilities" discourse - as in "whole family" approaches - the volunteers employed a social justice discourse that is looking mainly outside family for the causes and solutions to family poverty. This first set of insights contributes to a discussion about how to maintain an interest in children's needs, without losing sight of the family as a system reshaped through its networks and interpersonal interactions.

The second set of insights refers to the Techo approach of working with families. The volunteers perceived their work with families as a process of mutual learning. An attitude of increasing awareness, generating collaboration, and seeing families as partners generates practices of co-creation rather than expertise-led interventions. This stems from particular forms of social solidarity and social analysis that is not based on a "zero-sum" conception of power relations. Thus, interventions are not designed to revert to binary oppositions between "powerful" and "privileged" volunteers 
with "powerless" and "disadvantaged" families. Practices in the local context are rather understood as creating a common space for the cultivation of mutual understanding. Seeing families as partners also promotes family agency that is based on strengths and recognition of what is possible in the future.

Recognition of such family agency also benefits more effective practice as it allows joint assessment of when, whether, and how far solutions lie within families themselves, or in the socio-political context that impacts family lives and family's ability to sustain the wellbeing of its members. It also leads to developing alternative strategies such as increasing family capital and extending networks. The extension of networks was demonstrated in the examples discussed above, where family support "in its widest sense becomes the basis from which other work proceeds" ([25], p. 115) in the broader community. Involving community in the work with families, through provision of space and participation in events and assemblies, shows a particular interest in connecting (often separated/excluded) families with their micro-communities and the broader communities. This also can promote community responsibility for the families and especially for making sure the rights of the children within these families are secured by minimising the effect of structural barriers.

An important insight arising from the volunteer accounts relates to their focus on restoring hope and optimism against existing hopelessness and fatalism. This discussion of hope and fatalism demonstrates the importance of feelings in family agency. Such an acknowledgement of family and its members as social actors able to make decisions in both cognitive and emotional ways, introduces a different dimension in the exercise of agency beyond cognitive evaluation. In this type of agency, emotions act as "intelligent responses to objective circumstances" ([26], p. 2) and as "commentaries on our situations" ([26], p. 7). Volunteers appeared in the examples to support projective elements of agency by allowing families to assess and reconfigure their hopes and think about future alternatives. Working with families can act as terrain that enables family members to think about where they want to be or can be in the future, what possibilities of "manoeuvrability" are possible within existing structures, and to correspondingly engage in the partnership [27]. This is well exemplified in the experience of the director of Mexico's office when she narrates in a journal interview about her first experience of constructing houses in the south of Chile: "When we finished building I burst into tears because I thought the house we built was better than what they had before but it wasn't sufficient for them, and I said to the lady (for whom the house was being built for): 'this can't be the house of your dreams' and she responded: 'no it is not the house of my dreams but it is a roof that allows me to dream"” ([28], p. 10).

This projective element of agency involves the ability of families to distance themselves from their current experience, to generate alternative schemas, and to identify future possibilities for action taking into account family hopes, fears, and desires. It includes the capacity to construct the relevant narratives and to propose solutions on existing problems. It is in the last potential to propose solutions for action in the present that the value of projectivity lies: it is not the future outcomes on their own that are important, but also the socio-cultural processes generated when people engage in imagining the future, talk about it, and make commitments to these aims by altering behaviour in the here and now. Therefore, family working and fostering of agency through recognition of emotion, promotion of hope, and projective thinking is a point for reflection 
regarding current policy dominated by a tendency to privilege clear and routinised (technical/rational) forms of interventions. While a future focus is prevalent in current policy-and especially within policies focusing on strengthening family through child-focused initiatives - it stems from an interest to prevent risk and create social capital rather than an interest in exploring families' "social capacity to act, alone or with others, upon boundaries that shape one's fields of action" [29].

The final set of insights relates to the limits regarding work with families described in this article. Local power relations within communities undeniably affect the outcome of interventions and challenge romantic versions of community work that assume members of the community as transcending existing relations of inequality and working for the benefit of all members. Families choose to enter partnerships after assessment regarding access to resources, understandings of power, politics, and self-interest. Furthermore, families that experience multiple disadvantages often lack the skills, knowledge, and confidence to take part in community events and even more in decision-making processes. For Cornwall and Coelho ([30], p. 13) actors within communities might be encouraged to enter partnerships and spaces for participation, but as they may lack the skills to communicate their wishes, it is left to the mediators to represent them and as such this process bears the risks that the mediators or representatives might "amplify the voice" and "purify the knowledge" ([31], p. 146) of the participants by employing their own interpretations and means of communication. Even when families are engaged in partnerships, there is the potential for the creation of "empty spaces" [32] where structures are established in the community and are (despite their name) filled with participating community members but they lack the ability to deliver about social change due to existing power dynamics. Such power dynamics are expressed through existing tensions, and unequal access to services and support. For example, volunteers in Mexico discussed how decision making regarding the allocation of transitional housing for families in the community was based on the "hard data" provided by the residents when they administered their questionnaire. When decisions were challenged by the residents the volunteers attributed it to the computer: "we tell them it's not us...it's the computer...we insert their answers in the computer and the computer makes the decision". By seeking to invest their decisions with "scientific respectability" the volunteers attempted to manage tensions within communities regarding existing competition among families for scarce resources. This example fits well within arguments that challenge idealistic views of community as a site of radical transformation and free from unequal power relations. Power inequalities are also expressed through spatial segregation within slums themselves and affect the ability of families to take part and build partnerships. In the micro-community described at the beginning of this paper, for example, families that participate in partnership with volunteers tended to concentrate in the centre of the slum while those with less involvement are located towards the geographical margins of the camp.

The examples discussed highlight the importance of working with families as whole and as members of existing networks. At the same time, however, they generate thinking about how particular sections of the community and members of families may not be included in the process. Relevant here is a concern about the impact of such interventions on the weakest or silenced members of the families themselves such as children and women. Critiques concerned with issues 
of intra-familial resource distribution would assert that while fighting family poverty is important, it will not necessarily deal with issues of child poverty and lack of voice, or rights within the family structure [25]. Thus, while interventions may improve the wellbeing of family as a group their impact may be uneven for different family members, especially children and women. In this way, the dilemma and challenge for practice becomes how to strike a balance between considering family as a whole and at the same time retain an interest in the least heard voices within the family context itself.

The last three points highlight the strengths and complexities of such approaches and contribute to a discussion that underlines how families need to be understood as complex, dynamic, and context specific entities that are re-configured through their networks and interpersonal interactions, and subject to particular plays of power relations.

\section{Concluding Remarks}

This article provided an example of working with families which comes from a nongovernmental and youth-run organisation in the Latin American context. Most literature is focusing on families and their role to protect children from risks and to create future opportunities. The very nature of the organisation meant that approaches to working with families were not devised in tandem to formal government policies but according to the organisational priority of reducing poverty. This has given volunteers the flexibility to work and adapt their practices to what was working better with families and as such the approaches described here are the result of interaction and joint work with families. At the same time, organisational shift towards more long-term educational and social in nature interventions reflects the paradigm shift in the region from a focus on policies that construct poverty and work with poor families in terms of emergency relief to a human capital perspective. These paradigm shifts have major impacts on the strategies adopted regarding family interventions and especially where the attention is to be placed. The process that the volunteers described as a "shift" is to be located within a broader context of an effort to both retain a language and approach inspired by the theoretical innovations of social justice and transformative visions of learning pertinent to the region, and at the same time to incorporate projective thinking regarding the scope of social justice. Recognition that emergency housing for families addresses a particular family issue, but it may not alleviate other aspects of their vulnerability, led to a wider conceptualisation of poverty as multidimensional and reconfigured the aim and breadth of interventions to include a variety of issues beyond the lack of material necessities.

The aim of this article is not to suggest that this is a better or more efficient approach to work with families. As this is a highly contextualised example that reflects the socio-political shifts of the particular region, its applicability to other contexts is questionable. However, the examples in this article can be useful and can contribute to a discussion with regard to the rationale underpinning policy and practice in working with marginalised families. In particular to a discussion about how families and disadvantage is constructed, and also how routinised professional expertise and bureaucratization may interfere in processes and may create resistance among service users. In many of its aspects this approach reflects the basis of what Hughes [24] calls whole family approaches, in that it shares characteristics such as an empowerment intention, promotion of 
networks of support, wider conception of family, and family-led decision making. Despite cooperating with state agencies this project still functions in the margins of the state in the sense that it works with those left out of the official system of support or other NGO assistance. It, therefore, enjoys a degree of freedom or ability to innovate, and adapt methods in practice and in cooperation with those assisted.

As the policy context of Latin America (and elsewhere) becomes increasingly more child focused, with an interest in breaking the intergenerational transmission of poverty through early childhood programmes and education [33], it is of increased value to reflect on broader approaches like the one described in this article. Such broad approaches to working with families need further investigation to assess how to develop and sustain interventions that take into account the strengths of the family, and take on board the interest of all its members. From a development perspective Amartya Sen ([34], pp. 76-77), while he recognises the importance of a holistic approach in family work, he calls for analytical distinction and empirical differentiations which highlight the role of investing in children in particular, as "the whole might be more than the sum total of its parts, but we have to be quite clear as to what the parts are before we appraise the whole". Nevertheless, the flexibility and the ability within the organisation to contextualise practice to the particularities of each different country, is a good starting point for reflection.

\section{Acknowledgments}

The author thanks Nathan Hughes for his support regarding the implementation of this project and his helpful comments on the earlier version of this paper. This project was supported by the international research staff exchange scheme: "Understanding and supporting families with complex needs" (Marie Curie Actions/EU-FP7 Framework).

\section{Conflicts of Interest}

The author declares no conflict of interest.

\section{References}

1. Jane Jenson. "Diffusing ideas after neo-liberalism: The social investment perspective in Europe and Latin America." Global Social Policy 10 (2010): 59-84.

2. Mahia Saracostti. "Social Capital as a Strategy to Overcome Poverty in Latin America." International Social Work 50 (2007): 515-27.

3. Armando Barrientos. "Protecting Capability, Eradicating Extreme Poverty: Chile Solidario and the Future of Social Protection." Journal of Human Development and Capabilities: A Multi-Disciplinary Journal for People-Centered Development 11 (2010): 579-97.

4. Carole Rakodi. "Representation and responsiveness-Urban politics and the poor in ten cities in the south." Community Development Journal 39 (2004): 252-65.

5. Janet L. Finn. "The women of Villa Paula Jaraquemada: Building community in Chile's transition to democracy." Community Development Journal 36 (2001): 183-97. 
6. Humberto Lopez, and Guillermo Perry. "Inequality in Latin America: Determinants and consequences." Policy Research Working Paper 4504, the World Bank Latin America and the Caribbean Region Office of the Regional Chief Economist, Office of the Regional Chief Economist, Santiago, Chile, February 2008. Available online: https://openknowledge. worldbank.org/bitstream/handle/10986/6368/wps4504.pdf (accessed on 25 October 2014).

7. Kelly Hoffman, and Miguel Angel Centeno. "The lopsided continent: Inequality in Latin America." Annual Review of Sociology 29 (2003): 363-90.

8. Francesca Bastagli. "From social safety net to social policy? The role of conditional cash transfers in welfare state development in Latin America." Paper presented at the RC19 ISA Annual Conference on Social Policy in a Globalizing World: Developing a North-South Dialogue, Florence, Italy, 25 September 2007.

9. Francesca Bastagli. "Conditional Cash Transfers as a Tool of Social Policy." Economic \& Political Weekly 46 (2011): 61-66.

10. Ariel Fiszbein. Beyond Truncated Welfare States: Quo Vadis Latin America. Mimeo: The World Bank, 2005.

11. Armando Barrientos. "Social Protection." In Internationl Development: Ideas, Experience and Prospects. Edited by Bruce Currie-Alder, Ravi Kanbur, David M. Malone and Rohinton Medhora. Oxford: Oxford University Press, 2014, pp. 188-203.

12. Evelina Dagnino. "Meanings of Citizenship in Latin America." IDS Working Paper 258, Institute of Development Studies, Brighton, UK, November 2005. Available online: http://r4d.dfid.gov.uk/PDF/Outputs/CentreOnCitizenship/Wp258.pdf (accessed on 23 October 2015).

13. Lance W. Bennet. "The personalisation of politics: Political Identity, Social Media, and Changing Patterns of Participation." The ANNALS of the American Academy of Political and Social Science 644 (2012): 20-39.

14. Norman K. Denzin. "Interpretive interactionism." In Applied Social Research Methods Series, 2nd ed. London: Sage Publications, 2001, vol. 16.

15. Charles C. Ragin. The Comparative Method: Moving beyond Qualitative and Quantitative Strategies. Oakland: California University Press, 1989.

16. Bent Flyvbjerg. "Five Misunderstandings about Case-Study Research." Qualitative Inquiry 12 (2006): 219-45.

17. Norman K. Denzin. "Interpretive Interactionism: A Postmodern Approach to Everyday Life." In Encountering the Everyday: An Introduction to the Sociologies of the Unnoticed. Edited by Michael H. Jacobson. Basingstoke \& New York: Palgrave Macmillan, 2009, pp. 397-422.

18. Carolina Muñoz-Guzmán. "Liberation Theology and Social Work: Anti-Oppressive Common Grounds." International Encyclopedia of Social and Behavioral Sciences, 2015, forthcoming.

19. Liam Kane. "Community development: Learning from popular education in Latin America." Community Development Journal 45 (2010): 276-86.

20. Jenny Pearce, Joanna Howard, and Audrey Bronstein. "Editorial: Learning from Latin America." Community Development Journal 45 (2010): 265-75. 
21. Kate Morris, Nathan Hughes, and Harriet Clarke. Think Family: A Review of Whole Family Approaches. London: Cabinet Office, 2008.

22. Kate Morris. “Thinking Family?” British Journal of Social Work 42 (2012): 906-20.

23. Harriet Clarke, and Nathan Hughes. "Whole Family Approaches: Understanding and Responding to Complex Needs." Social Policy and Society 9 (2010): 527-31.

24. Nathan Hughes. "Models and Approaches in Family-Focused Policy and Practice." Social Policy and Society 9 (2010): 545-55.

25. Lena Dominelli. Social Work: Theory and Practice for a Changing Profession. Cambridge: Polity, 2004.

26. Anthony Sayer. "Chapter 3: Bourdieu Ethics and Practice." 2009. Available online: http://www.lancs.ac.uk/fass/sociology/papers/sayer_chapter3_bourdieu_ethics_\&_practice.pdf (accessed on 15 July 2013).

27. Mustafa Emirbayer, and Anne Mische. "What Is Agency?" The American Journal of Sociology 103 (1998): 962-1023.

28. Jose Sifuentes. "El Techo es el Primer Paso. Entrevista a Soledad Acuña, Directora de Techo Mexico." Initiativa Año 1 (2013): 9-12.

29. Clarissa R. Hayward. "De-facing power." Polity 31 (1998): 1-22.

30. Andrea Cornwall, and Vera Schatten Coelho. "Spaces for Change? The Politics of Participation in New Democratic Arenas." In Spaces for Change? The Politics of Participation in New Democratic Arenas. Edited by Andrea Cornwall and Vera Schatten Coelho. London: Zed Books, 2007, pp. 1-29.

31. Uma Kothari. "Power, knowledge and social control in participatory development." In Participation: The New Tyranny? Edited by Bill Cooke and Uma Kothari. London: Zed Books, 2001, pp. 139-53.

32. Ranjita Mohanty. "Gendered Subjects, the State and Participatory Spaces: The Politics of Domesticating Participation in Rural India." In Spaces for Change? The Politics of Citizen Participation in New Democratic Areas. Edited by Andrea Cornwall and Vera Schatten Coelho. London: Zed Books, 2007, pp. 76-94.

33. Ricardo Morán, ed. Escaping the Poverty Trap: Investing in Children in Latin America. Washington: American Inter-Development Bank, 2003.

34. Amartya K. Sen. "Investing in Childhood." In Escaping the Poverty Trap: Investing in Children in Latin America. Edited by Ricardo Morán. Washington: American Inter-Development Bank, 2003, pp. 61-81. 


\title{
Objective Structures and Symbolic Violence in the Immigrant Family and School Relationships: Study of Two Cases in Chile
}

\section{Rayen Cornejo Torres and Ariel Rosales Ubeda}

\begin{abstract}
The historical trend of migration processes in Chile faces a challenge given the incremental growth of immigration during recent years. This study focuses on the relationship between family and school, distinguishing within it the particular relationship between immigrant families and school agents. The qualitative approach applied here enabled a focus on the effect of the cultural diversity that immigration produces, including the configuration of conflicts between immigrant families and the school institution. The main issues discussed in this article concern the approach and the nature of interaction between schools and immigrant families. This approach is articulated with the observed emergence of symbolic violence. The characterization of the conflict of expectations among immigrant families and schools is also described, suggesting the need to rethink the practices associated with an inclusive education that allows the integration of immigrant families.
\end{abstract}

Reprinted from Soc. Sci. Cite as: Torres, R.C.; Ubeda, A.R. Objective Structures and Symbolic Violence in the Immigrant Family and School Relationships: Study of Two Cases in Chile. Soc. Sci. 2015, 4, 1243-1268.

\section{Introduction}

This study focuses on the relationship between family and school, distinguishing within it the particular relationship between immigrant families and school agents in Chile. Immigration has become a public problem in Chile, and a relevant issue in Latin America. According to the World Bank [1] there are more than 215 million international migrants ${ }^{1}$ worldwide. The 2011 study "Migration and Remittances" from the World Bank shows figures that help understand the context of international migration. The information presented by this study shows that more than 215 million people $(3.0 \%$ of the world population) live outside their countries of origin, a figure that has increased from the 191 million people in 2005 [2], but has decreased since 2011.

The main destinations of migration flows are the developed countries. The World Bank notes that the first migration destination is the United States (US) [1]. Nevertheless, between 2005 and 2010, there has been a surge in flows of immigrants into the United Kingdom (UK), mainly from Eastern Europe, as well as from Latin America and North Africa [1].

Latin American and Caribbean migrants represent an important percentage of the international migratory movement. The Comisión Económica para América Latina y el Caribe (CEPAL) estimated that there are about 28 million Latin Americans and Caribbeans living outside their home countries [3]. The volume of migration among developing countries has increased over the last

1 According to the International Office of Migration (2011), some of the reasons for international migration are the following: the political transition in North Africa and the Middle East in 2011, increased natural disasters and displaced people, increased armed conflict, and economic crises in developing countries. 
decade and is relatively higher than the Latin migration to high-income countries belonging to the Organization for Economic Co-Operation and Development (OECD). During the last decades Chile has increased heavily the numbers of immigrants arriving at our land.

During recent years, social diversity and cultural heterogeneity in Chile have increased [4]. Among the several phenomena that have strongly influenced the growing differentiation of the population, immigration has become key. The cultural diversity that accompanies immigration renders, in turn, the delivery of social services difficult.

The education system is a realm where several social agents interact, and it is organized mainly as a result of rules agreed on and regulated by the state. Within this social field different participants' expectations and dispositions meet, including those of students, families, school administrators, and teachers [5]. While there may be a high degree of functional harmony, this may also induce conflict. Each agent perceives, thinks, and acts differently, provoking disagreement and conflict. The various dispositions among these agents do not necessarily support each other, nor are they necessarily in agreement with the rules of the education system. This produces incompatibilities, discrimination, and violence in several directions, and this is what this article makes visible.

On top of these aforementioned challenges, immigrant families endure many difficulties affecting social integration, which may obstruct the learning process of their children [6]. The problems faced by families are diverse and with distinct complexities; these are associated with dispositions influenced by the size of a series of capitals - cultural, social, economic - giving support to the meaning of their practices.

On the other hand, the homogenous character of frameworks and demands of Chilean policy results in a lack of ability to fully and properly deal with the existing cultural diversity in educational institutions with high degrees of immigrant populations [7]. This obstructs the learning processes and affects the way students - and families - from external cultures integrate in the educational system.

Even though advances in coverage and quality of education are credited to the Chilean educational system, several challenges persist; one of these is associated with the recognition of social diversity in the educational processes and strategies. Thus, there are some deficiencies associated with the appreciation of alternative points of view of both indigenous people as well as immigrants who have become part of the national population.

In Chile, the immigrant population continues to increase steadily $[4,8,9]$, and schools and immigration-related institutions cannot merely neglect a new multicultural reality in the classroom. Hence, students from different corners of Latin America, along with their families, get incorporated as new actors in this social field.

In 2010, the Departamento de Extranjería y Migración (Department of Foreigners and Migration) [9] calculated proximally the presence of 352,000 foreign people in Chile. This figure corresponded to about $2 \%$ of the total population. This presented an important increase with respect to the census of 2002 [10]. In addition, $73 \%$ of the foreign residents in Chile corresponded to people from South America [9]. It showed an important contrast compared with the profile of immigration 
between the 19th and the first half of the 20th centuries, consisting mainly of people coming from Europe $[4,10,11]$.

The new profile of immigrants has acquired more visibility, giving a new meaning to the migration process $[4,12]$. There is currently a cultural dichotomy about appreciation/rejection. On the one hand, European immigration is considered positive for national development $[4,12]$. On the other hand, the arrival of Latin American immigrants is seen as harmful because they are stigmatized as delinquent, poor, and inferior to non-immigrants [4]. This situation has contributed to the perception that the current migratory movement is a social problem [13].

There are different causes for immigration from South America depending on the countries of origin. The immigrants from Argentina tend to arrive for familial reasons, while the people from Peru, Ecuador, and Bolivia seek employment [9,10]. In this last group, there is a predominance of females seeking work in domestic services. The latter has been labeled as "the feminization of migration",2 $[4,10,11,14]$.

According to Tijoux [15], one of the most important effects of this phenomenon is the increase of familial reunifications. This brings new difficulties to family life, since these newly arrived children lack the support of their extended families. Not unusually, these children are left alone, are taken care of by the neighbors, or stay simply locked inside. These situations influence the child's socialization [15].

Additionally, the cost of life in Chile and the difficulties in finding formal employment imply the danger of labor exploitation, of living in poor accommodation, and of experiencing discrimination. This context facilitates physical and psychological abuses of immigrant children, which negatively affects their emotional stability [16].

The international migratory movement has forced the reformulation program in various public services in recipient countries, as in the case of education in Chile.

Concerning education, Chile signed the International Covenant on Economic, Social and Cultural Rights. It recognizes the right of education for every child, whether Chilean or foreign [15]. Regardless of whether immigrant children have Chilean documentation or not, admission to the education system must be granted for all children.

According to OECD data, inclusion of immigrant students in Chile accounts for the $1 \%$ of total enrollment, similar to the rate of countries like Brazil, Colombia, Peru, Turkey, Hungary, and Thailand [8]. Various studies [7,8] indicate that the presence of immigrant students in the Chilean education system is mainly influenced by the socio-economic and employment situation from both families and countries of origin ${ }^{3}$.

While the distribution of students (first and second generation) from foreign origin is given throughout the country, it concentrates in the regions of Tarapaca, Antofagasta, and mainly in the metropolitan area, which has more than $60 \%$ of the immigrant population. Within this region, establishments with a high percentage of immigrant students are mostly in the areas of Santiago, Independencia, Estacion Central, and Recoleta.

2 According to Martinez (2003) one of the effect of the femenization of migration is family reunification, among others.

3 This article considers immigrants and children of immigrants born in Chile as a unit of analysis. 
Data on cultural heterogeneity of the Chilean education system indicate that 4711 of 12,063 (39\%) registered establishments in 2011 had immigrant students, while over 6000 establishments did not register any. The numbers indicate that, on average, there are about seven immigrant students per establishment. In schools with enrollment of foreign students the dispersion varies between $2 \%$ and $100 \%{ }^{4}$; in other words, there are institutions with very low immigrant populations and others where all students are children of immigrants [8].

The growing presence of foreign students in the Chilean education system has led the state to take action to promote the integration of immigrant students in schools through various initiatives. One of them is the "right to education for children and young migrants" program, which focuses on the student and downplays the importance of the relationship between schools and families in the educational development of students.

Therefore, immigration and school play a relevant role favoring integration and inclusion. In this article, the family-school conflict is analyzed in the context of a high foreign population within Chile's education system ${ }^{5}$. The study illustrates the described conflict by presenting three issues of particular importance. First, the aspects obstructing the interaction between families and schools are described. Second, differences in expectations constituting the basis of the conflict are considered. Finally, the establishment of the symbolic violence operating in this relationship is exposed.

Chile has not developed studies on the family-school relationship in the context of the migrant population. In this scenario, this study has a double significance. On one hand, it provides theoretical information about how the links between families and schools are presented in contexts of high migration, adding cultural diversity, something that has not been done so far in national studies. On the other hand, findings contribute to the development of cultural integration initiatives in education, by questioning the dynamic between actors and guiding the proposal designs to improve intercultural understanding in the relationship.

\section{Methodological Aspects}

\subsection{Aims}

The general aim of this article is to analyze, from a Bourdieuninan perspective, the conflict between family and school in a context of a high immigrant population. The characterization of the conflict, regarding different expectations in families and in schools, is performed using the

4 The data does not reveal if students are immigrants of first or second generation. In Chile there are only three schools with $100 \%$ foreign registration.

5 Chile's school system is complex and diverse in terms of its administration. It is characterized by a decentralized organization, meaning that its management is performed by municipal institutions, private individuals, and foundations (privates backed with state subsidies), who take the duty of providing education and keeping schools working. In this context, Chile's educational system has three types of schools: public (state-owned), fully private, and subsidized private schools. Along with this, the Ley Orgánica Constitucional de Educación (1990) guarantees the right of the education centers to elaborate on and apply their own teaching programs in an autonomous and non-centralized way. This legal entity ensures everyone the right to education from infant schools on, and establishes teaching liberty as the guiding principle of politics and educational organization in the country. 
theoretical perspective of Pierre Bourdieu [17] in order to qualitatively analyze the results of an empirical study in two schools in Santiago de Chile serving a relevant population of international immigrants.

Specific aims are:

(1) To characterize the main difficulties immigrant families faced during their process of integration into the socio-educative realm;

(2) To define the facets of the conflict between family and school;

(3) To explore the presence of symbolic violence in this relationship.

\subsection{Study Design and Sampling}

This is a qualitative study that explores the relationship between families and elementary schools in high-immigration areas in Santiago de Chile. This is exploratory research due to the lack of previous research in this area.

The selection of schools has non-random criteria, associated with the high number of immigrants present in each school. It stands out that, at a national level, there are two schools with the largest number of foreign students.

One of the schools, known in the study as RA, has received immigrant students since 2000 and has been considered a pioneer countrywide in teaching foreign students. Currently, this school implements its own educational project. The other school, known as ULA, has received foreign students for the last five years, and is still developing its educational project.

A convenience sampling was used ${ }^{6}$, hence the selected schools - serving both international migrants and Chilean students - are not representative of the Chilean school system as a whole. In summary, this non-random exploratory study does not guarantee the representativeness of the sample and, therefore, the results cannot be generalized. Nevertheless, the schools being studied receive the largest immigrant populations; therefore important practice developments can be highlighted from these two key institutions.

Inside of these schools the key informants for the study were chosen according to their degree of representativeness among the various actors involved in the educational community. In this way, this study incorporates the views of professional school workers such as teachers, social workers, psychologists, and school managers, who had worked in the school for at least one year. On the other hand, different kinds of families whose children attended the schools were also represented in this study. The sample includes immigrant parents (mainly from Peru, Ecuador, Colombia, Haiti) as well as Chilean parents because both are in the educational community and have their own views regarding the other families and the relationship with the school. The sample also included groups of parents with different levels of participation in the school (for example, some visited the activities organized by the institutions regularly and others only seldom), and the families, therein, were selected by recommendation from the school personnel, keeping in mind the above criterion of

6 This type of sampling selects research units that meet the requirements of the population under study, but nevertheless, they are not selected randomly. It is preferably used in exploratory studies. The pilot tests also often use this type of sampling. 
diversity. As a prerequisite, the children of these families must have attended the respective school for at least six months.

\subsection{Data Collection}

The data collection took place between March 2012 and July 2013 and included 38 interviews. These interviews were performed inside the schools, as a face-to-face conversation between the researcher and the parent. The average time of such a conversation was 50 minutes. There were two sets of questions: one for the parents, concerning their view of the school, their relationship with it and with other families - including nationals and immigrant families - and their family life, and another for the school team, regarding their role in the school and their relationship with families and immigrant families. In each instance, anonymity and confidentiality were ensured and informed consent was obtained. Interviews were transcribed verbatim. Fieldwork was finalized when the information obtained reached "saturation" along the triangulation by itinerancy of data [18].

Alongside the fieldwork, a literature review of academic research was undertaken, principally regarding Bourdieu's work [5,17,19-22], as well as research about immigration in Chile and education $[4,6-10,15]$.

\subsection{Analysis and General Discussion about Pierre Bourdieu}

In this article, a thematic analysis approach based on Bourdieu's perspective is adopted, and with this, the preliminary categories are developed (see the end of this section). This method identifies themes or patterns within the data [23]. All the information was codified according to the preliminary categories identified from the literature, with new categories subsequently developed from the data.

Pierre Bourdieu's theoretical perspective examines social order, and postulates that in order to do so, it is necessary to reject, as a sole possibility, both the structuralist point of view, according to which structures reproduce with the forced participation of agents under coercion, and the interactionist or ethno-methodological perspective, according to which the social world is a product of the actions of creation that, moment after moment, the actors perform [19]. For the author the answer lies in the articulation of both theoretical perspectives.

The social world implies a dual existence. It finds itself imbedded in an internal dynamism, which simultaneously includes objective structures - objects, institutions, etc. - as well as subjective structures associated with the agents' dispositions. Every society rests over the relationship of two dynamic principles: one is the objective structures, referring to the distribution of capitals - cultural, economic, social, symbolic, etc.- - as well as the mechanisms guaranteeing its reproduction; and the other is in the subjective representations of the agents. The relationship between these two principles tends to organize the social forms and the reproduction strategies that accompany them (see Table 1). 
Table 1. Definitions and expressions of capital according to Bourdieu.

\begin{tabular}{ll}
\hline Type of Capital & Definition \\
\hline Economic & $\begin{array}{l}\text { Control over economic resources. This type of capital can be converted into money, and is } \\
\text { an essential source of political power and hegemony [21]. }\end{array}$ \\
\hline Social & $\begin{array}{l}\text { Typically, intangible resources based on the membership to a group, relationships, } \\
\text { influence, and collaboration networks [21]. }\end{array}$ \\
\hline Cultural & $\begin{array}{l}\text { The categories of knowledge, education, skills, and advantages that a person has and that } \\
\text { give him/her a higher status within society. In principle, parents provide their children a } \\
\text { (institutionalized) } \\
\text { certain cultural capital, transmitting them attitudes and knowledge necessary to develop in } \\
\text { the current educational system [21]. }\end{array}$ \\
\hline Consists in a series of intangible properties inherent to the subject, which may uniquely \\
exist as long as they are recognized by the rest. It can only be attained after acquiring the \\
other capitals [21].
\end{tabular}

From such principles Bourdieu [21] defines society as a social space structured by the relationship between objective structures (capitals) and subjective (habitus) ones at the agents' disposal (among them the family). This structuralization transfers to different fields which compose the social world. Each field is relatively autonomous in its functioning; hence, each of them fixes their own rules to protect themselves from the heteronomic influences of the other ones [22,24]. From this point of view, there are different social fields coexisting in the social space whose limits are given according to their effectiveness to influence and implement rules that regulate the social relations of the agents.

Bourdieu [21] remarks that a "social field" is a space of action where agents interact and conflictive social relationships are established as a product of the differences between the dispositions of each of them. Social practices are based on regularities associated with a socially structured environment producing habitus [21]. Thus, habitus constitutes itself into the main generating principle of the social practices.

For Bourdieu, habitus ${ }^{7}$ is the set of generative schemes from which the agents perceive the world and act in it. These schemes are socially structured, meaning that they have been conformed to throughout the history of each agent and suppose the internalization of the social structure, the concrete field of the social relationships in which the social agent has conformed to as such. However, at the same time, they are structuring; they are the structures from which thoughts, perceptions, and agents' actions are produced [25].

The constitutive dispositions of the habitus - inculcated in a lasting way by the objective conditions and by a pedagogical action that tends to adjust to those conditions - are prone to engender expectations and practices objectively compatible with such conditions and are adapted ex ante to their objective requirements; put differently, by being a product of certain types of objective

7 The habitus is a system of different types of dispositions which enjoys a certain volume of expanded or diminished dispositions and a trajectory of acquisitions in time, making the agents have the capacity to generate practices and representations in the fields since these dispositions are engendered in their experience. Thus, the practices are meaningful and they are reasonable [19]. 
regularities, these general and transferable dispositions therefore tend to engender all "reasonable" practices which are possible within these limits, and only in their setting.

The theoretical core of Bourdieu's perspective maintains that social relationships are the result of the internalization of a set of cultural practices and social appreciations which are perceived as "normal" by the agents that experience them and which condition their social practices [19]. Related to this, Karen O'Reilly [26] approaches the migration phenomenon from the theoretic perspective of Bourdieu, specifically emphasizing how the habitus explains the internalized schemes of the social agents, since these vary with the migratory practice. There are also other perspectives interested in the migration phenomenon from Bourdieu's perspective that emphasize the notion of habitus as well ${ }^{8}$. This means that despite the differences in power, wealth, and a series of other resources and capitals, the ascribed and the incorporated habitus ${ }^{9}$ in the agents signals the trajectory and at the same time structures their axiological dispositions. In other words, the resources and activities of human capital (education), social capital (information, contacts, influences, networks), and cultural capital (values and behavior styles), among others, at the disposal of people and homes, allow them to improve or maintain their social insertion and/or reduce or reproduce their social vulnerability.

This shows that beyond the economic differences, in society, there are other distinctions separating the agents depending on the social environment and differentiation factors that are internalized and reproduced by the agents in various fields. Everyone adopts habits, behavioral ways, and attitudes of their original social environment, inheriting differentiated know-how and tastes whose profitability achieves to be differentially efficient in time within the social space. This means that every interaction has a cultural reference point and refers basically to a "way of life" shared by the people of the same original culture in given historical and societal contexts.

According to this view, it is assumed that social differences are not exclusively related to economic capital, since the latter is not the only one structuring social divisions, as classical Marxism would have it. There are other forms of capital - cultural, social, symbolic, political, bodily [19] - incorporated in the discussion around social distinction, which are structuring factors of the distinction. Along this line, the structuration of strata and social classes is nothing more than the product of the degree of existence of the different types of capital. This is to say that the ranking between the more and less privileged is a function of the distribution of the several capitals and their use in different fields of the social space; the differentiated position of the agents and social groups in the structured social space depends on the volume and capital structure.

8 For example, Pintor [27] develops a reasoning based on transnational habitus, pointing out how the effects of migration transform the lifestyles of the migrating subjects, their society of origin, and their host society, since migrants may live simultaneously in both of them.

9 The habitus is understood as a set of rules incorporated with personality, guiding choice, lifestyles, abilities, etc., which in the end generates social distinctions. The individuals resulting from the socialization process learn to behave, relate, and think in a specific way, and therefore, individuals get used to living under a certain expectation horizon, which is always conditioned by the horizon formed by the possibilities of action, which is composed by the degree of the different capitals possessed by the agents. It is through their habitus that the agents incorporate into their lives the usual practices that become normal and transform them into dispositions of their practices. 
Among the mentioned types of capital, [19] Bourdieu gives more importance to cultural capital because of its influence and profitability. The author remarks that this capital is acquired by multiple socialization instances, the more permanent and outstanding ones among them being family, education, and pedagogical work in the school. In turn, the author notices that pedagogical work in schools will have a differential productivity in the learners according to their social class of origin, depending on the material conditions of their existence. Hence, whenever there is a noticeable cultural distance between the habitus at the beginning of the student (natural) and the pedagogic contents to be taught, under the goal of efficiency, the pedagogical relationship must be arbitrarily imposed to vanquish the resistance exercised by the natural habitus, such as of the pupils of foreign roots.

The importance of the capitals - inherited or acquired - in praxis lies in that the agents and the social groups pursue strategies ${ }^{10}$ according to the volume and capital structure they possess, which is dependent on the position they occupy in the social space and the capacity to operate in diverse fields of action. Such strategies are oriented toward transforming or preserving the distribution structure of the capitals in society and in the different fields comprising it. The strategies, therefore, have the intention to improve or maintain social position and the situation of the agents within a particular field or within a total social space. In the end, strategies generate a sort of adaptation to social situations, and consequently have a producing and reproducing result.

In the development of the concept of cultural capital ${ }^{11}$, Bourdieu enables the introduction of the cultural variable in the context of educational research. In this regard, it has been empirically shown that schools play an increasingly important role in the transmission of the advantage through generations. In this line, Lareau [28] notes that different social classes defer in how parents see the happiness and success of their children. According to Lareau [28], middle-class parents actively promote the talents, opinions, and skills of children, which can be called "concerted cultivation". Some of the practices associated with this strategy are: enrolling children in organized activities, reasoning with children (answer questions with questions), and closely monitoring the experiences of children in institutions such as schools. Through this pattern of concerted cultivation, middle-class children gain an emerging sense of entitlement.

Additionally, Bourdieu's sociology [19] of education stands from the theory of symbolic violence and the general theory of social reproduction. For Bourdieu, every teaching, in school or at home, relies on authority and, hence, refers to relations of power. Here is where the concept of

10 Bourdieu remarks that in practice, strategies are varied, interdependent, and appear intertwined. Nevertheless, it is possible to classify and categorize them analytically. The author mentions the existence of strategies of type: biological investment, economic investment, couple-related, and symbolic investment, among others. These types of strategies, beyond supposing a rational and strategic behavior of the agents and social groups, express the habitus and the volume of capital present in them.

11 A dominant interpretation of cultural capital has teamed up with two key premises. First, the cultural capital with ease denotes knowledge or aesthetic culture, known as "cultured". Second, the cultural capital is analytical and causally distinct from other important forms of knowledge or competence (called "technical skills", "human capital", etc.). 
"symbolic violence" appears, which is seen as an imposition of systems of symbols and meanings over groups or classes, impositions that are regarded as legitimate within a functioning structure.

Keeping in mind that every culture has its own arbitrariness, coming from the socialization process, the educational system has its own cultural arbitrariness, which is that of the dominating classes. For this reason, the pedagogical action also reproduces the relationships of power by reproducing culture.

In particular, Bourdieu [21] considered that disposition toward culture, the institutionalized cultural capital, was rather a result of family education and the recognition of the importance given to education and inheritance. On the other hand, for Bourdieu, those who possess the political and economic capital dominate over those who possess the cultural capital, which is the principal means of cultural reproduction. Symbolic systems are doubly determined by the pressures derived by the intellectual field on one side and the class field on the other, whose interests are expressed in the form and content of the symbolic power [22,23].

From this theoretical perspective, the present article deconstructs the relationships between families, immigrants, and the school, exploring key points concerning the conflicts between these social agents. Put otherwise, this proposal allows us to objectivize the social relationships in the educational field in that it renders visible subjective-objective aspects and ways of thought and action of both families and the school. The following section describes the process of data analysis based on the collected empirical data and the described theoretical framework.

The analysis is structured as follows: in Section 3, we discuss the difficulties of the migrant families in the social-educational field; in Section 4, the dimensions of the family-school conflict are described; and in Section 5, the structuring of symbolic violence in the educational field, assimilation and domination, is expanded on. Lastly, in Section 6, the final conclusions are presented.

\section{Difficulties of Immigrant Families in the Socio-Educational Field}

An understanding of the conflict between schools and families requires a description of immigrant families, as well as the way it becomes an agent transmitting the habitus originated in the country of origin. The following section provides this.

The observations gathered through fieldwork showed that families presented diverse structures, usually associated with matriarchal single-parent and two-parent categories (See Table 2). These types relate, on the one hand, to the process of migration endured by the families, and, on the other, to family disintegration as a result of problems related to one of the parents with justice or through break-up.

From a theoretical point of view [19], families provide the tools for the students to interact with a larger context. This transference depends on the capitals the families have, since they allow them and the pupils to get used to diverse social fields. Prominent among these social fields are the economic capital, the social capital, the symbolic capital, and, fundamentally, the cultural capital, since it is through this one that some strategies that maximize the learning of immigrant students are transmitted. 
Table 2. Types of usual families observed.

\begin{tabular}{ll}
\hline Types of Families & Description \\
\hline Matriarchal single-parent & $\begin{array}{l}\text { Families where the head of the household is a woman and there is no male } \\
\text { paternal figure in the conjugal system } \\
\text { Two-parent }\end{array}$ \\
\hline
\end{tabular}

There are different difficulties in terms of family capitals (see Table 3). In a relational plane, family disintegration and the loss of networks implied by moving away from home reduce migrant families' social capital. In addition, the difficulty in adapting and the social segregation endured by most families make it harder to access new networks for childcare when parents work most days.

Table 3. Difficulties in terms of family capitals.

\begin{tabular}{lll}
\hline Type of Capital & Structure & Volume \\
\hline Economic & $\begin{array}{l}\text { Development of activities of low } \\
\text { qualification and long workday. }\end{array}$ & Low and unstable income generation. \\
\hline Social & $\begin{array}{l}\text { Break of social and family relationships as } \\
\text { a result of migration. }\end{array}$ & $\begin{array}{l}\text { Low support networks for childcare. } \\
\text { Cultural (institutionalized) } \\
\text { (scholarship) of the parents. }\end{array}$ \\
\hline Symbolic & $\begin{array}{l}\text { Recognition and empathy for the situation } \\
\text { of the families. }\end{array}$ & $\begin{array}{l}\text { Discrimination and abuse of power that } \\
\text { school exerts against families, and } \\
\text { national families against immigrant ones. }\end{array}$ \\
\hline
\end{tabular}

On the other hand, the educational level of the parents that participated in the monitored schools was relatively low, except for a few cases where the parents had professional degrees. Immigrant families, therefore, presented a low level of institutionalized cultural capital, which, as a result, curtails the capacity of parents to help their children with homework and other study-related activities.

The low level of institutionalized cultural capital of the migrant families deteriorates their supporting capacity which, in turn, could make the acquisition of academic support allowing the development of competence to better cope with other social fields harder. This difference between volumes of cultural capital is detected both by the families as well as by the school agents; the following sentences exemplify it:

"The child does not advance because behind him there is no support to do the homework, no support, no encouragement; for example, a little child could have a lot of problems, but whether the mother is there or not, the child is always going to try something. But these children do not perform and the mother neither. It is like nothing." [29].

"Not everyone has the same social class, but more than social class I would say it is a problem of education. They do not come with the same educational level to Chile. We have mothers that have arrived as total illiterates and others that came with university studies almost finished. And of course we can see the difference. Then I would say that more than the economic part it is the educational level [that matters]. The higher the 
educational level, the more the parents take care. The lower the educational level, the lower the value of education, and the higher abandonment of the parent." [30].

On the other hand, in the economic realm, it is observed that the adults of the migrant families generally undertake activities requiring lower qualifications and long working days. The first point translates into low remunerations, while the second one influences the direct relationship with the school in the sense that the parents do not have enough time, as required by schools, for meetings and other formal activities.

"Those who work cannot have a lot of time like those who do not work. Because I work, I must meet schedules. Then, I come, I pick up him and I leave him. But suddenly I cannot pick him up because of my job schedule. Then when I have one moment with the teacher, it could be in the morning for a little time for talking, and after, I leave very fast. It is less than the times for mothers that are not working. For example, now I am with postnatal leave period (protected nonworking time in Chile), I come and stay more time speaking with the teachers." [31].

"There has been a lot of absenteeism by the parents, and there are few parents that do come. Maybe not because they do not want, but the work precludes it. I try to come when possible." [32].

"But as a foreigner, I cannot... and I want that the people to be conscious, whether they tell me 'there is a meeting on such day'...I cannot, because if I request permission at work, and they do not give it to me. Neither, I cannot miss going to my work, because I would lose it. For this people must be conscious, because there are days with permission and others without permission." [33].

The socioeconomic level - identified by the accumulation of cultural capital - appears as a differentiating condition in the educational process. To schools, it influences the capacity of parents to support their children, and the promotion of education. A positive association is observed between economic capital and cultural capital, indicating that the higher the socioeconomic stratum, the more positive the valuation of education.

"I think that also depends on the socio-economical level of the immigrant person. Because when they have higher socioeconomic level, the immigrant people have other perspectives. But when they are from those little towns and rural areas, they do not have those perspectives. But in general, for the children here, we want that they go study to secondary school at least." [34].

Considering the previous context, there are some conditions obstructing the participation of immigrant students in the Chilean education system. Among these, socio-cultural and economic factors of the families are recognizable as elements that depend on the way they are manifested could make a student's integration in his/her new educational context harder. 


\section{Dimensions of the Family-School Conflict}

The educational system is a social field of fundamental importance for the socialization and transference of culture. By means of education, distinctions are created which make possible the production and reproduction of the social structure. At the same time, dispositions in the guise of cultural capital that serve as input for the practices of the agents in other social fields are produced.

Specifically, in the educational field, the school has become an important point of welcoming, meeting, and interaction in those societies/countries receiving migrant populations. Immigrants and locals must interact on a human scale inside this specific social field. In this section, we present some aspects underlying the conflict in expectations between the social agents (see Table 4), both immigrant and local families and schools, inside the observed socio-educational field.

It was noticed from the observations in the field that the conflict between families and schools touches on three fundamental aspects: a struggle of interests, the different dispositions toward action, and the divergence in expectations among the agents.

Table 4. Aspects associated with the conflict between the school and immigrant families.

\begin{tabular}{lll}
\hline Category & Code \\
\hline $\begin{array}{l}\text { Struggle of interests: Refers to differences } \\
\text { in the assessment of teaching and }\end{array}$ & - Value of education: low to high \\
educational space. & - Role of school: protector $v$ s. educator \\
\hline $\begin{array}{l}\text { Difference of dispositions: Refers to the } \\
\text { practical sense in the educational field. It }\end{array}$ & - Practical history: negative or positive \\
has to do with the different predispositions & - Adaptability: pro to unfavorable \\
Shown by families in the educational social & - Provisions: high or low expectations, indifference \\
field from their experience. & - Participation in educational activities \\
\cline { 2 - 3 } & - Relationship school-families \\
Mismatch of expectations: Refers to & - Purpose of education \\
differences between expectations in & - Educational accompaniment \\
a given situation. & - Future of the students \\
\hline
\end{tabular}

In the first instance, the interests of each agent come into conflict because of the logic they found in teaching and the educational space. With respect to the interests shown by the interviewed families, migrant and Chilean, regarding the education of their offspring, it was possible to tag three lines of argumentation.

For a first group of families, school has a specifically protective role. They see in it a place for their children to be safe as adults work, and there is not much more value assigned to whatever else school may mean for their future. In this group there are families that simply take their children to school in order to avoid legal issues, since in Chile it is obligatory for children of schooling age to attend schools.

"I think that the priorities are a little untidy, because the realities are very different with our opinion about what must be. Here there is a great number of parents that send their children because they must send them. Because otherwise someone is going to 
complain. Because otherwise, the children can fall in SENAME, because the law requires it." [35].

A second group of families say that school is important for their children, yet in reality they do not support the educational process of their offspring. Here the application of a certain well-intended discourse can be observed, which, however, does not translate into a transformation of the dispositions of families, since there is no actual positive valuation of education. Put otherwise, in these families, there is a difference between their discourse on education and the practices of educational support.

"They want their children to study. But one thing is that I want them to study, and other is what are my action to stimulate that." [36].

A third group of families value education, since they see in it better chances for the future of their children, which consolidates school as an important agent for their future well-being. These families, the difficulties in finding time to participate in the educational process of their children notwithstanding, seek ways/strategies in order to be present and not to miss informational and educational instances given and required by the school.

"It is a minor group that have the conviction that children need education, that they can opt to study, pursue a career, be a man or woman of good." [35].

Accordingly, this group is the one demanding schools provide more support, activities, and effective learning for students.

The school, in turn, imagines itself as performing a role fundamentally as educator, and sees education as a highly valuable input for the development of the children in other fields in the future. Thus, differences in the directions of conflicts were observed, since, on the one hand, for the school, it is problematic that the first and second groups do not respond effectively to their required role in the learning process. On the other hand, for the third group, it is a point of tension that schools do not respond to their demanding more participation and/or excellence. Key factors are the value of education and the role of the school.

Another issue related to the conflict between families and schools is in the difference of perceived dispositions by means of the practical sense of the agents in the educational field. This is related to the previous experience of the family groups and their trajectory in this field. Here it is observed that experience in the educational system predisposes families when facing schools and, at the same time, educational agents working for the school to be conditioned by their regular practices. This conditioning results in operating in ways not necessarily in tune with what families expect for the education of their children.

Therefore, the practical sense incorporated in the agents of the socio-educational field generates expectations on the agents and predisposes families to face a school's demands. According to the observations, the trajectory of family practices in the educational system generates two types of predispositions for insertion in schools. Basically, a good previous experience, associated with a positive relationship with the school and satisfaction with respect to the contents transmitted to the child, increases the value of education and, at the same time, generates high expectations regarding 
the educational process. This, in turn, favors the adaptation process of the children and the families to schools, whereas a less demanding experience - of lower value - makes insertion more difficult, which refers to negative or neutral predispositions with respect to the educational process.

The differences between the observed expectations point to the third dimension characterizing the family-school conflict (see Table 5). In it, the arrival of the immigrant families is key since it refers to the appearance of new social actors in the educational field, which generates new demands and interests that have an impact on the relationships in this system. The insertion of immigrant families in the educational space implies some variation in the social relationships associated with the teaching processes normalized in the school.

The immigrants, as agents, generate their expectations inside a socio-educational field with rules and contents specific and distant from those observed in the country. This produces a tearing point in the scheme of expectations of the immigrants and increases tension between social agents. The analyses of this study show that the difference in expectations between the school and migrant families is related to the distance between the set of dispositions of each of them. This difference of expectations translates in different ways of conceiving participation and education.

Table 5. Expectation gap between school and families.

\begin{tabular}{|c|c|c|}
\hline Expectation & From the School & From the Family \\
\hline $\begin{array}{l}\text { Participation in } \\
\text { educational activities. }\end{array}$ & $\begin{array}{l}\text { Participation limited by } \\
\text { quotas and depending on } \\
\text { specific activities. }\end{array}$ & $\begin{array}{l}\text { - Demands more spaces and opportunities for } \\
\text { participation in educational activities. } \\
\text { - Indifference regarding the existence of } \\
\text { larger spaces. }\end{array}$ \\
\hline $\begin{array}{l}\text { Relationship between school } \\
\text { and families. }\end{array}$ & $\begin{array}{l}\text { Precise relationship, related } \\
\text { information (highly formalized). }\end{array}$ & $\begin{array}{l}\text { - Aspiration integrated into the work of } \\
\text { the school. } \\
\text { - } \quad \text { They expect the fewest instances to meet. }\end{array}$ \\
\hline Goal of education. & $\begin{array}{l}\text { Transfer of contents and } \\
\text { discipline: pupils are expected } \\
\text { to be good students. }\end{array}$ & $\begin{array}{ll} & \text { Good education of students refers to: } \\
\text { - } & \text { Being a good person. } \\
\text { - } & \text { Future possible studies. } \\
\text { - } & \text { Children are well cared for. }\end{array}$ \\
\hline Family educational support. & $\begin{array}{l}\text { Families must co-participate in } \\
\text { the process. }\end{array}$ & $\begin{array}{l}\text { - } \quad \text { It is school's responsibility. } \\
\text { - } \quad \text { Also it is our duty. }\end{array}$ \\
\hline Future of the students. & $\begin{array}{l}\text { That students are well trained in } \\
\text { various subjects and can continue } \\
\text { studying (be professionals). }\end{array}$ & $\begin{array}{l}\text { - That they finish their education to } \\
\text { work soon. } \\
\text { - } \quad \text { That they be better than their parents. }\end{array}$ \\
\hline
\end{tabular}

\section{The Structuring of Symbolic Violence in the Educational Field: Assimilation and Domination}

This section discusses how symbolic violence is expressed through structured forms in the family-school relationship in the Chilean educational field. According to the observations, symbolic violence is structured in two main dimensions, namely structural rigidity and discriminating dispositions (see Table 6). In turn, each of these dimensions is categorized in different aspects, each 
of them codified and expressed in diverse manners. In the following table, these analytical distinctions are illustrated.

Table 6. Structuralization of symbolic violence.

\begin{tabular}{|c|c|c|c|}
\hline Dimension & Categorization & Code & Expression \\
\hline \multirow{3}{*}{ Structural rigidity } & \multirow{2}{*}{ Cultural assimilation } & Monolingualism & $\begin{array}{l}\text { Predisposition of only one } \\
\text { language in the family-school } \\
\text { relationship (Spanish speakers). }\end{array}$ \\
\hline & & Homogenization & 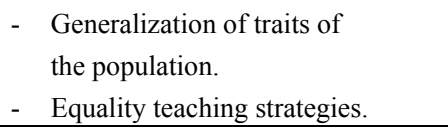 \\
\hline & Regulatory rigidity & Imposition of the rules & $\begin{array}{l}\text { - Families must conform to the rules } \\
\text { of the school. } \\
\text { - Lack of empathy for the situations } \\
\text { of families. } \\
\text { - } \quad \text { Abuse and insults } \\
\text { toward families. }\end{array}$ \\
\hline $\begin{array}{l}\text { Discriminatory } \\
\text { provisions }\end{array}$ & Dynamics of domination & $\begin{array}{l}\text { Xenophobic and racist } \\
\text { dispositions from the } \\
\text { national families }\end{array}$ & $\begin{array}{l}\text { - Standardization and reproduction } \\
\text { of discriminatory practices. }\end{array}$ \\
\hline
\end{tabular}

\subsection{Structural Rigidity and Cultural Assimilation}

The way in which teaching in the school is performed acts as a cultural assimilation device [37]. This is explained by the dynamics of teaching, which tend to homogenize students and accentuate common features in order to increase the productivity of teaching. Thus, the closer the student is to the "profile" or "stereotype" to be taught, the more adequate the individual will be regarding the pedagogical strategies to be implemented. Namely, the school aims at having agents adequate for its practices.

Within this dimension, one observed form of symbolic violence occurs when the school applies a norm dictated from other agents enjoying a higher level in the hierarchical relationships of this field level. Such is the case of the educational policy of monolingualism. Language barriers were observed. These made the relationship between Spanish speakers and foreigners with a different mother tongue more complex. Neither the school nor the families who speak Spanish are proficient in a second language allowing them to communicate better. The prominence of the Spanish language in the educational field excluded and segregated families and students not proficient in it.

The set of rules and dispositions presented in the educational field promoted monolingualism. Therefore, a certain distance was developed between those fluent in the dominating language and those who were not, as observed in the next example: 
"The communication with the Haitians parents is more difficult. They speak another language and I do it in Spanish. Then we put the kids between us for translation. Our communication has big difficulties. How I ask you to strengthen reading comprehension if the father does not speak Spanish? Then it is super complicated with parents who use another language. It is complicated..." [35].

As a consequence, the situation of students in a less advantaged position - in this case, foreign students - is a process that forces pupils to incorporate formal contents as dictated by the public institutions and that often fail to take care of what was part of the educational system of origin. This process, so demanding for the adaptation skills of foreign students, can be called a de-culturalization since it disregards the cultural resources acquired in their family and social class, and at the same time, it re-educates toward the cultural assimilation in linguistic terms.

\subsection{Normative Rigidity and the Imposition of Order}

Several examples illustrate the imposition of norms associated with the time and place in which the parents should or should not be at school. First, a feeling of insecurity regarding their children's protection is observed in the parents, since they are supposed to learn to blindly trust in those attending to their children.

"I think that the school needs to improve in this subject. Because when the children are standing in line, we must get out. They ring the bell and expel us outside, while the children stay there. I would like to stay there more time, to see, to know what is happening. It is very rigid." [38].

"It was like very suddenly. I was worried at first, the first day I was told to leave her at the school gate. I do not know, I felt worried." [39].

The way in which teaching is carried out is sometimes misunderstood and worrisome to the parents, who must accept and adapt to measures imposed by the school. This type of example has a larger impact on immigrant families, who interact with the school with their "migrant stigma". This implies that significant hesitation precedes the communication of any complaint.

"As a parent asking the school to improve, is always more difficult, because I am a foreigner. They would say 'no, he is not from here and is asking for school improvement!' So better I stay silent.” [33].

On the other hand, from schools also have a view of themselves as social agents who must impose the norms of the social relationship with the families. This means that it must be optimal for families to adapt to the established rules. Otherwise, the school shall implement strategies strengthening its position. This is done in a subtle way, and is not recognized as such, but is rather seen merely as foreign families necessarily adapting. It is, thus, assumed that a teacher's work may legitimately reproduce such impositions. 
"But why are you not integrated? This school permits to participate but only until one point, the school puts limits. It is ok, there are things for which it is necessary to put some limits, but not in the integration process. For example, do you know when are the parents invited to participate? For the international party...only then are we invited. And there are only a few who show up, why? Because they are almost always told 'no', and when you say 'no', they do not come again." [40].

The school limits the families' participation. Although there are instances for the integration of families into a school's activities, limits are too rigid, announcements come too late and are not sent to everyone, and whenever parents propose something, this is not taken into account as the school has already planned everything. Families are just supposed to attend.

"Meetings is where dad and the school have to go to get along. Not because the parents always work, we have to be available to them. They also have to step into the shoes of the school, where there are schedules and protocols to follow. We cannot do that on Monday at 7 p.m., to meet with the fifth grade, because regulation does not permit it." [41].

The abovementioned point is also perceived by some Chilean parents, who observe normative rigidity and violence both toward themselves and the students. The school does not seem to empathize with those parents lacking time to attend meetings. Therefore, the timing at disposal for schools is not in tandem with that of the parents. For instance, the proposed time for a meeting does not often suit parents, and if they arrive late, they may not be received.

"The other day, the supervisor called a mom to speak at 8 a.m., and the lady has two children who are in school, plus another little girl and a baby. She arrived a little late and said, 'I had to prepare the girl and the baby to come out, I cannot leave them alone', she had to come with both and it was winter. The supervisor said, 'No, I asked her to come to a specific time and did not attend her because she should have arrived at the time he had booked.' He is rigid, and in that regard I find that should not be the way in a supervisor." [42].

In addition, the structuralization of symbolic violence in the interaction between families and the school was observed. School is envisioned as a social agent working along rigid norms, which symbolically infringe those under them. These norms do not totally empathize with families, who have a disadvantage whenever they want to exercise their rights.

However, it is worth noting that there are agents who speak out their worries regarding the occurrence/reproduction of discrimination and stigmatization toward the people coming from abroad. They demand from the school and the broader school community a bigger acknowledgement of the socio-cultural diversity of their students, in order to foster respect and tolerance.

"That has to do with respect, dignity, tolerance. It seems to me very important also to be competent regarding knowledge. This is, I have heard professionals say 'black of the jungle' and fight because he is black and comes from the jungle. As far as I know, Colombia has more than just jungle. It also has asphalt, has cities, has democratic 
institutions, etc. So, I see a lack of important knowledge. Skills related to managing diversity." [43].

In the example, a denaturation of dispositions that reproduces processes of symbolic violence was witnessed. An alternative lies in the education of the same agents comprising the school.

In summary, the analysis shows that the Chilean school system is a highly institutionalized social field in which the social action rules are arbitrarily produced by the agents who dominate this field, and they can be regarded as the core of the symbolic violence emerging in the educational centers. The structuralization of the educational field is rigid and highly formal, producing exclusion and segregation of foreigners. At the same time, this has an impact on the relationships among the social agents subject to the norms of the school.

\subsection{Discriminatory Disposition from Some Social Agents: Domination Dynamics}

In the previous section, it was exhibited how, in the social educational field, there exist domination relationships incorporated into its structure. Hence, in the educational field, the school is an agent exerting naturalized dominating dynamics. This has an impact on the way differences are categorized. This is presented as an incentive to perceive and evaluate migrants (tall/short, white/black, etc.), thus establishing categorizations that become natural as distinctions in the social reality, in which the foreigner is categorized as an other, who is a victim of xenophobic and racist dispositions.

"Do you have relationships with immigrant families? No, I greet them only. But very little. Greeting, nothing else, but if they ask me something, I answer." [44].

"Why do I dislike Peruvians? I do not like them, do not like them. What do you dislike? They walk smelly. I do not like the smell, it's just smells like spices. I do not like it. I really hate to say it, but I do not like it. Is that...I cannot explain it well but I do not like it. I do not like the smell of them, I do not like how they hang out." [45].

"Have you ever had a Peruvian friend? I talk to two, but we are not friends, but we talked. But I reject them. I do not know why, really do not know if they have never done anything to me. I have never ever had a problem with a Peruvian. Never, but I do not know why I do not like and do not like them. I do not like them." [45].

In this scenario, it is possible to maintain that the forms of discrimination-bullying, racism, xenophobia, etc. - are expressions of symbolic violence and negative dispositions toward cultural differences. There are some families who deny migrant families the status as full interlocutors in social interactions, as a consequence of the incorporation of xenophobic patterns of social valuation.

According to observations, the social educational field can be considered as a space where the struggle among social agents provokes conflicts of varying magnitude. The school was presented as an agent that welcomes both migrant families and otherwise. This situation may have paradoxical affects, albeit it promotes social integration, it may generate certain exclusion mechanisms, since trying to integrate everyone in the same way provokes violent interactions between families. 
"The school from the beginning welcomed us, but there are others who are sometimes a little distant because you come from abroad. Because sometimes here Chileans are a little bit racist. When you approach them for something, or want to make a query, they ignore you" [32].

In this dimension it is worth noting that the violence context is not solely restricted to the migrant population, but it is inscribed in a context of generalized violence in which the relationships between families take part.

"I was treasurer in prekindergarten and this mom told me, 'I am going to stab if you to charge money.' And I told her that the money is for the participation of her daughter in the cerebration at the end of the year. She says me, 'You will see.' So they are very aggressive. These are Chilean parents. Migrants do not, they are good, quietly, speak the minimum." [44].

In the same fashion, migrant families find themselves in a disadvantaged position with respect to national families and the school. Migrant families have difficulties to obtain explicit and practical recognition from local ones. This is related to their relatively lower level of symbolic capital. Symbolic violence, expressed as racism and xenophobia, is reproduced inter-generationally. Many of the interviewed agents notice that children and their parents have incorporated an unconscious rejection of foreigners; they have normalized the discrimination of the cultural difference. This phenomenon is recognizable everywhere from schoolteachers to migrant parents.

"It made me wonder the attitude of the national children regarding foreign class mates. There is a racist attitude in the children. I think it should be family learnt. So, I do not know what the relationships among adults with migrants is. Because in reality children are a reflection of home. Sometimes you see attitudes very, very racist, xenophobic ones...it is striking. What they are hearing about it at home?" [46].

In the same way, it has been observed that the children have incorporated an imagery regarding the foreigner, and with it they have normalized verbal abuse, such as cursing, toward them. National families and their offspring position themselves naturally in a higher hierarchy than foreigners, which in connection to the dominating culture assigns them a higher symbolic capital in the school. In this sense, the unequal dispositions of symbolic capital have even affected the relationships between local and foreign students.

"We had problems because in the first year they discriminated against my son, there was a bit of discrimination." [47].

"In the early days, they cut his hair, peers, in the first year. Actually they are girls, they feel they are more valuable...the first day they broke his apron. Looks like being torn, whatever. But I found my son crying." [48].

Again, it is worth mentioning that it is not possible to generalize the idea that all national families have a negative disposition toward differences. Rather, it is possible to identify ideas in the 
social agents pointing toward educating the children in a way that assimilates diversity without discriminating or expressing negative feelings toward foreigners.

"My daughter once used the word black. I said, 'No, that is an ugly word' because it is discriminating, people are brunettes, they are well tanned, but not black because it is ugly. I think it is a derogatory word. Then my daughter usually says 'brown people'. I care for diversity of color, they are human beings as us, but the difference is in skin or hair. And the vast majority of black women use extensions because the hair is different, weird, I do not know. There is a little boy who has to go to kindergarten, his hair is curly...but not bad, but it strikes me, the diversity." [49].

Nevertheless, despite the existence of some local families having no negative feelings toward diversity, it is important that this form of teaching be assumed as a shared strategy between the families and the school, in which the latter must take on a mediating role between tense relationships. Observing the interaction between immigrant and national families, Touriñan [50] remarks that, in the educational system, the school becomes a co-habitation space for the immigrant and the national, where the dynamics of meeting and learning to accept each other are produced, and they are not exempt from problems, such as verbal, and sometimes, physical violence. Acknowledging that this process carries conflicts, the school is envisioned as playing a fundamental role in the generation of values associated with the respect of the foreigner and the rejection of discriminating practices [37].

"Sometimes some answer no, they are not from here and come to impose their laws on us. Here sometimes, I observed people with that attitude, but do not say it directly. And these parents are Chilean? Yes, they are Chileans, of course. Well, in the end it is the teacher who sometimes takes the word and explains to the people. The teacher is the one who seeks consensus." [51].

In summary, symbolic domination dynamics caused by structural rigidities (school-family) are observed, and these are not isolated from the structures of violence influenced by the dispositions of some social agents that participate in them. This is to say that the context shows a double form of symbolic violence, which is part of the dynamics in the field.

\section{Conclusions}

The purpose of this article was to analyze, from a Bourdieuninan perspective, the conflict between family and school in the context of a high immigrant population. The analysis performed in this article made it possible to identify, in the cases being studied, a conflict produced by capital diversity, different expectations, dispositions, and practices among the social agents. Migration in Chile has become an enduring process, bringing various difficulties in the general functioning of the social services. Social fields, such as health and education, have experienced a series of complications in serving the migrant/national population. Beyond the problems related to serving an increasing demand, there is an emergency of conflicts among users and between these and the institutions providing services. On top of this setting, the conflict in the family-school relationship 
within the Chilean educational field was analyzed. In particular, we focused on the discrepancy of interests and expectations between the agents and the correlated forms of symbolic violence operating in these relationships.

Concerning the specific objective of characterizing the main difficulties immigrant families faced during their experience in the socio-educative realm, we found differences in volume and in the structuration of the capital among the different agents being studied. The family groups possessed different levels of capital, impacting their relationships with the school. Generally, they had a low economic capital, expressed in unstable low-skill jobs and salaries. Families have relatively stable social relationships and support networks; however, migrant family groups have lost contact with their original support network and have trouble in kick-starting relationships with their neighbors and the school community, reducing the possibilities of care for their offspring. In other words, the social capital is high in families that have spent several years living in the same place and is reduced for families coming from abroad.

Beyond observing different levels of economic and social capital, the most differentiating aspect is the difference in cultural capital between the families. A high cultural capital institutionalized and referred exclusively to the level of schooling makes a good support for the educational process of the children; inversely, a low level of this kind of capital negatively affects the possibilities of school support of the families toward their children.

Along these lines, it was observed that through cultural capital the families generate different dispositions that have an influence on the expectations with respect to education and in the value assigned to schools. Three types of dispositions were observed. One type exhibits a positive valuation of education for the future of the children and highlights the educating role of schools. Another type disregards the connection between education and the future of the children, and only sees school as a place for protection and security for them. The third type asserts a neutrality of sorts: on a discursive level, education is given an important character, yet in practice, nothing is done to support the learning process. Here, school is merely a place for children to be while the parents work. It is highlighted that school is regarded as an expert agent in the transmission of cultural capital to the students, but it also must embrace its duty to confront the disposition the families have, which is clearly a complex task and not free of conflicts itself.

In relation to the specific objective to define the facets of the conflict between family and school, in order to understand the observed family-school conflict, it is important to consider the concept of habitus as introduced by Pierre Bourdieu. In the family-school conflict it was noticed that schools dealing with intercultural dynamics try to broaden the reference points between nationals and immigrants; however, the lack of communication and low empathy observed in the relationship facilitates the configuration of a conflict whose core is the juxtaposition of the habitus among the different agents belonging to the school community.

Regarding the problem of the symbolic structures operating in the interaction between the agents, it was remarked that the conflict between the migrant families and the schools is related to three fundamental aspects: the clash of interests, the divergence of expectations, and the different dispositions toward actions between the agents. The clash of interests refers to the differences in the valuation of education and the educational space. This has to do with the role that the agents assign 
to the school. For some families, the school is specifically a teaching being, whereas for others, it is a place for the protection of the children while they work. This is linked to the diversity of accompanying practices for the families in the formative process. The existence of families helpful in the educational process of the children, since they value education as a social mobility factor, was observed. On the other hand, a low valuation of the educational process does not promote supporting or assisting practices in the academic tasks of their offspring.

In turn, the differing dispositions relate to the practical sense/interpretation of the educational field. This is linked to the different predispositions shown by the families in the social-educational field as a result of their past experiences. The history of the family-school relationship is important in the present state of it. Positive experiences based on good service and teaching favor adaptation in schools and foster high expectations regarding the educational process. Opposite to this, negative experiences likewise influence the upbringing of the children, the adaptation of the families into schools, and neutralize or reduce the quality of the agents' expectations.

In relation to the last specific objective, to explore the presence of symbolic violence in this relationship, it was noted that a different angle of conflict is given to the disregard of social diversity. This implies symbolic violence in view of Bourdieu, due to the supremacy of norms and field rules not necessarily coherent with the variety of pre-constructed expectations of the families, both immigrant and local ones. Symbolic violence is structured based on two main dimensions: the structural rigidity promoted by the school, and the agents' discriminating dispositions.

The first one refers to the assimilationist logic with which schools work and has to do with the monolingualism and homogenization with which both national and foreign students are confronted. Likewise, a high degree of normative rigidity is observed, related to the imposition of specific rules by the school that limit the action scope and force families to abide to the institutionalized dispositions. Many of these norms are implicit and are normalized as day-to-day practices that often involve physical and verbal abuse toward the students or the omission of the family or work-related circumstances of the parents.

The second one, the discriminating dispositions, have to do with symbolic domination dynamics adjacent to xenophobic or racist dispositions in the national population, which deny or oppose the cultural diversity present in schools.

In view of the analysis undertaken, the social relationships between the agents appear determined by their dispositions. The practical sense agents present to participate in the educational field is structured according to their ways of thinking, feeling, and acting, and these stem from a cultural base that propels individuals, groups, and institutions apart. According to this, the conflict between the school and the families alludes to the distinction of the dispositions in the educational field, which, in the emerging integration process, generate convergences and divergences, power struggles, and conflicts of multiple meaning and complexity. Concretely, agents' different ways of thinking and acting generate a tension between the families' habitus, their expectations, and those of the school in the setting of the rules present in the educational field.

The results show that, in Chile, the school system that delivers education in a context of cultural diversity is not an appropriate model of social integration. It makes diversity invisible, and wastes the previous learning processes that students and families have. Faced by this, it is recommended to 
stand from a perspective that sees differences as a human feature and therefore understands them as "natural".

This implies taking into account families' expectations and, from there, generating strategies fostering intercultural understanding. On the other hand, immigrant families must use their operative capital to become visible as valid agents and interlocutors toward the school and the other actors in the social field.

Hence, by means of making flexible the relationships between the agents of this social field, along the lines of acknowledging strategies, progress toward a greater social justice is made. This implies that the family should be considered as a fundamental agent in the transmission of support and school valuation because agents produce forms of perception from what they learn from family interactions, and this gets translated into action within different social fields.

All this being said, a challenge, associated with schools' re-construction as a place of meeting for intercultural relationships, is identified. Since this is a platform of transformation of social imageries and acquisition of capitals (symbolic, social, and cultural), it has an impact even in the insertion of agents into other social fields, such as labor, and yields marked differences in the life quality of said agents.

This results especially true for migrants, who are more vulnerable, as they are immersed in a process of social integration in which many of them have a lower volume of capital than locals - fewer networks and links, lower wages, etc. - that operate as a helping device for their insertion in the host country.

In summary, the differences in the symbolic structures and the expectations of the agents, such as national or international families and schools, influence the configuration of conflict in the socio-educational field in Chile. However, there are also other symbolic structures influencing the conflict, which are associated with control mechanisms, educational road-maps, and forms of operation determined by the state as an agent that shapes the educational field. These context-dependent dimensions, which complicate the conflict further, will be investigated in a forthcoming paper.

\section{Acknowledgments}

I would like to thank the reviewers and editors for their constructive comments which vastly improved this article, as well as to "Understanding and Supporting Families with Complex Needs" for giving me the possibility to participate it. Finally, I thank Julio Daniel Backhoff Veraguas for his aid in translating this article.

\section{Author Contributions}

This article contains partial results from the research project "On the family-high school relationship as instrumental codependency in a context of high immigrant population: provisions and strategies for participation and educational support" undertook by Rayen Cornejo Torres in the framework of the project "Understanding and Supporting Families with Complex Need". Therefore the subject, research problem and fieldwork correspond to a study conducted personally by the author. Ariel Rosales Ubeda collaborated in the overall writing and in the discussion of the article. 


\section{Conflicts of Interest}

The authors declare no conflict of interest.

\section{References and Notes}

1. World Bank. "Datos sobre migración y remesas, Segunda edición." Available online: http://siteresources.worldbank.org/INTPROSPECTS/Resources/334934-1110315015165/Factbook 2011Spanish.pdf (accessed on 3 September 2015).

2. Organización internacional de migración (OIM). "Informe sobre las migraciones en el mundo 2011: Comunicar eficazmente sobre la migración.” Available online: http://publications.iom.int/ bookstore/free/WMR2011_Spanish.pdf (accessed on 3 September 2015).

3. CEPAL. "Taller sobre evaluación y estimaciones demográficas con información censal. Medición y análisis de la migración internacional según los censos, las potencialidades del Proyecto IMILA y otras fuentes.” 2012. Available online: http:/www.cepal.org/celade/ noticias/paginas/9/51449/jm_migracioninternacional.pdf (accessed on 3 September 2015)

4. Stefoni, Carolina. "Perfil migratorio de chile." 2011. Available online: http://priem.cl/ wp-content/uploads/2015/04/Stefoni_Perfil-Migratorio-de-Chile.pdf (accessed on 8 May 2015).

5. Bourdieu, Pierre, and Jean-Claude Passeron. La Reproducción. Elementos para una teoría del Sistema de Enseñanza. Mexico City: Distribuciones Fontamara, 1996.

6. Odina, María Teresa Aguado, Inés Gil-Jaurena, and Patricia Mata Benito. Educación Intercultural: Una Propuesta Para la Transformación de la Escuela. Madrid: Ediciones Catarata, 2005.

7. Stefoni, Carolina, Elaine Acosta, Marcia Gaymer, and Francisca Casas-Cordero. Niños y Niñas Inmigrantes en Santiago de Chile. Entre la Integración y la Exclusión. Santiago: Organización Internacional para las Migraciones, Universidad Alberto Hurtado, 2008.

8. Villalobos, Christopher, and Claudia Carrillo. "Inclusión/exclusión de estudiantes inmigrantes en Chile. La emergencia de un fenómeno sociocultural en el sistema educativo chileno.” Paper presented at I Bienal Latinoamericana de Infancia, Manizales, Colombia, 17-21 November 2014.

9. Departamento de Extranjería y Migraciones (DEM). "Informe Anual Sección Estudios. Gobierno de Chile.” 2010. Available online: http://www.extranjeria.gob.cl/filesapp/Informe\% 20Estimacion\%20Poblacion\%20Extranjeros\%202008.pdf (accessed on 8 March 2011).

10. Pizarro, Jorge Martínez. El encanto de los datos. Sociodemografia de la inmigración en Chile según censo 2002. Santiago: CEPAL/CELADE, 2003, vol. 49.

11. CEPAL/CELADE. "Migración Internacional." 2006. Available online: http://www.cepal.org/ es/temas/migracion-internacional (accessed on 3 September 2015).

12. Doña Reveco, Cristian. "Transnacionalismo y nuevas perspectivas de integración." Paper presented at Primer Coloquio Internacional, Zacatecas, México, 23-25 October 2003.

13. Hein, Kerstin. Migración y Transición: Hijos de Inmigrantes de Origen Latinoamericano en su Transición de la Escuela al Trabajo en Chile. Santiago: Revista Si Somos Americanos, 2012, vol. 12.

14. Mora, Claudia. “Globalización, Género y Migraciones.” Revista Polis 7 (2008): 285-97. 
15. Tijoux-Merino, María Emilia. "Niños y niñas de la inmigración y búsqueda de la reflexividad para enfrentar su discriminación.” 2014. Available online: http://www.junji.cl/SiteAssets/ JUNJI/documentos/2014/seminario_infancia_e_inmigracion/Tijoux_seminario_JUNJI.pdf (accessed on 8 May 2015).

16. Stefoni, Carolina. "Inmigrantes en Chile. Una integración diferenciada al mercado laboral." In Migración y Políticas Sociales en América Latina. Sopla: Konrad Adenauer Stiftung, 2008.

17. Bourdieu, Pierre. Meditaciones Pascalianas. Barcelona: Anagrama, 1997.

18. Flick, Uwe. Introducción a la Investigación Cualitativa. Edited by Ediciones Morata. Madrid: Fundación Paideia Galiza, 2004.

19. Bourdieu, Pierre. Las Estrategias de la Reproducción Social. Buenos Aires: Siglo Veintiuno Editores, 2011.

20. Bourdieu, Pierre. "The forms of capital." In Handbook of Theory and Research for the Sociology of Education. Edited by John G. Richardson. New York: Greenwood Publishing Group, 1983.

21. Bourdieu, Pierre. La Distinción. Buenos Aires: Alfaguara Ediciones, 2012.

22. Bourdieu, Pierre. El Sentido Práctico. Madrid: Editorial Siglo XXI, 2007.

23. Virginia Braun, and Victoria Clarke. "Using thematic analysis in psychology." Qualitative Research in Psychology 3 (2006): 77-101. Available online: http://dx.doi.org/10.1191/ 1478088706qp063oa (accessed on 8 May 2015).

24. Tovillas, Pablo. Bourdieu: Una introducción. Buenos Aires: Queadrata, 2010.

25. Henríquez, Andrés Aedo. "El habitus y la movilidad social: De la modificación del sistema de disposiciones a la transformación de la estructura de clases." Revista de Sociología 29 (2014): $57-75$.

26. O'Reilly, Karen. International Migration and Social Theory. Houndmills: Palgrave MacMillan, 2012.

27. Pintor Sandoval, Renato. "El habitus y los Campos Transnacionales en el Proceso del Transnacionalismo Migrante." Migraciones Internacionales 6 (2011): 159.

28. Lareau, Annette. Unequal Childhoods. Class, Race, and Family Life, with Update a Decade Later. Berkeley, Los Angeles and London: University of California Press, 2011.

29. Interviewee 1 (school team, Santiago, RM, Chile). Interview 9, 2013.

30. Interviewee 2 (school team, Santiago, RM, Chile). Interview 8, 2013.

31. Interviewee 3 (immigrant parent, Santiago, RM, Chile). Interview 2, 2013.

32. Interviewee 4 (immigrant parent, Santiago, RM, Chile). Interview 12, 2013.

33. Interviewee 5 (immigrant parent, Santiago, RM, Chile). Interview 22, 2013.

34. Interviewee 6 (school team, Santiago, RM, Chile). Interview 20, 2013.

35. Interviewee 7 (school team, Santiago, RM, Chile). Interview 7, 2013.

36. Interviewee 8 (school team, Santiago, RM, Chile). Interview 17, 2013.

37. Alarcón Muñoz, Gonzalo Esteban. "Las Políticas Inmigratorias De Chile En El Área Educativa. El Caso De Los Peruanos En Chile.” Master Thesis, University of Chile, Santiago, Chile, March 2010.

38. Interviewee 9 (immigrant parent, Santiago, RM, Chile). Interview 3, 2013. 
39. Interviewee 10 (immigrant parent, Santiago, RM, Chile). Interview 24, 2013

40. Interviewee 11 (immigrant parent, Santiago, RM, Chile). Interview 5, 2013.

41. Interviewee 12 (school team, Santiago, RM, Chile). Interview 11, 2013.

42. Interviewee 13 (national parent, Santiago, RM, Chile). Interview 6, 2013.

43. Interviewee 14 (school team, Santiago, RM, Chile). Interview 28, 2013.

44. Interviewee 15 (national parent, Santiago, RM, Chile). Interview 1, 2013.

45. Interviewee 16 (national parent, Santiago, RM, Chile). Interview 15, 2013.

46. Interviewee 17 (school team, Santiago, RM, Chile). Interview 18, 2013.

47. Interviewee 18 (immigrant parent, Santiago, RM, Chile). Interview 27, 2013.

48. Interviewee 19 (immigrant parent, Santiago, RM, Chile). Interview 32, 2013.

49. Interviewee 20 (national parent, Santiago, RM, Chile). Interview 29, 2013

50. Touriñán-López, José M. "La educación intercultural como ejercicio de educación en valores." Estudio Sobre Educación 10 (2006): 9-36.

51. Interviewee 21 (immigrant parent, Santiago, RM, Chile). Interview 21, 2013. 


\title{
The Need for Participative Interventions in Child Protection: Perspectives from Nuevo León State
}

\section{Elena Cabiati}

\begin{abstract}
This article examines characteristics and social work practices within the Mexican child protection system by combining observations of practice with the voices and the views expressed by managers, social workers, families, children and young people. The results of the study confirm the need for and desire to adopt a participatory approach, in preference to the individualistic ideas that currently dominates practice. The traditional Mexican culture, the implicit and explicit representation of family and the social problems connected to drug trade conflicts appear to have contributed to a child protection system with a "child-centered perspective", characterized by asymmetric power relationships, lacking the empowerment and engagement of service users. These practices seem to be counter to the legislative framework and appear ineffective. Reflections regarding how family needs are identified, understood and addressed reveal a commitment to find new ways of working with families among service users and providers. However, the biggest challenge in the Mexican context is to balance the protection of the child with support to their parents; without ensuring the former, the latter will remain a partial and counter-productive work practice.
\end{abstract}

Reprinted from Soc. Sci. Cite as: Cabiati, E. The Need for Participative Interventions in Child Protection: Perspectives from Nuevo León State. Soc. Sci. 2015, 4, 393-420.

\section{Introduction}

This article presents an overview of the characteristics and the functioning of the Mexican child protection system by presenting the results of research examining the testimony and the background of various actors in the field. The thoughts of these actors repeatedly highlight the need to re-think approaches to supporting two-generation families with complex needs. Considerations of the policies and in particular the social work practices will be presented, starting with the views expressed by social workers, children, youth and families. Subsequently, the specificity of the Mexican context will be considered, as well as the difficult current societal context characterized by the violent situation related to the war on the drug trade. The heterogeneity of the various actors that took part in the research and their different voices confirm the need for and desire to adopt a participatory approach in preference to the individualistic ideas that currently dominates practice.

\section{The Mexican Context}

As Jusidman argues [1], inequality has deep historical roots in Mexico and is complex and multifunctional, related to ethnic, gender and aboriginal discrimination. According to Jusidman, social policies addressing such inequalities are necessary to transform asymmetrical relations of power.

Despite the progress achieved in social development in the 1990s, Mexico still has high levels of poverty and inequality that directly affect children. In spite of the fact that Mexico is a country with 
medium-high income that has made important progress in matters of social development, a large proportion of the population still lives under poverty and disparity conditions [2]. Mexico is characterized by a traditionalist culture, with a high rate of Catholicism and a strong conservative ethos: intra-family violence is considered acceptable by many people $[3,4]$ and divorce is perceived as a problem that threatens the institution of family [5]. The everyday context is affected by violence and corruption in politics, justice and law enforcement, and citizens make use of solutions of private protection oriented to an individualism that may seem unrelated to Latin American culture. Since the 1990s, there has been a "drug war" involving armed conflict between the Mexican drug cartels and the armed forces of the Mexican government. The war started in Mexico in 1989 after the arrest of Miguel Ángel Félix Gallardo for cocaine trafficking. There was truce in the late 1990s, but since 2000, the level of violence has increased. The states that suffer the most from the conflict are Baja California, Guerrero, Chihuahua, Michoacán, Tamaulipas, Nuevo León and Sinaloa. Due to its geographical position, Mexico has been widely used as a transshipment point for drugs, illegal immigrants and smuggling destined for the US markets - all activities which are based throughout Latin America. Mexico appears to lack effective strategies to resolve this situation, perhaps due to a deep state corruption that seems to discourage, and in some cases thwart, the development of any enforcement actions [6].

The traditional culture of the Mexican state and the profound social problems related to the conflict of the drug war [7] seem to have contributed to the structuring of a welfare system that follows a bureaucratic statist model in which each state, in accordance with its own legislation, has autonomy over health and social welfare. The Mexican child protection system is dominated by a benefits welfare culture: the state recognizes itself as a strong power, and considers itself able to respond to the problems of its citizens through a system based primarily on the provision of welfare services to which people are entitled according to predetermined criteria for access. The government widely advertises its services through popular media in ways that reflect traditional images of families, and that seems to invite people to achieve a specific idea of well-being.

The Mexican system enjoys a good heritage of economic resources aimed at supporting all costs related to the institutionalization of children. In the year 2012, a state commission reviewed and evaluated the residential care for children in the State of Nuevo León, ordering the closure of more than 20 of 68 homes, due to violence, maltreatment and disappearance of children ${ }^{1}$. Since this review, a dedicated body regulates and monitors the operation of these residential care homes, including through the creation of an official register containing the names of the children in care, developed as a result of unclear transfers of children from one home care to another and episodes of disappearance. Analyzing the Mexican legislative framework, it is possible to observe a distance between the objectives set out in the national and local regulations and the practices of social work. Examples of this include the law "Ley de la procuraduría de la defensa del menor y la familia", which deals with the help to all family members in situations of vulnerability, and the national law "Ley para la protección de los derechos de ninas, ninos y adolescents" that recognizes the child's right to live within the family, and establishes the duty of the state to provide help and support to

\footnotetext{
1 The argument refers to the Unicef Country Report [2] and the data have been collected during the research actions.
} 
families to avoid the child being removed from the family. These ideas seem to contradict the trend of the Mexican child protection system, mainly focused on the recourse to institutionalization as a strategy of child protection and to help families in complex situations, including those in poverty. Mexican families in the child protection system are almost exclusively lower-middle class and appear fatigued by social problems such as poverty or lack of schooling. Many are not even registered to the civil registry, with 3 million children not guaranteed identity rights [8]. A further particular category of service users is represented by indigenous peoples (descendants of Maya, Aztec, Toltec, and other civilizations), who live in all Mexican states in conditions of marginalization and poverty. The needs that come to the attention of the services appear to be multiple and the recourse of placing the children in residential care is the only way to safeguard their rights.

Article 27 of the United Nations Convention on the Rights of the Child of 1989, ratified by Mexico in 1990, compels the state to adopt the appropriate measures to help parents or other people responsible for the child to ensure adequate living conditions for the child's development, and when necessary providing material assistance and support, in particular with regard to housing, nutrition and clothing. However, the system seems to be suffering a lack of alternative care and the knowledge of how to promote parental participation in the practices. The UN Committee on the Rights of the Child has the duty to examine the progress realized in the implementation of the Convention's provisions. In recent years, this Committee has expressed concerns with regards to Mexican policy and practice, particularly in relation to the question of removing children from their families. The Committee required from the delegated authority, on the one side, to strengthen the existing measures to prevent that from happening and, on the other, to increase the opportunities for children and teenagers to receive other types of guardianship.

\section{Review of the Literature}

In this section a review of the literature about the topics investigated during the current study will be presented, in particular in regards to institutionalization of children and involvement of their families. Although few efforts have been made to investigate this, the primary need in the system of Mexican Child Protection is to overcome the recourse to institutionalization of children and to develop alternative forms of aid to families with complex needs [9]. Next to the overcoming of institutionalization, an even greater challenge is the ability to support both the children and their families. The idea is that in the absence of a dedicated familial network, supporting the child will always be only a partial and at times counterproductive practice [10,11]. Young et al. [12], taking up the provisions of the Universal Declaration of Human Rights, suggest that the best approach to child protection actions should include a sufficient level of resources so as to ensure not only the development of the child, but also the participation of parents in the decision-making process, holistic support to the family, and the preservation of cultures and their different identities, rather than, as a first response, to remove children from a situation that is assumed to be high-risk, and only at a second stage to evaluate what can be done in reparation.

Following this idea, the same authors [12] have proposed the concept of "co-constructing social work" to indicate the processes between workers, families, children and communities, focusing on four key points which are seen to be essential for change: attention to children as active subjects 
and owners of rights; preservation of culture and tradition; consideration of the social capital of the family; and collective actions based on reciprocity.

To ensure the well-being of a child it is also important to focus on the support to their parents, so that the protective actions lead to positive results [10]. If the focus of the social workers is individualistic and centered on the child, it becomes extremely difficult to find a balance between the needs of children and those of their parents, even when the latter seem to be important in order to deal with the situation, or they arouse a genuine empathy in the practitioners [12]. An individualist or a technical-procedural approach, that professionals often follow faithfully, cannot be the only approach of services, because otherwise the assessments would be reduced to mere neutral processes of data collection and objective application of the results to different complex situations [13].

Participatory and reflective processes are essential ingredients in the success of attempts to support a child and his or her family. Sometimes social workers, absorbed in the urgency of the services, seem to live a kind of suspension of personal powers of reflexivity, depriving themselves of their internal conversation $[14,15]$. Folgheraiter [16] defines social work practices in terms of a developmental approach: in relational support, there is learning and development of the subjects even beyond the range of the specific provision, both for practitioners and service users. People who are motivated and able to act start a path of emotional and functional learning that keeps the impending problem under control and at the same time makes people grow in their basic human skills.

Although it is recognized that the complexity of the needs affecting families can influence the likelihood that children may return to their families [17], several contributions in the literature show the importance of working with the families, even in serious situations where the only solution is to resort to institutionalization of children. Several research studies [18-21] have pointed out that maintaining contacts between children and their parents is key to exiting protection procedures and to facilitating the return home of children and youth. For example, Cleaver [21] has indicated that the maintenance of the relationship is not a sufficient reason to promote the reunification, but that it is always essential to work with the parents on the problems that led to the child being placed in care.

Beside the needs of the child, it is also important to consider the needs of the adults, because their well-being or malaise has inevitable consequences on how and how much they are able to take care of the child, and on their degree of motivation to affect the change desired by the social workers. To improve the quality of everyday life of children in situations of risk or harm, the practitioners should support the parents in recognizing the need for change, in deciding how to make the necessary changes and maintain the changes made [22]. In addition to the family members of the children, social work practices should also be able to pay attention to other subjects that are or may be an active part in the situation. The failure to consider the social network around the family or the child may indicate social work approaches that center primarily, if not exclusively, on the subject under protection, giving little importance to the surrounding social and relational environment.

In this regard, Bronfenbrenner argued that child protection social workers are required to consider the whole world of the child by adopting an ecological perspective [23]. The guiding 
principle of a democratic and participatory approach includes different work practices characterized and mobilized by certain principles: the family has the right and the responsibility to meet the needs of its children; the family has strengths and resources to help their children; and the family is provided with the opportunity to participate in the design and implementation of interventions in favor of the child [24]. This holds not only for the "normal" family, but also the "complex family, with problems"; the family that is plunged into a reality we call "discomfort" should be considered a resource, rather than a repository of institutional provisions and of professional clinical aid [25]. In the planning stage it is crucial that the family can meet the challenge of reworking its situation and plan a life project together with the practitioners. In the relational perspective social workers should agree to reschedule their professional spirit in contact with family, pursuing a shared reasoning [26]. With this in mind, the planning of interventions can only be understood under a shared point of view, in which families and experts work together towards a desired purpose of well-being. The same commentators note that people that face problems that affect their lives become experts by experience. This life experience gives a precious sensibility that could drive complex actions, even those of the professional [27].

For the purpose of a fruitful and true collaboration, the research conducted by Thoburn et al. [28] and then by Buckley [29] has shown the importance of information sharing between social workers and parents. The testimony of the latter has repeatedly reported experiences of poor communication, in which the professionals would have kept the information about their children secret. Again, with reference to the supportive relationship between service providers and families, the conclusions of a Canadian study [30], written by child protection service providers with the involvement of parents and professionals, have shown that professional interventions of the social workers should concentrate first of all on the gap between them and the parents, recognizing and legitimizing the fears that the latter could feel. The authors report that: "Parents reported responding to intervention in three ways: 'fighting' through openly challenging and opposing practitioners in court; 'playing the game' by feigning co-operation; and working with services in what appeared to be genuine and collaborative relationships". Most researchers do not include conflict between practitioners and parents as a variable, even though conflict is a frequent occurrence in everyday practice $[31,32]$.

Again, with reference to collaborative practice, an Australian study [33] provides two key reflections regarding the operational practice of the social workers in child protection. The first is the lack of evidence that demonstrates that the practices of collaboration between social workers and parents are considered a goal or a result of the protection. The second concerns the twofold role of the social worker, commonly defined with the dichotomy "help and control". The research explains how this can be experienced in a problematic way, not only for professionals, but also for parents, since for the latter the operator is the only source of support and at the same time the person that removes the child from their home. In this study, the parents identified trust as an essential component for a successful supportive relationship with social workers, and explained that, in their opinions, it strengthens and consolidates itself by feeling respected, appreciated, and kept informed about their children.

Other research has been undertaken regarding attitude and power on the role of social workers in child protection, bringing to light that work practices that are respectful towards parents have never 
been common in social work services [9,34,35]. Some authors [36] have dealt with this specific subject, and claim that in complex situations of child protection the power of the family has to be restricted and valued at the same time. In welfare systems the concept of power appears to not only be counterproductive but also paralyzing, harmful and disabling because it completely bypasses the individual, the relationship and the context [37]. Professional knowledge is associated with powers and privileges [38] and, regarding this, Senge [39] argues that it is not that people and families are reluctant to change but that people are loath to the idea of being changed. While acknowledging the importance of anti-oppressive practices aimed at empowerment, social workers should not act on behalf of the service user because of preconceived distrust, but wait for them to act, support it, and possibly provide feedback to direct it [40].

The involvement in decision making is not just about the relatives and the other important subjects within the situation, but also about the children themselves. According to Ferguson [41], achieving high quality child protection involves the skillful management of actively engaging with children and their environment. However, the idea of listening to children and making them an active part of the decision-making processes is not readily apparent in highly focused operational approaches and social work practices such as child protection. On the contrary, some authors [13] highlight the risks associated with a "child-centered" perspective that does not allow children to express themselves nor involves them in the decision-making process, but merely seeks to protect or assist them. In the context of research on children living in residential care, Montserrat [42] reported the satisfaction that the children expressed about being consulted on decisions that affected them, reporting unhappiness and anger instead when they perceive that they were not being listened to. They like to be consulted regarding possible decisions in the reviewing of their case and are unhappy when they feel they are not heard. They show concern at having a change of caregiver without being previously consulted and criticize professionals harshly for not being honest with them about the reasons for the change. According to Cleaver et al. [43] the key to protecting and promoting children's well-being is the ability to understand their situation from their point of view.

\section{Methodology}

The research presented in this article is the result of two periods as a visiting researcher in the State of Nuevo Leòn as part of the project "Understanding and supporting families with complex needs" funded by the European Commission. The research was conducted by the Italian author of this article, in Spanish language. The author has a Ph.D. and is also an experienced social worker in child protection.

The goal was to understand how the Mexican child protection system engages families with complex needs through ethnography [44]. To this end, this qualitative research study used focus group discussions, interviews, shadowing, documentation and observations. Table 1 describes in detail the research activities carried out in the field in the relative goals. 
Table 1. Summary table of research activities.

\begin{tabular}{|c|c|c|c|}
\hline Method & Number of actions & Subjects & Goal \\
\hline Shadowing & 5 weeks & 5 child protection social workers & $\begin{array}{l}\text { Understanding work and practices of } \\
\text { social workers }\end{array}$ \\
\hline $\begin{array}{l}\text { Depth } \\
\text { interview }\end{array}$ & 13 & $\begin{array}{l}13 \text { child protection practitioners } \\
\text { ( } 6 \text { social workers, } 2 \text { psychologists, } \\
2 \text { lawyers, } 3 \text { care social workers) }\end{array}$ & $\begin{array}{l}\text { Gathering practitioners' opinions about } \\
\text { work criticality and potentiality }\end{array}$ \\
\hline Focus group & 3 & 6 child protection social workers & $\begin{array}{l}\text { Collecting social workers' perceptions } \\
\text { and opinions about work practices, in } \\
\text { particular about help relationships with } \\
\text { parents or relatives }\end{array}$ \\
\hline Observation & $\begin{array}{c}2 \text { group encounters on } \\
\text { behalf of care social } \\
\text { workers }\end{array}$ & $\begin{array}{l}\text { A conductor (psychologist) and } \\
10 \text { care social workers }\end{array}$ & $\begin{array}{l}\text { Collecting perceptions and opinions of } \\
\text { care social workers }\end{array}$ \\
\hline $\begin{array}{c}\text { Depth } \\
\text { interview }\end{array}$ & 7 & $\begin{array}{l}\text { Parents/relatives of children and } \\
\text { adolescents in home care institution } \\
\text { (4 mothers, } 1 \text { grandmother, } 2 \text { fathers) }\end{array}$ & $\begin{array}{l}\text { Gathering feelings and opinions about } \\
\text { their child protection institution } \\
\text { experiences as service users }\end{array}$ \\
\hline Interview & 6 & $\begin{array}{l}\text { Parents/relatives of children and } \\
\text { adolescents in home care institution } \\
\text { ( } 3 \text { mothers, } 1 \text { grandmother, } 2 \text { fathers) }\end{array}$ & $\begin{array}{l}\text { Collect their opinions and experiences } \\
\text { about the help process }\end{array}$ \\
\hline Observation & $\begin{array}{l}3 \text { group encounters on } \\
\text { behalf of parents or } \\
\text { relatives of children in } \\
\text { residential care }\end{array}$ & $\begin{array}{l}\text { The conductor (a social worker) } \\
\text { and } 5 \text { participants }\end{array}$ & $\begin{array}{l}\text { Observing the conductor role and the } \\
\text { group dynamics. Collecting information } \\
\text { about work process in progress }\end{array}$ \\
\hline Focus group & $\begin{array}{l}3 \text { group encounters } \\
\text { with boys and } \\
3 \text { with girls }\end{array}$ & $\begin{array}{l}7 \text { boys }(10-13 \text { years old }) \text {; } \\
6 \text { girls }(14-18 \text { years old })\end{array}$ & $\begin{array}{l}\text { Gathering needs, feelings, wishes and } \\
\text { thoughts of youth living in home } \\
\text { care institution }\end{array}$ \\
\hline
\end{tabular}

All the interviews were tape-recorded for later transcription. Through shadowing it was possible to understand the reality of practice [45]. Focus groups allowed the different participants to elicit their feelings, attitudes and perceptions about selected topics [46], and allowed the collection of a lot of information in a short period of time, while the group interactions stimulated the richness and differences in meaning [47]. For various reasons, during the research, it was not easy to meet families and collect their viewpoint. They often did not physically attend the services, and, due to security reasons, it was not practical to visit their home autonomously. Furthermore, the professionals' engagements with families were not appropriate situations to undertake research, and some of the families showed an initial distrust in being asked to share their experience. To collect families' viewpoints it was necessary to attend institutions' official "open-door" days for families; for example, on the September 15th national holiday when Mexicans celebrate independence day, families can attend the party arranged within the service. Although only about fifteen parents were effectively present at the party (230 children were in residential care), attending these events enabled interviews with a selection of fathers, mothers and grandfathers of the children.

Children's views and participation have received the least attention in research [48]. Interviewing children and adolescents is perceived to be more challenging than interviewing adults [49]. However, 
attracted by the presence of a foreign researcher and motivated by the possibility of satisfying their curiosity about a European country, during the focus group the interviewed children showed availability and openness, answering properly to the presented questions which were intended to gather some information about their experience in the institution, with references to positive and negative aspects and their future desires. Following the methodological approach of Corbin and Strauss [50], the transcripts collected through the focus groups were compiled and read, considering all possible meanings and examining the context carefully. After subsequent readings, elements of each narrative were labeled according to the identified construct. The interview schedule consisted of the following four main questions: "How are you feeling here?"; "Which are the positive and the negative aspects?"; "What are your desires for your future?" and "What is a family for you?" The first three questions were offered to both the groups of youth (one composed of boys and the other of girls), while the meaning of family has been researched only with adolescent girls, because they were older and more willing to deeply explore these issues. Given a reminder, in order to avoid any possible influence and support spontaneity and heterogeneity of opinions, the interviewed were first invited to write individually their answer on a post-it and to display it later and share it within the group. Finally, before the beginning of the focus groups, a step with the practitioners of the institution took place, in order to illustrate the goals of the work, to show the draft of the interview, and to receive instructions about the inappropriateness of using it with certain children. The referring operators stated no limitations about the work, only excluding children arranged in the ward of the structure of the interview used in the focus group.

The research design also involved an analysis of bibliographic and legislative material available on the topic of child protection and on major social issues present in the country.

The main scenarios in which the fieldwork was carried out were both social services and home care institutions, la Procuradoria de la defensa del menor and the houses of families. All these places are located in the city of Monterrey.

\section{Findings}

\subsection{Views on the Mexican Child Protection System}

In this section a general overview of the Mexican child protection system will be presented. To follow, data will be presented divided by actors interviewed. Interviewees consistently suggested that the Mexican security system is sufficiently resourced to ensure children and adolescents have good living conditions in terms of primary needs; children in residential care are entitled to medical care, including specialist care (dentists, dietitians, pediatricians), school and job training courses, games and sports, artistic and cultural activities (workshops, cinema, daycare centers).

The distinctive features of the Mexican child protection system are found not only in a benefits welfare mentality, but also in hierarchical organization according to a strict separation of powers, roles and tasks. The three levels of the system (policy, management and field-work) are conceived with a top-down approach, with processes governed by bureaucracy, control and efficiency. In this perspective, the need for support tends to become chronic and permanent, with an emphasis on 
preventing acute need or crisis, rather than in supporting a family to address the underlying difficulty so that they might disengage from the aid [51].

Another important point repeatedly reported during interviews was an increase in recent years in the number of children in residential care due to their abandonment by parents because of serious poverty in order to protect them from involvement in conflicts related to drug trafficking. The principles offered by the relational methodology [52,53] and by a comprehensive and participatory approach to family in the perspective of Family Decision Making [24,54] appears distant.

In addition, another important issue reported by managers is that there does not yet exist a foster care system, and therefore the only solutions available for a child removed from the family are institutionalization, adoption, or placement with a relative (in most cases almost exclusively grandparents that in Mexico have the parental authority upon grandchildren along with parents). Specifically, a director of a child protection social service explained that five years earlier he had tried to start a process aimed at the development of foster care but, faced with the refusal of the legislator to legitimize it and with some cultural resistance, the whole process was halted. Interviewees explained that the lack of this form of alternative care noticeably affects the quality of professional practices, especially for children with no parents.

\section{2. "Families Call Us Trampas": The Voice of Mexican Social Workers Engaged in the Work with Families and Children}

To get an idea of the reality of Mexican child protection, consider that in $70 \%$ of cases the residential care of children and adolescents occurs on the spontaneous request of the family. Workers reported this statistic and explained that most of these families have a strong social fragility resulting from a lack of literacy and education, unemployment or precarious employment, multidimensional poverty, and a lack of a parental support network to meet daily difficulties and the management of a crisis.

Social workers reported that economic and human resources are devoted to the large number of families who are in most serious need, as it is believed that the more affluent households have the economic, emotional and cognitive resources to refer themselves to consulting services or private therapy to resolve difficult situations.

The child protection professional team for each case consists of a social worker, a psychologist and a lawyer who serves as the child's legal representative so as to ensure his or her rights are respected. The voices of practitioners highlighted that working in child protection is both emotionally and professionally demanding; they described various pressures of child protection practice on their personal lives. This confirms the idea that social workers need to have both human and professional attributes to sustain their child protection role.

The opinion of practitioners and what was observed in their work show a "child-centered" practice tendency, concentrated around the primary goals of protecting the child and guaranteeing good living conditions. During the weeks spent alongside the social workers it was possible to observe how, essentially, no real measures exist to help the parents and accompany them towards the improvement of their own capability and consequently towards a better family welfare. Weeks of shadowing in the field demonstrated that, in regard to the difficulties of families to effectively 
care for their children, social work practices are implemented that focus on the rights of children and young people in care: the goal expressed by practitioners is their protection and little importance seems to be given to recovery of parenting skills. In this sense practitioners separate the protection of the child from the work with families with complex needs. The individualistic perspective that focuses energies and resources mainly on the child and does not extend its gaze to the entire family network deeply affects all work practices. In this regard, one practitioner reported that "Situations are very difficult...we work with children, unfortunately parents almost never are able to change" [55] and explained how often the strong level of prejudice causes the removal of children from families as the only option that can be offered to the child to guarantee his or her well-being.

Practitioners appear focused mainly on parents' vulnerabilities rather than on their strengths. For the practitioners, the recourse to child residential care represents a solution for the children, while their "wrong parents" continue to be considered irredeemable. The opinions of practitioners reflect few hopes for parents and confirm the lack of a comprehensive and participatory approach for families. From this perspective it's difficult to imagine a positive experience of support for families with complex needs. The aim of supporting a child, as recognized by the Mexican legislative framework, is unthinkable and unrealizable without a substantial engagement of parents or relatives. Although the importance of anti-discriminatory practices in social work is officially recognized, this study shows that this principle is not always respected. Mexican child protection legislation embraces a model of intervention on behalf of families with complex needs that is more democratic than the reality of social work practices.

\subsubsection{Social Work Practices}

Observing social work practices, the professional evaluations tend to focus almost exclusively on how parents fulfil their parental roles and tasks, rather than on their personal and social difficulties. The workers dedicate their energies to needs evaluation and to child protection procedures (the latter sometimes enacted even in the absence of certain elements or evaluation), which are implemented rigorously and promptly. Once the child or the adolescent is in care, little time appear to be dedicated to working with the families. In reality, even the assessment process itself takes an individualistic perspective: on arrival at the service (either because they are summoned or forced through police intervention) children and parents or responsible relatives are received separately by different professionals, and the assessment process unfolds through interviews and medical examinations that do not include the simultaneous presence of child and relatives. The impression this leaves is that, once the child is in care, the family continues to be seen mainly from the point of view of its dysfunction and poor chances of recovery or change.

Whilst social workers carry out home visits to the family's home, this intervention is used in an unusual manner compared to the traditions of social work. Except for situations of extreme urgency, when law enforcement agents accompany the social worker to the residence in order to immediately remove the child, or when the family goes directly to the social service to ask for the child's residential care, the home visit represents the first contact between the workers and the family. Given the great distances that characterize the city of Monterrey, the workers on shift 
dedicate an entire day to home visits, leaving in the morning and returning at the end of office hours. Furthermore, for security reasons, the procedure requires that home visits are always to be carried out in the presence of two social workers and with the help of a service vehicle.

The goal of home visits is to meet the family, summon them to the service through a convocation notice and gather information from the neighbors. Although called home visits, in reality, for security reasons, the workers almost never enter the families' houses and instead invite the family to go out on the street, thus transforming the home visit into a brief interview on the street. By not entering the house, the workers cannot understand or evaluate the household environment or observe the family dynamics and, as a result, they do not have the opportunity to gather comprehensive information about the household through direct observation of the people's living environment and their interactions [56,57].

Again for security reasons, during that first meeting, the family receives only partial and generic information regarding the fact that the service has received a report. During this intervention, the service's practice requires that no further such information is shared with the family, often leaving them visibly perplexed or disoriented. Still in the context of home visits, often the social workers acquire information from neighbors. It was observed that the social workers, remaining at the door, ask neighbors questions about the household, the most common of which were: "How long have you been living here? Do you know Mrs...? Do you see her children? Are they well taken care of? Do they leave them at home alone? Do you see drunken people? Do you hear shouting and crying? Is there anything important we should know?"

During the home visits some neighbors, despite obviously being inside the house, refused to answer, some claimed not to know the family and others gave only vague information. Invited to examine this practice more in depth during the interviews, the social workers reported that this first contact with the neighbors is rarely followed by a second one; one could therefore say that the social workers "invade" the family space by obtaining summary information from the neighbors and noting it on the file, but then they never see the neighbors again during the process and rarely consider them as natural sources of potential support to the family. On the contrary, it is conceivable that turning to the neighbors in this phase of the process, and without having first discussed the situation with the family, could influence negatively their informal relations, causing conflicts and increasing the level of distrust and insulation of people. In exercising this practice, the workers seem to be primarily driven by the desire to acquire information on the child, while the domestic, the relational and the social dimensions are neglected. The practice seems to have as its "object" the removal of the child, and not the relationship that bonds him with his family and social network. Fostered by the system's hierarchical logic that marks the relational asymmetry between the family's world and the world of the professionals, the individualistic approach adopted by the latter and by the organizations they belong to seems to focus all actions and all energy on the child and therefore his surroundings are cut out or considered of secondary importance.

In the case of parents with mental health problems, addictions or other problems for which they would require personalized help by a specialized service, the workers give the family a phone number and an address they can turn to, but no networking is done between the different services and neither is the person accompanied during the visit so as to receive help. 


\subsubsection{Defensive Attitude of the Social Workers}

From the information gathered it emerges that social workers maintain an attitude that Banks [58] would describe as "defensive": that is, an attitude aimed at executing the procedure by the letter and at fulfilling their duties and responsibilities as defined by the authority and by the law. In this case, doing one's professional duty means fulfilling their obligations towards the institution rather than taking the ethically correct action. With this professional approach, personal values and institutional values tend to remain separated and, when acting as a social worker, the latter are usually adopted. During the moments of exchange (even informal) with the workers, a divergence could be observed between what they think of the profession (agreeing on values and principles) and what they put in practice with the families (generally, a rigid, unwelcoming and not very thoughtful behavior). Observations of their practice suggest that the dominating trend is based on welfare practices marked by asymmetrical relationships of power, without the empowerment or the participation of those directly concerned and far from the ambitious goals set out in government regulations that speak of aiding all members of the family in difficulty. There is ample evidence in the literature $[59,60]$ of the sort of oppression which can be experienced by parents who are caught up in the child protection system: in terms of Mexican social work practices, the service users are not considered as partners in an aid project and, in a large number of cases, they are not even heard. The system's organization that weighs on the workers' shoulders seems to be determined by a logic that causes effects of disempowerment in which the families are left impotently looking from the outside at what is happening with their children, and the social workers are forced to question the aid relationship with the families, but also their relationship with the organization, to the point that they appear to act more defensive rather than reflective social workers. The representation that the professionals give of their work is one of executioners of an institutional mandate; however, the interviewed workers suggest that these procedures are not seen as a limit to their professional efficiency, but rather as a form of guidance and protection with regards to both the complexity of the situations and the responsibility for the workers' own actions towards the families and towards the organization itself. Little room seems to be left to the individual's initiative, to the valorization of professional creativity, to the independent search for improvement: the workers themselves claim to be looking for a work practice change, but from their narratives suggest a substantial difficulty in imagining a different system and the idea of change generates feelings of fear.

From the interviews with the social workers there emerged feelings of dissatisfaction, fatigue and frustration related to their work. The fear of not being a "good enough" social worker was identified as an issue by some participants, particularly the younger social workers, who suggested that they had little time for reflections on their approach and their own abilities.

During the focus groups on the issue of perceptions of working with families and children, various professionals strongly argued the need for change, referring in particular to three aspects. The first point they indicated covered the issue of responsibility. A social worker said: 
"I have a question which I cannot answer...it's the question of responsibility for these children...how far does mine reach and how far does that of the parents? I mean, how much of what happens or of what doesn't happen to these children is my responsibility?" [61].

These words express the difficulties of practitioners to work in challenging situations without clarity about their boundaries of personal and professional responsibilities. They have lost their own frameworks for making sense of their practice. In absence of this awareness, with regards to their interventions, it's difficult to imagine efficient practices able to support the parents without weakening their abilities and responsibilities and reducing the dependency of families on stateprovided services.

A second point to consider, raised by some workers, was related to working with the families:

“...we need to start working out the life plan of the child with the family as well...we cannot continue to do that by ourselves...it is difficult to talk about the life plan with the families, but I think it would be important to do so...it is important to know if they are okay with that... or if they want the child to return home..." [62].

This point raised by some social workers suggests the potential to encourage and support this idea of dialogue and cooperation with the families. According to Heino [49], listening to service users is part of social work both in a practical and theoretical sense. The more important intuition is that if the goal is the return of children to the family home, it's essential to "mend the gap" between practitioners and families, constructing together projects or plans. In the Mexican context this could represent a valuable change of perspective but requires support through adequate training.

A third point that emerged was related to the influence of problems related to organized crime on the practices, in particular with regards to the situation of a child whose family is involved with organized crime:

"These cases are increasing...The other day a father left a child outside the gate, saying that the child would've been killed if it were to stay with him...How can we work in such cases without putting in danger ourselves, the children and the family members themselves?" [63].

The social problems related to the conflict of the drug war affect social work practices and above all feelings and attitudes of the practitioners. This social problem directly affects the country increasing the level and the perception of insecurity, needs and complexity. The imagery of incidents occurring can intrude into the professional perspective. Practitioners' attitudes reflect the way that the system attempts to deal with the violence. In particular, the question raised by the workers required the development of new strategies, including the work of several actors engaged in facing this considerable problem.

With regard to these three topics, which emerged in the course of a focus group, there is a constant concern expressed by the workers regarded feelings of fear at the idea of change: 
"I think I want to change something...sure...I believe it's necessary...the families call us Trampas...but if we want to change the way we work and we don't know what needs to be changed... we can't do it tomorrow... and how? This scares me a lot" [62].

With regards to the approaches that in the literature [58] are recognized as facilitating the relationship between users and professionals, such as not emphasizing one's status as an expert, carrying out home visits, and keeping in regular contact with the service users, it was established that, in an examined context, these practices are not implemented. Clearly there is a link between the system and the social work practices. The child protection context appears defensive, as, at least in part, are the narratives of social workers from this field of practice. Adopting a defensive attitude, social workers run the risk of omitting the parents' perception of the situation and any areas of resilience which may be positively developed through support. To act in a unilateral manner means that the subjective perceptions of people are irrelevant.

\subsubsection{Las Encargadas}

Inside the institution, the daily support workers for children and adolescents are "Las Encargadas", roles that we could compare to professional caregivers in residential care, but that, in Mexico, lack a recognized degree. "Las Encargadas" take shifts in caring for the children. However, there is a lack of connection between them and the rest of the professional team; not recognized as professionally equal to the other workers, "Las Encargadas" do not take part in meetings and do not have direct contact with psychologists or social workers, unless authorized by their coordinator. During the interviews, "Las Encargadas" also reported that they are not supposed to meet the child's family:

“...we never meet the families, we don't know them because when taking care of the children, we shouldn't be influenced by what their parents say or by what we think of them...for example, we could get angry with them for what they made the children go through....we take care of the children and that's all...that's our job" [64].

This indicates firmly the impossibility for the parents to participate in the children's educational issues, because they are not supposed to know the people who take daily care of their children. In addition to the lack of opportunity for communication, participation and collaboration between workers and families, this practice also negatively influences the reasoning with which "Las Encargadas" perform their tasks, creating negative mental pictures of "bad" or "inadequate" parents, and pathologizing children's situations of living in adverse family contexts [48]. It is interesting to note how some Encargadas undertake these care tasks with the desire to make a difference in the lives of the children they have worked with. This inspiration to produce positive changes emerged from social workers' voices too, and is often what encourages practitioners to adopt a child-centered perspective characterized by asymmetric power relationships, lacking the empowerment and engagement of parents. For children and adolescents, these influences could moderate their possibility to express freely their feelings and wishes, and to feel fully accepted with their grievous family stories. 


\section{3. "It's Like This, They Decide Everything": The Voice of Relatives}

The national law "Ley de asistencia social" invites the social services system to develop actions aimed at empowering the exercise of responsible parenthood so as to guarantee the protection of the rights of children and the fulfillment of their physical and mental needs. Article 12 of the law "Ley para la protección de niñas, niños y adolescents", issued in 2000, maintains the principle that, when children and parents do not live in the same place, this does not relieve the latter from their parental duties. In the same law, chapter seven, titled "Del derecho a vivir en familia", explains that the lack of financial resources and situations of poverty cannot justify the separation of children from their parents and further declares that families are to be provided with support programs so that the lack of resources are not the direct cause of separation. The recourse to residential care for children should not therefore represent the typical solution to families in poverty or with complex needs. It should be an extreme solution and if necessary it should be for a limited time period. Furthermore, the recourse to residential care for children should not exclude the participation of parents in their children's education. Notwithstanding this law, however, the trend of the Mexican child protection system appears not only mainly focused on the recourse to institutionalization in response to child protection and to families with complex needs, but also characterized by the exclusion of parents or relatives.

Article 7.2.2 of the 2010 national law "Asistencia social. Prestación de servicios de asistencia social para niños, niñas y adolescentes en situación de riesgo y vulnerabilidad" encourages the promotion of parents' participation in the support and protection process of children placed in permanent or temporary residential care. However, counter to this, the voices of parents and relatives surface feelings of rage, shame and impotence; what really happens during the interaction with families and parents seems to deviate from what is recommended by the law.

The elements observed and the testimony of parents and families of children in care give the perception that parents seem to "wait on the outside" of the project, often with incomplete explanations or any possibility to effectively take part in action, not truly understanding what is happening to their child. Furthermore, while the child's legal representation is guaranteed through a lawyer who acts in his or her interest within each professional team, the family does not obtain any trusted or public defense. The deficiency in the relationship between families and practitioners, and the existing distance between regulatory guidelines and practical abilities seem to be blamed on the system, on the individual professional perspective of the practitioners. Parents and families do not participate in the project for the children and are not considered as partners to better the situation and to improve the well-being of the family. Dumbrill [30] explained that there are three ways adopted by parents in responding to professional interventions: (1) "fighting" through openly challenging and opposing workers in court; (2) "playing the game" by feigning co-operation; and (3) working with services in what appears to be genuine and collaborative relationships. In the observed context there emerged another reaction: the Mexican families seem to respond to professional practices through a passive position rather than openly fighting, a fake co-operation or a genuine collaboration. 
The interviewees had significant experience as service users and their children were in care for a minimum of two and a maximum of 8 years, with an average of 5 years. Among the interviewed people, some had spontaneously requested the residential care for children, while for others it had been forced upon them. The former group reported that they had done so mostly for economic issues (loss or lack of a job or a house) or to guarantee protection to the child in respect to an armed conflict; the latter group reported others problems, such as the demise of the partner or for the extreme aggressiveness and difficulty to manage the child. As it occurs in Western welfare contexts, the majority of the motivations that lead to a child placement in a residential service are therefore attributable to issues that do not have anything to do with the child, but are instead imputable to family relations and individual problems of the parents. The initial incentive given to the families I met was to share their experience in the child protection service; they expressed both positive and negative aspects. What they identified as positive was the concrete help activated by the service in favor of their children or grandchildren, showing confidence regarding the ways in which they are taking care of them daily, in some cases comparing the experience with the one in other institutes where children were mistreated.

"My two kids live here...they have food, they go to school and to the doctor....and I've asked to keep them here until the end of primary school...I think they're doing good here...I'm fine because I know they are treated well...I'm alone and it's fair that they help me...they're helping my kids more than me...they're growing up well..." [65].

Although they often expressed gratitude to the institution or to the state for its duty to help its citizens, according to the families, significant critical elements were also apparent. The main problems have been attributed to the lack of communication with practitioners, the partial understanding of the path in action, the difficulty in getting information about their child, not knowing what would happen in the next few months, and the slowness of projects in terms of time. Referring to this, even if they express a wish to meet with practitioners, parents described the project as something unrelated to them, rendering them powerless in relation to it. The picture they drew fits with the idea of the lack of involvement by families. Some parents described this powerlessness, through verbalized anger and dissatisfaction, while others seem to have adapted, assuming a passive waiting position. Parents seems to be limited in their "sense of agency". The Mexican child protection system seems to underestimate the parents' right to define what a good life is for themselves and their children.

"What I don't like is not knowing for how long my daughter has to stay here...they think I'm toxic but what they didn't like is that I'm in a relationship with a woman...one afternoon they took her away...she stayed three years at another institution...it was better for her there, because they gave her clothes...now she's been here for four years...in these four years I only had two interviews with the social worker...the last one was a month ago...things got better just because I got close to the Church...they told me my daughter should come back home but I don't know when and how...sometimes I think they want to keep children in here...sometimes they let them out only to give them to another family..." [66]. 
As was evidenced by this mother, parents reported that contacts with practitioners were unexpected and underline their passive and weak positions in the aid relationship. It was striking that some of them said that they had never had an encounter or interview in the last two years, others experienced one interview per year and others had interviews only at the beginning of the process or at the gate of the institution after visiting the child. For some parents the main questions they wanted to be answered were about how long the child was to stay in the institute, while for others this is a secondary concern related only to an exclusively contractual aspect, as emerged from the voice of this grandmother:

"I brought my grandchild here and I made a deal with them...we agreed three years, today we've extended to 5 years..." [67].

The lack of clarity regarding the care for child places the parents in subordinate roles and reduces the chance to adopt a reflexive and open approach to work in partnership with the professionals. Furthermore, making a decision about a long time period of institutionalization means that for the same parents and relatives it is not easy to imagine a positive change in their families and to have confidence in the future. Most of the parents did not have access to the residence where the children live and had never met the people (las Encargadas) who take care of them daily or the volunteers known as "Padrinos afectivos" 2.

"My three kids are here...they've been parted from their mother for four years, she had drug issues and we were separated...it didn't end up well for her...she was killed...I don't know how long the kids have to stay here...I made the drug test, they asked me to do but they don't tell me anything about what they do with them...they could live with my mother...I don't have a house or a job...they were living in another institute in Guadalupe...I went there one day, and they were not there anymore...they brought them here but I don't know why...no one tells me anything...I ask to talk with them and they tell me to wait but no one comes...only the lawyer came to me and asked me to sign a paper so that the children could go to another family...I didn't sign, I don't know who they are...but I don't even know why they can't get out with me or my mother...it's like this, they decide everything..." [68].

In these complex situations, the parents seems to be denied the chance to gain control, to heighten critical awareness and to stimulate a conscious involvement. Another important aspect that came to light from the stories told by the interviewees is regarding their feelings towards the professionals; even if they are grateful to the institution that takes care of their child and guarantees answers to material needs, stories of anger, shame and mistrust toward the professional have emerged. According to Schlink [69], the shame leads to deviant or defensive behaviors that are reticent, deceptive or damaging. Poor relations with social workers often risk increasing the sense of

2 This is a volunteer (man or woman) who is assigned a child or youth, becoming a reference point for them. The relationship involves regular visits to the child at the institution, taking an interest in the child's life and interests, offering time and a listening ear. The arrangement is established and managed by the institution and parental consent is not required. It's possible translate "Padrino afectivo" to "godfather". 
shame that people from the most vulnerable sections of society already have, as well as feelings of being ignored, misunderstood and unheard. Kaufman [70] observed that shame inhibits verbal communication. From the story of a grandmother, whose granddaughter is in an institution, it emerged that joining a group ("Escuela para padres" ${ }^{3}$ ) has permitted and simplified the communication with the social worker.

"I like going to the group...I thought it would be harder...I thought it would bother me the presence of the social worker but it's not like this...at least we can talk, the group and the social worker consider my views" [71].

From these words emerged a lack of self-confidence in being at ease with others, being able to engage with them, or having something to offer to them. Dynamics and positive effects of this kind are well known in groups, and especially mutual-aid groups. In order to develop supportive interventions that are more democratic and based on the resources of the parents and families, professional actions could be designed so as to support families to interact. Another aspect that emerged from the voices of parents or relatives is the subject of the power. The relationships between practitioners and families seems to be characterized by asymmetric power. In the current child protection social work practices, the rights and the power of parents (meant as the chance to be in disagreement, to express opinions or wishes, to share decision making) appear excessively restricted. These restrictions impede dialogue, cooperation and positive outcomes for all. Social workers do not have a reputation for valuing family and the spirit of family life. From the voices of parents, the impression is that practitioners directly help the children and bypass the families.

\section{4. "Maybe My Family Is This Care Institution": The Voice of Youth in Home Care Institution Fluctuating between Boredom and a Need for Protection}

Institutions support children of the State of Nuevo León in the duration of the period of residential care. For some institutions the period ranges from 1 to 3 years of stay, for others between 3 to 6 years, and for some the period of stay extends until adulthood. The boys and girls interviewed all told of long periods spent living in residential care, with durations varying between 4 and 16 years; some could not provide exact information because they were unable to remember the year of their entrance. For some, their home prior to alternative care had been with their own family unit or with relatives, while for others it had been another institution. Feelings of boredom and monotony were a common thread in the experiences of interviewees who mentioned the difficulty of living in the same place for a long period of time, simultaneously expressing a need for protection from the outside world, which is seen as frightening and dangerous.

"Sometimes I get bored and feel like a prisoner here. I'd like to walk through that gate more often, nothing new ever happens here...I always see the same people. It's dangerous outside though, there are people carrying weapons so I think it's safer for me to stay here...though sometimes I feel a bit worried in here, too...but outside, I feel extremely worried...like, 100\% worried" [72].

\footnotetext{
3 The translation is "School for parents". It's a training group for parents and relatives.
} 
The young people's feelings about their life in residential care demonstrates an acceptance of their surroundings, which they talk about unenthusiastically, lacking positivity, while at the same time acknowledging it as a better experience than earlier ones, partly due to the significant need for protection expressed. The need for protection has been linked to violent situations in the outside world, but the same sensation seems to be linked to their personal life experiences. These negative experiences could have structured a feeling of insecurity, danger and suspicion, only in part related to the actual social situation. They reported the satisfaction for the absence of danger and maltreatments rather than care and well-being.

"I feel safe here, dangerous things happen outside that are pretty scary...they're difficult to explain... Nobody hurts you here, it's never happened to me...no, no one has ever hurt me here...you feel safe, and that can be a good thing" [73].

This is in contrast to previous research [74] which has shown that children who have experienced domestic violence, once protected, begin to realize what they have lost, but without underestimating the value of feeling secure. In describing the positive aspects of their actual care, some young people have identified the possibility of access to material goods as beneficial, while others recounted experiences of an emotional nature.

"It's not bad here...maybe it's not good either, but better than when I was in another institution...I have more freedom here...oh, and another thing: I like the food here...yeah, the food is good and I have more friends...I like the other kids or I wouldn't be here...I might even be given a stereo soon!" [75].

From the voice of this boy emerged the topic of freedom, frequently limited by the organizational set-up into the care institutions. His thoughts call attention to wishes for normality (for example having friends or listening to music) and the words "I like the other kids or I wouldn't be here" highlights possible supportive and mutual relationships between the adolescents. In these contexts, which can often lack close and personalized relationships, to have peer-to-peer understanding is clearly important for one's well-being. Young people report using informal support by talking to their friends living in the institution. To maintain or create well-being it is necessary to preserve personhood: that means being in a relationship based on attention and reciprocity. For adolescents in care this is not a simple issue and is often underestimated by professionals, as evidenced in previous research [49]. The flaw is that what is best for any child or even children in general is often indeterminate and speculative: the opinions collected during the focus groups underlined that taking care of children requires a highly individualized choice between possible alternatives. The decisions for children seem to be based on rational reasoning more than subjective needs.

The topic of close relationships recurs in a discussion of negative aspects:

"One of the negative things is I feel lonely, there's no one in here you can trust...the caregivers have favorites...they never listen to me, they're unfair...sometimes I talk to myself" [76]. 
This girl suggested a lack of special, close relationships within the context of the care home, in particular in reference to care workers. Some girls seem to have lost trust in others or they fear that social workers will not be able to help them. They think that social workers have leeway in exercising discretion in giving weight to differing arguments and consideration when making decisions on their interest.

When encouraged to identify the negative aspects of their experiences in residential care, the adolescents also frequently referred to the monotony and limitations of an environment characterized by repetitive, standardized routine.

"I don't have much space in here...we don't get out much...I always see the same faces and the same things always happen...every day...no, Christmas is different...it's my favorite day... but everything else is always the same in here" [77].

\subsubsection{Looking to the Future}

When encouraged to imagine a positive future, the dreams of the adolescents interviewed involved various aspects such as meeting their parents, creating their own family, receiving visits and/or presents, and seeing new places. When prompted, a few related these dreams to difficult moments experienced with their family of origin and the lack of contact with their relatives, although they were not directly encouraged to do so. For example:

“On Christmas Day my mum set fire to our house, that's why I don't want to see her anymore...I have lots of relatives but none of them have ever come here...but I hope to have a family of my own soon...yes, one of my goals is to have a boyfriend and later a family" [75].

"My wish is easy to guess, it's what I think about every day...it's to meet my parents, learn who I am...I don't know anything about them, they told me my grandmother beat me and it was too dangerous for me to live at home, but I don't know anything about my parents...it would be right for me to know, wouldn't it? I want to know!" [76].

Amongst the hopes expressed by the children, the theme of the absence of family visits consistently emerged. Children interviewed expressed feelings of resignation, while voicing in a hopeful tone the request to be assigned a "Padrino afectivo". Feelings of resignation could be linked to fears of the idea of being rejected by other adults. The young people displayed defensive behaviors, probably to protect themselves from other frustrations.

Another significant concern expressed related to a preoccupation with planning for the future. Article 12 of the United Nations Convention on the Rights of the Child outlines the rights of children to express their views in decisions affecting their lives. There are positive benefits for children who are afforded this right, as evidenced by several authors $[42,43]$.

The overall impression emerging from the interviews is that the inclusion of children's views in projects and decision making is still partial. The child's perspective should be the basis for any decision about a child's best interests. Their opinions express a state of uncertainty about the future and a passive waiting position. Although the approach of the Mexican system affirms the intention 
to put the child in the center of the protection project, in practice there are clearly difficulties with the process of engaging with the child. The wishes of interviewed adolescents provide messages to support the development of engagement with children in their protection processes.

"A wish...What I want is a godfather or godmother...I'd prefer a godfather...yeah, better...we could play football...I wish Chui ${ }^{4}$ was my godfather, he's already godfather to a girl! I'm waiting for some other godfather, they have to look for someone, then we have to meet and get to know each other, and if it doesn't work out they'll look for someone else...in some cases it takes a long time... at first I didn't want a godfather because my brother was supposed to take me away from here, but they killed him in prison...so now they're looking for a godfather or a godmother for me...I'm sick of waiting" [75].

“I want to leave here with my mother, but she doesn't want me...I'm waiting for a godfather, someone I can talk to and come and pay me visits...someone who comes when he says he will, of course, my mother brought me here and told me I would only have to stay for a few days while she looked for a job, but I never saw her after that and she never came to visit me on Saturdays... ga godmother would maybe come and later I could go live with her" [77].

From these voices emerged boredom: they have lost trust with their families and the wait for caregivers. Imagining these care persons, the adolescents interviewed spoke about common wishes (such as having some to play football with) but at the same time they focused on relational aspects, visualizing idealized figures unable to disregard their wants. This could represent a critical aspect in establishing restorative relationships or in developing positive experiences.

When answering this same question about the future, a number of adolescent girls expressed the desire to leave and see new parts of the world, or to continue pursuing their education:

"I know what my wish is, I've had it for three years now...I want to go to Paris with someone...it doesn't matter who...I'd like to jump on a plane and go. I also have another wish: I'd like to become a beautician" [75].

Interviewees, made numerous references to painful, personal experiences.

"My brother...I want him to be alive...he was in a home care institution and then he disappeared. I haven't seen him in three years, nobody knows anything but I can feel he's alive. He's 11 years old now I want to see him, but more importantly I want to know he's alive" [76].

These words reflect the difficult situation in the Mexican child protection system, in particular with reference to the real problem of disappearance of children from residential care. This girl has been waiting for three years for information about her brother and from her story emerged an agonizing life experience. These complex situations could divert the practitioner's focus from where it should be: on the children, their families and social network. The support mission could be to foster

4 He is a social worker in a child protection service. 
the development of positive actions to contrast the negative ones more than to shift blame on parents or relatives for past events. The pain and strain experienced by so many families should not be reduced to the visible damages. The system seems to be suffering a lack of mutual collaboration between various actors in the field and "victim/offender" logic could separate the possibility to work together, amplifying feelings of incompetence and closure. The complexity of families cannot be seen solely as a combination of catastrophe, but rather as a combination of negative events and an opportunity for a better family life.

\subsubsection{The Dream of a Family}

The mood and atmosphere generated during the focus groups with the teenage girls provided the opportunity for questioning regarding the girls' idea of family. The responses to this stimulus brought out details of painful experiences and often linked to the topic of missed family visits.

"To me, it's nothing good in mine, they beat me, they almost killed me...to me, family is the way you're treated...if they treat you badly, they're not family...I wasn't happy" [77].

"Beautiful...without violence...the way you want it...my mother left home to look for her mother, and brought me here...I don't know whether she's still my mother, or whether she's part of my family, she didn't come visit me on Saturday, she only comes when she feels like it. I phone her and she doesn't answer: it doesn't hurt me anymore when she doesn't come, I don't know when she'll be coming and when she won't...but I don't cut my arm when she doesn't come, nor even a foot...I don't even cry...well, I cry sometimes, but...I haven't stopped studying because she doesn't come, I don't break a window because she doesn't come...I'm not interested anymore...I stopped living with her when I was six months old...maybe this place is my family..." [78].

“My mum died of cancer, I don't know my dad...I don't know what to think about family...my grandmother treated me badly, she beat me and I didn't like living with her...I think of family as...family is like having a controller..." [79].

From their testimonies, it appears that their experiences of living in residential care reflect aspects of custody and protection, rather than of care and education. The institution may be the first home some children have ever known. References are made to an appreciation of the material side of being sheltered (for instance, they acknowledge having a home, a bed, food, and physical safety as positive), which reflects their previous exposure to circumstances of deprivation and abuse. In referring to their own families, the children expressed feelings of abandonment in which differing coping mechanisms can be discerned, ranging between anger, defensiveness and disillusionment. The expression "family is like having a controller" refers to the need for protection from negative events or the need to receive boundaries from responsible adults able to raise children to take responsibility for their actions, attitudes and emotions. An evident connection to family reunification processes rarely emerged, probably because this is not an explicit goal or, because they do not perceive a change in parenting attitude or capacity. Although the theme of returning home is not expressed directly, hopes and demands are conveyed in the direction of substitute care figures such 
as the godfathers. The opinions and the life experiences of these adolescents underlined the need for alternatives and positive family patterns (for example, in family foster care).

The point of view and opinions of the young people have been clearly expressed, and their messages lead us firmly to the necessity of rethinking social practices to favor the participation of children and their families. Current social work practices, particularly the lack of collaborations between professionals and the families, produce different negatives effects for children in care. The overall impression is that the actual system seems to leave unaddressed the possibility of restoring and repairing familial relations. For children and adolescents, residential care appears to be the only way to safeguard their rights and so they are exposed to long term institutionalization, amplified also by the absence of family foster care. The chance to reconstruct a positive relationship with parents or relatives influences the possibility to establish further restorative experiences. The child protection system that weighs on the workers' shoulders seems powered by a logic that puts the children "under care" rather than "in care", adopting an approach that is far from a culture of advocacy. These elements cause effects of malaise and disempowerment in the children waiting for answers or decisions communicated by the practitioners. This long and passive wait could increase their feelings of anxiety, uncertainty, dissatisfaction and boredom.

\section{Conclusions}

To conclude, the main concepts arising from the statements of the people observed and interviewed during the research will be summarized. Child protection in Mexico appears to differ from, and in some ways even to contradict, international norms, particularly with regards to social work practices relating to empowerment, reciprocity and participation of service users. The research shows that relations between families and social workers are tense, sometimes even nonexistent, and generally tainted with shame, fear and inadequacy on both sides. The evidence seems to indicate that these feelings of unease are shared not only by parents and practitioners but by everyone else involved, including children in care. Lack of empathy aroused in practitioners, far removed from the necessary levels of care and understanding, may be caused by multiple factors, including: lack of faith in current work practices and in the system; rigid working rules applied; lack of training; general defensive reactions and high levels of frustration leading to feelings of impotence. From the interviewees' accounts, we can deduce that there exists a vicious cycle of dissatisfaction involving not only the children and their families but also the practitioners themselves [80].

The prevailing individual work approach appears insufficient to keep together the voices, needs, demands and resources of all stakeholders. The opinions garnered from the fieldwork suggest practical recommendations highlighting the need to rethink the child protection system in a new, global and participative perspective in which practitioners are enabled and qualified to manage risks in a more considered manner [81]. This would imply the services' adoption of more open, flexible working practices based on an appreciation of the resources of parents and families, and a more communicative support process [81], beginning from the assessment. The professionals could act differently in these complex situations following the idea to share risks, projects, worries and hopes with the family members. Following this approach, rather than trying to calculate the 
incalculable, social workers need to regain their former status as "experts in uncertainty" [82]. Child protection needs to be rethought and reprogrammed as a shared challenge and this possibility requires the commitment of policy, management and practices levels.

The perceptions of difficulty articulated by workers and families, together with the adolescents' requests, open the door to possible change, calling into question both models and practices considered culturally indisputable until only a short time ago. Positive signs are emerging in relation to the debate on overcoming the concept of the "traditional family" and the dichotomy on the care of children, which has until now been played out between the state and the parents. From the valuable feedback from interviewees, it would seem the question of child protection has until now been based on two conceptual and operational alternatives: there is either the family (including extended family) or there is the state offering residential care. In reference to the idea of "co-constructing social work" [12], it's possible to affirm that there is little attention to children as active subjects and owners of rights.

From the elements observed, it emerges that the absence of foster care, towards which steps are slowly being taken, is connected not only to a legislative gap, but also to a cultural dimension and attributions of meaning that become attached to the notion of providing help to children and families with complex needs. The experiences of the various protagonists met in the field have given us feedback which should not be ignored in this crucial time in which the topic of child protection in Mexico is attracting growing interest in practical, managerial, political and educational contexts. Adequately supporting professionals in the field will provide good opportunities for sustainable supportive practices through new approaches and/or redirecting key aspects of traditional child protection interventions. A participatory approach not only has the potential to shift the balance of power between the professional world and the client families, but also the potential to democratize decision making within families [24]. Balancing practices with the discourse of rights and participation of children and families in decision making is the biggest challenge in the Mexican context; however, it is not an easy task to undertake for practitioners. Revised official procedures and guidelines, and above all a change in child protection culture is necessary to develop greater co-operation between agencies and families. As recognized in the literature, a greater challenge is to become able to conceive in a unified way the protection of the children and the support of their parents and families. For an accurate analysis it is important to keep in mind that the organizational framework of child protection is heavily influenced by societal problems such as inequalities, violence, corruption, and discrimination, as well as the conservative ethos.

Social work education and training also has the responsibility to pursue the improvement and the development of the Mexican child protection system to a participatory approach. Crucially, social work education at qualifying and post-qualifying levels must show interest in this topic, acknowledging the obstacles faced by practitioners. Education and training could play an important role in stimulating reflexive practices and encouraging professionals to challenge the bureaucratic and individualistic dominances that can potentially occlude more democratic approaches.

The main ideas emerging from this study can be summarized in the following suggestions for reform to practices and policies: 
- The recourse to children's residential care should not represent the primary solution to families with complex needs. It should be an extreme solution and if necessary it should be for a limited time period. The issue is not just regarding whether the host institutions are effective or not, but rather if there are alternative forms of support which are better suited to the interests of children. In order to limit the time of children in residential care, it is important to develop alternative care (such as foster care), but first of all it is important to work with parents and relatives. The real power of the child protection system and residential care for children is in figuring out ways to create the some kinds of change in families, not only in children.

- To work efficiently and positively with the families, it is important to offer to the practitioners adequate training and support, and to develop guidelines for action and social work practices based on empowerment and advocacy. At the same time it is important to consider that change is required not just in methods or practices but in the child protection culture.

- Collaboration between practitioners must be enforced, including with the caregivers of children in residential care who are not currently involved in the complex plan of care of children and adolescents. Without real cooperation, the effectiveness of practices remains partial and the care for children fragmented. Children in care need to receive holistic care, without contempt for their family background.

- It is necessary to break the hierarchical structures inherent in the Mexican child protection system, including addressing relationships between policy, management and practice field, and between the practitioners, and families and children. It is unclear when the word "risk" entered child protection discourse, but it is relatively easy to understand how its use superficially solves some of the more intransigent problems of child protection practices [83].

- Voices from the field suggest that it is time to encourage cooperation so as to enter into dialogue with service users towards a relational and dialogical practice culture. If the professional expresses her/his worry instead of placing the problem with the service user, child or family, dialogue will emerge. According to Parton [84], social workers should construct a process whereby the theory of how to help the practitioners is generated mutually. In this sense there is an openness to the service users' experience and engagement in a process that enables them to communicate.

- The Mexican context presents serious social problems that afflict families with children, increasing the level of needs and complexity. There is hope on the horizon. Academics and social workers believe that the child protection system crisis could represent a new beginning in which to re-think approaches to supporting families with complex needs. To face the main difficulties a starting point could be address the concerns through dialogue, respecting the individuality of others, listening to all the voices, thinking together, and inviting responses [81].

\section{Conflicts of Interest}

The author declares no conflict of interest. 


\section{References}

1. Clara Jusidman. "Desigualdad y política social en México." Revista Nueva Sociedad 2 (2009): 190-206.

2. Unicef Country Report Mexico. "Study on Poverty and Disparities in Childhood." Available online: http://www.unicef.org/socialpolicy/files/Mexico_ChildPovertyandDisparitiesReport\% 281\%29.pdf (accessed on 1 November 2014).

3. Karina Elizabeth Sánchez Moreno, and Sandra Elizabeth Mancinas Espinosa. "¿Vivieron felices para siempre? Una mirada a la violencia en las parejas en México.” Perspectivas Sociales 14 (2012): 101-28.

4. Tamar Diana Wilson. "The Masculinization of the Mexican Maquiladoras." Review of Radical Political Economics Winter 34 (2002): 13-17.

5. Hector Mendoza Cárdenas, and Manuel Ribeiro Ferreira. "Del divorcio con causa al divorcio incausado. El caso del Estado de Nuevo León.” Perspectivas Sociales 16 (2014): 31-50.

6. Jorge Chabat. "Narcotrafico y Estado. El discreto encanto de la corrupción." Letras libres (2005): 14-17.

7. Alfredo Carlos. “'Mexico under Siege' Drug Cartels or US Imperialism?” Latin American Perspectives 41 (2014): 43-59.

8. CONEVAL. "Pobreza en Mexico." 2014. Available online: http://www.coneval.gob. mx/Medicion/Paginas/Medici\%C3\%B3n/Pobreza\%202012/Pobreza-2012.aspx (accessed on 1 November 2014).

9. Elizabeth Fernandez. Significant Harm: Unravelling Child Protection Decisions and Substitute Care Careers of Children. Aldershot: Avebury, 1996.

10. Mary Thorpe. Evaluating Open and Distance Learning. Harlow: Longman, 1993.

11. Susan Young, Margaret McKenzie, Liv Schjelderup Cecilie More, and Shayne Walker. "What Can We Do to Bring the Sparkle Back into this Child's Eyes? Child Rights/Community Development Principles: Key Elements for a Strengths-based Child Protection Practice." Child Care in Practice 20 (2014): 135-52.

12. Susan Young, Margaret McKenzie, Cecilie Omre, Liv Schjelderup, and Shayne Walker. "Practicing from Theory: Thinking and Knowing to 'Do' Child Protection Work." Social Sciences 3 (2014): 893-915.

13. Philip Mendes, and Badal Moslehuddin. "Graduating from the child welfare system: A comparison of the UK and Australian leaving care debates." International Journal of Social Welfare 13 (2014): 332-39.

14. Carolyn Taylor, and Susan White. Ragionare i Casi. La pratica Della Riflessività nei Servizi Sociali e Sanitari. Trento: Erickson, 2005.

15. Margareth Archer. Structure, Agency and the Internal Conversation. Cambrige: Cambrige University Press, 2003.

16. Fabio Folgheraiter. Relational Social Work: Toward Networking and Societal Practices. London: Jessica Kingsley Publishers, 2004. 
17. Fraser Mark, Elaine Walton, Robert Lewis, Peter Pecora, and Walton Wendel. "An experiment in family reunification: Correlates of outcomes at one-year follow-up." Children and Youth Services Review 18 (1996): 335-61.

18. Aldgate Jane. "The Identification of Factors Influencing Children's Length of Stay in Care." Ph.D. Thesis, University of Edinburgh, Edinburgh, UK, 1977.

19. Fanshel David, and Shinn Eugen. Children in Foster Care. New York: Columbia University Press, 1978.

20. Millham Spencer, Roger Bullock, Kenneth Hosier, and Martinet Kaak. Lost in Care: The Problems or Maintaining Links between Children in Care and Their Families. Aldershot: Gower, 1986.

21. Hedy Cleaver. Fostering Family Contact. London: The Stationery Office, 2000.

22. William Millner, and Stephen Rollnick. Motivational Interviewing. Preparing People for Change. New York: The Guildford Press, 2012.

23. Bronfenbrenner Urie. The Ecology of Human Development. Cambridge: Harvard University Press, 1979.

24. Kate Morris, Nathan Hughes, Harriet Clarke, Jerry Tew, and Paul Mason. Think Family: A Literature Review of Whole Family Approaches. London: Social Exclusion Task Force, 2008.

25. Lena Dominelli. Social Work: Theory and Practice for a Changing Profession. London: Palgrave, 2004.

26. Fabio Folgheraiter. Non Fare Agli Altri. Il Benessere in una Società Meno Ingiusta. Trento: Erickson, 2014.

27. Marian Barnes. Caring and Social Justice. Palgrave: Basingstoke, 2006.

28. June Thoburn, Ann Lewis, and David Shemmings. "Family participation in child protection." Child Abuse Review 4 (1995): 161-71.

29. Helen Buckley. Child Protection Work: Beyond the Rhetoric. London: Jessica Kingsley, 2003.

30. Dumbrill Gary. "Parental Experience of Child Protection Intervention: A Qualitative Study." Child Abuse \& Neglect 30 (2006): 27-37.

31. Doug Magnuson. "The Productive Uses of Conflict in Child Protection." Social Sciences 4 (2014): 672-86.

32. Bob Lonne, Nigel Parton, Jane Thomson, and Maria Harries. Reforming Child Protection. New York: Routledge, 2009.

33. Lissanne Davies. "Monsters and Heroes: Constructions of Clienthood: A Postcolonial Discourse." Ph.D. Thesis, University of Western Australia, Crawley, Western Australia, Australia, 2004.

34. David McConnell, and Gwynnyth Llewellyn. "Social Inequality, 'the deviant parent' and child protection practice.” Australian Journal of Social Issues 40 (2005): 553-56.

35. John Reich. Fixing Families: Parents, Power and the Child Welfare System. New York: Routledge, 2005.

36. Bernie Mayer. "Reflections on the State of Consensus-Based Decision Making in Child Welfare." Family Court Review 47 (2009): 10-20.

37. Ivan Illich, John McKnight, Irving Zola, Jonathan Caplan, and Harley Shaiken. Disabling Professions. London: Marion Boyars Publishers, 1977. 
38. Karen Healy. Social Work Practices: Contemporary Perspectives on Change. London: Sage, 2000.

39. Peter Senge. The Fifth Discipline Fieldbook Strategies and Tools for Building a Learning Organization. New York: Curreny Doubleday, 1994.

40. Bortoli Bruno, and Folgheraiter Fabio. "Empowerment." Lavoro Sociale 2 (2002): 273-81.

41. Harry Ferguson. "Walks, Home Visits and Atmospheres: Risk and the Everyday Practices and Mobilities of Social Work and Child Protection.” British Journal of Social Work 40 (2010): 1100-17.

42. Carme Montserrat. "The Child Protection System from the Perspective of Young People: Messages from 3 Studies.” Social Sciences 3 (2014): 687-704.

43. Hedy Cleaver, Ira Unell, and Jane Aldgate. Children's Needs-Parenting Capacity. London: The Stationary Office, 2011.

44. Emerson Robert, Fretz Rachel, and Shaw Linda. Writing Ethnographic Fieldnotes. Chicago: The University of Chicago Press, 1995.

45. Sclavi Marianella. La Signora va nel Bronx. Milano: Mondadori, 2006.

46. Sharon Vaughn, Jeanne Shay Schumm, and Jane M. Sinagub. Focus Group Interviews in Education and Psychology. New York: Sage, 1996.

47. Krueger Richard, and Casey Mary Anne. Focus Groups. A Practical Guide for Applied Research. California: Sage, 2009.

48. Jane Dalrymple. "Family group conferences and youth advocacy: The participation of children and young people in family decision making." European Journal of Social Work 5 (2002): 287-99.

49. Tarja Heino. Family Group Conference from a Child Perspective. Jyväskylä: National Institute for Health and Welfare, 2009.

50. Corbin Juliet, and Strauss Anselm. Basics of Qualitative Research. Los Angeles: SAGE Publications, 2008.

51. Luisa Raineri. "Chi pensa ai genitori? Comunità per childi e famiglie d'origine." Lavoro Sociale 2 (2010): 162-86.

52. Donati PierPaolo. Relational Sociology: A New Paradigm for the Social Sciences. London and New York: Routledge, 2010.

53. Fabio Folgheraiter. The Mystery of Social Work. Trento: Erickson, 2012.

54. Morris Kate, and Connolly Marie. "Family decision making in child welfare: Challenges in developing a knowledge base for practice." Child Abuse Review 21 (2012): 41-52.

55. Interviewee 1. D.I.F., Monterrey, Mexico. Interview, 2012.

56. Nicolas Joanna. Conducting the Home Visit in Child Protection. Glasgow: Social Work Pocketsbooks, 2012.

57. Maria Luisa Raineri. Linee Guida e Procedure di Servizio Sociale: Manuale Ragionato per lo Studio e la Consultazione. Trento: Erickson, 2013.

58. Banks Sarah. Etica e Valori nel Servizio Sociale. Dilemmi Morali e Operatori Riflessivi nel Welfare Mix. Trento: Erickson, 1999.

59. Lily T. Alpert. "Research review: Parents' service experiences-A missing element in research on foster care case outcomes." Child and Family Social Work 10 (2005): 361-66. 
60. Maria Harries. "The Experiences of Parents and Families of Children and Young People in Care.” 2008. Available online: http://finwa.org.au/wp-content/uploads/2011/09/Report_on_ the_Exp_of_Parents_v2.pdf (accessed on 21 May 2015).

61. Interviewee 2. Casa Paterna, Monterrey, Mexico. Interview, 2012.

62. Interviewee 3. Casa Paterna, Monterrey, Mexico. Interview, 2012.

63. Interviewee 4. Casa Paterna, Monterrey, Mexico. Interview, 2012.

64. Interviewee 5. Casa Paterna, Monterrey, Mexico. Interview, 2012.

65. Interviewee 6. Casa Paterna, Monterrey, Mexico. Interview, 2012.

66. Interviewee 7. Casa Paterna, Monterrey, Mexico. Interview, 2012.

67. Interviewee 8. Casa Paterna, Monterrey, Mexico. Interview, 2012.

68. Interviewee 9. Casa Paterna, Monterrey, Mexico. Interview, 2012.

69. Schlink Bernhard. The Reader. London: Phoenix, 1977.

70. Kaufman George. Shame: The Power of Caring. Cambridge: Schenkman, 1985.

71. Interviewee 10. D.I.F., Monterrey, Mexico. Interview, 2012.

72. Interviewee 11. D.I.F., Monterrey, Mexico. Interview, 2012.

73. Interviewee 12. Casa Paterna, Monterrey, Mexico. Interview, 2012.

74. Audrey Mullender, Gill Hague, Umme F. Imam, Liz Kelly, Ellen Malos, and Linda Regan. Children's Perspective on Domestic Violence. London: SAGE Publications, 2002.

75. Interviewee 13. Casa Paterna, Monterrey, Mexico. Interview, 2012.

76. Interviewee 14. Casa Paterna, Monterrey, Mexico. Interview, 2012.

77. Interviewee 15. Casa Paterna, Monterrey, Mexico. Interview, 2012.

78. Interviewee 16. Casa Paterna, Monterrey, Mexico. Interview, 2012.

79. Interviewee 17. Casa Paterna, Monterrey, Mexico. Interview, 2012.

80. J. Bar-On, and Adital Ben-Arie. "A survey of socially and economically deprived families in a regional council in the northern Negev." Society and Welfare 13 (1992): 3-12.

81. Seikkula Jaakko, and Arnkil Tom Erik. Dialogical Meetings in Social Networks. London: Karnac Books, 2006.

82. Kirsten Stalker. "Managing risk and uncertainty in social work." Journal of Social Work 3 (2003): 211-33.

83. Rick Hood. "Complexity and Integrated Working in Children's Services." British Journal of Social Work 44 (2014): 27-43.

84. Nigel Parton. "Rethinking professional practice: The contributions of social constructionism and the feminist ethics of care." British Journal of Social Work 38 (2008): 253-69. 


\title{
Child Welfare in Chile: Learning from International Experiences to Improve Family Interventions
}

\author{
Carolina Muñoz-Guzmán, Candice Fischer, Enrique Chia and Catherine LaBrenz
}

\begin{abstract}
Poor outcomes and several complaints to the judicial system against residential services for children have triggered a deep review of the Chilean child welfare services, particularly in relation to family reunification. This paper offers strategic guidelines to improve alternative care for children younger than six years of age, who are under protective measures. To define such guidelines, a case study was developed based on current models of residential services and foster home programs, which included local (Chile) and international evidence; also this research includes original empirical data collected through focus groups and interviews with key stakeholders of these programs in Chile and in two countries with advanced social services for children (Sweden and Italy). Findings refer to a structural need for reforming social services for Chilean children. Such reform should involve appropriate legislation to guarantee the rights of children and families; a substantial budgetary review leading to an increase in spending; and boosting professional specialization; and raising the capacity for offering integrated services.
\end{abstract}

Reprinted from Soc. Sci. Cite as: Muñoz-Guzmán, C.; Fischer, C.; Chia, E.; LaBrenz, C. Child Welfare in Chile: Learning from International Experiences to Improve Family Interventions. Soc. Sci. 2015, 4, 219-238.

\section{Introduction}

In 2013, the protection system for children whose rights have been neglected came to the forefront in Chile due to a project commissioned by the Supreme Court of Justice: the Levantamiento y Unificación de información de niños/as en el sistema residencial Chileno collected and standardized information about children in the Chilean residential care system. Its main outcome was the Jeldres Report [1], which provides an account of serious rights violations occurring in the residential system of the National Service for Children (SENAME).

Drawing from the findings of the mentioned project and subsequent report, a research project was designed to provide strategic guidelines to improve alternative care models provided by the State for children under the age of six who are subject to protection measures. To define these guidelines, case studies were conducted on residential services and on foster families, incorporating national and international evidence, as well as original information compiled through focus groups and interviews with key stakeholders of these programs in Chile and in two cities of countries with advanced child welfare services, namely Umea in Sweden and Milan in Italy.

Different studies [2-4] have shown that in these residential services children usually do not have meaningful contact with their families or friends; there have been revelations about physical and sexual abuse in residential care over several decades, and monitoring to ensure that children are safe, healthy and receiving proper services, appears as a permanent weakness of the system; at the same time, residential care for children is perceived as staffed by a largely unqualified workforce. 
Residential service has been also criticized around the world for its high cost [5]. In Chile there is a great deal of concern regarding the tendency to continue giving priority to residence as an alternative, over and above the possibility of strengthening and extending the use of foster families.

The aim of this study is to identify guidelines for reform of current foster families and residential services intervention models for children under the age of six who are in State care due to parents having temporarily lost parental care rights.

Specific aims are:

(1) To identify components of the residential services and foster family models implemented in Chile that favor or restrict the full exercise of rights by children without parental care.

(2) To identify factors of residential services and foster family intervention models that have been proved successful in international policy and practice.

(3) To provide recommendations to improve the residential services and foster family models implemented in Chile.

The article first describes the research strategy and analytical approach; current literature about residential and foster care services is then reviewed to enlighten the analysis of fieldwork results on Chilean residential and foster care services. The analysis considers gaps between policy guidelines and current implementation of services, as well as considerations coming from the literature review. These results are compared with international services, acknowledged as having good practices. The conclusions include main weakness and strengths of these services.

\section{Methodology}

The research strategy was the design of case studies, using exploratory questions for interpretation purposes [6]. The selection of cases corresponded to a theoretical sample and could be defined as of polar cases, since foster care and residential programs appear as contrasting cases. Constant comparison was the backbone of the analysis strategy both within each case (within analysis) as well as among cases (cross case analysis) [7].

The data collection techniques for achieving aims 1, 2, and 3, respectively, were:

(1) Group discussions with key stakeholders involved in each residential services and foster care program modality in Chile

(2) Interviews with experts and implementers, as well as participant observation in countries that have developed successful residential and foster care programs models (Sweden and Italy)

(3) Secondary source documental analysis

Interviews with the head of one residential program and one foster care program were conducted in Santiago, Umea and Milan. Also, a focus group was conducted in each city with professionals implementing residential as well as a foster care programs. The number or participants were different in each city. For residential programs the number of the focus group participants was three in the case of Umea, eight in Milan, and nine in Chile. For foster care programs, it ranged from four in the case of Umea and Milan to six in Chile. Questions in interviews and focus groups were 
related to the participants' professional background, intervention models, underlying perspectives to understand child welfare, costs of the programs, and characteristics of the population served.

The interviews and focus groups were recorded, with the participants' permission, and the data was later transcribed. Next, a thematic analysis of the qualitative data retrieved in the interviews and focus groups was undertaken. The analysis contemplated within and cross case data analysis, including documental analysis, such as national policies, policy guidelines and job descriptions. Single case analysis involved a comparison between the planned intervention declared by policy guidelines and the effective implementation, according to implementers' description. The analysis evidenced the accomplishments and shortcomings of the policy. Thematic analysis demonstrated how analysis of the raw data progressed towards the identification of overarching themes enlightening new guidelines for Chilean policy.

\section{Residential Services and Foster Families: Literature Review}

The characterization of children and families using alternative care determines the services being provided; the international literature has identified common features for this population. Connor et al. [8] has indicated that children using residential services tend to present high rates of medical problems, as well as evidence of extensive family dysfunction, including high rates of parental alcohol use, violence, and physical or sexual abuse. In Sweden [9,10], children under care have been characterized by coming from single-mother families and absent fathers, with evidence of a long history of social exclusion and continued marginalization during their life. Parents present high rates of substance abuse and mental disorders. McCue Horwitz et al. [11], point out that children in residential services have prior experiences of ill-treatment, and that their families are under high levels of stress due to unemployment, addiction, poverty, violence in the community, and family violence. Other studies carried out in the USA [12,13] state the biological mothers of these children have suffered physical violence perpetrated by their partners $(45 \%)$, and among these, $29 \%$ had occurred in the last twelve months. Factors associated to children victims of physical violence were: children of young mothers suffering depression, or with substance dependence, and prior history of reports to social services. Considering all these conditions, the reparation response given by alternative care services should ensure professional specialization and the material and financial resources necessary to cover the special needs of these children.

However, findings from international research show that these requirements usually are not met. In the United Kingdom (UK), the tendency to dramatically reduce residential institutions was produced by findings related to:

"numerous and widespread scandals surrounding the abuse of children and young people, particularly those in residential child care institutions. Factors associated with such abuse, include: failings in relation to staff recruitment, training, and supervision; ineffective management and systems of accountability; the development of inappropriate institutional cultures; public ambivalence towards children in care; the slow footed response to the threat posed to children and young people by dangerous men and other 
youngsters in care; and the long-term policy failure to develop coherent and integrated systems of child welfare in the UK" [14].

Similar findings were presented by Gallagher [15] who asserted that abuse in children's homes related to the lack of concern by State and society was expressed in poor policies, with few resources, and inadequate staff supervision and training. With these assessments in mind, the tendency in Chile to continue giving priority to the residential response sparks concern.

Other research $[5,16,17]$ specifies the negative effects of residential services on children resulting from group care contexts and the shift system offered by these services, which does not favor interaction and the development of significant long-term individual relationships, instead leading to highly disorganized attachments. It should be noted that children affected by inappropriate care subsequently not only demonstrate difficulty for inclusion in society, but also lead to high costs in all areas of health: physical, mental, aid, and so on.

Worldwide, residential services have been criticized both for their negative effects on children as well as for their high cost. When compared to the cost of foster families programs in the USA, residential services costs are six to ten times higher, and hence it may be deduced that there is no cost-benefit ratio in favor of continuing with this alternative, as long as there is another option for alternative care [18].

Nevertheless, there are some very specific cases when residential type care would appear to be more appropriate. This is the case for children with mental health problems who require treatment or a more restrictive setting; or care for adolescents, since their inclusion in a new family could be more contentious than in a residential system. The results of the systematic review performed by Hair [19] on the outcomes for children and adolescents after residential care carried out from 1993 to 2003 showed those children and adolescents with severe emotional and behavioral disorders were able to benefit and showed positive outcomes from residential treatment based on a holistic and ecological model. The authors warn of the limitations of generalizing these findings.

Within this framework, everything would seem to suggest that it is more appropriate to ensure individualized care for children through the foster families system; and in fact, according to indications by SENAME, the Chilean State has planned to reduce residential services and to extend the supply of foster families for children under the age of three.

Regarding foster families services, although outcomes have been better assessed than residential services in the international literature, they are not exempt from difficulties. According to Susan White [20], an expert in alternative care in the United Kingdom, the problem with foster families would mostly be operational and related to the shortage of foster homes, the deficient training and support provided to them, limitations in placing siblings together, and in generating permanency in a single home. Furthermore, the loyalties of children to their birth families occasionally affects their ability to appropriately settle in, added to the fact that prior abuse makes caring for the child difficult given behavioral problems, producing breakdowns in placements. This fact has been confirmed by the systematic review by Rock et al. [21] pointing at the negative consequences in the psychological, social, and academic spheres in children who have suffered a break in their foster families' experience. 
The difficulties of settling-in with a family other than their birth family should not be underestimated, especially in the case of older children. In their review, the authors found aspects that hinder and others that favor stability in foster families. Among the obstacles is the situation of older children suffering mental health problems; the existence of long stays in State care (with residential experience as the first); separation from siblings, which could lead to insecurity; and not having the option of a kinship family, which usually offers greater stability given the unconditional support and sense of duty of the caregiver, with an ample sense of acceptance of the child [21]. It follows from the above that preference for a foster family system over and above the residential service is conditional upon certain characteristics of the associated intervention models and the population being served.

\section{Residential Services and Foster Families in Chile}

Loss of parental rights in Chile occurs only by court order, stemming from a violation of rights suffered by a child and for which the parents are deemed responsible. Subsequently, the child is referred to an alternative care state program. A Family Court magistrate makes the mandate and it is compulsory.

Residential service is provided at institutions for groups of children through a shift system of non-relative caregivers. Within this type of care service, there is a period of transitory residential program while the best care option is assessed; hence, it is transitory short-term measure, aiming to provide immediate protection and assess best alternatives. There is also a medium to long-term residential service, which seeks to provide shelter while improving a family situation. The number of children in this type of residences is variable. There are facilities for infants in large numbers, such as Casa Nacional del Niño (National Home for the Child), which can host more than 90 children, and smaller residential facilities hosting 20 to 30 children on average. International recommendations indicate residences with a reduced number of children (six to eight) are preferable.

A foster family is another alternative, which provides care in a home for one or two children, who may or may not be siblings. This service is implemented through kinship families. It can also be provided by an external family - a family not blood related to the child — which can provide specialized or simple care, depending on the case. Implementation of these alternatives will depend on the existence or not of a kinship family prepared to protect the child while a decision is made regarding whether the birth family can recover their care. It will also depend on the special needs the child might have.

The protection system for children whose rights have been neglected has become particularly visible in Chile during 2013 because of the dramatic findings of a study conducted by United Nation International Children Economic Fund (UNICEF) and the Family Courts, which came into public light in July that year [1]. The confirmation of serious violations of rights occurring within the SENAME residential system has made evident the need to review the protection models implemented to date. The report in question indicates that children currently in SENAME residences suffer sexual abuse, violence, and ill treatment. These violations are present throughout the entire system. The report radically questions the protection provided to these children and places at the heart of the discussion the urgent need for an intervention of these programs. In this 
context, one possible response by public policy could be to move towards a quick eradication of the residential system - currently under serious scrutiny - in favor of other mechanisms such as family reunification and foster families. Nevertheless, experience shows it is essential to avoid over-simplifying the solutions. The urgency of the matter does not release policy makers from their duty of fully addressing the issue, which should include a planned transition to foster care programs when appropriate, and reforming the residences which, as previously noted, could represent an alternative for specific problems. All in addition to the fact that total closure of RSs would be unfeasible.

According to Vivanco [22], SENAME has 14,742 placements for children between 0 and 18 years of age, whose parents have lost parental rights. It represents the $0.2 \%$ of Chilean children population between those ages. These placements are distributed among 297 residences throughout the country, managed by SENAME's collaborating agencies, which as a whole provide care for the $78 \%$ of children under state care, and 47 foster family programs which are also implemented by collaborating institutions, looking after the remaining $22 \%$ of children that are under state care. From this data it is understood that in Chile, despite the deinstitutionalization strategy implemented since the $1990 \mathrm{~s}$, the dominating program line continues to be residential programs for the care services of children whose rights have been seriously damaged and require separation from their birth families.

Within the whole population of children under state care, $19 \%$ corresponds to infants aged zero to six years; out of this percentage, $63 \%$ were in residential services and the remaining $37 \%$ were in foster families. In other words, children aged zero to six years of age in alternative care represent a relatively small proportion (19\%) of all children without parental care who are looked after by SENAME, but most of them are in residential care $(63 \%)$.

Below there is a short characterization of each of these programs in Chile. Firstly, there is a description of the services as planned by the State, using policy guidelines provided by SENAME as a source, wherein the main requirements of the program are outlined. Subsequently, based on primary sources (focus groups and interviews) and secondary sources (mainly Martínez [23] and Fundación León Bloy [24]), there is a narrative regarding how these interventions are actually implemented. All these aspects will provide a more complete picture of the interventions effectively implemented today in Chile. The section concludes with an analysis of the differences and common points among planned and actual program implementation.

\section{Findings about Residential Service in Chile}

The technical guidelines for residential services for infants and preschoolers make a distinction between the residences managed directly by SENAME and the ones managed by collaborating agencies. The first are transitory, for assessment, whereas the second conduct interventions that are aimed at reparation and reunification.

Despite the substantial difference in their function, it is striking that the requirements in terms of professional staff teams are exactly the same in both cases. Also, that job descriptions of professionals involved in assessment roles are given in great detail, whereas the reparation role is scarcely outlined. Furthermore, although the technical guidelines determine residential services 
have a clearly differentiated audience, aiming at infants and preschoolers, the detailed intervention criteria and processes show no substantive differences. This seems to indicate that despite the differentiated needs and causes of admission of this population, the services provided are homogeneous. Furthermore, limited staffing and a high caseload assigned to professionals ( 25 cases per professional) hinder appropriate intervention to ensure the necessary time to work appropriately with the birth families.

More than $65 \%$ of the mothers and fathers of children arriving at residential services have only attended primary education; $10 \%$ have no formal education, and close to $20 \%$ have completed secondary education. $69 \%$ of children in residential services are poor, but not indigent; only $30 \%$ of these children are registered with FONASA (the national health fund). These findings show that these children come from contexts with multiple difficulties, quite similar to the evidence reviewed in point 2 of this study.

In terms of how users are perceived, the available information [23] indicates that families as well as children are perceived by the professionals from residential programs in a rather negative light. The biological families, in particular, are seen through a stigmatizing prism. Residential services' staff claim that the profile of current children ("more complex") would create difficulties of "loss of control", in relation to which the teams would have neither the resources nor the appropriate tools to respond. This negative framework comes in stark contrast with a promotional framework, as promoted by the policy's statements, which would aim toward developing the capabilities of the children, families, and communities, based on the acknowledgment of their potential.

At an organizational level, there is an evident shortage of resources, along with high staff turnover and scant inter-professional work. There is also a strong disassociation between the daily care workers' duties and work performed by the professional team. The first base their actions in common sense and previous experience; their functions are focused on domestic tasks and behavior management. Daily care workers are not involved in intervention plans.

In line with the above, the interviewed teams acknowledge having methodological shortcomings addressing family reunification intervention. In general, they believe they do not have the required specialization in order to work with this population and its complexities. It seems remarkable that the only two strengths of the residential programs mentioned by the implementers in the discussion groups were the mutual support relations within the work teams and the team's commitment with the tasks undertaken. Seemingly, reciprocal contention and appreciation of social and emotional competence plays a compensatory function in the face of limitations in the area of professional competence and skills.

\section{Findings about Foster Families in Chile}

As in the case of residential services, professional teams from foster care programs are mostly comprised of social workers and psychologists, assisted by social operators that carry out the task of connecting with families, services, and community networks. The child to professional ratio also tends to be high, 20 to 1 on average.

The technical guidelines for foster families include some lessons gained from international experience, outlined in Point 2. For example, the priority assigned to the kinship family, which is 
considered to be more stable than families without blood ties. There is a distinction between regular foster families (kinship or external) and specialized foster families, where the latter host children who require contention and specialized care, because they have suffered severe violation of their rights. It seems puzzling that, despite this distinction, the measures set forth for the treatment of both populations are homogeneous, and criteria for the selection of professionals as well as foster families show no differences.

Another aspect to be highlighted from the technical guidelines [25] is the preference given to placing children over the age of two in foster families - but not younger children - under the argument of the vulnerability of children under the two years threshold. This is in spite of evidence showing that residential care for children under the age of three years is highly counterproductive for their development.

Technical guidelines for foster care programs consider parameters for foster families' recruitment are very general. Greater precision would be required to certify the fulfillment of standards in terms of foster families' motivations, caregiver aptitudes, and need for coaching. To date it would appear these precisions are left at the discretion of the collaborating agencies that implement foster care programs.

Only general guidelines are provided to define the professional relationship between foster families and birth families. This allows for ample flexibility in addressing the specific needs of families, but in turn it denotes certain ambiguity with regard to the level of specialization expected of these programs. This is a relevant point since, as pointed out by Rock et al. [19], the relationship with the professional responsible for the case is also a decisive factor in the stability/instability of the foster family, and the lack of a specialized professional may threaten this relationship. Also, program leaders complained about the constant turnover of the professional teams, which turned to be detrimental for a consistent relationship with families. Attention is drawn to the fact that, given the relevance of the role, there is little clarity in the policy guidelines for foster care programs in Chile as to whether the individuals in charge that liaise with foster families are social operators or professionals. Lastly, the foster care programs consider a regular financial contribution, which is designed as a subsidy for these families to help cover the expenses associated to the child placed in their care.

It should be pointed out that interviewed teams report scarce development of standards for the recruitment of foster families. It must be noted that in fact foster families recruitment has become increasingly difficult due to a number of reasons: weak promotion, lack of incentives (financial, professional support, among others), and negative stereotypes associated with the role of foster families. Additionally, changes in the makeup of families in Chile come into conflict with the concept of eligibility of a foster family for hosting a child, e.g., mothers working outside the home, lack of support by extended family in those homes, or simply lack of physical space.

In terms of the financial compensation received by foster families, professional teams assess the issue as problematic. Although the contribution is designed as a subsidy, this contribution is insufficient to cover the needs of the children and it also tends to act as a perverse incentive (by becoming the main motivation in high social vulnerability contexts). It also tends to create dependence. This issues point back to the criteria for family recruitment. 
Teams interviewed admit to possessing stigmatizing perceptions towards biological families. There are no other references in the information gathered referring to the specific work done with these families. However, staff refer to these families as not good enough to rise their children, even though it seems they do not have much time to know them and offer them pertinent help to improve their parenting.

In general, the teams report a series of structural weaknesses (salaries, working hours, caseload, and infrastructure conditions, among others) that have a negative effect on their interventions. It is not by chance that, as in the case of residential services, the main strength revealed in the interviews is their own commitment to the duties they perform. This commitment enables them to somehow offset the complexity of the difficulties and also shortcomings such as the lack of resources (the study by Fundación León Bloy [24], indicated State contributions on average only covered $40 \%$ of the total cost of these programs).

Other shortcomings mentioned in the interviews related to the legal framework are the absence of standards for decision-making in terms of alternative care and the lack of protocols for linking foster famlies programs to adoption programs. In the first case, there is the perception that in the judiciary system there are magistrates with absolute powers, who despite having the advice from interdisciplinary teams, adopt their final decision with absolute discretion. There are no known and established procedures for channeling their decisions in this regard. The second point highlights that adoption and foster families are currently mutually exclusive and differentiated programs, to the extent that a foster family is legally prevented from becoming the adoptive family of the children they host, and that families interested in adoption cannot be a foster family.

Lastly, it is worth underlining that the interviewed teams, consider that foster care programs and residential services are not mutual substitutes. Neither program is perceived as in competition or playing equivalent functions, but rather as supplementary, since they respond to different situations and diverse profiles of children.

\section{Residential Services and Foster Care Programs in Chile: Main Critical Nodes}

Although international evidence on residential and foster care programs shows the latter as better in terms of safeguarding the care and development of children, the analysis of the programs currently implemented in Chile introduces a more complex scene. In fact, available information reveals both alternatives are affected by serious limitations that even place at risk the overall protection of children in State care. Aside from the differences between these programs, there are precarious conditions commonly in place in both residential as well as foster care programs. Some of these shortcomings are related to the technical guidelines, however the great majority are found in the more structural conditions that prevent the existence of minimum standards for implementation of the programs as originally designed. The result is that in both alternative care programs, the interventions actually implemented are discretionally shifted to some intermediary point between the model as designed and what contextual restrictions actually allow.

Below is a summary of the main nodes of conflict, common to both models. The overview begins with those embedded in the programs as such and their interventions, moving towards those in the institutional and legal framework. 


\subsection{Critical Node 1: Insufficient Technical Guidelines}

In both cases, what first stands out is the lack of clear protocols for acting in crucial stages of treatment, including recruitment in the case of foster care programs, staff selection, or intervention for family reunification in the case of residential programs, and so on. In the case of foster families' recruitment, the lack of interested families mentioned earlier threatens the prospective of reducing residential services and extending foster families. In this sense, strategically designed recruitment actions are urgently required. The issue of the deficit in the number of foster families ultimately blankets the discussion about minimum standards to become a caregiver or professionally intervene in a highly complex population.

Furthermore, although official guidelines make appropriate distinctions between publics with different needs, and even consider allocating them into different sub-programs, such as foster families/specialized foster families, in practice the profile for professionals and also the interventions to be carried out are homogeneous. This homogeneity, once again, does not come as a consequence of the existence of homogenizing protocols, but rather the absence of any specific procedures. Hence the main part of the intervention relies excessively on the criteria of the professionals involved.

Lastly, clinical work with in residence children, biological families and foster families are left at the discretion of each professional team working with the families. With such a framework, it comes as no surprise that the dimensions known as favorable in both programs are linked more to the volunteering spirit of program stakeholders than objective characteristics that could be made extensive to other programs.

\subsection{Critical Node 2: Low Specialization}

Shortcomings in the technical guidelines are aggravated in the light of the low level of specialization present in most professionals in practice. They mostly have limited knowledge about interventions that have proven to be effective with families that have lost custody of their children and with foster families. Neither have they received specific training in the skills required to work with children whose rights violations can be categorized as highly complex. In general, programs show difficulty in recruiting and retaining specialized professionals and an appropriate level of staffing. This situation can be extended to the daily care workers who are directly in touch with the children. In the first case, precarious working conditions, low wages, and the difficulty of the task, make this field not very attractive to specialized professionals. This leads to a greater proportion of young under-specialized professionals and high turnover. In the case of the caregivers directly in touch with the children, the shifts system is increasingly less attractive in urban sectors where there is greater availability of jobs, and where wages are too low for the market. All of this compromises the current organization and challenges the development of alternative care strategies.

\subsection{Critical Node 3: Stigmatization of the Biological Families}

The behavior of professionals and staff who work directly with children appears suspicious and somewhat stigmatizing of birth families, which tend to be defined as inadequate and not deserving 
of the care over their children. This attitude is rooted in a pro-institutionalizing organizational culture that prevails and has been legitimized for many decades. The recent introduction of a children's rights and pro-family-reunification approach has been unable to substantially modify this attitude, even though its persistence is counterproductive for the aims of the current intervention.

\subsection{Critical Node 4: Fragmentation of Services for the Child}

In Chile, public supply for safeguarding access to public goods and services operates in a highly compartmentalized manner and by service sector. Thus residential and foster care programs are challenged to resolve access to basic services that should be safeguarded by right (health, education, justice) but that are scarcely available and, by default, fall under the responsibility of a single service.

In addition, within SENAME there is also great disarticulation among the various institutional services offered. The radical separation between foster care and adoption programs is one of the clearest examples of this. In fact, in many cases the child stays with a foster family for a considerable period (more than one year) and significant attachment is forged, whereby the child, especially infants, see their caregivers as their parents. This can lead to a significant sentiment of loss and mourning, both for the foster family as well as for the child at the time of separation. The question that arises here is why the foster family is not given top priority for adoption of the child, in contrast to adoptive parents who have followed the adoption process for the child in parallel.

\subsection{Critical Node 5: Discretionary Work of Judges within the Framework of the Minors Act}

The Minors Act allows Family Judges almost absolute powers when making decisions about family life, usually with limited information and a lack of standardized criteria to decide on the future of the children. The perception of the interviewed teams, who implement these decisions, is that the lack of counterbalance and technical criteria in this process leads all too often to inappropriate decisions that go against the best interests of the child. Examples of this situation refer to the tendency in giving priority to a relative to take care for the child, despite the fact that that option may not be ideal (in families entirely linked to drug trafficking, sexual abuse, family violence, or simply the inability to provide care in the long-term).

\subsection{Critical Node 6: Lack of Resources}

Several of the indicated deficits have a common structural background, and it is the State subsidy that is highly insufficient when it comes to covering the actual cost of the programs required to work with these populations. The shortage of funding becomes particularly evident on seeing the precarious working conditions of the professionals as well as the technical staff. Low wages, overburdened teams, reduced staffing, high turnover, and under-specialization are all aspects that are having a drastic negative impact on the quality of the interventions, and especially on the coaching received by the biological families and foster families.

It is clear from the interviews that the low sense of professional efficacy and of achievement among the teams leads to a constant feeling of pessimism and burnout. Furthermore, in the case of 
residential services, funding is insufficient to provide appropriate infrastructure, which results in homes with a shortage of space and privacy for daily living. Most recent information about the status of protection residences speak of various centers even having difficulty in satisfying the basic material needs of children.

Professionals claim that funding from State is insufficient both to maintain the appropriate running of a residential service as well as for foster families to provide decent care that at least covers the basic needs of the children in their care; far less could one think they will be given high quality professional and technical care and that the support programs to which they have access may also be of high quality.

Many explanations have been given for not having higher funding: the financial contribution being symbolic because all the services required by the child (health, education, social services, and so on) are provided separately; or foster families cannot use the subsidy as a business, referring to the risk that families could take financial advantage of the money received. The first type of explanation does not consider the quality of the services provided is often insufficient, or that waiting lists to access to public services are too long. Explanations of the second type, however, express prejudice toward foster families that does not favor collaborative work between staff and families.

The issue of funding for residential and foster care programs is a crucial dimension when explaining the success or failure of the implementation of a program. Nevertheless, this is inexplicably one of the points systematically avoided by policy makers. In this sense, if in Chile it has been proven that budgets for programs, such as the ones analyzed, are well below the actual cost of the planned interventions, the origin of the failure or insufficient performance should be initially sought in the funding difficulties and not the judges, professionals, families, or institutions. Ultimately, aside from their specific actions or omissions, the structural impact of the underpinning financing system and legal framework is far greater. Specific amounts of funding are discussed in the following section.

\section{International Cases of Alternative Care: Lessons for Chile}

As noted above, analysis of international cases was conducted through a series of interviews and focus groups with professionals that implement residential and foster family programs in Sweden and Italy. Both countries have advanced in prioritizing care alternatives that safeguard the right of the child to live in a family, protect the interests of the child, and their enjoyment of the right to survival and development, avoiding all forms of discrimination, and all dimensions in line with the general principles established by UNICEF.

One general finding to be noted in terms of residential care is that this option is reduced to a minimum but stable level, for children with special needs who are well covered by the structure of the residence. However, neither in Sweden nor Italy are there any residential provisions for children under the age of six, except when residences offer care to a complete family such as it occurs in Sweden; or under an absolutely transitory period while finding a foster family as occurs in Italy. 
Certain dimensions affecting foster care programs have been identified which are useful to explain some of the findings in the Chilean case and to propose improvements, both to the child protection system in general as well as the programs being analyzed. It should be pointed out that in the studied countries foster care programs have faced shortcomings and difficulties in their design and implementation. Below are four main lessons learned from the cases studied, always from the viewpoint of reforming alternative care models for children under six years of age in Chile.

\subsection{Lesson 1: Decentralization, Articulation, and Joint Decision-Making for a Child Policy Model}

The European cases are characterized by a different social welfare approach than the liberal/conservative North American approach and closer to that of Chile. This approach has an emphasis on social solidarity and democracy on the basis of social rights, equity, and the construction of citizenship avoids reducing people solely to their role as subjects of assistance. The satisfaction of social needs is understood as a collective responsibility and social welfare offer constitutes a right, which is accepted voluntarily [26].

This view affects the type of society that is constructed and its predominant values [27], affecting the existing forms of social connections, the inclusion of individuals, their position in society as well as their treatment and participation levels. It also affects how families are seen and treated when they have faced difficulties in their children's upbringing, which may have resulted in damage to the rights of their offspring.

These options translate into the existence of child protection systems that are not fragmented from the overall protection of the family, and where various programs converge (work, education and health, among others) and society collaborates in a sort of partnership with families that require support. These child welfare services stress a social service approach by focusing on providing support, and including a strong belief in the beneficial results of state interventions in families. These services have high legitimacy and support in public opinion. The indicated emphasis appears different from those found in the Chilean child welfare system, which is compulsory for families if the judge determines a protection measure, and where there is a predominant stigmatized view over users, families and children.

On top of these differences, in Milan and Umea we found decentralized and flexible systems, with a broadly diversified supply of services to cover the specific requirements of families. In comparison with the Chilean model, which is centralized and unitary, marks a profound distance in decision-making and participation by the stakeholders involved in social services and in the articulation of their provision.

In terms of the specific aspect of possible articulations among foster families and adoption programs, we found that in Sweden, adoption is not contemplated for children under State care. The biological family retains custody at all times. In Italy, on the other hand, adoption processes are extremely long and it is difficult for families to comply with all the requirements necessary to be eligible.

Lastly, judicial decision-making in the cases studied is not concentrated in isolated units. Within the same decentralized framework described, municipal teams dialogue on horizontal terms with the judiciary, favoring informed decisions in the best interests of the children. 


\subsection{Lesson 2: Specialized and Heterogeneous Human Resources for Diverse Needs}

In the cases analyzed, professionals from residential and foster care programs are highly specialized; daily caregivers as well as social workers and psychologists possess specific training. The complexity of the users is acknowledged in the residential services, and it is taken for granted the fact that they require specific professional care. The residences that host complete families do not require daily care staff because the families themselves perform the tasks involved in daily care; and highly competent professionals address families' difficulties.

In the case of foster care programs, there are clearly distinct processes for recruitment, selection, and coaching of foster families, ensuring basic conditions for the work carried out by caregivers. There is also a differentiation of foster family type according to the specific needs to be covered. In Sweden, some foster families are headed by one parent who is a professional and paid as such for their exclusive dedication to the case. In Italy there are also similar cases, although in general foster families are similar to the USA, where they receive a smaller amount of money, in comparison to the professional wage, to help out with the children's basic expenses.

In sum, the complexity of the demands presupposes very precise levels of selection of the professionals that comprise the alternative care systems. In addition, specialization allows adjusting to the various needs of the families, and hence supply is characterized by an ample diversity of foster families: day care, once or twice a week, with or without overnight sleeping, and so on.

\subsection{Lesson 3: Recruitment, Selection and Connection to Foster Families}

Criteria for the selection of caregivers in residential and foster care programs in the countries studied are multidimensional and clearly defined, covering motivational aspects as well as emotional and educational capacities. In Italy, recruitment is performed by specialized programs, linked to the local communities where the recruitment takes place. The recruitment process includes foster families already in the system; they play an important role by sharing their experiences and offering support to the new foster families. Partnerships between professionals and the foster family works as a core aspect for programs success. In this setting, foster families' compensation does not lead to suspicion by the professionals in terms of any perverse incentives, since the motivations of foster families are made clear right from the start.

\subsection{Lesson 4: Sufficient Resources}

Although it may appear to be evident, it is worth pointing out that program financial resources are estimated and guaranteed in order to ensure a basic standard of living for children in alternative care. Appropriate funding impacts on the quality of the intervention securing some of the "good practices" already mentioned, such as having appropriate human resources for the challenges to be addressed.

We have already highlighted the importance of financing as a condition for the success of these programs. The following table (Table 1) provides a comparison of funding for the international programs studied which despite their limitations offer more complex services for the children and their families than the Chilean case. The amounts quoted vary according to the programs or the 
states where they are implemented. The benchmark is the income per capita of these countries in 2012. Despite the fact that Chile has the lowest income among the compared countries, the differences in the amounts of money assigned to the programs are far greater than the differences in income. A chance to improve the supply of alternative care in Chile would hence require a substantive increase in funding since in the case of least difference, foreign funding doubles the funding in Chile (foster care program); and in the cases of greatest difference these can be up to 10 times more, according to the income per capita in Chile (residential services).

Table 1. Comparative table showing monthly subsidies in different countries based on per capita income (in US dollars).

\begin{tabular}{ccccc}
\hline Country/Amount & FF & Specialized FF & RS & Income per Capita 2012 \\
\hline Chile & $\$ 180$ & $\$ 180$ & $\$ 203$ & $\$ 15,363$ \\
Italy & $\$ 520$ & $\$ 520$ & $\$ 3896$ & $\$ 33,049$ \\
Sweden & $\$ 1170$ & $\$ 3700$ & $\$ 13,520$ & $\$ 55,245$ \\
\hline
\end{tabular}

\section{Conclusions}

This study was based on the premise that foster care programs as an arrangement that offers significant individual relationships for the children is a more desirable model at the time of providing alternative care for children under age of six who have been temporarily separated from their families. However, the study on the implementation of Chilean programs, and its comparison with international experience, lead us to reach the following conclusions:

(a) At present, the quality of the intervention in both programs reveals important shortcomings; hence, none of them are, for the time being, a suitable alternative.

(b) The shortcomings detected are mostly common to both programs, and are mostly found linked to structural features proper to the Chilean legal-institutional framework in matters of the child.

Certain strategic outlines stem from the analysis of critical nodes that hinder the supply of alternative care in Chile, in the light of international lessons. These are presented below, $\mathrm{f}$ irstly addressing those related to the transit of public policy for children towards a comprehensive rights approach. We begin with this more macro level, in view of the second conclusion mentioned above. Subsequently we describe the guidelines linked to more specific aspects of each intervention model.

\subsection{Guideline 1: Comprehensive Rights Approach to Child Welfare}

In 1990 Chile ratified its position as signatory to the International Convention on the Rights of the Child (ICRC), thereby committing to gradually modify its institutional framework regarding policies for the child, in order to adapt them to the rights approach underpinning the ICRC ${ }^{1}$. In

1 The guiding principles of the ICRC are non-discrimination, superior interest of the child, survival and development, and participation. 
very broad terms, what this doctrine proposes is the no longer valuation of children as mere recipients of "assistentialist" practices or objects of protection, but as subjects of rights who should enjoy the same guarantees as adults, plus additional rights on account of their particular condition [28]. In this new paradigm, judicial protection of rights should recognize and promote rights, not restrict them; judges should exercise their activity limited by guarantees.

During the 1990s, but with much greater force as of 2011, Chile began a gradual reform process in its child welfare institutional framework; in order make these rights effective. Despite the important progress made, civil society organizations that work with children (many of these being organizations that collaborate with SENAME) have on innumerable occasions indicated that transition towards a comprehensive protection model is far from finished. This view is shared by the National Institute of Human Rights (INDH_Instituto Nacional de Derechos Humanos) and by international organizations such as UNICEF and the Committee on the Rights of the Child for whom the Chilean State is still to address the challenge of embarking on a series of reforms that would enable the country to have a modern and effective institutional framework respectful of the rights of all children and adolescents [28-32]. Specifically, the Committee on the Rights of the Child, in its regular examinations in 2002 and 2007, recommended Chile to reform the Minors Act [33] (since its spirit contradicts the ICRC principles in substantive terms) and establish a single regulation for comprehensive protection of children and adolescents, guaranteeing their effective enjoyment of rights.

All these changes should be approached from a view similar the European child welfare, promoting social solidarity and the construction of citizenship based on rights.

Within this framework, and with regard to a comprehensive protection of children approach, we propose the following recommendations, which are understood as basic conditions for the implementation of alternative care models:

- Abolish the Minors Act.

- Integrate child protection services with universal social protection to enable the provision of a broad array of care options for covering the individual needs of children and their families.

- Provide mechanisms for children and their families to participate systematically and effectively in decision-making about the most appropriate care options and in the long-term aim of the placement; this results easier under a decentralized system.

- Establish criteria to guide decisions of judicial system.

- Review regularly protection measures for their continuous adaptation and justification.

\subsection{Guideline 2: Residential Services}

In general terms, strategies for deinstitutionalization must consider three dimensions already identified in 2002 when mass deinstitutionalization processes began in Chile [34]:

(1) Long permanencies of children in these residences;

(2) Few interventions are made in RS for family reunification; and 
(3) The organizational cultures of residences tend to consider children long permanencies as a protection factor. Hence, any effort directed at reducing RS and increasing the supply of FFs should identify pathways for family reunification.

Our recommendations along this lines aim to:

- Recognize that deinstitutionalization is complex process that cannot be addressed by shutting down institutions in one go. The international lessons show the need of counting with a stable offer of residential services for children presenting special needs.

- Improve criteria for the selection of caregivers; following the international experience daily care workers should have special training at higher educational level, something far from the current Chilean experience.

- Increase flexibility of residential alternatives through models such as family residences.

- Create conditions for specialized staff recruitment and retention (professional and technical staff).

- Continue with the strategy to reduce numbers at residences.

To accomplish the above, greater investment is crucial.

\subsection{Guideline 3: Foster Families}

Today foster care programs in Chile are few, therefore there is a need of awareness about the dangers of placing all hopes on this system, especially if in the meantime the legal-institutional framework and resource allocation is not improved accordingly. In this sense, the priority is to have greater investment.

It would be highly appropriate to reassess the relation between adoption and foster care programs. In this respect, we suggest a review of Bulletin 9051-18 [35] on the adoption of minors, establishing that "Foster families accredited by the National Service for the Protection of Minors or its accredited agencies shall not be prevented after one uninterrupted year in charge of a boy, girl, or adolescent from participating in the procedure for adoption of the minor, when fulfilling the same requirements to be adoptive parents there is also effective attachment among them".

It is necessary to improve alternative caregiver selection, training, supervision, and support. The Italian experience offers a good example of specialized programs for foster families' recruitment, different from programs that work with birth families and children. This experience has facilitated the implementation of specific strategies for recruitment at local level.

The proposed guidelines make it possible to address the deficits produced in the implementation of the programs; these deficits relate to contextual values, methodologies, and purposes that are in competition with policy discourses [36-38]. Therefore, there is a need for a cultural change aimed at the construction of citizenship in collaboration with and not blaming families requiring support by State.

For the Chilean case, in a context of restrictions for both programs studied, added to stigmatized visions of users, low specialization in the staff, lack of availability of foster families, the question of closing-down residences and transferring their entire population to foster care services is not a the most suitable at the moment. Certainly, it is necessary to review the technical elements of 
residential services intervention. In parallel, it is necessary to review current foster care program strategies to improve them and learn from the errors gained by international experience. Lastly, it is fundamental, once and for all, to give the child the place they deserve on the public policy agenda and assign the necessary budgets to guarantee what is owed by right.

\section{Acknowledgements}

This work was supported by Fondecyt, Grant Number 1131128; by the Center of Public Policy of Pontificia Univerisdad Católica de Chile and the Project May Curie Action, Understanding and Supporting Families with Complex Needs, EU.

\section{Author Contributions}

Carolina Muñoz-Guzmán developed the literature review, field work in Chile and Milan (Italy), analysis of general data, drafted de paper and reviewed final version. Candice Fischer developed field work in Chile, contributed to analysis of international cases and English editing. Enrique Chía studied the comparative costs of the programs being studied in each case. Catherine LaBrenz developed the field work in Umea, Sweden.

\section{Abbreviations}

SENAME: National Service for Children;

UNICEF: United Nation International Children Economic Fund.

\section{Conflicts of Interest}

The authors declare no conflict of interest.

\section{References and Notes}

1. Fondo Internacional de Naciones Unidas por la Infancia. "Proyecto levantamiento y unificación de información de residencias." Available online: http://www.unicef.cl/web/wpcontent/uploads/doc_wp/Descripcion_Proyecto_Levantamiento_y_unificacion_de_informacio n.pdf (accessed on 24 February 2015).

2. Utting, William. Children in the Public Care: A Review of Residential Care. London: The Stationery Office, 1991.

3. Utting, William. People like Us: A Review of the Safeguards for Children Living away from Home. London: Department of Health, 1997.

4. Cliffe, David, and David Berridge. Closing Children's Homes: An End to Residential Child Care? London: National Children's Bureau, 1991.

5. Barth, Richard. Institutions vs. Foster Homes: The Empirical Base for the Second Century of Debate. Chapel Hill: University of North Carolina, School of Social Work, Jordan Institute for Families, 2002. 
6. Yin, Robert. Case Study Research: Design and Methods (Applied Social Research Methods). London: Sage Publications, 1994.

7. Glaser, Barney. Basics of Grounded Theory Analysis: Emergency versus Forcing. Mill Valley: Sociology Press, 1994.

8. Connor, Daniel, Leonard Doerfler, Peter Toscano, Jr., Adam Volungis, and Ronald Steingard. "Characteristics of Children and Adolescents Admitted to a Residential Treatment Center." Journal of Child and Family Studies 13 (2004): 497-510.

9. Vinnerljung, Bo. Swedish Research on Foster Care: A Review. Stockholm: Liber Utbildning/ CUS, 1996.

10. Hessle, Sven. Child Welfare and Child Protection on the Eve of the 21st Century. Stockholm: Stockholm University, Department of Social Work, 1997.

11. McCue Horwitz, Sarah, Michael S. Hurlburt, Amy Heneghan, Jinjin Zhang, Jennifer Rolls-Reutz, Emily Fisher, John Landsverk, and Ruth E. K. Stein. "Mental Health Problems in Young Children Investigated by U.S. Child Welfare Agencies." Journal of the American Academy of Child \& Adolescent Psychiatry 51 (2012): 572-81.

12. Hazen, Andrea, Cynthia Connelly, Kelly Kelleher, John Landsverk, and Richard Barth. "Intimate partner violence among female caregivers of children reported for child maltreatment." Child Abuse and Neglect 28 (2004): 301-19.

13. Webb, Mary Bruce, Kathryn Dowd, Brenda Jones Harden, John Landsverk, and Mark Testa, eds. Child Welfare and Child Well-Being: New Perspectives from the National Survey of Child and Adolescent Well-Being. New York: Oxford University Press, 2009.

14. Colton, Mathew. "Factors associated with abuse in residential child care institutions." Children \& Society 16 (2002): 33-44.

15. Gallagher, Bernard. "The Abuse of Children in Public Care." Child Abuse Review 8 (1999): 357-65.

16. Carlson, Mary, and Felton Earls. "Psychological and neuro-endocrinological squeal of early social deprivation in institutionalized children in Romania." Annals of New York Academy of Sciences 807 (1997): 419-28.

17. Schechter, Daniel. "The developmental neuroscience of emotional neglect, its consequences, and the psychological interventions that can reverse them." American Journal of Psychiatry 169 (2012): 452-54.

18. Hair, Heather. "Outcomes for children and adolescents after residential treatment: A review of research from 1993 to 2003." Journal of Child and Family Studies 14 (2005): 551-75.

19. Rock, Stephen, Daniel Michelson, Stacey Thomson, and Crispin Day. "Understanding foster placement instability for looked after children: A systematic review and narrative synthesis of quantitative and qualitative evidence." British Journal of Social Work, 2013. doi:10.1093/bjsw/bct084.

20. White, Susan. Institute of Applied Social Studies, University of Birmingham, Birmingham, UK. Personal communication, 2013.

21. Vivanco, Flor. "El acogimiento familiar: Una apuesta preventiva a la institucionalización, respetuosa del derecho a vivir en familia y en comunidad." Revista Señales 5 (2012): 17-27. 
22. Martínez, Víctor. "Resumen Ejecutivo: Caracterización del Perfil de Niños, Niñas y Adolescentes, Atendidos por los Centros Residenciales de SENAME." Available online: http://www.sename.cl/wsename/otros/resumen_SENAME_UNICEF.pdf (accessed on 24 February 2015).

23. Martínez, Víctor. "Informe final: Análisis evaluativo del programa familia de acogida especializada de SENAME." Available online: http://www.sename.cl/wsename/otros/ estudios_2012/Informe_Final_FAE.pdf (accessed on 24 February 2015).

24. Fundación León Bloy para la Promoción Integral de la Familia. "Informe final proyecto evaluación-estudio de gastos de las líneas de acción de los centros residenciales, programas de familias de acogida y programas de protección especializada, específicamente de explotación sexual comercial infantil." 2009. Available online: http://www.sename.cl/wsename/otros/ estudios_2012/Infrome_Final_EVA.pdf (accessed on 24 February 2015).

25. Servicio Nacional de Menores. Orientaciones Técnicas Familias de Acogida. Santiago: Departamento Protección de Derechos Servicio Nacional de Menores, Ministerio de Justicia, 2004. (In Spanish)

26. Khoo, Evelyn G., Ulf Hyvönen, and Lennart Nygren. "Child welfare or child protection: Uncovering Swedish and Canadian orientations to social intervention in child maltreatment." Qualitative Social Work 1 (2002): 451-71.

27. Maingon, Thais. Balance y Perspectivas de la Política Social en Venezuela. Caracas: Instituto Latinoamericano de Investigaciones Sociales (ILDIS), 2006. (In Spanish)

28. Cortés, Julio, and Consuelo Contreras. Infancia y Derechos Humanos: Discurso, Realidad Perspectivas. Santiago: LOM, 2001. (In Spanish)

29. Fondo Internacional de Naciones Unidas por la Infancia. "Serie Reflexiones: Infancia y Adolescencia: Nueva institucionalidad de infancia y adolescencia en Chile (Aportes de la sociedad civil y del mundo académico)." Available online: http://www.unicef.cl/web/ wp-content/uploads/doc_wp/WD\%2013\%20Ciclo\%20Debates\%20WEB.pdf (accessed on 24 February 2015).

30. Instituto Nacional de Derechos Humanos. "Infome Anual 2010: Situación de los Derechos Humanos en Chile." Available online: http://www.indh.cl/wp-content/uploads/2010/12/ Informe_Final_Corregido1.pdf (accessed on 24 February 2015).

31. Instituto Nacional de Derechos Humanos. "Resumen Ejecutivo: Informe Anual 2011." Available online: http://www.indh.cl/wp-content/uploads/2012/03/resumen-ejecutivo-2011.pdf (accessed on 24 February 2015).

32. Instituto Nacional de Derechos Humanos. "Resumen Ejecutivo: Informe Anual: Situación De Los Derechos Humanos En Chile 2012." Available online: http://www.indh.cl/wpcontent/uploads/2012/12/resumen-ejecutivo-2012.pdf (accessed on 24 February 2015).

33. Ley de Menores, LEY-20032, DFL-1 Código Civil (2000).

34. Fondo Internacional de Naciones Unidas por la Infancia. "Desinternación en Chile: Algunas lecciones aprendidas.” 2005. Available online: http://www.unicef.cl/archivos_documento/125/ WORKINGPAPER4a.pdf (accessed on 1 March 2015). 
35. Cámara de Diputados Moción de la Cámara del 05-08-2013 modificando el Artículo 20 de la Ley No. 19620. Available online: http://www.camara.cl/pley/pley_detalle.aspx?prmID= 9458\&prmBL=9051-18 (accessed on 7 March 2015).

36. Lipsky, Michael. Street Level Bureaucracy: Dilemmas of the Individual in Public Services. New York: Russel Sage Foundation, 1980.

37. Winter, Søren. "Integrating implementation research." In Implementation and the Policy Process, Opening the Black Box. Edited by Dennis Palumbo and Donald Calista. New York: Greenwood Press, 1990, pp. 19-38.

38. Ryan, Neal. "A comparison of three approaches to programme implementation international." Journal of Public Sector Management 9 (1996): 34-41. 


\title{
Bringing the Family Back in: On Role Assignment and Clientification in the Swedish Social Services
}

\author{
Ahmet Gümüscü, Lennart Nygren and Evelyn Khoo
}

Abstract: In Sweden, municipal social services provide help and support for vulnerable people with a variety of needs. Although the family has long been understood to be a focus of social work interventions, it is unclear how it is brought into the casework process in the highly individualised and specialised municipal social services. Therefore, in this study we investigated processes of client-making and role assignment in five service sectors: social assistance, child welfare, substance abuse, disability, and elderly care. We carried out focus group interviews with social workers in each of these sectors in a mid-sized community in central Sweden. Findings showed that clienthood and the family are interpreted in different ways. The family is brought into or kept out of service provisions in ways that are connected to social workers' construction of the family either as expert, client or non-client. However, the role of the family may also change during the casework process. Findings are examined in relation to theories of the welfare state and implications for family-focused practice are discussed.

Reprinted from Soc. Sci. Cite as: Gümüscü, A.; Nygren, L.; Khoo, E. Bringing the Family Back in: On Role Assignment and Clientification in the Swedish Social Services. Soc. Sci. 2015, 4, 117-133.

\section{Introduction}

In this era of globalisation, family policies and social welfare services are at the intersection of increasingly diverse family constructions and complex welfare environments. Although the family is the primary unit of socialisation and is responsible for the economic and social well-being of its members, when it cannot fully carry out these tasks the family becomes a priority area of the social work profession. At the same time, how social workers provide service is highly dependent upon the social, political and organisational contexts in which they work. In Sweden, the state assumes a high degree of responsibility for citizens through broad ranging institutional involvement in service provisions carried out in the municipal social services where the majority of professional social workers are employed [1]. Enshrined in law, the state has been given the responsibility to provide necessary measures to promote "good enough" living conditions to all individuals and families living in Sweden's 290 municipalities (Social Services Act, chap. 1, Section 1 [2])

Although the private (for profit or non-profit) and voluntary sectors also play a part in the overall provision of welfare [3], the municipal social services ultimately must offer information, support and help for vulnerable individuals and families. However, because of municipal autonomy, and since local structural conditions and access to resources may differ [4], there may be variations in how service delivery is organised [5]. Dealing with conflicting political, legal, organisational and public expectations may also lead to variations in how social workers target families as clients [6]. Finally, unlike "think family" developments in the UK [7,8], successive governments in Sweden 
have formulated individualising and defamilialising policies that have reduced personal dependence on both the labour market and family relationships [9].

And while criticisms have been levelled with regard to typologies of Sweden as an individualised [10], universalised and defamilialised [11] welfare state, these studies have emphasised examinations of choice, financing and service intensity respectively. There is less empirical evidence of how social workers as "street-level" bureaucrats implement the policies of the welfare state within the "rule-saturated" [12] environment of local social services. What happens to the family in a welfare environment that is suffused with ideals of individual rights and choice? How is the family given access to services that it may need or want? In addition, what happens to the family in the casework process? We explore these questions in this study of families and clientification in five key sectors of the social services. These are: (i) social assistance (SA); (ii) child welfare (CW); (iii) substance abuse (SUB); (iv) disability (DIS); and (v) elderly care (EC). Our interest was to uncover when and how social workers consider "family" in casework from intake and investigation to service implementation. We connect our analyses of the clientification of the family to the purportedly individualised and defamilialised Swedish social services as well as to the concepts of universalism and residualism that prevail in typologies of welfare states.

\section{Clientification and the Family in Social Work}

Clientification is a process whereby individuals or families become the objects of investigation and decision-making by social workers and other professionals [13]. As clienthood is a temporary social construction, the interventions received by individuals and family members depend on how they are constructed and accepted as clients by social workers ([14], p. 16) as well as how they see themselves in the client-worker relationship ([15], p. 12).

Organisational rules further restrict whether individuals and families are accepted within a particular organisational framework. These rules can be established by both the organisation but also by social workers as people are processed and transformed into the raw material of human service organisations [16]. Clients take on a bureaucratic identity that is standardised on the basis of pre-specified variables allowing a person to fit into a particular administrative category [17]. Swedish social work research has shown that clientification includes a categorisation process which transforms a human problem or need into a "case" which fits predetermined organisational frames of understanding before support and care can be provided [18-20].

Piltz and Gústavsdóttir [21] describe how the role of the family is not immediately considered by social workers given that society largely perceives the causes of and solutions to social problems as residing within the individual. When they do turn their professional gaze to the family, they may see it in terms of the kinds of roles it may play in the professional relationship. These roles include: the consumer who uses the offered services; the consultant holding important knowledge about family members' backgrounds and personal circumstances; the colleague who may sometimes share tasks with social workers; and the client who has a problem or is in need of help. But, when are these roles taken on and why? Can roles change during the casework process and are roles established according to the sector in which services are being offered? 


\section{Method}

\subsection{The Focus Group Interview}

To explore how social workers consider the family in the casework process, we carried out focus groups in the five key sectors of the social services. Focus group interviews have been used as an effective method in data collection in social work research [22-25]. They have been increasingly used to investigate experiences of service provisions [26], to explore discursive practices [27] and to approximate what social workers really do when more direct methods of data collection (such as ethnographic studies) are not feasible or are unethical. The focus groups enabled us to call upon group experiences of the client-making of families in the casework process and provided us the methodological advantages of being able to explore responses and reactions between group members [28], whose viewpoints about service provisions could vary. Participants knew each other through their work, which facilitated their interaction and could therefore complement, enrich and build on each other's perspectives [29].

\subsection{Sample Selection and Characteristics}

Five focus groups were carried out in one municipality (population $c a$. 100,000 inhabitants) located in central Sweden in order to get a broad view of how families are processed through a social service organisation and become clients. Although there may be some variation in the organisation of social services in Sweden [5], almost all municipalities organise their social services into specialised practice areas. In this way, knowledge gained by studying this municipality may be transferable to other contexts.

Between ten and eighteen caseworkers were employed in each sector and we succeeded in recruiting five or six persons for each group $(N=27)$. All participants but one had a social work degree (one participant had 1.5 year vocational training in homecare work). Work experience varied widely between participants but the average work experience was about eleven years. The social assistance and child welfare sectors were additionally divided into several specialised sub-units such as those working with different age groups and those working with specific types of problems.

\subsection{Procedure and Ethics}

The interview guide contained thematic questions about characteristics of the participants' work, defining "family", how families become involved in services, and the processes whereby families become clients and may be offered interventions. Each focus group interview was carried out in Swedish and lasted about $2.5 \mathrm{~h}$. Both of the focus group facilitators spoke Swedish and one was also a native English speaker. The interview guide was semi-structured and allowed the authors to ask follow-up questions [29]. We posed open questions since it was important to get the group participants' own and group-wise co-constructed definitions and understanding of family and the meaning of family in relation to their work. The Regional Ethical Review Board approved this 
project [2010-390-31] and we carried out the study in conformance with the ethical principles of the Swedish Research Council [30].

\subsection{Data Analysis}

Analysis began with the verbatim transcription of the audio recorded interviews and importing all material to the software program NVivo10. The use of software is an efficient way to manage, sort and categorise data [31] from focus groups. Transcription and analyses were done initially in Swedish. Later in the process of manuscript development, quotes were translated to English. To ensure the veracity of translation, we (as native English and Swedish speakers) re-checked quotes. The authors adopted a qualitative content analysis approach to analyse the data $[32,33]$. We began with a cross-sector naïve reading of each of the transcripts, reviewing each several times to obtain a "sense of the whole" [34]. We then carried out a sector-by-sector analysis in which we identified meaning units and coded these; codes were derived mainly as in vivo codes and sorted into thematic categories. A cross-sector analysis then took place where we examined the transcripts for the presence or absence of thematic categories across the five sectors being analysed. These categories were clustered into two themes with varying properties that were found to occur in all five sectors. One theme describes how families are processed as cases and the second theme that describes the various roles that families take during the investigation process.

\section{Results and Analysis}

\subsection{Processing Cases through the Social Services}

The Swedish social services offer support in the form of "hard benefits" (cash, accommodation and "goods" of various kinds) and personal social services provided by caring professionals, including (but not exclusively) social workers. The legislative frameworks of social work practice regulate eligibility for support and the forms that support takes. Key legislative areas include: general or framing legislation found in the Social Services Act; compulsory care legislation in the Care of Young Persons (Special Provisions) Act (LVU), Care of [Substance] Abusers Act (LVM) and the Compulsory Mental Care Act (LPT); and rights based legislation such as the Law regulating Support and Service to Persons with Certain Functional Disabilities (LSS). We theorise about legislation as a "mediating mechanism" in social work practice elsewhere [35].

Before support can be offered, a problem or need of assistance must first become a "case" by the social services intake unit which handles self-referrals/applications or reports of need or concern referred most often by schools, police or health authorities. The intake unit has a "gatekeeping" purpose that determines whether or not the client will be granted further access to the social services. If access is granted, the case is transferred for further investigation to the service sector specialised to meet that kind of need or problem. Each sector is then further divided into sub-areas and internal groups with a variety of specialisations based on the age of the client (e.g., child, youth, adult, or elderly), stage in casework process (investigation or on-going work) or by client type where on-going work is further specialised according to the objectives of work with highly 
specific client types (e.g., individuals who may or may not have the capacity to enter the labour market within specific time frames).

The processing of a "case" is, in and of itself, not unique in that a case is initially screened in the intake process before a more thorough assessment is carried out, followed by decision-making and the implementation of support and care services. What is important is that the family as a whole is not defined as the "case". The individual is. When the family first meets the gaze of the social worker, it is deconstructed to fit the organisational constraints of the social services. As one child welfare social worker stated,

“...you could say that we are a really functionally divided organisation". (respondent CW)

\subsection{The Family's Roles and Functions in Social Service Processes}

In all sectors, social workers described working individually but having the family in mind after receiving a referral or request for service, when assessing needs and when targeting interventions. In our analyses of their descriptions of the casework process, we observed that the family could take on a number of different roles and functions in its relationship with the social services. In sociological terms, a role can be understood as a positioned set of rights, obligations and expected behaviour patterns [36] that the family takes on in the social service process. Functions are the things that a person does in performing a particular role. In our study, the family could function as expert in the roles of consultant or colleague or it could function as a service user in the roles of client or consumer. Roles and functions are elaborated upon in the text that follows.

Although the social worker is primarily interested in serving the needs of the individual client, the family could be brought into the service process and be assigned different roles in it. As also described by Piltz and Gústavsdóttir [21], these roles included: consultant, colleague, consumer and client. However, we also uncovered a non-client role when the family is perceived as demanding, disruptive or in need of services outside of the mandate of the particular sector. These roles are not rigidly established but rather may vary depending on where in the social work process the service user is positioned (e.g., intake, investigation, service provision; Table 1). It is important to note that these roles are not explicitly defined by the social workers themselves. In the text that follows, we describe the various roles that the family takes on and the functions served by each of these.

Table 1. The family's roles in casework and clientification processes.

\begin{tabular}{|c|c|c|c|c|c|c|c|c|c|c|c|c|c|c|c|c|}
\hline \multicolumn{2}{|l|}{ Phases } & \multicolumn{5}{|c|}{ Application/Report } & \multicolumn{5}{|c|}{ Investigation } & \multicolumn{5}{|c|}{ Service Provision } \\
\hline \multicolumn{2}{|l|}{ Roles } & $\begin{array}{l}\text { 䔍 } \\
\text { 莺 } \\
\text { ठ }\end{array}$ & 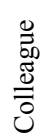 & 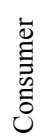 & 离 & 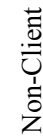 & 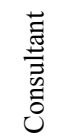 & 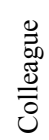 & $\begin{array}{l}\bar{\Xi} \\
\Xi \\
\bar{\Xi} \\
\tilde{0}\end{array}$ & 节 & 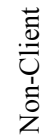 & 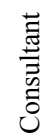 & 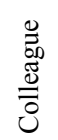 & $\begin{array}{l}\overline{\vec{b}} \\
\text { 离 } \\
\tilde{0}\end{array}$ & 总 & 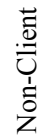 \\
\hline \multirow{5}{*}{ Sectors } & Elderly care (EC) & $\mathrm{X}$ & & & & $\mathrm{X}$ & & & & & $\mathrm{X}$ & & $\mathrm{X}$ & $\mathrm{X}$ & & \\
\hline & Disability (DIS) & $\mathrm{X}$ & & $\mathrm{X}$ & & & $\mathrm{X}$ & & & & $\mathrm{X}$ & & $\mathrm{X}$ & $\mathrm{X}$ & & \\
\hline & Substance Abuse (SUB) & $\mathrm{X}$ & & & & $\mathrm{X}$ & & $\mathrm{X}$ & & & $\mathrm{X}$ & & $\mathrm{X}$ & & $\mathrm{X}$ & \\
\hline & Child Welfare (CW) & $\mathrm{X}$ & & $\mathrm{X}$ & $X$ & & $\mathrm{X}$ & & $\mathrm{X}$ & $\mathrm{X}$ & & & & $\mathrm{X}$ & $\mathrm{X}$ & \\
\hline & Social Assistance (SA) & & & & $\mathrm{X}$ & $\mathrm{X}$ & & & & $\mathrm{X}$ & & & & & $\mathrm{X}$ & $\mathrm{X}$ \\
\hline
\end{tabular}




\subsubsection{The Family as Expert}

There are two ways in which the family can be constructed as an expert. In every sector of the social services except social assistance the family functioned as an expert source of knowledge about the primary client in the initial stages of the casework process i.e., intake and investigation. As the casework process progressed, the importance of the family as a knowledge expert diminished and in some cases the family became expert as a service provider instead.

\section{Consultant Role}

It makes intuitive sense that at the intake stage, the family is often brought into the casework process as a source of vital information regarding the client. Worried family members or others in an individual's wider social network, including authorities such as health care, schools or the police, may submit referrals. Then, during an investigation, the family is often involved in the process by providing information regarding the individual who is the subject of investigation or the family may be a source of support for the individual because of the knowledge they bring regarding the person's circumstances.

"If there is a person with dementia, for example, then relatives come here first." (respondent EC)

The consultant role is something that can be initiated by the family at the intake stage but, in cases where the client is an adult, the client's consent is required in order for the family to be able to remain as a knowledge provider in the casework process. A social worker in the substance abuse sector describes it this way:

"So maybe a parent calls us as says, 'I'm so worried, we have to do something'...and I say, I hear what you're saying, you can definitely tell me what you know...but I can't say so much. And so that gap is so great if now Kalle doesn't say 'it's ok, go and talk to mom and dad or whoever'... of course it would be easier if he did.” (respondent SUB)

\section{Colleague Role}

In some cases, the family may be drawn into social services in a collegial way. All social workers, except for those who worked in social assistance, identified the family as a source of support and help for the client. The kind of helping role that was expected of the family differed between sectors but, regardless of the specific kind of input they provided, their contributions reduced the extent of involvement by the social services. As a colleague, the client's children, parents or relatives could provide support by helping to complete an application, taking part in meetings, helping the client with information, choosing available services and convincing the client to accept these. Family could also provide care during the daytime or evening so that the social services would not need to be called in. In some cases, the colleague role could become blurred and overlap with the client role such as when a family itself was provided short-term relief in order to be better able to cope in providing care itself over the long-term. 
“...say there's a child, 4-5 years old. Their parents do not have to go on a short-term stay but we grant the intervention anyway in order to give the parents the strength to cope (...) so that the child may continue to live at home..." (respondent DIS)

Within the substance abuse sector, respondents said that family was often non-existent but that they would still ask relatives and persons in the client's network for help that could reduce isolation and maybe even motivate the client to accept help. They could only pursue this contact if they had the consent of the client who was over age 18 . The family could be the source of a referral to social services. By being engaged with the individual, they would also be assisted in getting help and support to handle the substance abuse problem. In the following quotations, L, H and K are labels we put on group participants in order to keep their utterances separated.

"L: ...The family can call and report their worries to us..."

"H: ...We offer family treatment for them out there also..."

"K: ... So maybe if a parent calls with a worry..." (respondents SUB)

When the social worker sees the family as a resource or source of help to the client, collaborative efforts become less problematic. The example below illustrates a problematic situation where an elderly person cannot express his needs and the social worker tries to involve the family in a collegial way so that intervention can begin.

“...maybe that person needs to come into a care facility...we can hope that there is a relative or trustee who can certify or tell us that the person needs help from time to time...we assume the relatives will agree because you have to think that our intentions are good anyway..." (respondent EC)

\subsubsection{The Family as Service User}

In recent years, social work has been challenged to critically re-think terms used to describe the relationship between those who provide a service and those who are recipients of these. Attaching a label to relationships is never unproblematic because these reflect different kinds of power relationships [37,38] but also may bear with them nuanced meanings understood in various ways by different people. Hübner [39] further problematises the use of terms such as service user, client, and consumer in the Swedish social services. For the purposes of this study, we use the term "service user" to describe the general function of the family as receiving some kind of service. To carry out this service user function, the family must take on the role of consumer or client in their relationship with the social worker and social services.

\section{Consumer Role}

When the family assumes the role of consumer, it may apply for or purchase measures of its own choice. These measures are directly connected to the individual's needs and can be sought by either family members or relatives. Our study found differences between how cases involving exclusively adults or also involving children are handled. Nevertheless, the family may be considered a "consumer" of measures offered if these are made available to ease the problems or 
stresses of everyday life. As consumers, they may actively apply for these types of services, which are offered in addition to those connected to formal needs-assessment.

"From the age of 15 you can apply yourself although you might still need to have the custodial parent's approval. For example, if you want to have a guide for something that costs money, you need to pay yourself and then the parents can automatically say no. So the best thing is for both parents and youth to apply together. And, services offered under [disability] are voluntary so you can't force anybody to accept a service." (respondent DIS)

In child welfare, parents can choose for themselves to apply for counselling services or parent education courses as long as there are no immediate signs of risk to a child's well-being.

"It is an offer to the parents, that there is a support if they want it... But it is voluntary.

They have to choose for themselves." (respondent CW)

\section{Client Role}

In most cases, when an application or referral is received, the social worker will direct attention to the individual as a means of narrowing down the problem. As a case investigation begins, social workers assess how the family constellation might impact the individual. Many social workers described how those who seek help from the social services are the most vulnerable and isolated in society. The problems may be seen as located either within the individual or in the family. When social workers assess individual needs, it may be discovered that family members or the family as a whole needs support or services. However, their needs are generally passed laterally to other service sectors, which then carry out their own needs or risk assessments. A social worker in social assistance expressed it this way:

"Pure delegation-wise, if it shows up that the rent is in arrears and the electric bill isn't paid and then it lands with us. Then, if there is a child or if there are concerns about...it can get into addiction or mental illness...with young people, it's often a neuropsychological diagnosis...they may be investigated by social workers [in other sectors]." (respondent SA)

Even though family members may also receive services within the same sector, the social worker must carry out an investigation of each individual. Casework becomes problematic if these needs are seen to being in conflict with each other. In child welfare, the child is identified as the primary client but parents can receive supportive counselling and other services. In this sense both the child and the parents are understood as clients. A shift to child-centred practice occurred with the implementation of a new child welfare approach which, translated to English, is called "Child's Needs in the Centre (BBIC)". BBIC is a framework for assessing, planning and review in child welfare. It is a systematic approach including structured tools to collect and document information on children and young people's developmental needs in relation to their parents' capacities to meet these needs and the environmental contexts in which they live. BBIC is based on England's Framework for the Assessment of Children in Need and their Families. 
"But it is individual ... even if there are for siblings that are the subject of investigation, there is one investigation and one measure for each child." (respondent $\mathrm{CW}$ )

“...It's very individually focused — on each individual; it's because of how we use BBIC, how we investigate, how we document. But I mean it is very important that even in the guide book and the internal education we got that you should actually think of the family as a system. It's really tricky. Once I investigated two children with two completely different needs. One was autistic and the brother had Tourette/ Asperger/ADHD. Their needs were diametrically opposed and to try to help this poor mother who had to parent according to each child's individual needs." (respondent CW)

Support for the family is often connected to the needs of the primary service recipient. In elderly care, disability care and substance abuse, commonly the client has family members who need information or support to cope or understand the client's problems. In such cases, family members can receive measures such as relief, respite or shared care so that they will be able to continue to care for the client in the long run. A social worker in elderly care expressed it this way:

$\mathrm{K}$ : "Yes, exactly if you are caring for a relative or feel like you need a rest...you can come here and apply for respite..."

$\mathrm{V}$ : "Or rotating care..."

$\mathrm{K}$ : "Yes but it's just if it is regular and on-going, then you can have short term care if your daughter want to go on a trip or something." (respondent EC)

\subsubsection{The Non-Client Family}

Respondents were quite clear about who was (and who was not) included as a client within each service sector. The client was perceived as being the person who was the main subject of an investigation. Even as families were given roles as consultants, colleges, consumers or clients, they could also be perceived as being non-clients, to be sorted and passed on or be excluded as ineligible for services but at the same time disruptive or demanding. In child welfare, non-custodial parents must have the permission of custodial parents to participate in investigations. Therefore, sometimes one biological parent can be kept out of participating in a child welfare investigation. With the non-client family, social workers felt that their hands were tied in ways that limit the work that they might otherwise want to do with whole families.

"Well, we just see whether or not we can provide financial assistance. If there are other problems we usually pass them on to those who work with the family or children. But, then we have to take all of that into consideration in our decisions but it's not we who sit and investigate a child's needs...that's how it is". (respondent SA)

In the above example, the family really has no role or function if it does not fit within the institutional frames of a particular service sector. When the individual's family is seen as a hinder or interruption to the casework process, social workers may then want to close themselves off from this disruptive element and work exclusively with the individual. 
"Relatives can be terribly difficult at times... they may even interfere with the individual we are trying to help (...) one would sometimes say you (family) may sit here and we can go to another room and talk to the individual, and we should really do that sometimes... one has to say that... now you should sit here so I can talk to the one who needs the help if possible... something like that..." (respondent EC)

In other cases, conflict arises when the family may be perceived as being demanding and absolving itself of responsibility toward the client. The family may have another opinion about their perceived responsibilities and what should be the social worker's. In the substance abuse sector, the family is often perceived as demanding, having given up on having a sense of responsibility for the client.

"L: But sometimes...people in the surroundings think we can [should do more than we can]...like providing transportation back and forth between places...we might think that the individual should be here on a short term basis only [in the social services] and then go out and be independent. But, sometimes I feel like parents and family think, 'it's your responsibility'..." (respondent SUB)

"K: Yeah, social services has been like that where they think we should be like, an extra appendage to the family, a long arm". (respondent SUB)

\subsection{Functions and Patterns of Family Involvement in the Social Services}

When the family takes on or is given different roles in relation to social work this may be understood to be part of a clientification process. However, although social workers bring the family into consideration in the casework process, the family is not always made into a client in the broader sense of that word. Our analyses revealed two functions carried out by the family in connection with the different roles that it is given. These are: (1) an expert function wherein the family acts as either an expert consultant providing knowledge about the primary client or when family members become colleagues in relation to social workers, acting as auxiliary service providers; (2) a service user function where in the family is a consumer of services in its own right. It may purchase these supplementary services or family members may be seen as clients with needs of their own. The non-client maybe understood as having a non-function in the casework process. The non-client is seen as unhelpful to the social worker who instead sees this client as disruptive, demanding or someone else's responsibility. Although roles and functions may change as the family moves through the casework process, particular patterns emerged as we examined the roles and functions consigned to the family in the different sectors.

At the intake stage, the family almost always assumed the role of consultant, functioning as an expert in providing information. This was not the case in the social assistance sector where the family was seen as a client only. Indeed, it exclusively maintained a client role through the entire casework process. Families in the child welfare sector were most similar to those in social assistance. The family assumed a client role immediately at the intake stage although it could also be assigned a consultant role - or even choose to be a consumer itself by attending open services (drop in pre-school, parenting groups) that do not require a prior investigation. The strongest 
consumer and colleague roles could be found in disability and elderly care. These roles were strongly connected to the social workers' recognition of the family's right to support itself but also its role in providing for the needs primary client. The role of the family was most varied in the substance abuse service sector. It began its relationship to the social worker as either a knowledgeable consultant or demanding non-client (which it often remained as). When possible, it would be brought in to help or support the substance abuser (colleague) and eventually could be identified as needing services itself to eventually support the primary client.

In our examination of five sectors of the social services it became clear that there are essentially two ways of bringing the family back in to the casework process from intake and investigation to service provision. Social workers could bring the family back in to function as experts or as service users. However, we observed that particular patterns emerged. In the disability and elderly care sectors, the family was most often seen as having a consumer role connected to its service user function. When the family was not in a consumer role, it was brought into casework as a "care" expert. In the case of child welfare and social assistance (and to a lesser extent substance abuse) the family were residual clients of the welfare state.

In the substance abuse sector, the family's role as a client of the social services was less clear. They could reluctantly be given a client role when the services they received could be seen as helping the primary (substance abusing) client. However, when the primary client was an adult, their expert knowledge was uni-directional. They could give information but were not entitled to more than general information about the dynamics of addiction. Consideration of the family looked different in the child welfare and social assistance sectors with the immediate clientification of the family. Indeed, the family never shed its primary client role but it could take on the additional role of "knowledge" expert.

\section{Discussion}

We acknowledge that local variations and different organisational approaches to specialisation set limits on the degree to which the results of our study can be transferred to other social service contexts. Nevertheless, we maintain that our findings allow us to analytically generalise to broader constructs and theory surrounding welfare state development. The Swedish welfare state has been described elsewhere as the "crown jewel" of the Scandinavian welfare model [39] with its extensive and publicly funded social services being regarded as "keys" [40] in the promotion of universalism and facilitation of reduced dependence on the family [10] to meet the needs of individuals. Services are provided in the highly specialised organisational context of the social services. Bergmark [1] calls this specialisation the most far-reaching and exhaustive trend of the last 30 years.

While organisationally specialised social workers may be able to target a narrowed area of problems, unless they receive advanced education and training there is no certainty that they will be more competent or equipped to solve complex problems. Rather, clients with multiple problems will increasingly encounter an array of specialists instead of one or perhaps two social workers. From the perspective of clients there will only be an increased complexity in contacts with the social services. Efforts to coordinate services within such organisational structures become difficult with 
resources diverted away from client support and consumed by the coordination requirements of the fragmented organisation. We have described elsewhere [41] that functional specialisation does more than just make accessing services difficult for families. The family itself is "deconstructed" into the raw material of the social services, making whole family approaches to service provision impossible if the family's problems or needs span several sectors.

Social workers, as "street-level bureaucrats" $[42,43]$ and the dominant profession in the social services, are also tasked with the responsibility of working out the complexities of the welfare state in their interactions with individuals and families. Their tasks are carried out in a specialised workplace but are socially organised according the supposedly universalised and individualised intentions of the Swedish welfare state. This too has implications for the positioning of the family in its engagement with the social services (Figure 1). This article has shown that a much more complex picture emerges when the family is considered in relation to the Swedish social services. Visions of the de-stigmatised client meeting in solidarity with a social worker within the macro-context of a universal and individualised welfare state are muddied by the realities of a highly specialised social service.

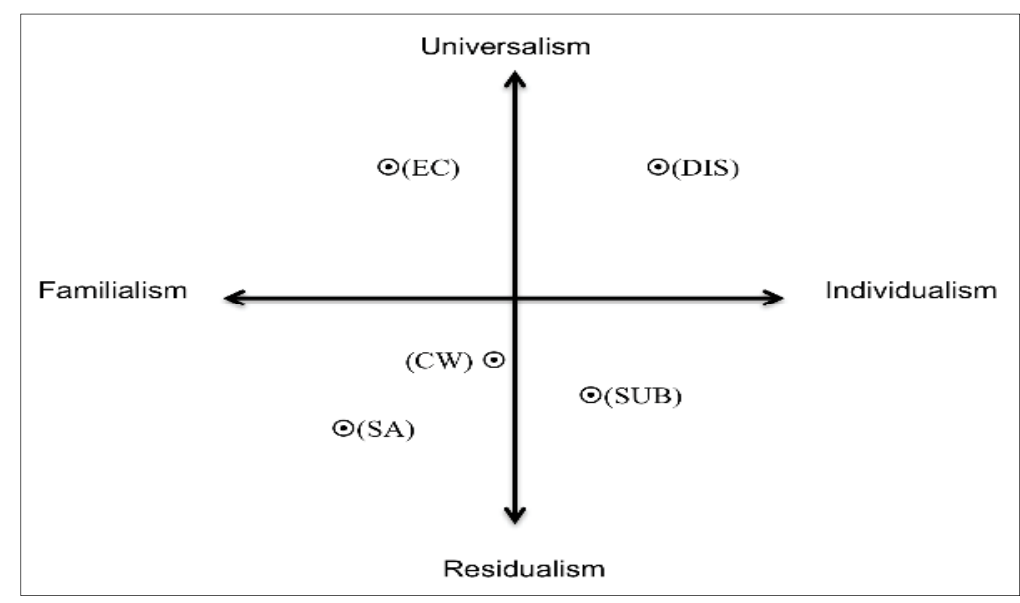

Figure 1. Positioning the family in relation to welfare state dimensions.

On the one hand, universalising trends were clear in the disability and elderly care sectors. There was at least a presumption on the part of respondents that universal social services were to be provided to all citizens in need of the respective service. Entitlements of the primary service users as consumers means that they can make choices about who shall supply services and decline services if they are viewed as unsatisfactory [9]. We found that the family also becomes a consumer of the universal welfare state when it is given access to supplementary support services. Only to a limited extent are eligibility tests and fee-for-service costs supposed to restrict access to these kinds of services. Supplementary services are meant to relieve to some extent family members from care obligations but perhaps also further the independence of care-dependent individuals.

On a rhetorical level, primary service users have a right to service but this is legislatively conditioned in that the right is limited to those "whose needs cannot be met in any other way" 
(Social Services Act, chap. 4, Section 1 [2]) or-by their own families. Thus, when the family is brought into casework as the "care expert" it is brought in to limit the utilisation of services by the primary service user. By bringing the family back in to manage the limits of universalism, the elderly care and disability sectors become re-familialised [44]. To some extent, adult children are expected to provide for their aging parents. Similarly, parents of disabled children are expected to provide for their needs. Where the disability sector stands apart from elderly care, however, is in the case of the disabled adult. Here, individualisation of service provision dominates. People with disabilities are entitled to receive the support they need to live as independent a life as possible. This is connected to political ideological efforts to normalise the lives of people (adults) living with disability. Another normative ideal of family is brought into the equation when there is a child with a disability. In normalising the parent-child relationship, expectations are placed on parents to carry out their responsibilities toward the disabled child if the child is otherwise seen as functioning at a normal developmental level. That is, social workers appeared to normalise the disability to the extent that they assigned little social significance to the disability in connection to their expectations of parents' capacity to meet their children's needs.

In the child welfare, social assistance, and substance abuse sectors the family becomes or remains a residual client of the welfare state. Walton [45] calls people with these social problems "residuals" who are stigmatised and excluded from the market economy. As recipients of residual services they risk the debilitating effects of dependency whilst social workers manage and screen them from the "comfortable majority" [38]. It has been argued elsewhere that Sweden has a family service orientation particularly in the child welfare sector [46]. This perspective refers to a familialised way of thinking where problems are perceived as symptoms of dysfunctional families and where interventions are aimed at reducing dysfunction through therapeutic measures involving the family and its members. However, even the socio-ecological foundations of BBIC may be prevented from being truly whole family approaches as services now emphasise a child-perspective and the individualised child at the centre of casework planning.

The position of the family in need of social assistance is slightly different. Means testing places stringent limits on the family as a household in which members have varying responsibilities to each other. Adults have financial responsibility for children (up to the age of 21 in some conditions) and cohabitating couples have responsibilities to each other. Social assistance thus remains both highly residualised and familialised. In the area of substance abuse, the reintegration of socially or economically marginalised individuals is in focus; the family may either facilitate or stand in the way this objective. Therefore, supplemental family-oriented services are aimed at supporting the family to help the individual [47]. In contrast to social assistance, the family only has rights and responsibilities for the substance abusing young person until they reach the age of eighteen. This creates a discrepancy in how social workers in different sectors are able to respond to the needs of the family where there is a substance abusing youth.

When a family with complex needs seeks support for its problems, it may encounter not a universalised and defamilialised social service but a highly fragmented and specialised organisation with potentially conflicting service orientations. These orientations range from universal to residual and familialised to individualised. Transformations in social service provision are on-going. 
Nevertheless, this paper's ambition has been to contribute to the academic discourse surrounding welfare regime typologies by problematising considerations at the level of social work where welfare policy meets municipal social services and the family.

\section{Conclusions}

The service sectors that we studied are all affected by ongoing transformations in social service provision, where New Public Management, increased specialization and reduction of resources are influential external pressures on social workers' professional autonomy. The social work profession can learn from our study about how their constructions of and relationship with clients - and especially families with complex needs - are conditioned by these transformations. More research is also needed to fully grasp the consequences of the roles and functions that client can take in this landscape of fragmentation, specialisation and individualisation. This already complex situation is even more complicated by the increasing diversity of new family forms, migrating families and refugees. Different cultural backgrounds and experiences of crises and wars indicate a more complex catalogue of needs that social workers will meet. In a sense, social workers are caught between structural pressures that steer their work conditions and an inflow of new challenges in terms of their professional knowledge and practice.

\section{Acknowledgments}

This work was supported by the Swedish Research Council for Health, Working Life and Welfare. The authors also gratefully acknowledge those social workers that participated in this study.

\section{Author Contributions}

Ahmet Gümüscü wrote, conducted and transcribed the focus group interviews. He carried out the coding and analyses and generated the first draft of this paper. Lennart Nygren assisted at various stages in the analysis and contributed to the re-drafting of the paper. Evelyn Khoo co-facilitated the focus groups, co-analysed the data and generated subsequent revisions of this paper. All authors discussed analyses together and contributed to the final draft of this paper.

\section{Conflicts of Interest}

The authors declare no conflict of interest.

\section{References}

1. Åke Bergmark. "Social work in Sweden." In Social Work across Europe. Accounts from 16 Countries. Edited by Peter Erath and Brian Littlechild. Ostrava: University of Ostrava, ERIS Albert, 2010, pp. 160-70.

2. Socialtjänstlag [Social Services Act], SFS 2001:453 1, §1, 4§1, 2001. 
3. Tommy Lundström, and Sune Sunesson. "Socialt arbete utförs i organisationer." In Socialt Arbete. En Grundbok. Edited by Anna Meeuwisse, Sune Sunesson and Hans Swärd Stockholm. Stockholm: Natur och Kultur, 2011, pp. 183-94. (In Swedish)

4. Bo Davidson, and Margareta Bredmar. Familjer $i$ Socialtjänsten-Levnadsvillkor, Livssituation och Erfarenheter av Socialtjänsten: Ett FoU-projekt om Barn, Ungdomar och Deras Föräldrar $i$ Sex Kommuner $i$ Östergötland: Slutrapport Fas 1. Linköping: FoU Centrum för Vård, Omsorg och Socialt Arbete, 2012. (In Swedish)

5. Minna Lundgren, Björn Blom, Stefan Morén, and Marek Perlinski. "Från integrering till specialisering: Om organisering av socialtjänstens individ- och familjeomsorg 1988-2008." Socialvetenskaplig Tidskrift 2 (2009): 162-83.

6. Åke Bergmark, Tommy Lundström, Renate Minas, and Stefan Wiklund. Socialtjänsten $i$ Blickfånget: Organisation, Resurser och Insatser: Exempel Från Arbete Med Barn och Ungdom, Försörjningsstöd, Missbruk. Stockholm: Natur och Kultur, 2008. (In Swedish)

7. James Cornford, Susan Baines, and Rob Wilson. "Representing the family: How does the state 'think family'?" Policy and Politics 41 (2013): 1-18.

8. Kate Morris. "Thinking family? The complexities for family engagement in care and protection.” British Journal of Social Work 42 (2012): 906-20.

9. Gøsta Esping Andersen. The Three Worlds of Welfare Capitalism. Cambridge: Polity Press, 1990.

10. Anne-Marie Lindgren. "Are financialisation, privatisation and individualisation the same thing? The Swedish experience." In Rethinking Social Risk in the Nordics. Edited by Ville-Pekka Sorsa. Helsinki: Foundation for European Progressive Studies, 2011, pp. 67-90.

11. Dietmar Rauch. "Is there really a Scandinavian social service model? A comparison of childcare and elderlycare in six European countries." Acta Sociologica 50 (2007): 249-69.

12. Tony Evans. "Organisational rules and discretion in adult social work." British Journal of Social Work 43 (2013): 739-58.

13. Greta Marie Skau. Mellan Makt och Hjälp: Om det Flertydiga Förhållandet mellan Klient och Hjälpare. Stockholm: Liber, 2007. (In Swedish)

14. Malcom Payne. Modern Social Work Theory: A Critical Introduction. Basingstoke: Macmillan, 1991.

15. Kirsi Juhila, Tarja Pösö, Christopher Hall, and Nigel Parton. "Beyond the universal client." In Constructing Clienthood in Social Work and Human Services. Interaction, Identities and Practices. Edited by Christopher Hall, Kirsi Juhila, Nigel Parton and Tarja Pösö. London: Jessica Kingsley, 2003.

16. Yeheskel Hasenfeld. "The attributes of human service organizations." In Human Services as Complex Organizations. Edited by Yeheskel Hasenfeld. Los Angeles: Sage, 2010.

17. Yeheskel Hasenfeld. Human Services as Complex Organizations. Newbury Park: Sage, 1992.

18. Leila Billquist. Rummet, Mötet och Ritualerna: En Studie av Socialbyrån, Klientarbetet och Klientskapet. Göteborg: Institutionen för Socialt Arbete, Göteborgs Universitet, 1999. (In Swedish) 
19. Roine Johansson. Vid Byråkratins Gränser: Om Handlingsfrihetens Organisatoriska Begränsningar i Klientrelaterat Arbete. Lund: Arkiv, 2007. (In Swedish)

20. Kerstin Svensson, Eva Johnsson, and Leili Laanemets. Handlingsutrymme: Utmaningar $i$ Socialt Arbete. Stockholm: Natur and Kultur, 2008. (In Swedish)

21. Karl Gustaf Piltz, and Kristin Gústavsdóttir. Den Osynliga Familjen: Samarbetspartner Eller Syndabock. Göteborg: Ask och Embla, 1992. (In Swedish)

22. Donald Linhorst. "A review of the use and potential of focus groups in social work research." Qualitative Social Work 1 (2002): 208-28.

23. Kajsa Billinger. "A focus group investigation of care-provider perspectives in Swedish institutions for the coercive care of substance abusers." International Journal of Social Welfare 14 (2005): 55-64.

24. Ulla Melin Emilsson. "Recognizing but not acknowledging: On using research information in social work with elderly people suffering from dementia." British Journal of Social Work 35 (2005): 1393-409.

25. Virginia Schmied, and Peter Walsh. "Effective casework practice with adolescents: Perspectives of statutory child protection practitioners." Child and Family Social Work 15 (2010): 165-75.

26. Karen Newbigging, and Nigel Thomas. "Good practice in social care for refugee and asylum seeking children." Child Abuse Review 20 (2011): 374-90.

27. Torbjörn Forkby, and Staffan Höjer. "Navigations between regulations and gut instinct: The unveiling of collective memory in decision-making processes where teenagers are placed in residential care." Child and Family Social Work 16 (2011): 159-68.

28. Alan Bryman. Social Research Methods, 4th ed. Oxford: Oxford University Press, 2012.

29. Steinar Kvale, and Svend Brinkmann. InterViews: Learning the Craft of Qualitative Research Interviewing, 2nd ed. Los Angeles: Sage Publications, 2009.

30. Vetenskapsrådet. Good Research Practice. Stockholm: Vetenskapsrådet, 2011.

31. Pat Bazeley, and Kristi Jackson. Qualitative Data Analysis with NVivo. London: Sage, 2013.

32. Ulla Hällgren Graneheim, and Berit Lundman. "Qualitative content analysis in nursing research: Concepts, procedures and measures to achieve trustworthiness." Nurse Education Today 24 (2004): 105-12.

33. Hsiu-Fang Hsieh, and Sarah E. Shannon. "Three approaches to qualitative content analysis." Qualitative Health Research 15 (2005): 1277-88.

34. Amedeo Giorgi. The Descriptive Phenomenological Psychological Method: A Modified Husserlian Approach. Pittsburgh: Duquesne University Press, 2009.

35. Evelyn Khoo. Protecting Our Children: A Comparative Study of the Dynamics of Structure, Intervention and Their Interplay in Swedish Child Welfare and Canadian Child Protection. Umeå: Umeå University, Studies in Social Work, 2004.

36. Bruce J. Biddle. "Developments in role theory." Annual Review of Sociology 12 (1986): 67-92.

37. Catherine McDonald. Challenging Social Work: The Institutional Context of Practice. Basingstoke: Palgrave Macmillan, 2006. 
38. Hugh McLaughlin. "What's in a name: 'Client', 'patient', 'customer', 'consumer', 'expert by experience', 'service user'—what's next?” British Journal of Social Work 39 (2009): 1101-17.

39. Lena Hübner. "Constructing relations in social work: Client, customer and service user? The application and relevance of the term user in social work discourse." Nordic Social Work Research 4 (2014): 218-29.

40. Jorma Sipilä. Social Care Services: The Key to the Scandinavian Welfare Model. Aldershot: Avebury, 1997.

41. Ahmet Gümüscü, Evelyn Khoo, and Lennart Nygren. "Family as Raw Material-The Deconstructed Family in the Swedish Social Services." Journal of Comparative Social Work 2 (2014): 1-27.

42. Michael Lipsky. Street-Level Bureaucracy: Dilemmas of the Individual in Public Services. New York: Russell Sage Foundation, 1980.

43. Tony Evans. Professional Discretion in Welfare Services: Beyond Street-Level Bureaucracy. Burlington: Ashgate, 2010.

44. Linda Hantrais. Family Policy Matters: Responding to Family Change in Europe. Bristol: Policy Press, 2004.

45. Ron Walton. "Social work as a social institution.” British Journal of Social Work 35 (2005): 587-607.

46. Gunvor Andersson. "Child and family welfare in Sweden." In Towards Positive Systems of Child and Family Welfare. Institutional Comparisons of Child Protection, Family Service, and Community Caring Systems. Edited by Nancy Freymond and Gray Cameron. Toronto: University of Toronto Press, 2006, pp. 171-90.

47. Kate Morris, Nathan Hughes, Harriet Clarke, Jerrey Tew, Paul Mason, Sarah Galvani, Ann Lewis, Lucy Loveless, Saul Becker, and Gale Burford. Think Family: A Literature Review of Whole Family Approaches. London: Cabinet Office, 2008. Available online: http://www.cabinetoffice.gov.uk/social_exclusion_task_force/families_at_risk/review_analysi s.aspx (accessed on 2 October 2014). 


\title{
Different Welfare System-Same Values? How Social Work Educators in Norway, Chile and Argentina Comprehend Core Social Work and Social Policy Issues
}

\section{Rolv Lyngstad}

\begin{abstract}
During 2013 and 2014, five focus-group interviews were conducted in Norway, Chile and Argentina in order to understand better how professors at social work programs understand professional issues and controversial social policy issues in their countries. In the focus groups, the participants were asked to reflect upon a vignette which was a fictitious discussion about professional issues and dilemmas in social work practices. Three themes were deployed in the vignette. The first related to different attitudes with respect to how social problems in society should be approached and treated (with a special focus on the relationship between the public, private and civil sectors in solving welfare problems). The second was about social work dilemmas in the contested space between universal equality values and local freedom values/discretion embedded in local self-determination. The third focused on welfare states' principles distinguishing welfare benefits and services and how public welfare policies should be designed. The three countries are very different with respect to variables affecting welfare policies and social work practices. The most profound difference is likely that Chile (and to a lesser degree Argentina) since the dictatorship is highly influenced by neo-liberal policies advocating small public involvement in social policy, whereas Norway is a typical social-democratic welfare state. This fact, however, does not affect the reflections and apprehensions of the issues in a substantial way. The professional attitudes of the professors are surprisingly equal in spite of their different backgrounds.
\end{abstract}

Reprinted from Soc. Sci. Cite as: Lyngstad, R. Different Welfare System-Same Values? How Social Work Educators in Norway, Chile and Argentina Comprehend Core Social Work and Social Policy Issues. Soc. Sci. 2015, 4, 239-259.

\section{Introduction}

The paper takes as its point of departure some key issues very much debated within a public and academic audience in the Nordic countries. The issues are controversial among politicians as well as scholars working with welfare topics, social work and local democracy. The issues relate to three themes and contested issues and questions:

- What are the relationships between the public, private and civil sectors in solving social problems in society?

- Given a public responsibility, what level of professional, political and administrative decision making should have the prerogative and discretion to decide the policy?

- What is the best principle for designing the deliverance of welfare benefits and services (the selectivity or universality principle)? 
The apprehension of these issues is of course not developed and presented in a vacuum. The attitudes to and conceptions of these themes will have some contingencies. At least two main factors will probably affect the attitudes and conceptions. Firstly, belonging to a profession and teaching in the same main subject (social work and social policy) will presumably reveal resembled reflections. Secondly, it is likely that the comprehension of the issues will be affected by the societal circumstances, such as cultural traditions, national policies, economic situations and welfare regimes. The study will not, however, treat these factors as independent variables affecting the conceptions, but use the societal circumstances as a backdrop to understand the attitudes and reflections of the professors.

This paper will focus on how professors of social work and social policy in different contexts reflect upon and conceive different issues related to the degree of public involvement in social problems, the degree of political decentralization and the degree of selectivity/universality in welfare deliverance. Five focus-group interviews have been conducted: two in Norway, two in Chile and one in Argentina. The paper will present and analyze their discussion and reflections about the issues.

The research has been done as a part of a Marie Curie-funded project called "Supporting families with complex needs", a European Union-funded "international research staff exchange scheme". The project gave me the opportunity to visit universities in these three countries and due to the professional contact I had with professors teaching social work and social policy, I succeeded in conducting the focus-group interviews. In the interviews, the family focus is not predominant, but family is a central aspect of several of the themes as, for example, regarding the role of the public, private and civil sectors, and in how public welfare policies should be designed. The main focus is reflections about the themes mentioned above and the following paragraph will elaborate more on those accordingly.

\section{Some Controversial and Contested Issues}

\subsection{A Comprehensive Welfare State}

Figure 1 is useful for outlining some of the issues concerning how welfare problems and challenges are addressed in contemporary societies. The triangle represents collective welfare problems in society and shows the degree of involvement from, and reliance on, the public sector (the state), the private sector (the market) and the civil sector (families and NGOs) in solving welfare issues. The relative importance of the sectors varies between countries and many controversial themes arise. There are at least three important issues: How big should the sectors be (white fields)? What are the challenges when three sectors have to collaborate in the "grey" zones (grey fields)? What happens with the issues in which none of the sectors are involved (black fields)? These three issues are universal and significant in social work discourses and social policy discussions worldwide. To some degree, they will make a framework for the discussions in the focus groups.

All the Nordic countries are decentralized unitary states characterized by a universalist, egalitarian and public system of services very typical for a social democratic welfare state [1-3]. Thus, a feature of the Nordic welfare model is both universalism and local autonomy. According to Hilson [4], the Nordic welfare state has been successful because the model is consensual and compromise-driven, social-democratic in outlook and able to combine a comprehensive and redistributive welfare state with 
a successful capitalist economy. To understand these features, it is important to realize the strong influence from Keynesianism, emphasizing that the state must use money to stimulate the economy. Social policy and redistribution through social policy measures and lowering of income differences are regarded as factors important to guaranteeing smooth economic growth. Thus, "the social" and "the economic" are integral and inseparable parts of the same development.

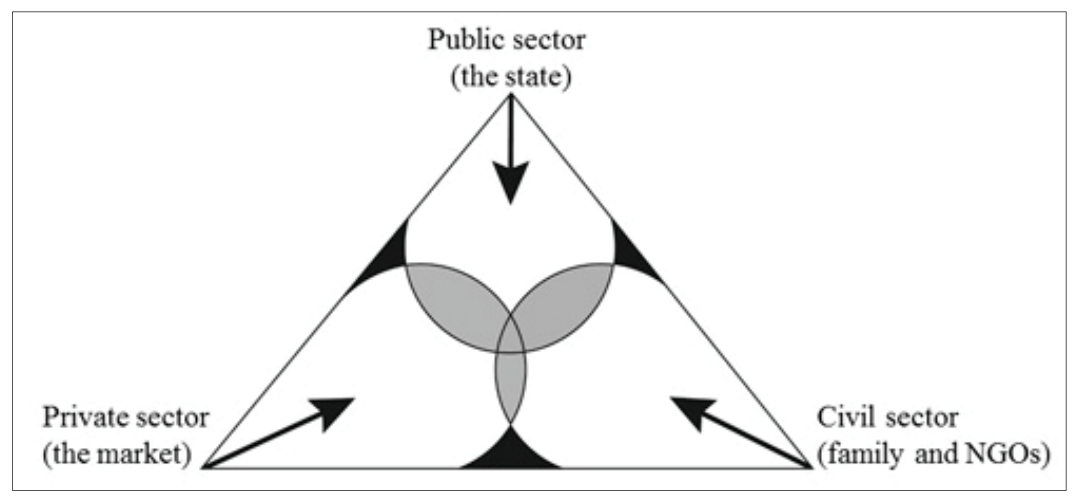

Figure 1. The welfare triangle.

However, the Keynesian influence has been challenged over the last few decades. According to neo-liberal thinking and traditional economic theory, scholars advocating this paradigm would assert that: welfare states will not be successful economies because high taxes are detrimental to work and investment incentives; large public sectors create inefficiencies; benefit systems create dependencies which depress private initiative; and welfare states will not be sustainable in the long run. Neo-liberal economic dogmas argue that equality and redistribution are often obstacles to economic growth. We must choose between growth and equality. We must downsize the public sector and get the high tax level down. The message has been that in order to be competitive, the Western countries - especially those with high welfare expenditures and "big" welfare states - must reduce their social security to enhance growth and meet the challenges caused by globalization.

In many Western countries, including the Nordic countries, the so-called New Public Management with its influence from neo-liberal thinking has had an impact on public administration and welfare policy. Privatization strategies and more focus on devolution/decentralization have received a lot of attention in the public debate and professional discourses. The universal principle for deliverance of welfare is questioned, more focus is given to cooperation between the public and civil sectors, and such a slogan as "from welfare state to welfare society" is frequently used to advocate less public involvement in welfare problems.

Some challenges for the traditional welfare state are also due to postmodern tendencies in which a comprehensive welfare state is no longer looked upon as a grand narrative. Relativism, fragmentation, differentiation, subjectivism, individualism and ambivalence are more typical features in contemporary societies than common and joint knowledge, understanding and values characterizing the traditional welfare state [5]. Some sociologists argue that we are living in an era of reflexive modernity in which the influences of tradition, class, religion and family are no longer as 
strong as they once were [6]. People have to choose from a variety of lifestyles in order to develop their own self-identity.

According to this postmodern development, the core value seems to be self-realization, and thus universal moral criteria may be weakened. The question is how this individualism affects the conditions of solidarity. Ideological and political changes in post-industrial capitalism, in contemporary Scandinavia as elsewhere, will most likely have some impact on the structure and function of the Nordic welfare state and to some extent be affected by postmodern individualism and neo-liberal economic trends.

In spite of these influences from neo-liberalism and deeper societal trends, the Nordic welfare model seems to be robust with a strong commitment to ideals of equality, social justice, social security, solidarity and social integration. The degree of trust among citizens has been, and still is, very high ${ }^{1}$. This fact may explain that most inhabitants regard government and public authorities as the solution to a problem and not the problem itself, as is the case in some neo-liberal countries. There seems, however, to be a growing interest for more collaboration between the public, civil and private sectors in solving welfare problems in society. How big the "grey zones" should be between the sectors in approaching and solving welfare problems is controversial-politically as well as professionally.

\subsection{How Much Discretion to Local Government}

The local and county authorities have a long tradition as local democratic agencies in most of the Nordic countries. Local governments are supposed to be democratic bodies as well as service bodies and executors of nationally decided policies. These roles may be antagonistic. A dilemma arises when the outcome of local elections gives a democratic mandate to local politicians to make different priorities than the national government. Sometimes the challenge will be to accommodate values of national equality to values of local freedom. To establish a well-functioning working division between levels of decision making is difficult and controversial, but is nevertheless a much-debated issue in the Nordic countries.

During the last few decades, local government, especially in Norway, has experienced reduced discretion in political decision making, welfare policies included [7]. According to recent policy documents [8,9], these changes have gone too far and national politicians intimate a "re-capture" of local decision-making power. For social workers, issues related to how changes in local discretion are impacting central social work values and professionalism in social work practice are of special importance. How much discretion should be given to local decision makers in the name of local democracy? How much difference should be accepted in the name of diversity?

Within social work discourses, these questions must be related to core professional values like social justice, equality, diversity and human rights as well as commitment, empowerment and responsiveness. Concurrently, it is possible to argue that good social work must be contextual [10]

1 It should be noted, however, that in the last election to parliament in Sweden (14 September 2014) a far-right populist party gained $12.9 \%$ of votes, and in addition to a very restrictive immigration policy, the party strongly asserted a mistrust towards public authorities and politicians in general. Also in Norway, we find a political party in government that traditionally has been very critical of public authorities. 
and professional discretion at the local level is a necessary prerequisite to success. Thus, current discourses related to the controversial relationship between the central and local levels of decision making and how it might affect democratic ideals and professional social work as well as users of welfare services are some of the most interesting issues in contemporary social work discourses in the Nordic countries and elsewhere.

\subsection{From Welfare to Workfare}

In addition to a discussion about how comprehensive the welfare state should be, there seem to be increasing controversies about important eligibility principles and concepts such as universality/ selectivity, stigmatization, decommodification and citizenship rights.

Universal benefits and services are benefits available to everyone as a right, or at least to whole categories of people (like "the elderly" or "children"). Everyone is eligible based on their democratic rights as citizens, and thus all citizens are endowed with similar rights, irrespective of class or market position [11]. Therefore, there are few stigmatization problems related to this eligibility principle. However, there are some justice objections to universalism. The argument is that wealthy people do not need the same amount of benefits and they can afford to pay for the services themselves. In this respect, universal benefits are unfair and a waste of money. In Norway, this is a growing debate mostly related to child benefits, which are universal.

Selective benefits and services are reserved for people in need. Thus, means-tested poor relief or social assistance is given to those in the most need. Targeted groups are offered a safety net of a last resort. Benefits are often intentionally restricted and associated with stigma, designed to make people motivated to participate in the labor market. Selectivity is often presented as being more efficient: less money is spent to better effect. There are problems with selective services, however. Because recipients have to be identified, the services can be administratively complex and expensive to run, and selective services sometimes fail to reach people in need. Finally, the main objection is the stigmatization problem. Because it is not regarded to be a matter of right but a kind of charity, many people feel ashamed of receiving, or people regard it as shameful to receive benefits based on the selectivity principle.

This is why the decommodification principle has been so important in Nordic welfare states. Decommodification [1] as a concept comes from the idea that in a market economy citizens (and their labor) are commodified. Given that labor is a citizen's primary commodity in the market, decommodification refers to activities and efforts (generally by the government) that reduce citizens' reliance on the market (and their labor) for their well-being. Decommodification occurs when a service is rendered as a matter of right and when a person can maintain a livelihood without reliance on the market. It refers to the degree to which individuals, or families, can uphold a socially acceptable standard of living independently of market participation.

The decommodification concept must also be related to a discussion about citizenship rights and what this implies. T. H. Marshall has distinguished three types of rights associated with the growth of citizenship [12]: Civil Rights which refer to the rights of the individual in law, like freedom of speech and religion, the right to own property, the right to equal justice before the law etc.; Political Rights which, for example, refer to rights to participate in elections and democratic actions; and 
Social Rights which refer to the freedom or the right of every individual to enjoy a certain minimum standard of economic welfare and security. In most societies, social rights have been the last to develop. This is because the achievement of civil rights and political rights is the basis upon which social rights have been fought for, and none of these rights can be taken for granted.

Welfare policies building on the principles and concepts mentioned in this paragraph are under scrutiny and there seems to be a growing understanding that the authorities should have more focus on getting people to work and not to rely upon generous public welfare, hence the slogan "from welfare to workfare" [13] even though in the Norwegian context it is more a matter of the so-called work-line strategy in welfare policies. This seems to imply increasing acceptance of inequality among a growing number of people, more use of selective instead of universal principles in welfare policy, more use of user charges in welfare services, more use of private insurance in addition to public funding, the receipt of benefits more in accordance with one's contribution than individual need, and stronger emphasis on workfare and benefits more linked to contribution in the working life.

\subsection{Some Important Differences between the Countries}

The apprehension of these controversial and contested issues will presumably have some contingencies. Features of the nation's welfare regime, economic situation and cultural traditions are examples of factors that may explain the attitudes and understandings. Accordingly, a study that defines some background factors as independent variables explaining professional opinions would of course be interesting. The methodological design used in this study does not admit to such an approach. This is a qualitative study exploring how some professors in social policy and social work from three different countries comprehend issues relevant to social work discourses, and a definite determination of the relationship between independent and dependent variables is not possible. However, as a backdrop to understanding and reflecting upon differences in attitudes and approaches, some statistics would be of interest.

Norway is a typical social-democratic welfare state [1] with a large public sector. The public sector is the main provider of welfare services and benefits, and the provision is comprehensive, universal and redistributive with a high degree of social equality. Municipalities have a heavy responsibility for a great deal of services; approximately three-quarters of local governments' expenses are related to welfare issues (education and kindergartens included).

The categorization of Latin America's welfare regimes has been done in different ways (see for instance [14-17]). Aspalter [15] has in addition to Esping-Andersen's three welfare-state regimes [1] (social-democratic, Christian-democratic and liberal) identified one East Asian and one new ideal-typical welfare regime in Latin America. The last type includes Argentina and Chile and he names the regime "the anti-welfare conservative welfare regime" in which a high degree of stratification and small and means-tested social assistance programs are typical features. Thus, Aspalter's "anti-welfare conservative welfare regime", typical for Argentina and Chile ${ }^{2}$,

2 It is important to note that both Argentina and Chile are influenced by neo-liberal ideology but, due to influence from unions and social movements, the impact of neo-liberalism has been lesser in Argentina than in Chile. 
contrasts in many important ways the social-democratic welfare regimes that are typical in the Scandinavian countries.

A major theme in the focus-groups interviews has been how social and welfare problems in society should be addressed and solved. Are the problems mainly a responsibility and duty for the public sector (the state), the civil sector (family and NGOs) or the private sector (market)? What are the relationships between the sectors in approaching and tackling the problems? The attitudes to this main issue will probably be affected by some features of the three countries, respectively. Many statistics could be presented as showing core differences. I have chosen to use government consumption, unemployment, the poverty rate, an index for inequality in the countries and GDP per capita as a kind of backdrop in order to understand the differences. Table 1 is based on statistics from The World Factbook [18].

Table 1. Some indicators of the economic situation in Argentina, Chile and Norway.

\begin{tabular}{|c|c|c|c|c|c|}
\hline Country & $\begin{array}{c}\text { Government } \\
\text { Consumption }{ }^{3} \\
(\mathbf{2 0 1 3})\end{array}$ & $\begin{array}{c}\text { Poverty } \\
\text { Rate }^{4}\end{array}$ & $\begin{array}{c}\text { Unemployment } \\
\text { Rate } \\
\text { (2013) }\end{array}$ & Gini Index 5 & $\begin{array}{c}\text { GDP per capita } \\
\text { (US dollars) } \\
\text { (2013) }\end{array}$ \\
\hline Argentina & 18 & $30(2010)$ & 7.5 & 45.8 (2009) & 18,600 \\
\hline Chile & 12 & $15.1(2009)$ & 6.0 & $52.1(2009)$ & 19,100 \\
\hline Norway & 21.6 & $7.7(2011)$ & 3.6 & $25.0(2008)$ & 55,400 \\
\hline
\end{tabular}

The table shows clearly that Norway has the biggest public sector, the fewest poor people, the lowest unemployment rate, the lowest degree of economic inequality and by far the largest economy per capita. Besides, the welfare sector's segment of the public sector in Norway is substantial [19]. The participants in the focus groups are highly aware of the differences between the countries that are revealed in the table, and their reflections should be understood with these figures as a backdrop. I will not, however, treat these differences as independent variables explaining differences in attitudes and reflections.

\section{Method of Analyses}

As mentioned in the introduction, the apprehension of these issues is not developed and presented in a vacuum and, accordingly, it is interesting to learn more about how professors in social work and social policy from different countries conceive and reflect upon these issues. Their opinions, values

3 Percentage contribution of government consumption to GDP. It consists of government expenditures on goods and services. These figures exclude government transfer payments, such as interest on debt, unemployment, and social security, since such payments are not made in exchange for goods and services supplied.

4 National estimates of the percentage of the population falling below the poverty line are based on surveys of sub-groups, with the results weighted by the number of people in each group. Definitions of poverty vary considerably among nations. In Norway, for instance, we are using a relative definition where households earning less than $60 \%$ of medium income is defined as poor.

5 This index measures the degree of inequality in the distribution of family income in a country. Low numbers mean little inequalities in the country.

6 The value of goods produced per person in a country. 
and reflections about the themes will most likely affect the public debate and discourses within the profession and practice of social work. Therefore, we conducted five focus-group interviews. It turned out to be rather difficult and time consuming to gather sufficient participants at a time that was convenient for all. Some of the groups were small, but this fact does not seem to have had any negative impact on the discussions and reflections disposed. All the participants had positions as lecturers and professors in social work programs, and most of them had been working as social workers in the field. All the interviews lasted approximately two hours. The first group consisted of four professors at the University of Nordland and was conducted in February 2013. The second interview was with three professors at Pontificia Universidad Catolica de Chile in Santiago, conducted in March 2013. The third group consisted of five educators from different social work programs at many universities in Santiago and the interview was conducted in April 2013. The next focus-group interview was done in November 2013 with four professors at the University of Stavanger, and the last interview was with four educators at Universidad National de Cordoba in Argentina, conducted in February $2014^{7}$.

The starting point of the interviews was a vignette that all the participants were asked to read before the interviews. The vignette was a fictitious discussion concerning professional issues and dilemmas in social work practices between social workers from a local social welfare office, a local politician, a bureaucrat from the local government and a voluntary, non-professional person working in a local NGO. In the vignette, the discussion was followed up by some related questions ${ }^{8}$.

Three themes were deployed in the vignette. The first relates to different attitudes with respect to how social problems in society should be approached and treated (with a special focus on the relationship between the public, private and civil sectors in solving welfare problems). Examples of questions following the fictitious talk were: Should clients ask their families for help before asking public agencies? Do you expect voluntary organizations to play a more dominant role in delivering welfare services in the future? What are the main pro and con arguments for public responsibility for welfare issues and problems in society?

The second theme was about social work dilemmas in the contested space between universal values and local diversity values, and how to approach possible conflicts between national decision making and the values of local freedom and discretion embedded in local self-determination. Examples of questions asked were: Is the separation of work between central and local level of decision making a contested issue? How much difference and inequality should be accepted in the name of local self-governance and cultural diversity? Is the use of media and whistle-blowing an accepted strategy to change local decision-making approaches?

7 This specific sample of focus-group members was chosen because they were all related to the international social work network program funded by the Marie Curie exchange scheme and thus had an interest in the study. Since the study is not aiming to identify independent variables explaining variations in comprehensions, I regard the sample as adequate.

8 Vignettes as well as focus-group interviews have been more and more common in social science research [20-22]. A vignette can be a fictitious construction of a scenario upon which participants in focus groups will reflect and discuss. 
The third theme focused on the principles underlying welfare benefits and services, and how public welfare policies should be designed. Examples of questions following the talk were: Are the universality principle and the selectivity principle contested in contemporary discourses in your country? Is there a stigmatization problem related to specific benefits and services? Is the growth of welfare expenditure regarded as a problem that needs to be addressed by politicians, and do we see a change "from welfare to workfare"?

As previously mentioned, these three themes and fictitious talks, together with some follow-up questions, were sent to the participants in the focus groups beforehand. We asked them to read the talks and reflect upon the themes and the questions before the interview started. When the focus-group interviews started, the participants had hopefully already reflected upon the themes presented in the vignette. We were not looking for unanimous opinions; disagreement about professional attitudes was interesting. The crucial point, accordingly, was to reveal some typical reflections and attitudes about the issues described in the vignette.

All the interviews were typewritten, transcribed and translated into English. I myself had a role as a moderator, but since my Spanish is not adequate I had (in the Spanish-speaking interviews) to rely upon help from a co-moderator who spoke Spanish and English. Those co-moderators were also participants in the focus group. The transcriptions consist of approximately 150 pages, and a summary was needed ${ }^{9}$. The analyses are based on those summaries. When reading these transcripts, we realized that there are some translations that appear unclear. This could have been avoided if the researcher (main moderator) had more competence in Spanish and thus guided the informants towards relevant themes in the vignette. In addition, we realized that some reflections in the interviews would have benefited from adequate follow-up questions. We believe, however, that the quality of the interviews is not seriously reduced.

The following is a review and summary of the main reflections and conceptions that were revealed in the interviews. The transcripts were read several times to ensure that the summaries reflect the informants' views in a proper way. Only reflections that are related to the vignette and subsequent questions are presented. I use some quotations (in italic) from the transcripts in order to illustrate the reflections and opinions. Therefore to identify who said what is not particularly interesting. Where the participants have different opinions will be apparent from the text. The summary will be organized according to the themes in the vignette.

\section{Findings Based on a Summary of the Focus-Group Discussions}

\subsection{Theme 1: The Relationship between the Public, Private and Civil Sectors in Resolving Welfare Issues}

All five groups assert that social problems mostly have societal causes; accordingly, all groups agree that, in principle, the public sector should be the main provider of services and benefits in society. The Norwegian groups especially agree that elected politicians and public agencies need to

9 Because of the magnitude of data, only some of the reflections will be further elaborated. The material, however, will be available for analyses. 
take the main responsibility even though more collaboration with actors from the civil sector will be more compelling in the future. They emphasize that to receive help is a matter of right, and public responsibility will enhance social rights as important citizen rights. They argue that there is a kind of reciprocity involved in public welfare. Citizens pay taxes and expect something back from the state when in need of help or support. Another argument mentioned is a democratic one. A good democracy is built upon involvement, commitment and participation, and public responsibility for welfare will enhance and probably facilitate citizenship in society.

The causes of social problems were a theme in the Chilean groups as well, and they seemed to agree that individual problems mostly have societal causes. They do not believe in an individualistic conceptualization of human beings but assert that sometimes it is hard to decide how to approach a social problem, and it is really difficult to distinguish based on structural constitution, and it is really difficult to distinguish what is your responsibility and what isn't [23]. They argue that a protective and benevolent state that facilitates solutions is necessary. They also assert that when we activate individual solutions we do it not because we trust that it is the best solution, but rather because it is the fastest way to come to a solution [23].

The Norwegians stress that it is important for the educational programs to keep a macro-perspective in their teaching, though they are not sure that this understanding will survive in the educational systems. One Norwegian group referred to the fact that many professors in social work and social policy obtained their education in the radical decade of the 1970s, a decade in which macro-level explanations, structure and political consciousness were important elements in the ontological understanding of how society works. To understand problems as social problems was a fundament most social work teaching was built upon. They wondered if these understandings and values acquired in the 1970s and early 1980s would prevail. Will the contemporary trend towards more individualization affect the way educators are looking upon social problems and their causes? Thus far, the predominant comprehension among scholars in social work is that most problems must be related to characteristics within the society and, accordingly, the public authorities must take on major responsibility. If the focus in public discourses shifts from the society to the individual, with more focus on poor morals and bad choices, then this will certainly affect the teaching.

One of the Chilean groups had a great deal of reflections about what is characterizing the Chilean way of regarding the relationship between the individual and society. They commented that the saying "each person is the architect of his own fortune" is engrained in all of us and this has to do with the logic of individual capital that was changed in two or three generations to be the way of resolving public problems, in that you resolve them privately [24]. Therefore it is "difficult to be poor". The logic of individual capital lacks the vision of solidarity [24]. Many people do not care about people in need if they are not affected themselves. The logic is residual assistance; poverty and equality gaps are tolerated. They seem to be very critical to contemporary features of Chilean society and one participant put it like this:

The logic produces and the society produces inequality. Not only produces, but tolerates and hides. The collective solidarity is not installed, it's lost. The system is built upon individual insurance, no collective solidarity or societal responsibility. Individuality is the maximum expression. Privatization has been contrived as an icon of modernity, but 
it is really the icon of the neo-liberal model. For most people it is hard to imagine other systems, but for many Europeans it is hard to understand the degree of privatization that is characterizing the Chilean society [24].

The issue about conditionality seems to be much debated in all three countries and is built upon a kind of a contract between the state and the citizen. In the Norwegian context, however, there seems to be a rights-based focus emphasizing that the state is obliged to help if the citizen for some reason is not able to manage alone. In Chile, there seems to be more focus on the individual's responsibility, and one of the groups talked about the social protection system as being built upon two pillars, one aid pillar and one contribution pillar. They say that the system pivots between a universal logic of wellbeing led by demand and a subsidy logic. There are many conditional transfers and the system of social welfare is based on conditionality. It is likely that the system in the future will be less universal and less based on rights [24].

The focus group from Argentina asserted that liberal reformism and social Catholicism at the beginning of 20th century shape two strong traditions that have always disputed sense, meanings and orientations of social work and society. These two traditions have had a big impact on the professional debate and they still rule the Argentinean debate. They argue that the degree of public responsibility is much debated in contemporary Argentina, and it is a public and social debate and not only regarded as a subject for academics. They say that the debate about social policies in Argentina breaks through many sectors of the population such as businessmen, union representatives, mass media, the Catholic Church, etc. They are also concerned about the influence of neo-liberalism and the privatization trend that started in the 1990s. Many good programs have been introduced but at the same time there exist a poor adjustment with real practice. There seems to be a divorce between what the law proposes and reality.

The two groups from Chile were particularly very skeptical as to how realistic it will be to give more responsibility to the public sector in resolving welfare problems in contemporary Latin-American countries. One of the groups maintained that the state is a benefactor, small, residual and focusing on the very poor. Present Chile is heavily influenced by neo-liberalism affecting public policy and political decision making [24]. Moreover, this will affect how professionals work. The system is based on an idea of conditionality, and people in need must meet a series of requirements before getting help.

The focus-group participants in Chile and Argentina claim that the divide between public and private responsibility in addressing welfare problems has historical reasons and weak public involvement is due to the neo-liberal influence in Latin-America in the 1980s and 1990s. Latin-America has a family-based residual system where resources in the family must be used before help can be expected from the state. The discussions in these groups indicate, however, that this system is not supported by the educators. In a Norwegian, situation most benefits are regarded to be a matter of right for the individual regardless of how rich the individual's family might be. Nevertheless, also in a Norwegian context, it will be relevant to involve resources in the network and the family if the individual agrees. With respect to the use of NGOs in resolving welfare issues, the participants in the focus groups are not very clear. In Argentina, the influence of the Catholic Church has been substantial but also very controversial. That is also the case in Chile, whereby here the 
participants talked about a system of transfer, not a system of collaboration between the public and civil sectors. Generally, the Norwegians are very skeptical of using market mechanisms in welfare policies. They differentiate between idealistic and non-profit organizations on one hand and for-profit NGOs on the other. The first, they maintain, may contribute substantially to solving social problems, but for-profit organizations are not appreciated as providers of welfare services.

All the groups are in favor of using civil sector organizations in a working collaboration with public agencies. At the same time, they are skeptical of the commercialization of the services. The Norwegian groups particularly emphasize that it is important to differentiate between ideal and non-profit organizations on the one side and commercial for-profit organizations on the other. Both the Chilean groups maintain that civil organizations and citizens groups (together with social workers) have an important role to play in visualizing social problems in society because we are living in a society that silences serious problems. There is a lot of collaboration but it is probably more right to talk about a model of transfer, not a model of collaboration [24]. Accordingly, they are critical of the outsourcing trend. This trend is an issue discussed in both Norwegian groups as well. They are critical of the profit part of it, but they welcome more collaboration between public and civil sectors. At the same time, they agree that the dominant attitude and conceptions among contemporary politicians and in general public in the future probably will be that social problems are a collective and public responsibility even though some trends towards downsizing public responsibility are visible.

Attitudes towards family-based welfare reveal the biggest differences between the focus groups, and the differences correspond to nationality. The participants in the focus group from Norway are very clear that to ask the family of a client to resolve the client's problem is not appropriate. They all maintain that we have passed the time when the state and social workers could expect family members to solve the client's problem. Relying on families should not be among the principles we are building social work and our welfare system on [25]. To get help is a matter of right and the family's income is not relevant. They are, however, positive to collaborating with family resources and the network around the client in order to find appropriate solutions for the problem, but they emphasize strongly that this does not release the state from having the main responsibility.

The focus groups from Chile and Argentina are correspondingly clear that if a client has a rich family and the client needs some economic support, it will not be expected that public authorities should help. One of the groups from Chile elaborated more on this issue and explained that in Chile clients must rely on individual and familiar resources, labelling, blaming and holding responsible. This has something to do with the fact that in our countries there is a more familiar resolution to problems versus in Europe where there is a resolution demanded from the State [23]. They argue that it is necessary to use the family in resolving the problems and assert that Chilean social workers consider the family as a means of support. All the focus groups argued that it is relevant to include the family situation and the network around the client when the social workers have to review the possibilities and give an assessment of what can be done.

The groups from Argentina and Chile were critical of the way the authorities are approaching the issues, and argued that the policy is not adjusted to the real needs of society. The state seems to ignore the problems, and there is a constant conflict between problems and lack of resources. Furthermore, 
they argue that sometimes there is a divorce between what the laws say and reality, and there is a lack of political decision and courage to implement the laws. This seems to be the case in Argentina and in Chile. They welcome, however, the debate about how to involve public authorities in welfare issues. The Norwegian participants are proud of public involvement, and argue that the success of the welfare state is the best argument for a strong public engagement also in the future, even though they can see a trend towards more privatization and neo-liberal thinking in a Norwegian context as well. They anticipate, however, that benefits that are too generous may imply a welfare trap that is difficult to avoid, and therefore the work-approach strategy is necessary. Some also indicated that it is not necessarily certain that welfare benefits always meet real needs, and they asked whether the welfare services adequately address the people who really need state assistance. Accordingly, one of the focus groups mentioned an eventual problem related to being too self-satisfied with the welfare system and this can obscure critique and consideration of other welfare perspectives and systems.

The different apprehensions of the situation have much to do with the welfare systems which mirror a well-known and controversial political and social policy discourse: is a comprehensive welfare state the problem or the solution of the problem? The standpoint is apparently dependent upon preconceptions and can be explained according to historical experiences and of course political and ideological views. Latin-American countries have been under the influence of neo-liberal ideologies, and, according to the interviewed professors, this ideology has had a negative impact on welfare policies. Therefore, they advocate more public responsibility in addressing welfare issues. The Norwegians refer to a well-established and successful welfare state, and prefer a comprehensive welfare state for the future, even though some political trends may indicate a downsizing of public responsibility ${ }^{10}$. This reveals a somewhat paradoxical situation: a small welfare state requests more public responsibility, while a big welfare state focuses a need to downsize the public sector.

\subsection{Theme 2: Dilemmas Related to Local Discretion and Decision Making}

The vignette invited reflection about latent competence-conflicts and other problematic issues arising from the division of competence between different levels of decision making within the public sector. Equality in service and benefits across local and regional borders is important in social work and social policy. To ensure this value, centralized decision making and service deliverance are sometimes necessary. At the same time, diversity is a value in the profession and local discretion will often be a prerequisite for success. Thus, national equality, which is a core social work value, may conflict with values of local freedom, which politicians at the local level appreciate very much as do local professionals who want to adjust social work to local conditions and circumstances.

None of the focus groups had issues related to competence-conflicts in "grey-zones" between levels of decision making that has already been mentioned as a very controversial issue. However, all the groups agreed that it should be an issue, and they wanted more discussions by professionals about dilemmas in the contested working division between levels of decision making. Especially in the Norwegian groups, the fact that Norway is a decentralized unitary state could create a lot of

10 The outcome of the parliament election in September 2013 replaced the social-democratic "red-green" government with a conservative "blue-blue" government. 
controversies between national decisions makers building on national equality values and locally elected politicians adhering to the value of local freedom. Accordingly, a crucial question could be; how much difference can we accept in the name of local self-governance? One of the Norwegian groups agreed that there must be space for professional discretion because local circumstances vary a great deal although, at the same time, it is necessary to avoid too much difference in the quality of services among municipalities and inhabitants. They argued in favor of tailored welfare policies according to local needs and circumstances, and more centralization may counteract this. They seem to conclude that local professional discretion within certain minimum economic standards will be the best arrangement and they recommended more use of professional discretion. The other Norwegian group was more doubtful about local discretion because, as one participant said, local democracy is advantageous for powerful groups in society [26].

The Norwegian focus groups spent much time reflecting upon pro and con arguments for local self-governance. One group was particularly skeptical of local autonomy because professional competence is sometimes lacking, especially within the child-protection area. The participants are not sure, however, whether lack of competence is due to local self-governance. One informant put it like this: The more unclear and diffuse the need for help is, the more uncertain the resources will be. But is this due to local self-determination? Or due to different attitudes among professionals working without very clear frames? [26]. They assert that if criticism arises in the public debate about how professionals manage their jobs and conduct their duties, they protect each other, and it is almost impossible to reveal what is really happening [26]. Differences in the quality of services seem to be caused more by differences in professional competence than political attitudes or the fact of local responsibility.

The focus-group participants realized that there are differences between municipalities, but not necessarily due to conflicting values. One of the Chilean groups affirmed that in general inequalities are more about the fact that some neighborhoods are rich and some are poor, not so much due to decision making and different values in local government [24]. During the Pinochet period, many tasks were decentralized, causing many differences in welfare services. Today, they think that the local demand is to decentralize, but with resources [24]. One of the participants asked do we confuse discretion with autonomy? [23]. They argued that professional discretion is difficult because of lack of autonomy in the decision-making structure. There seems to have been more opportunities to reflect upon issues in a collaborative way in the past. Today the professionals are influenced by ideas of control and hierarchical attitudes, and this hierarchical tendency has been strongly implemented in current social policies. There is much management control as well as control over social processes [23]. Professionals spend most of their time filling out paperwork. This is a way of infringing upon autonomy. It takes away autonomy from the professionals, and the focus is placed on control and supervision. Thus, professional discretion is difficult.

They seemed to have had bad experiences in the Pinochet era when a lot of decision making was decentralized, resulting in many differences between the municipalities. They argued, however, that sometimes local decision making is good, but not without resources and some national parameter being necessary. The concepts of discretion and autonomy were problematized, and they argued that professional discretion is useless if formal autonomy is restricted. The Argentinean group talked 
about the possibility of central politicians using funding as a weapon to pressure local decision making. However, there seems to be less central interference today than earlier and there are some efforts to give more autonomy to local governments. Thus, the state of the art is somewhat confusing: professionals see the advantages of national parameters in social work in order to ensure equality values, and therefore are in favor of some national influence on local priorities, but at the same time they advocate more professional discretion at the local level. Simultaneously, there seems to be more power given to local political decision making. That is probably why some of the groups argue that political connections and knowledge are important if the social work profession is to influence public policy.

Another issue was about differences due to cultural background. The moderator asked if it should be acceptable that parents spank their children, proposing that it is necessary in the upbringing of children. The Norwegian groups answered very clearly in the negative; it is not acceptable to use culture as an excuse for smacking children for the purpose of upbringing because corporal punishment (in Norway) is against the law and therefore illegal. Sometimes it is difficult to know where to draw the line and, as an example, one participant said that there are groups and religious minorities in Norway who argue very strongly and act accordingly that women should stay home and take care of the children. Is this attitude within or outside the law? [26]. It is important that social workers learn more about cultural differences in order to do better professional work. However, core social work values and ethical standards must be at their roots, and they assert that some social workers have not internalized these values and ethics well enough.

The informants from Chile argued that cultural diversities that violate dignity should not be accepted. International human rights are important for social workers to attend to, but it is not always easy to decide where to draw the line between acceptable differences and unacceptable attitudes and actions. The children's right to education is important even if it violates cultural norms. The informants had a discussion about individual rights and rights according to cultural norms and concluded that there are situations where this issue is difficult (as an example they mentioned the circumcision of children), but they seemed to conclude that as a general rule the social worker must stick to human rights and that violation of these rights is not acceptable. Even though the international convention on human rights is based on a Western culture, everyone including the social workers should be trained to ensure the rights of people. In the focus group from Argentina this issue was not much discussed. The participants seemed to agree that because Argentina is a quite homogeneous society with few cultural differences there are few problems with cultural differences violating core social work values. The public school system ensures a whole of general shared norms in this country [27]. But some aboriginal groups claim that the transmission of their culture and rights could be better provided for.

Altogether, the issue about how much difference in social policy is acceptable in the name of local self-governance and cultural diversity brought about a lot of discussion. Professional reflections are necessary and the issue should be talked about, discussed and problematized. As one interviewee said: we need deliberation and discussion all the time, but some values are so important that they are protected by law. Besides the professional "code of ethics" should be normative [27]. This code emphasizes that some values are universal and independent of context. It seems hard to draw a clear 
line but some parameters are necessary, as for example, concluding that it is unacceptable that diversity should violate a person's dignity. The focus groups in Chile and Norway emphasized strongly that the international convention of human rights is very important to use as a guideline even if it violates cultural norms like the circumcision of girls. The Argentinean focus group did not see the difference/diversity issue as a big problem because the country is quite homogeneous.

The need for whistle-blowing has received a lot of attention in the media. However, in spite of (or maybe because of) that, many social workers seem to be afraid of doing so. The Norwegian groups argue that some social workers are afraid of being "frozen out" if they go to media or the public with criticism. The worker may get a reputation as a whistle-blower and trouble-maker and therefore whistle-blowing is probably too infrequent at the local level. Workers are afraid of losing their jobs or of being "frozen-out" and people think is it worth it? [25]. Besides, there seems to be a strong demand for loyalty from their employers.

The Norwegian groups argue that sometimes blowing the whistle is necessary, but one must first use the proper channels for changing the policies. They argued that local professionals should involve central authorities to a greater degree even though this is seldom done. The participants argued that as a part of social workers' mandate, they should inform politicians and decision makers about the state of things. If people with power to change current practice do not have relevant information and knowledge, it will be hard to influence the necessary changes:

If you do not succeed with your point of view and you think it is a matter of great importance, you should try to involve a higher level of decision making. It can also be a possibility to involve the labor union (which in Norway is a professional union, as well). If there are important issues at stake, and you feel the local decisions violate your social work identity, it will be okay to involve the media [25].

The participants in one group discussed how important it is to teach students about values, and that there are crossroads where the students have to ask themselves if it will be right to continue in the job. It is important to give the students confidence with regard to social work values and to show that professional social workers belong to a professional community. The other Norwegian group maintained that whistle-blowing is accepted and legitimate, but that the professionals seldom do it. When the moderator asked about the frequency of whistle-blowing by the professionals, they argued that it should be a duty for professionals to inform politicians and speak out about things that are wrong or do not work well. They claimed that the professionals do speak up about it, but in a very hidden way. The professionals should speak loudly and publicly, but it seems to be very difficult. If they do, whistle-blowers will have many problems. One participant put it like this:

There are many closed systems and fringe benefits that one will not achieve if you are known as a whistler. There is a lack of transparency and a lot of things happen behind closed doors [26].

Whistle-blowing and the use of media in order to focus disagreement and concerns about how local authorities treat welfare issues seem not to be very relevant in the Chilean and Argentinean contexts. One reason could be that the degree of decentralized decision-making is higher in the Scandinavian countries. Furthermore, participating in a public debate about social policy issues does 
not seem to be very common. One group from Chile said that we (the social workers) aren't participating in public policy, we aren't participating in the debate, we aren't lobbying and we aren't supporting with evidence [24]. The other Chilean group asserted that this lack of engagement is a problem and therefore we need social workers with a political view who can influence the policy [23]. The focus group from Argentina said that social workers can involve the professional association and he/she can try to influence public opinion by writing in newspapers [27]. They also emphasized that there is a culture of protest among us but we are not always successful with our claims [27]. This slight difference between Chile and Argentina in the culture of protest is interesting and may indicate some important differences between Chile and Argentina with respect to political awakening. Unfortunately, the focus groups did not elaborate on this difference.

\subsection{Theme 3: Appropriate Principles in Regard to the Delivery of Welfare Benefits and Services}

The third theme was about which principles should be used when the state determines who is entitled to welfare services and benefits. Both Norwegian groups lean towards the universal principle, meaning that all who meet certain criteria will get support (for instance, retirement pension and child allowance) regardless of how rich they may be. They argue that universalism will reduce the problem with stigmatization, which is important. Using universal principles will enhance a conception that welfare support is regarded as a matter of right benefitting everyone and not just a few as a charitable gift from the state. Accordingly, stigmatization in contemporary Norway is probably not very common but if stigmatization happens, we need to work against it [25]. However, there are contemporary political trends that advocate more selectivity and means-testing.

The Norwegian groups argue that the attitudes with respect to the use of principles are dependent on political opinions. If you have a liberalistic or conservative attitude, you will probably be in favor of using the selectivity principle while social-democratic parties are more inclined to prefer universalism [25]. One participant saw the development in a historical light. He argued that in the beginning of the welfare state in Norway, when universalism was initially introduced, many people were poor and there were very few rich. Now few are poor but many more are rich. We are therefore living in a different landscape and what are the implications for the principles we use? [25]. Thus, this fact may have an impact on what kind of principles that have support in public opinion. In earlier times, more people would benefit from solidarity attitudes but today relatively few people are poor, and therefore solidarity values may lose popular support. Solidarity will change from "solidarity between equals" towards "solidarity with the other", and the question will be how this will affect the attitudes to the principles on which we base the welfare system.

The moderator wanted to have the participants' opinion about a growing understanding that the welfare state is too comprehensive and generous, creating conditions in which some people are not motivated to find work. All the Norwegians (as mentioned earlier) are adherents of a comprehensive welfare state built on universalism, but they agreed that it is not certain that welfare benefits always meet the real needs, and they asked, does the welfare state adequately address the people who really need support from the state? They agreed, however, that currently there is more focus on work-approach strategies and the slogan "from welfare to workfare", partly because of a change in political attitudes associated with the change of government. One group talked about the welfare trap, 
and therefore argued strongly that the government is responsible for facilitating work opportunities instead of welfare benefits, thus supporting the "workfare" policy. Without being explicit, they argued that the work approach implies a "contract" between the individual and the society, where the state is obliged to help if help is needed (cash benefits or help to facilitate the possibility of work). This is not new. What is new is a stronger emphasis on the work approach in order to escape the welfare trap. The participants doubt that there is a lot of misuse. One said that my impression is that there are very few who really try to misuse the system [26]. They argue that the recipients first option is all the time to get some work and work for the money Because our self-respect is related to being able to contribute in society. This feeling is important and it is important that social workers do not approach welfare users by saying that you are lazy and not capable of working in the ordinary labor market. They assert that the work approach is important in spite of the fact that the welfare state has not well facilitated work for all especially for handicapped people. They agree, however, that over the last few decades there has been an increase of focus on the work-approach strategy and the slogan "work must pay".

One Chilean group emphasized that "stigmatization" and "deserving" are concepts that are closely related to each other. They can be seen from at least two perspectives. From the perspective of deserving: To deserve it you must show that you are poor, demonstrate that you have been violated in your rights [23]. Another perspective is to see victimizations as a strategy to achieve benefits and services:

So they have to victimize themselves, and this grabs my attention, because I feel that there is a stigma, certainly, but this stigma functions for their benefit. It makes me really mad when people say, "There are the poor, they are accustomed to being dealt handouts" and that this is their strategy [23].

All the informants from Chile agreed that universalism as a fundamental feature with the Chilean welfare system seems to be very rare. Means-testing based on the selectivity principle is much more usual than universalism where categorical and "objective" criteria (without discretionary power from different kinds of gatekeepers) determine who are entitled to services and cash benefits. Thus they argue that the saying poor policies for the poor [23] describes very well the situation in Chile. When it comes to the Argentinean situation, the focus group argued that in social policy the authorities are use a combination of principles and we are constantly debating the boundaries of the universal and selectivity principles [27]. They say that because the selectivity principle in the 1990s was promoted through programs oriented exclusively to the poor sector, it has a rather bad connotation [27]. Therefore, there is a discussion about the principle among professionals as well as politicians.

The focus groups from Chile underscored that the welfare system is built upon two pillars, one aid pillar and one contribution pillar. They argued in favor of universal principles because it will reduce the stigmatization problem, but there seems to be a tendency towards more use of the selectivity principle, and there is constant tension between these pillars. They claimed that the expression "each person is the architect of his own fortune" is well established in society and they asserted that the whole system is based on an idea of conditionality where people in need must meet a series of requirements before getting help. Poverty is accepted and equality gaps are tolerated. Thus 
they argued that the influence from neo-liberalism in the last two generations has made solidarity values difficult to uphold. The rights-based perspective seems to have a difficult future.

\section{Conclusions}

There are substantial differences in the traditions, cultures, policies, economies and welfare systems of Argentina, Chile and Norway. The welfare systems in the two Latin-American countries are family-based and residual, while Norway has a universal and egalitarian system with comprehensive state responsibility for welfare services and benefits. The main finding is that these well-known differences do not seem to have a substantial impact on educators' apprehensions of important issues in social work and social policy, even though the degree of attention to the issues varies. This indicates that being an educator in the same field has an impact on the apprehensions regardless of differing contexts. This does not imply that professional social work is not contextual. "Good" social work practices must always consider the context and environment in which they operate. The point here is that belonging to a profession and teaching in a social work program seems to have a profound impact on the educators' apprehensions regardless of national differences.

The structural differences are, however, associated with some important disparities regarding reflections about future developments. The participants from Argentina and Chile expect a decrease in neo-liberal influence and more public responsibility for welfare problems, whereas the Norwegians, due to political trends, anticipate a reforming of the welfare model with more collaboration from civil sector actors. All the participants in the groups agree that welfare problems mostly have societal causes, and that the public sector should accordingly assume the main responsibility in addressing the issues. The Norwegian groups, however, expect more use of fees and the selectivity principle in welfare deliverance, even though they disagree with such a development. All groups agree that some forms of conditionality are apparent and that there are conditions connected to receiving help from the welfare state. In Norway, the so-called work-approach strategy is prevalent in order to ensure that "work must pay". This strategy presupposes that jobs are available, which is not always the case.

Another difference relates to levels of decision making. Norway has a decentralized structure for decision making, which may bring competence conflicts between the levels of decision-makers; this is not as obvious in a centralized structure as in Argentina and Chile. In the Norwegian context, democratic as well as instrumental arguments are used to justify local decision making in social policy and social work. Transparency, accountability, relevance and adequacy in the service deliverance of welfare policies are supposed to be better when local decision makers and professionals have substantial influence on policy formation and implementation. However, one of the Norwegian groups doubted this understanding when they asserted that "local democracy is advantageous for powerful groups in society". They doubted the value of local discretion and therefore asked for more national direction in local policy and priorities. Besides, local discretion and decision making may promote many difficult dilemmas between conflicting values in social work practices. Two of these dilemmas concern the questions: (1) How much inequality between individuals and municipalities can we accept in the name of local self-governance? (2) How much difference can we accept in the name of cultural diversity? This is an important debate and reflects the controversy between the 
"universal" (human rights values) and the "particular" (recognizing diversity) in social work education and social work practices.

All the groups refer to human rights and the code of ethics for social workers as important guidelines when conflicts arise. The more decentralized the system is, the more obvious the dilemma will be. Accordingly, it makes sense when whistle-blowing is more frequently discussed in the Norwegian context. Both groups, however, call for more use of whistle-blowing if the quality of welfare falls below certain standards or if cultural differences indicate violation of human rights values. The problem seems to be that social workers will experience problems if they blow the whistle, as both Norwegian groups indicated. The professors in the focus groups regard this to be a substantial problem.

\section{Limitations}

This study is not a quantitative study analyzing variables affecting professional comprehensions of core social work and social policy issues. The empirical data does not allow for such analyses. However, the fact that professional attitudes and apprehensions are surprisingly equal indicate that the profession has internalized some values and comprehensions that trumps different national backgrounds and circumstances. This findings needs to be corroborated by more quantitative research.

\section{Acknowledgements}

This study has been made possible through economic support from EU-FP7/IRSES Marie Curie's Actions project. I am grateful to Siv Oltedal for letting me be part of an interesting international social work network and for useful discussions with her. I especially thank Carolina Munoz at Pontificia Universidad Catolica de Chile, Nelly Nucci at Universidad National Cordoba in Argentina and Liv Schjeldrup at university of Stavanger in Norway for helping me to recruit participants for the focus groups. Most of all, I want to thank the participants in the groups who kindly used their time to reflect upon the themes in the vignette.

\section{Conflicts of Interest}

The authors declare no conflict of interest.

\section{References}

1. Gøsta Esping-Andersen. The Three World of Welfare Capitalism. Princeton: Princeton University Press, 1990.

2. Nanna Kildal, and Stein Kuhnle, eds. Normative Foundations of the Welfare State: The Nordic Experience. London: Routledge, 1995.

3. Christopher Pierson. Beyond the Welfare State?: The New Policy and Economy of Welfare. Cambridge: Polity, 2006.

4. Mary Hilson. The Nordic Model: Scandinavia since 1945. London: Reaktion Books, 2008.

5. John Carter, ed. Postmodernity and the Fragmentation of Welfare. London: Routhledge, 1998. 
6. Anthony Giddens, ed. The Global Third Way Debate. Cambridge: Polity, 2001.

7. Anne Lise Fimreite, Yngve Flo, Per Selle, and Tommy Tranvik. "Når sektorbåndene slites. Utfordringer for den norske velferdsmodellen." Tidsskrift for Samfunnsforskning 48 (2007): 165-96.

8. White paper, Meld. St. 12 (2011-2012).

9. Recommendation to the parliament, Innst. 270S (2011-2012).

10. Rolv Lyngstad. "Contextual social work and internationalizing social work education: Two sides of the same story?” Journal of Social Work 13 (2012): 400-18.

11. Paul Spicker. Social Policy: Themes and Approaches. Cambridge: Policy Press, 2008.

12. Thomas H. Marshall. Class, Citizenship and Social Development. Chicago: University Press, 1964.

13. Neil Gilbert. Transformation of the Welfare State: The Silent Surrender of Public Responsibility. Oxford: University Press, 2002.

14. Santiago Levy, and Norbert Schady. "Latin America's Social Policy Challenge: Education, Social Insurance, Redistribution.” Journal of Economic Perspectives 27 (2013): 193-218.

15. Cristian Aspalter. "The development of ideal-typical welfare regime theory." International Social Work 54 (2011): 735-50.

16. Jennifer Pribble. "Worlds Apart: Social Policy Regimes in Latin America." Studies in Comparative International Development 46 (2011): 191-216.

17. Juliana Martinez, Maxine Molyneux, and Diego Sánchez-Ancochea. "Latin American capitalism: Economy and social policy in transition." Economy and Society 38 (2009): 1-16.

18. Central Intelligence Agency. "The World Factbook." Available online: https://www.cia.gov/ library/publications/the-world-factbook/fields/2212.html\#228 (accessed on 17 March 2015).

19. Statistics Norway. 2014. Available online: http://www.ssb.no/offentlig-sektor/artikler-ogpublikasjoner/offentlig-forvaltning-storrelse (assessed on 19 March 2015).

20. Tom Wilks. "The Use of Vignettes in Qualitative Research into Social Values." Qualitative Social Work 3 (2004): 78-87.

21. Sharlene Nagy Hesse-Biber, and Patricia Leavy. The Practice of Qualitative Research. London: Sage, 2011.

22. Nancy E. Schoenberg, and Hege Ravdal. "Using vignettes in awareness and attitudinal research." International Journal of Social Research Methodology 3 (2000): 63-74.

23. Anonymous. Pontificia Universidad Catolica de Chile, Santiago, Chile. Focus-group interview 3, 2013.

24. Anonymous. Pontificia Universidad Catolica de Chile, Santiago, Chile. Focus-group interview 2, 2013.

25. Anonymous. University of Nordland, Bodø, Norway. Focus-group interview 1, 2013.

26. Anonymous. University of Stavanger, Stavanger, Norway. Focus-group interview 4, 2013.

27. Anonymous. Universidad National de Cordoba, Cordoba, Argentina. Focus-group interview $5,2014$. 


\title{
"Como Arrancar una Planta": Women's Reflections about Influences of Im/Migration on Their Everyday Lives and Health in Mexico
}

\author{
Eva K. Robertson
}

\begin{abstract}
The aim of this study is to analyze women's reflections about how experiences of $\mathrm{im} /$ migration from rural to urban settings in Monterrey, Mexico, influence their everyday life experience and health and that of their families. The participants were eight women from heterogeneous indigenous backgrounds, one woman with a mestizo background, two health professionals, three persons from organizations supporting indigenous groups, and two researchers. I collected data from personal observations, documents, and interviews that I then analyzed with a critical ethnography methodology developed by Carspecken. The women emphasized that food habits were the first to be adapted to circumstances in an urban everyday life constrained by working conditions. Together with their experiences of discrimination and violence, urban living determines the challenges and the priorities of daily life. Urban life affects how they perceive and treat their own and their family's health and wellbeing. Nevertheless, their sense of belonging and home remains in their communities of origin, and they strive to reach a balance in their lives and preserve a connection to their roots, motherhood, and traditional knowledge. However, the women handle their im/migration experiences in diverse ways depending on their own conditions and the structural forces limiting or allowing them to act in decisive life situations. Im/migration is not just a matter of choice; it is about survival and is influenced by social determinants and "structural vulnerability" that influences and/or limit human agency. These, together with an unsustainable economic situation, make migration the only option, a forced decision within households. Structural forces such as social injustice in welfare policies restrict human rights and rights for health. Social determinants of health can constrain decision making and frame choices concerning health and childbearing in everyday life.
\end{abstract}

Reprinted from Soc. Sci. Cite as: Robertson, E.K. "Como Arrancar una Planta”: Women's Reflections about Influences of Im/Migration on Their Everyday Lives and Health in Mexico. Soc. Sci. 2015, 4, $294-312$.

\section{Introduction}

Migration has always been a part of the lives of human beings. War, persecution, climate conditions, and economic hardship have forced people to move across the globe, in search of improved living conditions and a better future for their children. Migration movements are a life process affecting the agency of the displaced for several generations, both in the new country and the country of origin [1]. Inherent to migration and resettlement are the adversity and constraints of daily life. These struggles lead to several disparate experiences that influence the agency, initiatives, and decisions of the displaced. Consequently, the migrant is forced to live in a state of limbo, in between different realities $[2,3]$. 
Several researchers caution against using the terms "migrant" (movement that is temporary, seasonal and/or circular) and "immigrant" (uni-directionality and permanence) interchangeably, as they are not synonymous [4-6]. Although these terms are intended as neutral descriptions of groups or individuals in policy papers and research, it is often not the choice of an individual or group to attain migrant or immigrant status; instead, they are at the mercy of local authorities with the power to enforce immigration policies. To acknowledge the shifting and illusory nature of the distinction between migrant and immigrant, the open-ended term "im/migrant" has been created [4-6], and will accordingly be used in this study.

All over the world, indigenous people are exposed to extreme poverty, marginalization, discrimination, and conflict. Their traditional lands are threatened and they are forced into dispossession. In addition, their belief systems, cultures, languages, and ways of life continue to be threatened, sometimes even by extinction. Because of the persistence of stereotypes regarding indigenous peoples, in urban areas, they often become an almost invisible population, living in informal, sometimes overcrowded settlements with other poor people [7]. In Latin America, 34 million indigenous people (8 percent of the total population) live in severe poverty [8].

Indigenous populations in Mexico have their roots and traditions grounded in culturally advanced civilizations, going back 2000 years. The ancient population, thought to be as high as 20 million at the time of the conquest in 1519, was decimated to approximately two million a century later through the destruction of socioeconomic structures and the importation of European diseases. The introduction of mining and cattle ranching - a system of forced wage labor - contributed to the dismantling of socioeconomic structures. Furthermore, indigenous people were tricked into debt-bondage and became virtual slaves under the hacienda system. After the revolution of 1910-1920 that left Mexico in chaos, indigenous rights were still ignored. They were encouraged to become "Mexican". Mexico's indigenous groups/individuals found themselves at the bottom of the social order of the mixed Mexican population, whereby approximately 60 percent are mestizos, i.e., of mixed Spanish and indigenous descent. Together with those poor mestizos, they suffer from a land shortage that has forced many to become low-paid agricultural laborers and to migrate. There have been many reports of human rights violations against communities, with political killings, detention, "disappearances", and torture of indigenous people for defending their land rights [9].

In Mexico, there are 15.7 million people considered indigenous, of which 6.9 million speak one indigenous language (about 65 languages recognized by the authorities). There are also 9.1 million people who see themselves as ethnic indigenous although they do not speak their mother tongue. Of those that have an indigenous mother tongue, 15.9 percent do not speak Spanish [10]. The poverty rate at 90 percent among indigenous people in Mexico (in 1980) has remained consistently high (in 2000), without showing any signs of diminishing [8]. Poverty is 3.3 times higher in Mexico among indigenous people than the rest of the population [11].

A national survey on discrimination in Mexico in rural and urban areas found that when indigenous people were asked which of their rights most needed to be respected, the right to justice (17.6\%) came first, while the right to education came seventh (4.6\%), and the right to a decent job came eighth $(3.8 \%)$. To the question of how to eliminate discrimination against them, they answered 
that society should create work opportunities (17\%) and provide education for indigenous people $(15.5 \%)[12]$.

Health challenges include illnesses from pesticides in agroindustrial cultivation and extractive industries, malnutrition, diabetes, HIV/AIDS, and mental health issues such as depression, substance abuse and suicide $[9,13]$. Health challenges faced by indigenous peoples stem from the neoliberal policies and economic markets hitting local production, the contamination and depletion of their land and natural resources, and from forced displacement from their territories [9].

In healthcare and public health research, the focus is placed on the personal responsibility for our health and lifestyle without considering the social determinants of health. Social determinants include socio-economic circumstances and support, physical circumstances such as working conditions and environment, healthy child development, one's individual capacities including education and health practices, but also the whims of those in power and whether or not they are vested in research and health service, which is ultimately influenced by policies, commercialization of everyday life through local and global economies, and sociocultural norms [14,15]. Several researchers have shown that the context of our living conditions in terms of social injustice as well as socio-cultural, gender and socioeconomic status (SES) is decisive for our health and lifestyle [16-18]. Despite this knowledge and the complex causality, im/migrants are often subverted by cultural stereotypes and blamed for their social and health situations [6]. The voices of minorities and im/migrants are often left out, or homogenized, thereby hindering a deeper understanding of their priorities, decisions and agency. However, different indigenous groups in Mexico are organizing themselves, or with support from organizations, to reclaim their rights. Internationally, already in 1985, work started on the drafting of a declaration on the rights of indigenous peoples. It took until 2007 for the General Assembly of the United Nations to adopt the Declaration on the Rights of Indigenous Peoples [19]. It was an important step forward for the recognition, promotion and protection of the rights and freedom of indigenous peoples.

Health in traditional medicine of indigenous people can be seen as grounded in a struggle for harmonious and balanced coexistence of human beings, intertwined with nature, themselves, and others. It includes an integral wellbeing, manifested by spiritual, individual, and social wholeness and equilibrium. A barrier stated in a document from PAN American Health Organization (PAHO) is the attitudes and inability of the health systems to incorporate practices from both traditional and biomedical medicine, thereby limiting possible choices and creating a polarization between the two systems [17]. However, medical pluralism has been a major characteristic of Mexican healthcare, despite the state having given pre-eminence to biomedical medicine. Certain systems of traditional medicine and homeopathy have had some limited federal and state support, but the diversity of medical options available is not known [20]. Medical pluralism means coexistence of multiple systems of medicine, such as folk, popular, and traditional systems. Currently, however, we have limited knowledge on how different therapeutic modalities relate to each other [21]. Nevertheless, indigenous healing traditions or practitioners as well as other alternative medicines are heterogeneous; they are dependent on individual skill, and ethical approach, and can be marked by power and inequalities in gender, rank, and age. 
The aim of the present study was to analyze women's reflections on how their experiences of migration from rural to urban settings in Monterrey, Mexico influenced their everyday life, their own health, and the health of their families.

\section{Method}

This project and study is part of an international research exchange program, "Understanding and Supporting Families with Complex Needs", that seeks to address a recognized deficit in family-focused research by developing links between divergent disciplines and knowledge streams, both nationally and internationally.

In this study, critical qualitative research (CQR) was chosen as the methodological approach to deepen the understanding of how women reflect on their experience of how migration influences their health and the health of their families. CQR seeks to understand the relationship of culture to social structures since, despite going largely unnoticed, they influence how they act [22]. In addition to health promotion, CQR has the goal of attaining emancipation and can be a useful approach when investigating everyday experiences of health and social wellbeing that are produced and reproduced in a sociocultural context [19].

CQR is often referred to as critical ethnography and addresses the two social-theoretical domains that are analytically distinct from each other: lived culture vs. social system [22]. It articulates the subtle and overtly oppressive structures in society and confronts these structures on such grounds as racism, sexism and classism to enable all to take part in unhindered citizenship [23]. In this study, I have used the methodological approach of Carspecken [24] that underlines knowledge as intersubjective and formed within social relations involving power [22].

\subsection{Participants and Data Collection}

Participants were voluntarily recruited through non-governmental organizations (NGOs) supporting im/migrants in Monterrey, Nuevo Leon, Mexico. I was first told that the im/migrant women were generally reluctant to participate in interviews. However, they had requested in the NGO workshops some midwifery knowledge. When I informed them about my long experience as a professional midwife working with women im/migrating to Sweden, they invited me to participate in two workshops that focused on sexual and reproductive health. At the end of the workshops, I told them about my project and several women volunteered to participate; however, due to local celebrations in their communities of origin together with Christmas/New Year and school vacation, several women were travelling and, in the end, only six women were able to participate. Through the snowball method, two women who had participated in earlier workshops and recently volunteered in the organization to support women were included to participate in the study. Another woman with $\mathrm{im} /$ migrant experiences was recruited directly at the appointment for the interview when it became clear she had a mestizo background. The interview was very rich and enlightening and thus included in the study.

Furthermore, I interviewed three persons from NGOs supporting migrants in Monterrey. I also interviewed two researchers, one at the university and another in a research center. These interviews 
helped me with background material such as documents, reports, and up-to-date research for this study that I used in the first phase of analysis [24]. I visited and made observations in a health center and a public school in a suburb of Monterrey and interviewed a general practitioner. Because the women had been requesting information about midwifery, I wanted to learn more about the situation for midwives in Mexican society and thus chose to visit a maternity center connected with a midwifery school in a small town, one of the few officially recognized and approved educational institutes for midwives in Mexico. The school prioritizes students from rural areas with mothers or grandmothers who are traditional midwives in order to integrate a biomedical knowledge base, from a midwifery perspective, with the traditional (organic) knowledge of childbirth. There, I interviewed a (professional) midwife that started her career as a traditional midwife and worked both as a midwife in the maternity center and as a lecturer.

The participating women were informed about the purpose of this study and its strict confidentiality. They were subsequently assured that their identities would remain secret. They were enrolled and gave their written consent with adequate permissions [25]. In total, 16 interviews were performed (from November 2013 to January 2014). Eight women with self-defined, heterogeneous indigenous backgrounds (Mixteco, Masahua, Otomí, Nahuatl) and one woman with a mestizo background participated (interviews 1-9). Their communities of origin were in the states of Veracruz, San Lois Potosi, Puebla and Oaxaca. In addition, three staff members from non-governmental organizations supporting indigenous groups (interviews 10-12), two healthcare professionals (interviews 13-14), and two researchers were interviewed (interviews 15-16). The women volunteered themselves and were not selected purposely. The focus of this study was not a specific individual's characteristics or those of indigenous groups; rather, the focus was to understand the female experience of $\mathrm{im} /$ migration from rural areas to urban settings. I conducted all interviews in Spanish; I audiotaped and transcribed all interviews with the women's permission. In addition to the interviews, I used participant observation during eight weeks while I visited families in suburbs for the workshops, went to the health center, schools, and university, and attended seminars and meetings for the non-governmental organizations for im/migrant women. I spent some Sundays at Plaza Alameda observing and talking to people, and visited markets where women/families were selling handicrafts or other goods and came into conversation with some of them. I also read documents and research and governmental reports resulting in a huge amount of material that I analyzed with the CQR methodology developed by Carspecken [24].

The interviews lasted about one hour each and the women decided on the setting, either in their homes or in an undisturbed room in the support organization. The open-ended questions I used in interviews were: “Tell me about your and your family's experiences of migration", followed by “Tell me about how your and your family's health is impacted by migration in everyday life and childbearing". For the participants working with the organizations, and the physicians, midwives and researchers, the question was modified to "Tell me how migration experiences from rural areas to urban (Monterrey) influences women's and their families' health in everyday life and childbearing". Follow-up questions were used: "What do you mean?" and "Can you give me an example?" 


\subsection{Data Analysis}

Carspecken's (1996) five-stage structure for conducting CQR captures two methodological, orientations: the cultural conditions interpretive that captures the insider's position, and the functional methodology to represent the outsider's position [22]. Carspecken's methodological theory of critical ethnography contains five stages: observation and description; analysis of these data; dialogical data generation; analysis of these data to discover relationships between individuals, groups and systems; and examining findings in relation to existing theories of society $[23,26]$. See Table 1 for an outline of the analysis.

Please note that the analysis in the monological, dialogical and theoretical stages is not presented in the findings as separate entities; the stages have been combined into one [22].

Table 1. An outline of the data analysis.

\begin{tabular}{|c|c|c|}
\hline Stage Description & Data Collection & Example of Analysis \\
\hline $\begin{array}{l}\text { 1. Observation and } \\
\text { description from an (etic) } \\
\text { outsider perspective } \\
\text { Fieldwork: nonparticipant } \\
\text { observer, monological, } \\
\text { unobtrusive, reflection }\end{array}$ & $\begin{array}{l}\text { - Searching and collecting } \\
\text { information and documents } \\
\text { about system and situations } \\
\text { of im/migrants in Monterrey } \\
\text { from rural areas; } \\
\text { - Establishing contacts } \\
\text { through organizations that } \\
\text { support women; } \\
\text { - Observations }\end{array}$ & $\begin{array}{l}\text { Field notes when collecting data through } \\
\text { observations made at: } \\
\text { - health centers } \\
\text { - a birth center } \\
\text { - schools } \\
\text { - } \text { seminars } \\
\text { - } \text { workshops for im/migrant women, } \\
\text { - participants' homes } \\
\text { - } \text { organizations } \\
\text { - markets } \\
\text { - when traveling by bus and subway to the suburbs } \\
\text { - engaging in informal chats with people } \\
\text { - recollecting and reading documents, reports, } \\
\text { research }\end{array}$ \\
\hline $\begin{array}{l}\text { Perspective analysis of } \\
\text { observational data }\end{array}$ & $\begin{array}{l}\text { - Preliminary reconstructive } \\
\text { analysis; } \\
\text { - Monological }\end{array}$ & $\begin{array}{l}\text { Analysis of the field notes from all observations } \\
\text { (achieved experiences) and documents beginning with } \\
\text { a description of the sociocultural context through key } \\
\text { issues (meaning units and forming initial categories } \\
\text { that are further explored in step 4). }\end{array}$ \\
\hline $\begin{array}{l}\text { 3. Dialogical (emic) } \\
\text { data generation, } \\
\text { collaborative stage }\end{array}$ & $\begin{array}{l}\text { Fieldwork: participant } \\
\text { observer, interactive, } \\
\text { interviews, reflection }\end{array}$ & $\begin{array}{l}\text { In-depth interviews with the } 16 \text { participants using a } \\
\text { dialogical approach aiming to understand the } \\
\text { insider's (emic) position. After listening to the } \\
\text { interviews, together with notes, I came back to some } \\
\text { participants with follow-up questions. Reflexivity } \\
\text { was an essential part of the research process. }\end{array}$ \\
\hline
\end{tabular}


Table 1. Cont.

\begin{tabular}{|c|c|c|}
\hline Stage Description & Data Collection & Example of Analysis \\
\hline $\begin{array}{l}\text { 4. Describes systems } \\
\text { relations to broader } \\
\text { context } \\
\text { Analysis to discover } \\
\text { relationships between } \\
\text { individuals, groups, } \\
\text { and systems }\end{array}$ & $\begin{array}{l}\text { - Conducting systems analysis } \\
\text { between locales/sites/cultures } \\
\text { (discovery); } \\
\text { - Dialogical }\end{array}$ & $\begin{array}{l}\text { Analysis and synthesis of the interviews. I read all } \\
\text { interviews to catch the whole, coding and taking } \\
\text { out meaning units, while preserving the core of the } \\
\text { text and involved back-and-forth movements } \\
\text { between the whole text, the codes, and the } \\
\text { categories. Then I revisited the material from stage } \\
1 \text { and } 2 \text {, in light of the new understanding, moving } \\
\text { between the understanding gained in the } \\
\text { interviews( insider/emic perspective) and through } \\
\text { the documents and observations (outsider/etic } \\
\text { perspective) through reflections to deepen my } \\
\text { understanding and developing categories/themes }\end{array}$ \\
\hline $\begin{array}{l}\text { 5. Explains relational } \\
\text { systems examining } \\
\text { findings in relation to } \\
\text { existing theories of society }\end{array}$ & $\begin{array}{l}\text { - Links findings to existing } \\
\text { macro-level theories } \\
\text { (explanation); } \\
\text { - Theoretical }\end{array}$ & $\begin{array}{l}\text { The deepened understanding I linked to a broader } \\
\text { context using theoretical approaches and concepts } \\
\text { such as structural vulnerability, decision-making } \\
\text { agency, social determinants of health, embodiment, } \\
\text { and health rights, to discover connections and } \\
\text { patterns between social discourses applied in the } \\
\text { context of everyday life of the interviewed } \\
\text { participants' experiences. }\end{array}$ \\
\hline
\end{tabular}

\section{Findings}

\section{1. "Como Arrancar una Planta" (like Transplanting a Plant)}

The plant analogy, as expressed by one interviewee, well illustrates the findings of this study. When a plant (a person, group) is going to be replanted (im/migration), the environment is decisive (the context) for its survival and growth (to get light, sun, fresh air, water, nutrition, but also suitable climate). There are distinct similarities between this metaphor of transplantation and the common themes brought up in the interviews: (1) The art of feeding versus the easy choice of fast food; (2) Im/migration can both split and reunify families; (3) Im/migration implies difficult and unregulated working conditions; (4) "Health matters as a medical question". In addition, to continue with the plant imagery, when moving a plant, it is crucial to keep the roots in the original soil to avoid challenging or subverting future growth (takes longer time to set root and start growing again when the roots are removed without the original soil). This imagery is exemplified through the categories: (5) Violence is everywhere, hitting women in rural and in urban life; (6) Health as part of a whole-life context; and (7) "Sense of belonging means 'to survive' versus 'being alive' in everyday life". Furthermore, often bigger plants (older people) take a longer time to-or actually never recover from - the displacement, whereas tinier or younger plants (younger generation) can more easily set roots and adapt to the new environment. These categories will be further developed below. 


\subsection{The Art of Feeding versus the Easy Choice of Fast Food}

The women stressed that their food habits were the first tangible adaptation to the living circumstances and working conditions in everyday life in urban settings. The women underlined that "fast food is not a healthy choice" (interview 5). Furthermore, some women reported that clean water has become a luxury; water from pipes tastes bad and therefore they often substitute it with sweetened soft drinks, coffee, or chocolate. They also stressed that everyday life means long and exhausting workdays and a host of responsibilities that need to be prioritized. The cheap, fried fast food is thus an easy choice, being both convenient and easily accessible. To keep the traditional healthy food habits in the new urban area, one must travel long distances to the market and cover the cost of transportation; the women explained that they lack the time for proper food preparation and have limited food storage and cooking facilities. A woman stated: "Fast food and soft drinks are everywhere, even in the most remote rural areas" (interview 9). The women mentioned that fast and junk food and soft drink consumption is connected with modern life and is, in reality, also an issue in rural areas where people need to work outside their communities. Nevertheless, when living together with the older generation, it is easier to maintain traditional food habits even after $\mathrm{im} /$ migration as the elder generation is stricter and more concerned with preparing and eating traditional foods.

The erosion of traditional food systems and decreased food security has led to an increasing reliance on imported processed foods that have little nutritional value and are often high in sodium and fat, causing obesity and diabetes [27]. Heavy marketing has increased consumption of sugar-sweetened beverages worldwide, particularly in low- and middle-income countries [28]. This is currently a major challenge for public health authorities and, in Mexico, the levels of sugar-sweetened beverage intake have never been recorded as higher in a nationally representative survey among adolescents and adults [29]. There is a clear link in science between sugar-sweetened beverage consumption and the risk of chronic diseases. Escalating healthcare costs and the rising burden of diseases related to poor diet create an urgent need for solutions and political action [30].

\subsection{Im/Migration Can Both Split and Reunify Families}

Some of the women detailed how they live together with extended family and former neighbors from their communities of origin. Parents who work as itinerant traders left their children with their extended family, thus helping each other in everyday life. A woman stated: "When I was a kid our parents went away trading and we took care of each other, it was a funny childhood and we were very independent" (interview 7). In addition, living in such "congregates" made it easier to preserve food habits, the mother tongue and traditions, and even their festivals. Other women mentioned that they and their partners rented a room in houses comprised of people from different indigenous or mestizo backgrounds, from several different states and communities of origin, thus necessitating Spanish as a common language. One woman commented: "We try to help each other with the children, although it is not the same as your family" (interview 5).

Some women said that they hardly knew their mother tongue, as their parents saw it more as a burden, and did not see any value in transferring it to them. Other parents consciously (or because of 
necessity) left their children for some years with their grandparents in their community of origin to learn their mother tongue. However, some women stressed that these children often had problems in school when returning to urban areas because of a lack of adequate Spanish. Teachers are evidently still punishing children when they do not speak Spanish. The women also highlighted bullying as a severe problem for children with indigenous backgrounds in school. A woman emphasized: "When a schoolmate did not speak much Spanish but English after some years in the US, she was never punished, contrary to other children that spoke their mother tongue in school...how can knowledge of different languages be so differently valued?'(interview 6). Nevertheless, all the interviewed women underlined the importance of education for their children, and some were sorry for that they did not have that possibility for themselves earlier in life.

Indigenous children drop out of school much earlier than non-indigenous children to look for work. Illiteracy rates among the urban indigenous population are four times higher than rates for non-indigenous people living in cities. This systematically leads to low-paid, low-skilled employment [9,31].

The interviewed women stressed that the contact with their family/relatives in the community of origin is important but there are barriers. These barriers include the high costs of traveling and short vacation time, if there is any at all. As a result, only a few members of the family travel, often just the mother and children. Several women emphasized the yearly obligations of collective work in communities of origin. It creates conflicts and deters im/migrants from travelling to their communities or, even worse, to be rejected as comuneros.

As stated by Mutersbaugh: "Migration may disrupt or enhance village involvement in regional development networks, and, since these networks provide an important source of village income for both family and collective consumption, stay-at-homes may be adversely affected" ([32], p. 490). The agency of im/migrants is complex and they need to include this contradictory impact on their family versus the community of origin in their decisions to migrate [32].

\subsection{Im/Migration Implies Hard and Unregulated Working Conditions}

Several of the women narrated that they had migrated as teenagers (14-16 years old) to work as a housemaid, living "inside" with Sundays off. Some of them left in accordance with their family to support and send money home, others to gain a certain (economic) independence. On Sundays, they met at a central square, "Parque Alameda" with friends, cousins, or other family members from their home state or communities. Many met boyfriends there, getting pregnant young and therefore starting family life early or becoming a single mother. The women's ability to take care of their child depended on their economic situation. Available alternatives to women were to either leave the child with the grandparents in their community-of-origin, providing financial support (a common solution not only for single mothers), or to give the child up for adoption. One woman told me, “...my mother left me when I was seven with an earlier employer to raise me and get education, I even called her mother" (interview 2).

Jobs in domestic services or working as a housemaid was what was most commonly available to young women from indigenous families. They were often left without any rights, and provision of benefits was left up to the goodwill of the employer [33]. One of the interviewed researchers 
(interview 15) emphasized studies that illuminated the unregulated working conditions and how important it is for domestic workers to achieve access to employee benefits including performance rewards, social security, and safe conditions at work [12,33].

Several of the interviewed women stressed that they are worried about their male partners due to their hard working conditions. The men work six days a week, often more than 12 hour shifts, and were exhausted during their days off, either staying in bed sleeping or consuming alcohol to be able to relax. A woman stated: "I hardly speak with my husband, either he is working or on his day off he is drinking beer with peers and sleeping" (interview 2).

One of the interviewed researchers (interview 16) stressed that many im/migrants have problems with documents when they work in unofficial sectors. To transfer documents from their community of origin is complicated and costly, but without documents, they have no legal rights in Monterrey. In a study of working conditions, it was shown that among people with indigenous origin, 68.2 percent have no health insurance, 80 percent no vocational rights, and 78.3 no retirement savings [10]. Finkler (1997) underlines the position of immense disadvantage endured by poor men with low or basic education (three years), their hard working conditions, and the daily discrimination they face in Mexico [34].

\subsection{Violence Is Everywhere and Affecting Women in both Rural and Urban Life}

Women mentioned the physical violence in family, inter-partner violence both in communities of origin and urban settings. They emphasized that most violence is connected with alcohol consumption among men that affects the whole family. Some women stressed that the physical violence is worse in rural areas, as people live in more isolated situations, far from neighbors where anybody can hear or know when women are being beaten. A woman said '...in my 'rancho' it was 'natural' with fights among adults and couples...the life was much more physical bodily expressed in all sentence" (interview 8) Some women believed that, in urban settings, when people live close to each other, it acts as a sort of barrier to physical violence. Others, however, insisted it resulted in more threats, impedance, silence, ignorance and devaluation. A woman detailed: "My sister and I interfered and questioned our father when he mistreated our mother. First he got angry and argued but we told him about the laws, that he was not allowed to mistreat our mother. Then he became ashamed and it made him change as he recognized and felt embarrassed for his behavior and manners. The relations in our family got much better and my mother dared to talk and give her opinions" (interview 7). Nevertheless, the women mentioned gender roles as varying in different indigenous populations; there are some communities and groups wherein women have a great deal of power and influence in both family economy and community matters. A woman stated: "My mother was the one that ruled the commerce and trading, she travelled a lot and had the main responsibility of income. Meanwhile, my father was taking care of us children and the house" (interview 8). For others, and occurring more frequently in Mexican society, the men rule and decide nearly everything outside the household. A woman declared a common utterance: "tengo los pantalones entonces es yo que mando" ("I rule as I wear the trousers") (interview 4).

In addition, the inter-partner violence is directly correlated with the exploitation of disadvantaged men. Alcohol consumption combined with working conditions that are hard to bear causes them to 
lash out. Some men feel they can at least retain their self-esteem at home where they are in command and can subordinate their women with beatings [34]. The effect of physical coercions on one's health is cumulative; the insult, moreover, is internalized on many levels, resulting in increased sickness [34]. In the NGOs (Zihuame and Zihuakali in Monterrey, interviews 10-11) that support $\mathrm{im} /$ migrant women, workshops are given concerning general health matters, sexual and reproductive health, and violence (combined with practical work and handicrafts). These workshops also involve interactive discussions about rights and laws in society to create awareness, agency, and support among the women [33].

Some women in their interviews stressed the influence of violence and machismo in Mexican society, which limit their everyday life and make them tense. In a visit to "casa de immigrantes" the personnel told me stories about persons that had succeeded to escape after being kidnapped close to the U.S. border and were forced to participate in violent actions. Others were kept as slaves, threatened with death. Violence has been impregnated strongly into Mexican society over the centuries and is also expressed through human rights violations against indigenous communities. Over the last few decades, the violence has escalated with organized crime and a corrupt police corps resulting in ad hoc violence throughout society, leading to insecurity, abuse and people being killed on the street or kidnapped and tortured [12,35]. Of the several states of Mexico, Oaxaca and Chiapas (where some of the im/migrants in Monterrey have their origin), have more documented political killings, detention, "disappearances", and torture of indigenous people for defending their land rights $[9,35]$. Indigenous people have experienced a collective history of different forms of violent forces that persist today in the form of development aggression, war, forced displacement and economic exploitation, thereby leading to high rates of distress and mental health problems [36].

\subsection{Health Matters as a Medical Question}

All women reflected on how life in urban settings made them change the way they treat themselves, their children, and their family's health. Some women mentioned that they went to different health centers (could be state, organizational or implemented by programs) when they needed assistance regarding their own or their children's health. Some women stressed that they were welcomed into these centers and were overall treated well. Nevertheless, the same women expressed worries about their children, who are steadily affected by infections and coughs in wintertime due to air drafts in their poorly insulated houses (the children had to wear jackets indoors), as well as air pollution. A woman said: "I am worried about the effect of the medicines, it is as my child always needs stronger medicine to get rid of the infections, I am worried that she gets like addicted...now it never is enough with just something for fever" (interview 1). However, she did not find it possible to voice these concerns during the health encounters: "There is no time and space for such questions" (interview 1). Barriers exist even when there is full access to biomedical (Western) healthcare, due to lack of communication skills and understanding of social and cultural factors [37].

The interviewed women also mentioned experiences of discrimination in their exchanges with local authorities, school figures, and healthcare practitioners. They experienced being ignored or neglected and many reflected that they had to assimilate and keep quiet to survive. Some women explained that they avoid health centers as they had already experienced ignorance and mistreatment. 
A woman mentioned that when her second baby was four months old, she was strongly advised to stop breastfeeding because her milk was just water, harming the child and putting him at risk of malnutrition. She said "One gets confused and worried - my first child I breastfed until he was two years without any growth problem" (interview 3). The distrust made them search particular physicians and pay to get better care when needed. For example, a woman mentioned how "in healthcare settings my mother always pretends not being able to understand Spanish. It is the only way for me to be permitted to accompany her in the medical consultation as my mother otherwise fears inadequate care or mistreatment" (interview 8). Several women came to distrust healthcare after experiences of mistreatment. An example that many of the interviewed women gave was cases of sterilization without a consent. They recounted how sterilization was commonly used and performed at the time of childbirth by caesarean section in the hospitals. It is also documented in the literature, which states that proper information before or consent to is not always given due to communication failures and ignorance [38]. On the other hand, the interviewed physician stated that: "People do not value their health more than any material... Unfortunately, most people in the city do not make any effort to take care of their health, because of lack of knowledge and education" (interview 13). Furthermore, the physician stated that even if healthcare professionals made huge efforts to inform people, they do not seem to care or take in the information. The physician questioned how people deal with emotions as they seem to be very distanced. The physician recounted the example of an initiative for a women's support group for victims of violence. Because it achieved no recognition in the health organization, when there was a lack of resources and budgeting concerns, the program was cut. Furthermore, the physician underlined that, sadly, there is ignorance among people towards their health, and stressed that it is also a huge problem that needs to be further investigated.

These concerns of the physician corroborates what is asserted by Quesada: "the conventional biomedical paradigm largely fails to translate the documentation of social forces into everyday practice and epistemology" ([39], p. 341). It is grounded in an approach where the imaginary gaze defines "the other" without giving space or listening to their voices. The medical experts value/diagnose people's symptoms and their health situation in a way that masks the multiple dimensions of social inequality at both structural and individual levels $[2,40]$. For example, when the professionals communicate during healthcare encounters with patients, they always start from their own perception of the situation by asking the question: "What do we see the person needing?" Carrying out the consultation from this (limited) "first imagined" knowledge professionals overlook "the other", objectifying and defining that person. The question that should be asked first is: "What does this person see herself needing?" Full attention should be given to finding the answer. The question cannot be answered with the professional's own concepts, for that would imply that they introduce their own perceptions/view to their actions (Spradley and McCurdy 1972, in [41]).

\subsection{Health as Part of a Whole-Life Context}

Several women discussed their traditional way of perceiving health as part of a whole-life context. They explained that their health interrelates with nature and the environment. Health is embodied and intertwined with their traditions, stories, customs, and values. Knowledge among elderly 
generations is transferred (orally and embodied) to the next generation through storytelling, myths, wisdom, traditional treatments with herbs, and healing. This is presently more difficult because $\mathrm{im} /$ migration means less contact with elderly generations; a great deal of traditional knowledge and medicine is not only lost, but is disrespected and threatened in modern society. An example the women stressed is the fact that there are hardly any midwives left. The interviewed midwife (who has both a professional and traditional background) explained: “...the most knowledgeable midwives are they who learned since they were young from their mother or grandmother: they have accumulated knowledge from generations and they were well-known and trusted in the communities..." (interview 14). She continued by saying the care offered to women included dietary advice, herbs and massage (sobada) throughout the pregnancy and support during childbirth with their family around them. A study shows that most traditional knowledge and medicine are treated as superstitious, redefined as dangerous, devalued, repressed and even prohibited by the medical authorities and health system [38]. Nevertheless, all the interviewed women and the midwife underlined the importance of medical advances, knowledge and treatments.

All women complained about how they were treated in hospitals and health centers during pregnancy and childbirth; often they were met with distrust and ignorance, left alone, ignored even when begging or crying for support, and were not allowed to be accompanied by a family member. Many women spoke about complications and instrumental childbirth such as caesarean sections. A woman recounted: "...when my second child was born in the hospital, nobody came when I cried that I had to push and needed assistance. The baby was born when I was alone and it took a while before he cried. Afterwards when I complained, the physician blamed me for what happened" (interview 3). A study concludes that when women experienced barriers in healthcare and felt discriminated against, they became more tense, insecure and frustrated. When they were "taken seriously", however, they felt well cared for and they recognized their capabilities and embodied knowledge, boosting their sense of self [2].

The interviewed midwife argued that: "it is a constant effort to get acceptance for facilitating normal physiological birth in the healthcare system" (interview 14). In Mexico, there is an insufficient number of midwifery schools. Those that exist are plagued by a strained financial situation, thereby limiting the ability to train midwives who could then live and stay in remote rural areas to support women, and to select and send the women that need more advanced medical assistance in pregnancy or childbirth to nearest medical center/hospital $[42,43]$. Because the majority of indigenous women lives in remote rural areas, four out of 10 do not have access to healthcare during pregnancy and childbirth [12]. It is an oppression of poor and indigenous women, a burden of "triple jeopardy"-ethnicity, socio-economic-status (SES) and gender [44,45]. Siegel investigated in her study how when the medical authorities were retraining (educating and transforming) traditional midwives, they would suppress, ignore and devalue the knowledge they brought in with them. The biomedical perspective was taken for granted; their way of treating childbirth was the right and only way. Everything else was prohibited [38], thus presenting a paradox: as in several countries in the world women are fighting to regain the knowledge about natural physiological childbirth that has been lost. In addition, there is increasing evidence illuminating the consequences of iatrogenic effects of intervention without cause in childbirth $[38,42]$. 


\subsection{Sense of Belonging Means to "Survive" versus "Being Alive" in Everyday Life}

The women stressed that the most common reason to migrate was purely economical; these were decisions made by the family in hopes of a better income and future outside of the community of origin. A woman recounted: "My parents told us they had no alternative, no other option. They wanted to give us, their children, opportunities to get an education and a better life" (interview 7). However, they declared that migration is felt as a loss, as a necessity to survive and as a sacrifice that hurts. A woman mentioned that she is depressed and has difficulties coping with urban life, which she perceives as stuffy and restrictive. Some women reflected about (young) im/migrants "losing the face", which includes absenteeism and feelings of shame. The modern, urban life has an accelerated speed that is nearly impossible to resist. A woman reflected: "It is easy to get lost in commercialism and consuming of things, relations and nature" (interview 6). Nevertheless, with a low income, it is impossible to consume in accordance with the norms in society, demarcating a visible marginalization.

The decision to migrate is triggered by survival needs, as a consequence of neoliberal policies, economic factors such as the North American Free Trade Agreement (NAFTA), and national and global politics [35]. It is often not up to individual decision or choice; rather, the household is a decision-making unit that sends some family members to work outside the community (Wood 1982 in [35]). However, these situations are complex and neither the individual/family nor the structure completely determines one's actions. It depends on the context, the challenges, and uncertainties of social life [32].

All women underlined that their home and their sense of belonging continue to lie in their community of origin despite having lived for several years or even having grown up in urban settings. A woman expressed: "A day renders much more: the air is clear and fresh, the nature is close, one can see trees, animals and hear birds singing, and the sky looks so pretty at sunrise and dawn" (interview 5). However, some women asserted that the life conditions and lifestyles in rural areas have changed. Many communities of origin in remote areas have become "ghost villages" as most people have already im/migrated. Furthermore, the exploitation of natural resources and pollution of rivers and land in rural areas make it difficult to live in remote areas and earn a living from farming [32].

Indigenous and poor people in society are defined not according to what they are but in terms of what they lack [46]. Their traditional lifestyle is disappearing, portrayed as a relic from the past in contrast to the "white" modern society that has been allowed to evolve and change without losing its defining cultural anchorage. Consequently, indigenous and poor people have learned to recognize themselves not as social human beings with equal rights, but as a diminution, if not an absolute negation, of people who are superior in society. This negation is internalized and creates a focus on the individual's failures, causing shame and influencing self-esteem and health $[6,41,47]$.

\section{Conclusions}

The analogy of an uprooted plant illustrates the complexity of women's experiences of $\mathrm{im} /$ migration from a rural to urban setting in Monterrey, Mexico. Everyday life includes a complex interaction of interconnecting factors and relationships that influence women's experiences, choices, 
and decisions. The women had to set daily priorities for their families depending on the changing life circumstances including food habits, living and working conditions, and health challenges. Nevertheless, they envision a better future for their children.

In this study, some of the women reflect on the importance of keeping connected to their roots (traditions of their community of origin), even when living in urban areas, in order to retain their sense of agency in spite of the societal barriers they face such as discrimination and violence. The violence that affects them is not only intra-partner/domestic violence connected with alcohol use/abuse, but also the structural violence in society, which has escalated over the last few decades in the public areas of different Mexican states due to organized crime and corrupt police corps. The end result of increased societal violence and crooked authorities is ad hoc violence directed towards the already marginalized indigenous women [12,35], through discrimination (such as disrespect for mother tongues and traditions); gender inequality, and prejudices and devaluation (the imaginary gaze defining "the other"). Structural violence persists in the biomedical model of birth. It is exerted on women's bodies by way of, for example, sterilization after caesarean section without consent. Such an act represents the institutionalization of surgery within the biomedical model of birth $[42,48]$. Women internalize these accumulated vulnerabilities, and begin to embody this socially devalued identity [6]. Some of the interviewed women expressed confusion about instructions given in healthcare centers. One example is being told that breastfeeding after four months would harm the baby. Consequently, mothers become insecure about how to best take care of their children and families, and begin to question what they know. They also struggle to handle the discrimination and barriers they meet when in contact with authorities. Foucault talks about bio-politics manifested through peoples' bodies and daily practices, leading to subjugation of themselves through self-surveillance [49]. This is a form of subjugation especially used concerning gender, women's reproductive health, and motherhood [48].

Mainstream biomedical research and policies often focus on individual behaviors and ignore the influence of social determinants of health and the structural forces that constrain choice and health $[18,50]$. The concept "structural vulnerability" can be useful to understand the position of an individual in the hierarchical social order [6]. Risk and risk behavior is commonly viewed as individually chosen and includes a moral judgment, although often subtle. This view can be questioned when structural vulnerability together with social determinants of health are taken into account [14,15]. The Millennium Goals have aimed to reduce poverty and, significantly, it is the indigenous populations all over the world that are primarily struck by poverty. People living outside the official sectors and markets in societies are invisible and disappear into statistics that do not value or take into account traditional knowledge, customs, and culture [9,31]. As Quesada puts it: "structural vulnerability requires an analysis of the forces that constrain decision-making, frame choices and limit life options"([39], p. 342). People are subtly blamed for their choices and risk-taking in their everyday life situations even if other forces such as economic and political structures determine the vulnerability of a group of people [6].

In contrast to the legal and formal rights concerning policies, the concept of deservingness illuminates the moral worth and addresses ethical consequences of those implicated in local health settings; especially regarding who gets cared for and how their needs are met [6,51]. These aspects 
and the findings in this study bear significant ethical implications in practice about (intercultural) communication [52]. In social practices and healthcare training, it is implied that the culture of the patient/client is the problem that needs to be understood, the barrier that can and should be overcome [46]. Without asking "what does this person see herself needing" and giving full attention to the answer, instead, the dominant culture introduces its perceptions/views of the other person's actions [41,47]. Some individuals have the capability in certain situations to put power relations aside, raise their voice, and express what they need. Not all people have that strength, and their voices are missing from society.

Regional, national, or international im/migration is influenced by social determinants and the structural vulnerabilities that limit human agency. However, agency as expressed through human action is neither totally determined by structures nor free of the individual's desires and intentions. In public discourse, we are overwhelmed by a few voices, particularly those of the "experts", with an "imaginary gaze", and the power to define and denominate "the other". This dominance leads to the exclusion of marginalized voices, leading to the polyphonic nature of other voices and opinions getting lost. The question is how laws and legislation concerning human rights and rights to healthcare are applied in practice, and whether or not they are affected by perceptions of deservingness and their ethical implications. This is a question that urgently needs to be explored further. It is a matter of human value, dignity, social justice, and equality.

\section{Acknowledgments}

I thank all the women and participants whose collaboration made this study possible. I am grateful to have had the possibility to participate in the project "Understanding and Supporting Families with Complex Needs". In addition, thanks to reviewers and editors for constructive feedback and suggestions.

\section{Conflicts of Interest}

The author declares no conflict of interest.

\section{References}

1. Stephen Castles. Ethnicity and Globalisation: From Migrant Worker to Transnational Citizen. London: Sage Publications, 2000.

2. Eva K. Robertson. “'To be Taken Seriously': Women's Reflections on How Migration and Resettlement Experiences Influence Their Healthcare Needs during Childbearing in Sweden.” Sexual \& Reproductive Healthcare, 2014. doi:10.1016/j.srhc.2014.09.002.

3. Trinh T. Minh-Ha. Elsewhere, Within Here. NewYork: Routledge, 2010.

4. Sarah S. Willen. "Migration, 'illegality', and health: Mapping embodied vulnerability and debating health-related deservingness.” Social Science Medicine 74 (2012): 805-11.

5. Heide Castañeda. “'Over-Foreignization' or 'Unused Potential'? A critical review of migrant health in Germany and responses toward unauthorized migration." Social Science Medicine 74 (2012): 830-38. 
6. James Quesada. "Special issue part II: Illegalization and embodied vulnerability in health." Social Science Medicine 74 (2012): 894-96.

7. United Nations Human Settlements Programme (UN-HABITAT). "Report of the International Expert Meeting on Urban Indigenous People and Migration.” 27-29 March 2007. Available online: http://www.un.org/esa/socdev/unpfii/documents/6session_crp8_en.doc (accesssed on 2 December 2014).

8. Harry A. Patrinos, Emmanuel Skoufias, and Trine Lunde. "Indigenous Peoples in Latin America: Economic opportunities and social networks." 2007. Available online: http://elibrary.worldbank. org/doi/pdf/10.1596/1813-9450-4227 (accessed on 3 December 2014).

9. United Nations. "State of the World's Indigenous Peoples." 2009. Available online: http://www.un.org/esa/socdev/unpfii/documents/SOWIP/en/SOWIP_web.pdf (accessed on 1 December 2014).

10. Instituto Nacional de Estadística y Geografía (INEGI). "Anuario Estadístico de los Estados Unidos Mexicanos 2010.” 2010. Available online: http://www.inegi.org.mx/prod_serv/ contenidos/espanol/bvinegi/productos/integracion/pais/aeeum/2010/Aeeum10_1.pdf (accessed on 2 December 2014).

11. Economic Commission for Latin America and the Caribbean (ECLAC). Panorama Social de America Latina 2006. Santiago de Chile: United Nations, 2007.

12. Carlos Sanchez Gutierrez, ed. Reporte Sobre la Discriminación en México 2012. Mexico City: Consejo Nacional para Prevenir la Discriminación (CONAPRED), 2012. Available online: http://www.conapred.org.mx/userfiles/files/Reporte_2012_Trabajo.pdf (accessed on 1 December 2014).

13. Estela Guzman Ayala. "Health at Work: The Case of the Agricultural Workers." La Journada, 19 April 1997, p. 46.

14. WHO. Ottawa Charter for Health Promotion. Ottawa: World Health Organisation, 1986.

15. WHO. "Closing the Gap in a Generation: Health Equity through Action on the Social Determinants of Health." In Commission on Social Determinants of Health-Final Report. Geneva: World Health Organization, 2008.

16. Richard G.Wilkinson. Unhealthy Societies: The Afflictions of Inequality. London: Routledge, 1996.

17. Michael Marmot, and Richard Wilkinson. Social Determinants of Health. London: Routledge, 1999.

18. Nancy Krieger. "Embodiment: A Conceptual Glossary for Epidemiology." Journal of Epidemiology Community Health 59 (2005): 350-55.

19. United Nations. "Implementation of General Assembly Resolution 60/251 of 15 March 2006 Entitled 'Human Rights Council'." 2006. Available online: http://www2.ohchr.org/english/ bodies/hrcouncil/docs/A.RES.60.251_En.pdf (accessed on 3 December 2014).

20. Eduardo Martínez-Martínez, Maria Luisa Zaragoza, Elmer Solano, Brenda Figueroa, Patricia Zúniga, and Juan P. Laclatte. "Health Research Funding in Mexico: The Need for a Long-Term Agenda.” PLoS ONE, 2012. doi:10.1371/journal.pone.0051195. 
21. Gustavo Nigenda, Lejeune Lockett, Cristina Manca, and Gerardo Mora. "Non-Biomedical Health Care Practices in the State of Morelos, Mexico: Analysis of an Emergent Phenomen." Sociology of Health \& Illness 23 (2001): 3-23.

22. Doris Georgiou, and Phil F. Carspecken. "Critical Ethnography and Ecological Psychology: Conceptual and Empirical Explorations of a Synthesis." Qualitative Inquiry 8 (2002): 688-706.

23. Kay E. Cook. "Using Critical Ethnography to Explore Issues in Health Promotion." Qualitative Health Research 15 (2005): 129-38.

24. Phil F. Carspecken. Critical Etnhography in Educational Research: A Theoretical and Practical Guide. New York: Routledge, 1996.

25. World Medical Association (WMA). "World Medical Association Declaration of Helsinki Ethical Principles for Medical Research Involving Human Subjects." Paper presented at 59th WMA General Assembly, Seoul, Korea, October 2008.

26. Mary-Ann Hardcastle, Kim Usher, and Colin Holmes. "Carspecken's Five-Stage Critical Qualitative Research Method: An Application to Nursing Research.” Qualitative Health Research 16 (2006): 151-61.

27. Ida Nicolaisen. "Overlooked and in Jeopardy: Indigenous People with Diabetes." Diabetes Voice 51: (2006): 35-38.

28. Lenny R. Vartainen, Marlene B. Schwartz, and Kelly D. Brownell. "Effects of Soft Drink Consumption on Nutrition and Health: A Systematic Review and Meta-Analysis." American Journal of Public Health 97 (2007): 667-75.

29. Lucia Hernandez-Barrera, Maria Lizbeth Tolentino, Juan Espinosa, Shu Wen Ng, Juan A. Rivera, and Barry M. Popkin. "Energy intake from beverages is increasing among Mexican adolescents and adults." Journal of Nutrition 138 (2008): 2454-61.

30. Kelly D. Brownell, Thomas Fawley, Walter C. Willett, Barry M. Popkin, Frank J. Chaloupka, Joseph W. Thompson, and David S. Ludwig. "The Public Health and Economic Benefits of Taxing Sugar-Sweetened Beverages." The New England Journal of Medicine 361 (2009): 1599-605.

31. Secreteriat of the Permanent Forum on Indigenous Issues (UNPFII). Report of the Meeting on Indigenous Peoples and Indicators of Well-Being. Available online: http://undesadspd. org/indigenouspeoples/meetingsandworkshops/indicatorsofwellbeing.aspx (accessed on 1 December 2014).

32. Tom Mutersbaugh. "Migration, Common Property, and Communal Labor: Cultural Politics and Agency in a Mexican Village." Political Geography 21 (2002): 473-94.

33. Séverine Durin. "En Monterrey Hay Trabajo Para Mujeres. Proceso de Inserción de las Mujeres Indigenas en el Área Metropolitana de Monterrey.” 2009. Availble online: http://www.cdi.gob. $\mathrm{mx} / \mathrm{dmdocuments} / \mathrm{en} \_m o n t e r r e y \_h a y \_t r a b a j o \_p a r a \_m u j e r e s \_d u r i n \_2009 . p d f$ (accessed on 2 December 2014).

34. Kaja Finkler. "Gender, Domestic Violence and Sickness in Mexico.” Social Science Medicine 45 (1997): 1147-60. 
35. Seth M. Holmes. “'Is it worth risking your life?' Ethnography, risk and death on the U.S.-Mexico border." Social Science Medicine 99 (2013): 153-61.

36. Alex Cohen. "UN Report." In The Mental Health of Indigenous Peoples: An Overview. Geneva: WHO Nations for Mental Health, 2009.

37. Pan American Health Organization (PAHO). "Health of the Indigenous Population in Americas." 2006. Availble online: http:/www2.paho.org/hq/dm/documents/2009/ResCD47inf1_Eng.pdf (accessed on 1 December 2014).

38. Veronica Siegel. "Modernizacion rural y devastacion de la cultura tradicional campesina." In Faculdad de Trabajo Social y Derarolle Humana. Monterrey: Universidad Autónoma de Nuevo Leon, 2004.

39. James Quesada, Laurie K. Hart, and Philippe Bourgois. "Structural Vulnerability and Health: Latino Migrant Laborers in the United States.” Medical Anthropology 30 (2011): 339-62.

40. Lynn Weber. "Reconstructing the Landscape of Health Disparities Research. Promoting Dialogue and Collaboration between Feminist Intersectional and Biomedical Paradigms." In Gender, Race, Class\&Health: Intersectional Approaches. Edited by Amy J. Schulz and Leith Mullings. San Fransisco: Jossey-Bass, 2006, pp. 21-59.

41. Edmund Edvardsen. "Den Innbilte Andre (The Imaginary Other)." In Klientens StemmeHjelperens Blikk (The Voice of the Client-The Gaze of the Professional). Edited by Edmund Edvardsen and Holgeir Holthe. Oslo: Universitetforlaget, 2013, pp. 163-80.

42. Robbie Davis-Floyd, Lesley Barclay, Betty-Ann Daviss, and Jane Tritten, eds. Birth Models That Work. Berkley and Los Angeles: University of California Press, 2009.

43. Laura Mills, and Robbie Davis-Floyd. "Creating the Casa Midwifery Model of Care and Making It Work." In Birth Models That Work. Edited by Robbie Davis-Floyd, Lesley Barclay, Betty-Ann Daviss and Jane Tritten. Bearkley and Los Angeles: University of California Press, 2009, pp. 307-35.

44. Sara Moore. "Reclaiming the Body, Birthing at Home: Knowledge, Power, and Control in Childbirth." Human \& Society 35 (2011): 376-89.

45. Emily Martin. The Woman in the Body: A Cultural Analysis of Reproduction, 3rd ed. Boston: Beacon Press, 2001.

46. Seth M. Holmes. "The clinical gaze in the practice of migrant health: Mexican migrants in the United States." Social Science Medicine 74 (2012): 873-81.

47. Michael Jackson. Politics of Storytelling: Violence, Transgression and Intersubjectivity. Copenhagen: Museum Tusculanum Press, 2002.

48. Vania Smith-Oka. Shaping the Motherhood of Indigenous Mexico. Nashville: Vanderbilt University Press, 2013, p. 239.

49. Michel Foucault. Discipline and Punish: The Birth of the Prison. NewYork: Vintage Publisher, 1995, vol. 2, p. 333.

50. Michel Marmot, Carol D. Ryff, Larry L. Bumpass, Martin Shipley, and Nadine F. Marks. "Social Inequalities in Health: Next Questions and Converging Evidence." Social Science Medicine 44 (1997): 901-10. 
51. Carol Sargent. "Special issue part I: 'Deservingness' and the politics of health care." Social Science Medicine 74 (2012): 855-57.

52. Adrian Holliday, Martin Hyde, and John Kullman. Intercultural Communication: An Advanced Resource Book. NewYork: Routledge, 2004, p. 423. 


\title{
Understanding the Effects of Crime on Women: Fear and Well-Being in the Context of Diverse Relationships
}

\author{
Natalia Hanley and Leah Ruppanner
}

\begin{abstract}
The risk-fear paradox, whereby people who experience the least criminal victimisation report the greatest fear of crime, has been established in the extant literature. That this paradox is gendered, notably that women report greater fear yet are less likely to experience crime, has also been consistently identified. However, there remains a largely unanswered call to explore further the distinctive experiences of women and men. There are likely to be substantial within-group differences as well as between-group differences in experiences of crime and reported fear of crime. For instance, women may experience fear differently by relationship type. Specifically, women in non-traditional families, notably same-sex couples and single, divorced and widowed women may be more fearful. Therefore, for women, the risk-fear paradox may not function equivalently across relationship types. What is more, the impact of experiencing crime may have broader effects on women's well-being, with those in families with complex needs shouldering a greater burden. We apply 2012 European Social Survey data to investigate reports of experiencing crime, feeling unsafe and anxious and sleeping restlessly for a sample of European women $(n=28,768)$. Our results demonstrate that single, separated and divorced women are more likely to experience crime than married women. Divorced and widowed women, as well as those who experience crime, are more likely to report feeling unsafe. Single women, compared to married women, who experience crime are more likely to feel anxious and sleep restlessly. Our results indicate that crime has differential effects on women by relationship type particularly regarding well-being. These findings offer important nuance to the experiences of women.
\end{abstract}

Reprinted from Soc. Sci. Cite as: Hanley, N.; Ruppanner, L. Understanding the Effects of Crime on Women: Fear and Well-Being in the Context of Diverse Relationships. Soc. Sci. 2015, 4, 276-293.

\section{Introduction}

Despite the significant amount of research exploring the fear of crime and its relationship to gender, a detailed explication of women's crime and fear experiences is conspicuously absent. Moreover, the homogenizing assumptions that underpin most of the research on women's experiences of crime and fear of crime have been critiqued rather than countered [1,2]. There is a comparatively small but compelling evidence base which demonstrates that women report diverse levels of fear of crime; moderated by crime type, family circumstances, previous experiences of victimization and age [3]. There is also a growing body of work which explores the effect of relationships on fear of crime. While this literature does not typically explore in detail the unique experiences of women, it does indicate that fear of crime is both a social and individual phenomenon. Relationship status and family measures such as the presence of children in the household have an effect on fear of crime. More specifically, fear of crime may be individual fear-fear for oneself — and/or altruistic fear-fear for someone else [4,5]. However, this literature is limited by its 
narrow focus on heterosexual relationships [6]. Taken together, the research evidence highlights three issues: first that experiences of crime and fear of crime are not uniform for all women. Second, comparing the experiences of men and women may obscure the distinctive, varied and poorly understood experiences and effects of crime and fear on women. Third, the relationship circumstances that women are experiencing may impact on their likelihood of experiencing crime, their reported levels of fear of crime and their resultant wellbeing.

What is more, the bulk of research on crime and fear focuses on single-country samples (see [7-9]). These studies do not explicitly model fear of crime by family status, especially vulnerable populations including same-sex couples and single and divorced women who have experienced crime. While these single-country samples provide great insight into experiences of crime and the risk-fear paradox, they lack a comparative component and cannot speak to broader patterns of inequality [10]. Further, these studies include marital status as a demographic control but are unable to capture numerically small yet vulnerable groups such as same-sex couples and crime victims by marital status. We address these limitations by exploring the impact of crime on women by marital status across a range of groups including single, separated, divorced, widowed, cohabiting and same sex partners. By pooling our sample for all European countries, we are able to estimate these effects for a more representative sample of European women in diverse relationship types. Indeed, alternative family forms are proliferating in Europe and thus estimating women's experiences in these family types is essential $[11,12]$.

Finally, the majority of the crime and fear literature focuses on the risk-fear paradox in general, age or gender gaps in fear of crime more specifically, or conceptual and methodological challenges associated with measuring fear of crime. Yet, the experience of crime is consistently shown to have broader psychological and health effects see [13-17]. Indeed, psychological research demonstrates that experiencing a crime has immediate effects on mental health including levels of anxiety [16], but little is known about how family type is associated with health and wellbeing. Single women who experience crime may be more vulnerable to negative psychological and health outcomes than married or partnered women as having a partner in the home may buffer women from some of these negative effects. Our models assess these relationships cross-sectionally to provide some insight into these associations.

This paper addresses three important research questions for a sample of European women. First, we ask: are married women less likely to experience crime and more likely to report fear than those in other family types, including the most vulnerable groups (divorced, widowed, same-sex attracted women)? To this end, we assess whether, for women, the gap between experiences of crime and fear of crime is related to marital status. Second, we ask: is fear of crime motivated exclusively by those who experience crime, estimating separate effects by marital status? This allows us to determine whether marital status is associated with women's greater vulnerability. Finally, we ask: does experiencing crime have broader effects for women on anxiety and sleep, estimating separate effects by marital status? This allows us to determine whether marital status structures the longer-term health and well-being of women who experience and/or fear crime. To determine these effects, we apply data for a pooled sample of European women aged 18 and older from the 2012 European Social Survey (ESS; $n=28,768$ ) [18]. By pooling our sample to Europe, we are able to compare crime, 
fear, anxiety and sleep experiences for theoretically important yet small groups, including same-sex couples, and experiencing crime by marital status. Thus, while we are unable to make strong country-to-country comparisons, we are able to determine how relationship status structures women's complex experiences of crime, fear and well-being in diverse family structures, thereby responding to the call to explore variations within gender groups.

\section{Literature Review}

The paradox surrounding fear and anxiety about crime and its uneven relationship with risk of criminal victimisation has been well established across theoretical and empirical literature. This paradox has come to be regarded as a criminological truism [1,3]. From this broad base, fear of crime research has moved through several empirical moments. After establishing a disjunction between the groups of people who are most fearful and the groups who are most at risk of victimisation, fear of crime research considered why this paradox might be. Various explanations emerged at individual, social and environmental levels.

At an individual level the risk-fear paradox has been theorized as a reflection of real or imagined vulnerabilities. Early work based on the British Crime Survey for example represented women and older adult's fear of crime as an irrational individual response to a statistical unlikelihood [9] structured by, for example, "sensitivity to risk" [19]. Conversely, an absence of fear about criminal victimisation in the face of a statistical likelihood of victimisation was explained by the influence of masculinity, which could both serve to mask perceptions of risk or reduce the likelihood of admitting to feeling fearful to researchers [20]. Over time, critical scholarship has worked to problematize the notion of irrationality in fear of crime. Instead, critical commentators have highlighted the structuring conditions of gender that give rise to real risks of gender-based violence and consequently heightened levels of fear [21].

The "risk" of criminal victimisation has been disaggregated into physical and social vulnerabilities. In this context, physical vulnerability refers to defensive capacity. Older adults, women, and in more recent literature people with poor health status, are presented as fearful about crime because of their relative disadvantage in defending themselves against an attacker. Social vulnerability refers to social characteristics that may increase vulnerability to crime victimisation such as race/ethnicity and socio-economic status at the individual level [22]. This body of research generally supports the idea of a gender gap in the fear of crime but it also highlights the complexity of variables influencing levels of fear complicating the conclusions of early work that found that women's fear was "irrational". Moreover, the literature forwarding vulnerability-based explanations has generally excluded consideration of relationship status as a potential factor in reported fear of crime. There are at least two ways in which relationship status might connect with vulnerability: first, partnered women may feel more secure as their partnership protects them from feelings of insecurity or vulnerability. However, in the case of same-sex attracted partnerships, being in a relationship may increase the risk of some types of victimization and therefore fear of crime. Second, relationship patterns change over the life course, with single women more likely to be younger than divorced or separated women, and widowed women more likely to be in the older age groups [23]. This means that the consistently identified age-fear effect - whereby age and fear of crime are positively 
related - may mask a relationship status effect, or an interaction between relationship status, age and fear of crime.

As noted above, a key focus of the extant risk-fear literature has been gender. Stanko's important work in the mid-1990s critically engaged with questions of gender, risk and fear by exploring the ways in which social control governs how women can and do use public space, with a range of hidden consequences [24]. Reflecting on the now large body of gender gap knowledge, Rader describes this literature as presenting two hypotheses which bring together individual and social level explanations [25]. First the sexual assault hypothesis suggests that women particularly fear sexual victimisation, and heightened concern about this raises women's levels of fear more generally. Second the socialization hypothesis suggests that two core beliefs are part of women's socialization - that men are necessary for protection and that women are at risk from strangers in public space. Both explanations highlight that fear of crime is structured differently for men and women, and that fear is not directly related to experiences of crime, calling into question the usefulness of gender based comparisons and highlighting the need to look at, as well as beyond, experiences of crime. Instead, it has been suggested that further exploring variation within gender groupings is a more fruitful direction for fear of crime research [26]. Both explanations also have potential to explain why women in varying family structures may be differentially impacted by experiences of crime. While the first hypothesis-that women particularly fear sexual victimization - might be universally experienced, it is possible to speculate that partnered women may perceive themselves to be at lower risk from sexual victimisation as they spend less time alone, or feel generally more secure. The socialization hypothesis also suggests that by meeting normative expectations about proximity to men as protectors some partnered women feel less vulnerable to crime risks. However, this work does not further our understanding of women's feelings of vulnerability in same sex attracted partnerships.

\subsection{Fear of Crime and Well-Being}

A large body of research across many disciplines has examined the relationship between wellbeing, happiness and relationship status. Across that work, it is clear that significant life events such as marriage, divorce and widowhood have an effect on happiness and by association, wellbeing. However, it is also clear that the relationship between wellbeing and relationship status is gendered with married women performing comparatively poorly on wellbeing measures compared with married men [27]. What is more, these women tend to rebound more quickly after divorce, indicating marital status has differential effects by gender [28]. This compels the need for further research which examines women's experiences in greater depth than comparative research may afford.

Fear of crime has been negatively connected to good mental health and general wellbeing $[13,14,16]$, with impacts on participation in everyday activities, use of public space and interaction with others $[15,17]$.

This growing research literature indicates that as fear of crime is unevenly experienced, so the effects of fear of crime on health and wellbeing are unevenly felt. Unsurprisingly, this literature identifies that the impacts of fear of crime are disproportionately felt by women and the elderly [13] and are related to poor mental health, including increased anxiety and depressive symptoms [16] 
although the direction of causality is not well established [13]. Cossman and Rader considered self-reported health status and its impact on fear of crime. They concluded that, for women, perceived health — as opposed to objective indicators of health — was a significant predictor of higher reported fear of crime. They conclude that "the personal vulnerability hypothesis may be a much more appropriate framework for understanding women's fear of crime (with age, race, marital status and health status all playing a role in how safe women feel in their own neighborhoods) than for men" ([29], p. 159). Similarly, Canadian research concluded that for both elderly men and women individuals expressing fear of crime also experienced greater levels of anxiety, depression and cognitive distress [13]. Although the authors did not concentrate their analysis on the particular experiences of women their results do support the general view that fear of crime and wellbeing are connected. This research further highlights the importance of examining closely the links between health and fear to expose women's particular vulnerability to negative consequences flowing from increased fear of crime.

Fear of crime and health has a complicated relationship which includes both direct and indirect effects. For example, higher levels of fear of crime may increase heart rate and therefore cardio-vascular effects; alternatively, higher levels of fear of crime may reduce engagement in physical activity outside of the home which may have an indirect negative impact on overall health and wellbeing [16]. Protective factors for good mental health such as regular physical exercise and socialising were also impacted by fear of crime, indicating an indirect relationship between increased fear of crime and overall wellbeing [30]. The presence of a spouse or partner may also buffer women from the negative consequences of crime, in part by providing a support network within the home.

In this literature too, the paradox between fear of crime and risk of victimisation is highlighted. However this distinction is less important given the effects of fear of crime, as succinctly argued by Pearson and Breetze:

What makes investigating the fear of crime on wellbeing outcomes of particular interest is that it is not the actual threat of being a victim of crime that elicits negative stress responses in individuals but the perception of risk of being a victim of crime. When the perception of risk is great, fear abounds, and manifests itself in certain physiological changes and unhealthy behaviour patterns. ([16], p. 289).

More recent work by Jackson and Gray complicates the assumption that fear of crime is intrinsically problematic [31]. Instead, they argue, fear of crime has both positive and negative effects. Some fear of crime is useful - it motivates people to take precautions against criminal victimisation which in turn increases feelings of safety and security. It is only at the point that fear of crime impacts upon quality of life (which is not inevitable) that it has a negative effect [32]. It is here that wellbeing research can usefully explore some of the negative impacts of fear of crime.

\subsection{Families and Fear of Crime}

There is limited, but emerging evidence that family structure is relevant to understanding the fear of crime. For example, Whitley and Prince reported that mothers in low income households were more likely to be negatively impacted by fear of crime [19]. Pearson and Breetzke ([16], p. 286) demonstrated that "as age, partner status and income increased, so did mental wellbeing" indicating 
that family structure in conjunction with age and financial security had a positive impact on fear on crime. Similarly, Rader et al found support for the effect of both physical and social vulnerabilities on fear of crime. This research considered family type, albeit to a limited extent, and concluded that as the percentage of a neighbourhood that was married increased, fear of crime decreased indicating that family type has some influence on levels of fear [33].

Earlier work by Warr and Ellison described the ways in which consideration of family structure problematised established findings about fear of crime and gender arguing that women may be more fearful for themselves but men are "highly susceptible to altruistic fear when it comes to their wives and children" ([5], p. 574). Therefore fear is not evenly distributed across the family and the nature of fear reportedly experienced by women has a qualitatively different character to the fear reported by men. Further, Warr and Ellison argued that the social dimensions of fear have been underexplored compared with the individual dimensions of fear. This is important in light of their conclusions that individuals may be fearful for themselves and/or others, and fear of crime potentially impacts the emotional wellbeing of the household. While the European Social Survey data does not enable us to explore the altruistic fear of crime, our research responds to the gap in knowledge about the social or relational dimensions of fear of crime and wellbeing by considering relationship status.

Taking a narrower focus on married men's fear of crime for themselves and others (altruistic or vicarious fear), Rader argued that marriage had an effect on men's personal fear of crime: "Before entering marriage, men claimed they did not worry much about their safety but once they entered marriage, realized they needed/wanted to be around for a long time to take care of their spouse and enjoy their family." ([22], p. 45). Indeed Rader's earlier work highlighted the relevance of relationship status to understanding fear of crime [17]. Here, Rader explained that both married and divorced women may designate "fear work" to their partner. This "fear work" might include, for example, securing property and physical protection. However there is a paucity of empirical research which interrogates specifically the distinct experiences of women identified by Warr and Ellison [5], or the relevance of family and relationship circumstances to fear of crime identified by Rader [33]. Still less considers the experiences of same-sex attracted women. In one of the few exceptions, Otis examined the perceived risk of victimization and fear of crime reported by lesbians and gay men [6]. In this study women were more likely to fear personal victimization than men, but the effect of gender was low. These findings suggest that when you consider the experiences of particular groups of women the existing truisms that operate in fear of crime work become less convincing.

\subsection{Measuring Fear of Crime}

The complexity of measuring fear of crime is evident [34]. For some authors, a distinction ought to be made between measures of perceived risk of victimisation and emotional responses such as worry or fear [14]. Traditional measures have typically included questions about fear of walking alone at night - a measure that some critics have argued is less relevant or useful for older research participants [13]. Similarly, local patterns of crime and reporting of crime events challenges national and cross-jurisdictional approaches. More specifically, it has been argued that reported levels of fear are related to specific crime type, and therefore generalised inquiries about risk or fear would be unlikely to pick up the nuances in people's lived experiences of fear of crime. Moreover the relationship 
between gender and fear that has been established repeatedly in the literature is also called into question by a crime-specific analysis. Here, sceptics argue that it is actually fear of interpersonal violence that explains women's higher levels of fear, rather than a generalised anxiety about crime, or a particular type of crime experience, such as assault and burglary as measured by the European Social Survey 2012 [34,35]. The absence of standardized measure of experiences of crime and fear of crime make it difficult to distinguish and compare research findings across the extant literature.

As highlighted above fear of crime research can be characterised by contradictory or equivocal findings [6]. Critical scholarship has called into question some of the criminological truisms presented earlier in this paper. More specifically, there is now a large body of complicating research on the interaction between age and fear which suggests that older people may not have higher levels of fear at all [1]. At least some of the variation in levels of fear has been explained in relation to methodological limitations and inconsistencies [6]. For example, the extent to which questions about levels of anxiety or practices such as walking home alone accurately measure fear of crime has been questioned. Critics have also suggested that men may not experience lower levels of fear of crime at all, but that this effect may be a result of their lower likelihood to report fear of crime [20]. Similarly, there have been calls to consider research conclusions about women's higher reported fear of crime in the context of their victimisation experiences in the home and in more "mundane" everyday settings which nonetheless contributes to a general, and gendered, sense of unease [36].

While making much of the distinction between fear of crime reported by women compared to men, or older adults compared to younger adults there has been relatively little work which has systematically examined the experiences of women in a nuanced way, starting from the perspective that women are not all the same, and their experiences of crime, fear of crime and resultant wellbeing are also likely to vary. Furthermore, almost exclusively, extant work is interested in adult's fear of crime and does not distinguish between individuals or communities with diverse family and sexuality configurations [6]. In summary, this research landscape highlights the importance of addressing fear of crime in addition to crime prevention. While many authors have argued for the importance of understanding fear of crime because of its range of negative impacts on individuals and communities, relatively few have interpreted the task to include centrally the notion of wellbeing [37]. Fewer still have explored the relevance of relationship status to understanding risk and fear of crime or the uneven relationship between the two.

\section{Data}

This study applies cross-national data from the 2012 European Social Survey (ESS) [18]. The ESS is collected annually by a consortium of top European academic agencies on a rotating list of topics. While the 2012 ESS is on the module on Understanding of Democracy, questions on crime, fear, anxiety and sleep are present in each wave of the survey. Thus, we selected the 2012 module which is the most recently released data from the ESS. The ESS provides strict accountability to maintain the rigor, validity and consistency across countries and is considered the top general social survey of European countries [38]. The 2012 wave provides a representative sample of respondents across 29 countries. These include: Albania, Belgium, Bulgaria, Cyprus, Czech Republic, Denmark, Estonia, Finland, France, Germany, Hungary, Iceland, Ireland, Israel, Italy, Kosovo, Lithuania, the 
Netherlands, Norway, Poland, Portugal, Russia, Slovakia, Slovenia, Spain, Sweden, Switzerland, Ukraine and the United Kingdom. We restricted our models to women aged 18 and older which produced an effective sample size of 28,768 respondents across all 29 countries. We estimate our models for the pooled sample in order to test for significant differences among small yet theoretically important populations. All of our models apply design weights and are estimated as binary logistic regressions as our outcome measures are discrete. We present the log-odds units (B) and the odds ratios (exponentiated $\mathrm{B}$ ) to ease interpretation.

\subsection{Dependent Variables}

We apply three dependent variables measured dichotomously. The first captures whether the respondent experienced crime or not. Respondents were asked to report whether they or a member of their household was a victim of a burglary or assault over the past 5 years. This measure was dichotomously coded for those who reported yes to this measure (experienced crime $=1$ ). This crime measure is not without limitation, specifically in that it asks for a narrow set of experiences over a long period of time for multiple family members. Yet, this measure is validated across a range of studies as a general indicator of experiencing crime [4,11]. In a major limitation, this question asks for crime experiences for the respondent and/or their household members. This limits our ability to definitively state whether the respondents, themselves, experienced the crime. Yet, this measure likely underestimates the positive effect of experiencing a crime on perceptions of fear, anxiety and restless sleep. Thus, our significant coefficients are likely much lower than if this question was asked about respondents' experiences exclusively.

Our second dependent variable captures feeling unsafe through the following question: "how safe do you — or would you - feel walking alone in this area after dark?" Responses are on a four point scale ranging from very safe $(17.9 \%)$, safe $(48.3 \%)$, unsafe $(25.1 \%)$ and very unsafe $(7.1 \%)$. For consistency across measures, we collapsed this measure to capture reports of feeling unsafe ( $32 \%$; value $=1$ ) but we also estimated ordinal regression coefficients which produced equivalent results to the binary models. Our third dependent variable reflects respondents' reports of feeling anxious. Respondents reported how often they felt anxious over the past week with responses ranging from none or almost none of the time $(43.0 \%)$, some of the time $(41.8 \%)$, most of the time $(10.8 \%)$, all or almost all of the time (3.4\%). Given the right skew in the data, we dichotomously coded this measure for those who have felt anxious over the past week $(56 \%$; value $=1)$ compared to those who reported none or almost none of the time (value $=0$ ). Finally, sleep is restless captures respondents' reports of experiencing restless sleep over the past week on an equivalent scale to the anxiety measure. We collapsed this measure to capture those who reported experiencing any restless sleep $(61 \%$; value $=1)$ compared to those who did not experience restless sleep $(39 \%$; value $=0)$. We are interested in those experiencing any level of anxiety or sleep disturbance in the last week. While this includes those with less severe anxiety and sleep disturbances with those in more extreme circumstances, the link of anxiety and disturbed sleep with poorer health outcomes is established [39-42]. Thus, even minor disturbances in sleep and anxiety have serious consequences for well-being. For these reasons, we estimate models across this broader group to identify whether experiencing crime increases the odds of anxiety and disturbed sleep rather than focusing on those with the most severe cases. 


\subsection{Main Independent Predictors}

Given our focus on the impact of complicated family-types on experiences of crime, we estimate a series of dummy measures capturing distinct family groups. In one measure, respondents were asked to report their current marital status. From this measure, we coded respondents into five groups: married or living as married (comparative group), single-never married, separated, divorced, and widowed. To capture same-sex and cohabiting respondents, we used the family register to identify respondents reporting living with a husband/wife/partner of the same sex (same-sex partnerships) and those who reported none or not applicable in the legal marital status questions yet report living with a husband/wife/partner of the opposite sex (cohabiting partnership). Consistent with other large representative surveys, same-sex couples account for a small percentage of the total sample $(0.4 \%$ or 122 cases). Without a direct sexuality question, this modelling strategy underestimates the true number of lesbian women in our sample. Further, this small sample limits our ability to investigate countries separately and rather requires the data to be pooled. Yet, it is important to note capturing this sample, in the absence of a direct sexuality measure, is an important advantage upon previous ESS research which includes these respondents among the other marital status measures, thus confounding these relationships [43,44]. We also estimate the presence of a child in the home $($ value $=1)$. Further, to determine whether family status structures the impact of experiencing a crime on feeling unsafe, anxious and sleeping restlessly, we also estimate a series of interaction terms by relationship and parental status.

\subsection{Individual Controls}

We estimate a series of socio-demographic controls. Employment status compares those who are employed full-time and part-time to those who are currently not in the labour market (comparative group). Age captures the respondents' age at the time of the interview. Household income is measured on a ten-point scale asking the respondent to weigh her income relative to others in her country with higher values reflecting greater relative household income. Respondents reported their highest level of completed education in their country-specific systems which were harmonized, on a four-point scale, by the ESS team for cross-national comparability. Higher values reflect more completed education. All of the models also include country dummies to account for country-to-country differences in our dependent measures, with Sweden as the omitted group.

\section{Results}

Table 1 provides a descriptive overview of our sample. As most of our estimates are coded dichotomously, we present the percentage of the population in each category. Continuous measures are presented as means. Across our dependent variables, 61 percent of our sample reported sleeping restlessly in the past week, the most common experience. Feeling anxious is second with 56 percent reporting anxiety in the past week. One-third of our sample, 32 percent feel unsafe walking down the street and only 16 percent have experienced a burglary or assault in the past 5 years. The modal family type are women who report being married (49\%) followed by single women (23\%), widowed $(15 \%)$, divorced $(11 \%)$, separated $(1 \%)$, same-sex $(0.4 \%$ or 120 respondents) and cohabiting (not 
legally recognized $(0.3 \%$ or 95 respondents). Close to half of the sample report having a child present in the home (43\%). Among these groups, 7 percent of married women experienced a crime compared to 4 percent of single women, 2 percent of widowed and divorced women, and 0.1 percent of separated, cohabiting and same sex respondents. Clearly, the percentage of separated, cohabiting and same-sex respondents experiencing crime is small and should be interpreted with extreme caution. Yet, we estimate these effects in order to ease the interpretation of the interaction effects. Women with children account for 7 percent of those who experienced a crime compared to 8 percent who do not have children in the home. Of course, the presence of a child and marital status are not mutually exclusive. For our individual controls, 67 percent report working 30 plus hours in a typical week, while only 15 percent report working less than 30 hours and 18 percent are not in the labour market. The mean age of the sample is 50 years old. Further, respondents report a mean household income of 4.8, roughly half of the ten point scale. Yet, the education level is quite high with the mean reporting the highest level of education at 3.9, or completing a high school diploma.

Table 2 addresses our initial research question: are women in different marital groups more vulnerable to crime and reports of fear than others? Across all of the models, we control for country dummies. Thus, the results can be interpreted as the effect of marital status, net of country-to-country differences in women's reports of experiencing crime and feeling unsafe. As these models present binary regression coefficients, we also present exponentiated values of the log-odds of reports to indicate the magnitude of the effects. Model 1 presents the coefficients for reports of experiencing crime. Single, separated and divorced women are more likely to have experienced a crime than married women. By contrast, widowed, cohabiting and same-sex respondents are no more likely than married women to experience crime. In ascending order, the odds of experiencing a crime are 68 percent higher for separated women $\left[\left(e^{0.524}-1\right) \times 100=68.9\right], 24$ percent higher for divorced women $\left[\left(e^{0.220}-1\right) \times 100=24.6\right]$ and 14 percent higher for single women $\left[\left(e^{0.131}-1\right) \times 100=14.0\right]$ compared to married respondents. Counter to expectations, the odds of experiencing a crime are not significantly different for same-sex and cohabiting couples. The small sample sizes for the same-sex respondents may result in this failed significance or these may be truly non-significant relationships. The odds of women with children in the home experiencing a crime are 18 percent higher than women without children in the home $\left[\left(e^{0.169}-1\right) \times 100=18.4\right]$, indicating that mothers are more vulnerable to crime than non-mothers. Turning to our demographic controls, employed, higher earning and more educated respondents have a higher odds of experiencing a crime. By contrast, reports of experiencing a crime deteriorate with age. 
Table 1. Descriptive statistics of dependent and independent variables (ESS $n=28,768)$ [10].

\begin{tabular}{|c|c|c|c|}
\hline & Mean or Percentage & Std. Deviation & Range \\
\hline \multicolumn{4}{|l|}{ Dependent Variables } \\
\hline Experienced burgulary or assault in past 5 years & $16 \%$ & 0.363 & $0-1$ \\
\hline Feel unsafe walking down street & $32 \%$ & 0.467 & $0-1$ \\
\hline Feel anxious in past week & $56 \%$ & 0.496 & $0-1$ \\
\hline Slept restlessly in past week & $61 \%$ & 0.488 & $0-1$ \\
\hline \multicolumn{4}{|l|}{ Main Individual Predictors } \\
\hline Married & $49 \%$ & 0.500 & $0-1$ \\
\hline Single & $23 \%$ & 0.420 & $0-1$ \\
\hline Separated & $1 \%$ & 0.076 & $0-1$ \\
\hline Divorced & $11 \%$ & 0.312 & $0-1$ \\
\hline Widow & $15 \%$ & 0.354 & $0-1$ \\
\hline Cohab & $0.3 \%$ & 0.057 & $0-1$ \\
\hline Same Sex & $0.4 \%$ & 0.064 & $0-1$ \\
\hline Child Present & $43 \%$ & 0.495 & $0-1$ \\
\hline \multicolumn{4}{|l|}{ Interaction Terms } \\
\hline Married $\times$ Experienced Crime & $7 \%$ & 0.263 & $0-1$ \\
\hline Single $\times$ Experienced Crime & $4 \%$ & 0.202 & $0-1$ \\
\hline Separated $\times$ Experienced Crime & $0.1 \%$ & 0.039 & $0-1$ \\
\hline Divorced $\times$ Experienced Crime & $2 \%$ & 0.133 & $0-1$ \\
\hline Widowed $\times$ Experienced Crime & $2 \%$ & 0.128 & $0-1$ \\
\hline Cohab $\times$ Experienced Crime & $0.1 \%$ & 0.025 & $0-1$ \\
\hline Same Sex $\times$ Experienced Crime & $0.1 \%$ & 0.029 & $0-1$ \\
\hline Child Present $\times$ Experienced Crime & $7 \%$ & 0.260 & $0-1$ \\
\hline No Child Present $\times$ Experienced Crime & $8 \%$ & 0.275 & $0-1$ \\
\hline \multicolumn{4}{|l|}{ Controls } \\
\hline Full-time (30 plus hours) & $67 \%$ & 0.470 & $0-1$ \\
\hline Part-time ( 1 to 29 hours) & $15 \%$ & 0.356 & $0-1$ \\
\hline Not in the labour market & $18 \%$ & 0.125 & $0-1$ \\
\hline Age & 50.024 & 18.052 & $18-102$ \\
\hline Household Income & 4.865 & 2.811 & $1-10$ \\
\hline Education level & 3.931 & 1.885 & $1-4$ \\
\hline
\end{tabular}

Model 2 estimates these effects for feeling unsafe. In this model, experiencing a crime becomes a central predictor for feeling unsafe. Consistent with expectations, experiencing a crime has a positive and large effect on feeling unsafe. In fact, the odds of women who experience a crime feeling unsafe are $120 \%$ higher than for those who did not experience a crime $\left[\left(e^{0.787}-1\right) \times 100=119.6\right]$. Similarly, the odds of divorced and widowed women feeling unsafe are $15 \%$ and $18 \%$ higher respectively than for married women $\left[\left(e^{0.143}-1\right) \times 100=15.4 .6 ;\left(e^{0.171}-1\right) \times 100=18.7\right]$. Interestingly, although the odds of single and separated women reporting experiencing a crime are higher, the odds of them feeling unsafe are no higher than those for married women. Women with a child in the home, although reporting greater odds of experiencing a crime, have $14 \%$ lower odds of feeling unsafe suggesting that the fear-crime paradox does not structure their experiences $\left[\left(e^{-0.159}-1\right) \times 100=14.7\right]$. Turning to the demographic controls, the odds of feeling unsafe are lower for those with higher 
household incomes and educations. While we identify clear family-type patterns, our models beg the question, is marital and parental status driving these effects or is it the interaction between marital status and experiencing a crime that structures these reports? Table 3 addresses this question.

Table 2. Binary logistic regression coefficients for experiencing a burglary or assault in the past 5 years $(\mathrm{ESS} \mathrm{n}=28,768)[10]$.

\begin{tabular}{|c|c|c|c|c|}
\hline & \multicolumn{2}{|c|}{ Experienced Crime } & \multicolumn{2}{|c|}{ Feeling Unsafe } \\
\hline & \multicolumn{2}{|c|}{ Model 1} & \multicolumn{2}{|c|}{ Model 2} \\
\hline & B & $\operatorname{Exp}(B)$ & $\mathbf{B}$ & $\operatorname{Exp}(B)$ \\
\hline \multicolumn{5}{|c|}{ Main Predictors } \\
\hline Experienced Crime & - & - & 0.787 & 2.196 \\
\hline \multicolumn{5}{|c|}{ Compared to Married } \\
\hline Single & $0.131 * *$ & 1.140 & -0.067 & 0.936 \\
\hline Separated & $0.524 * *$ & 1.689 & -0.016 & 0.984 \\
\hline Divorced & $0.220 * * *$ & 1.246 & $0.143 * *$ & 1.154 \\
\hline Widow & 0.115 & 1.122 & $0.171 * * *$ & 1.187 \\
\hline Cohab & 0.294 & 1.342 & -0.207 & 0.813 \\
\hline Same Sex & 0.284 & 1.328 & -0.090 & 0.914 \\
\hline \multicolumn{5}{|c|}{ Compared to no Child in the Home } \\
\hline Child Present & $0.169 * * *$ & 1.184 & $-0.159 * * *$ & 0.853 \\
\hline \multicolumn{5}{|c|}{$\begin{array}{c}\text { Controls } \\
\end{array}$} \\
\hline \multicolumn{5}{|c|}{ Compared to Those not in the Labour Market } \\
\hline Full-Time & $0.156^{* *}$ & 1.169 & -0.019 & 0.981 \\
\hline Part-Time & $0.201 * *$ & 1.223 & -0.048 & 0.953 \\
\hline Age & $-0.008 * * *$ & 0.992 & 0.0005 & 1.000 \\
\hline Household Income & $0.020 * *$ & 1.020 & $-0.041 * * *$ & 0.960 \\
\hline Education Level & $0.060 * * *$ & 1.062 & $-0.081 * * *$ & 0.922 \\
\hline Constant & $-1.294 * * *$ & 0.274 & $-0.967 * * *$ & 0.380 \\
\hline R-Square & \multicolumn{2}{|c|}{0.062} & \multicolumn{2}{|c|}{0.131} \\
\hline
\end{tabular}

Notes: $* p<0.05 ; * * p<0.01 ; * * * p<0.001$; all models control for country dummies (Sweden comparative group). 


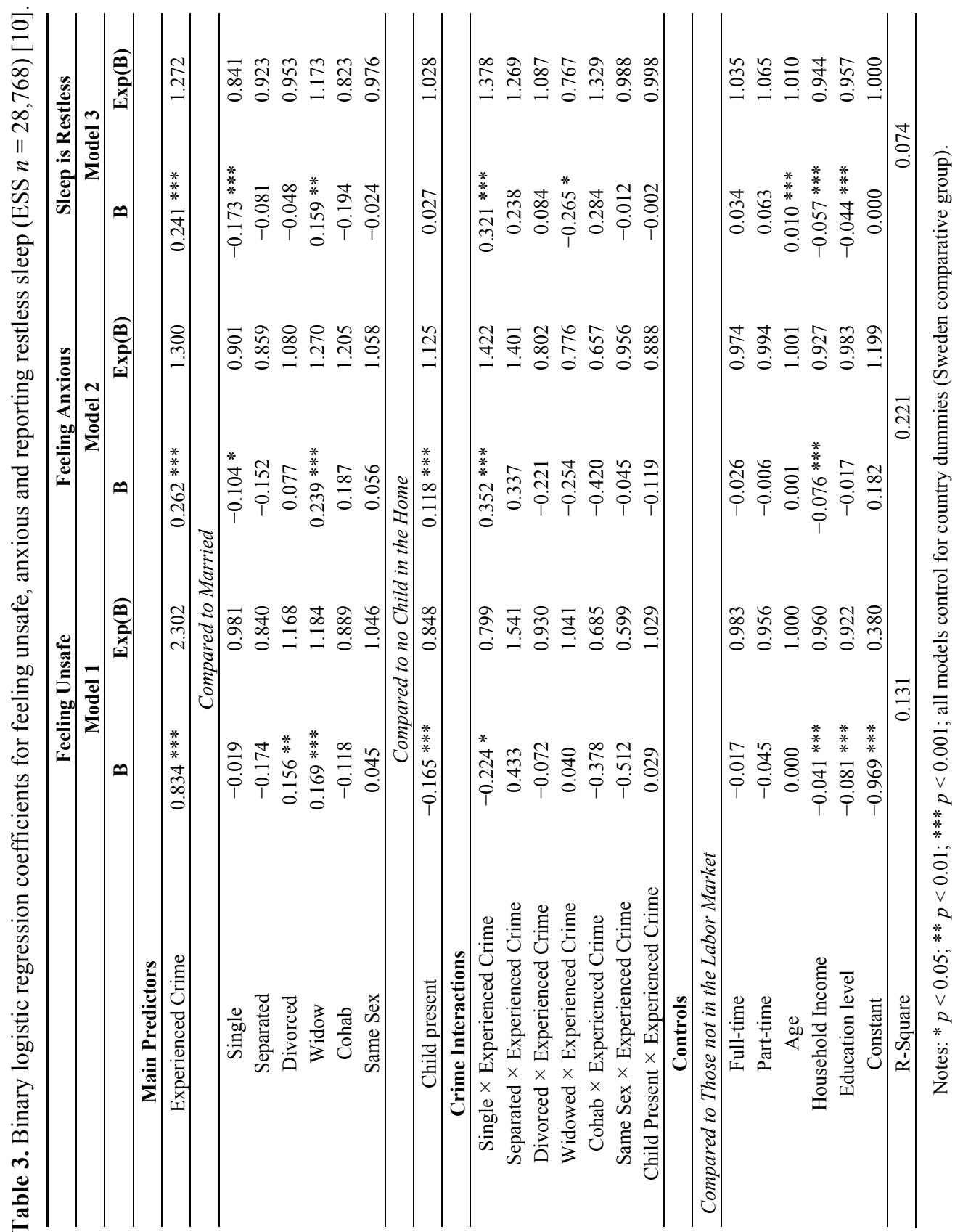


Table 3 estimates whether the interaction between family-type and experiencing a crime significantly effects reports of feeling unsafe, anxious and sleeping restlessly. Model 1 estimates these effects for feeling unsafe. Consistent with the previous table, respondents who are divorced or widowed or have experienced a crime have a higher odds and women with a child in the home have a lower odds of feeling unsafe. With the exception of the weakening effect for single women who experienced crime (single women's reports log-odd units $=0.83-0.22=0.61$ ), none of the crime interactions are significant. In other words, all women who experience a crime are more likely to report feeling unsafe regardless of marital or parental status. Model 2 estimates the spillover effects of experiencing a crime and relationship status on reports of feeling anxious and produces some striking results. Consistent with expectations, respondents who experience a crime are more likely to feel anxious during the past week (log-odd units $=0.26$ ) but this positive effect is significantly larger for single women who have experienced a crime (single women's log-odd units $=0.26+0.35-$ $0.10=0.51$ ). This positive effect is startling in light of the negative effect of being single on feeling anxious. The odds of single women reporting feeling anxious are 10 percent lower than married women $\left[\left(e^{-0.104}-1\right) \times 100=9.9\right]$. But, the odds of single women who have experienced a crime reporting anxiousness are 66 percent higher than married women who experienced a crime $\left(\left[\left(e^{0.26+}\right.\right.\right.$ $0.35-0.10-1) \times 100=66.5]$. In other words, experiencing a crime deteriorates all of the benefits of singlehood on reports of anxiety. While widows and women with a child in the home are more likely to report feeling anxious, there are no differential effects for these groups when they experience a crime versus not.

Model 3 further explores these relationships for reports of restless sleep over the past week. Consistent with the previous model, experiencing a crime is positively associated with reports of restless sleep ( $\log$ odd-units $=0.24$ ) but this positive relationship is magnified for single women who experienced a crime (single women's log odd-units $=0.24+0.32-0.17=0.39$ ). In other words, the odds of a single women who experience a crime reporting restless sleep in the past week are 47 percent higher compared to their married counterparts $\left[\left(e^{0.24+0.32-0.17}-1\right) \times 100=47.6\right]$. These results parallel those for anxiety as the odds of single women who have not experienced a crime on feeling restless are 16 percent lower than married women (log odd-units $=-0.173 ;\left[\left(e^{-0.173}-1\right) \times 100=15.9\right]$ ); yet, this negative effect is expunged for single women who have experienced a crime. For widowed women, the positive effect of experiencing a crime on sleeping restlessly is slightly smaller (widowed women's $\log$ odd-units $=0.24+0.15-0.26=0.13$ ) than for married women who experienced a crime. Yet, the odds of widows who have not experienced a crime to report sleeping restlessly are higher suggesting that this may be an aging rather than marital status effect. Yet, our demographic controls demonstrate that widowhood has a larger positive effect above and beyond aging (log odd-unit $=0.01$ or $1 \%$ for every year). In terms of controls, household income and education have some buffering effects on anxiety and sleeping restlessly. Ultimately, our results demonstrate significant patterns by marital status and experiencing a crime.

\section{Conclusions}

The results from the 2012 European Social Survey (ESS) [18] demonstrate that there are significant nuances in women's experiences of crime relative to fear of crime and wellbeing. Notwithstanding 
the aforementioned methodological limitations, these nuances appear to be structured by experiences of crime and family type. First, single, separated and divorced women are more likely to have experienced a crime than married women. The experience of crime measure sought reports about assault and burglary and is therefore likely to have underestimated experiences of alternative types of crime such as intimate partner violence. As expected, for all women experiencing a crime in the last five years has a positive and large effect on feeling unsafe. However the effect of experiencing a crime on feeling unsafe is moderated by family type with divorced and widowed women more likely to report feeling unsafe than married women. This finding suggests that partnerships may buffer some women who experience crime from the effects on fear of crime. In contrast, single and separated women are more likely to report experiencing a crime yet they are no more likely than married women to report feeling unsafe. Similarly women with a child in the home, although more likely to experience a crime, are less likely to report feeling unsafe. These results suggest that divorced and widowed women are more likely to transfer experiences of crime into generally feeling unsafe than women residing in alternative family structures. Also of note, we found no significant relationship effects for same-sex women. One explanation may be that discrimination based on sexual orientation may not translate into fear. Or, our sample size may not lend enough statistical power to document significant associations. In light of these results, additional investigation for this group is warranted.

In terms of wellbeing effects, measured by restless sleep and anxiety, women who had experienced a crime were more likely to feel anxious. Here too the positive effect was moderated by family type. Specifically, single women who had experienced a crime reported greater anxiety in the past week. The increase in anxiety for single women who had experienced a crime was startling, given that without the crime experience single women reported comparatively low levels of anxiety compared to married women. This finding suggests that experiencing a crime deteriorates all of the benefits of singlehood on self-reported anxiety. These results are replicated in the effect of experiencing a crime on restless sleep. Here too the positive relationship between restless sleep and experience of crime is magnified significantly for single women suggesting that the impact of crime on wellbeing may be somewhat cushioned by marriage. These results further compel a close examination of the methods used to establish women's fear of crime, indicating that broader wellbeing measures such as anxiety and sleeplessness may pick up the effects of crime that are not captured by questions about worry walking alone after dark.

These results suggest that when the particular experiences of women are explored there is less evidence of a discrepancy between risk and fear. The women experiencing the most crime - single and divorced women - also felt the least safe. Widowed women were outliers because they reported a greater level of fear of crime relative to their experience of crime when compared to women in alternative family types. This was not explained by age and therefore warrants further investigation. It should be noted that the complex issue of untangling whether there is a direct or indirect relationship between experiences of crime, fear of crime and wellbeing is not resolved by these results [7]. This is further complicated by the ESS measure which does not focus only on personal experiences of crime. 
These results lend support to calls to further interrogate women's fear of crime. We have found that women have a variety of experiences of crime and fear of crime and that these experiences are moderated by family structure. What is more, these experiences have differential wellbeing effects suggesting that partnerships, such as marriage, act as a protective buffer against the negative impact of fear of crime. Further research might build on these results by considering the duration of this protective effect.

\section{Acknowledgements}

The authors would like to thank the reviewers of this article for their helpful feedback.

\section{Author Contributions}

Hanley drafted the literature review, Ruppanner drafted the methodology and results. Editing, introduction and discussion drafting was shared.

\section{Conflicts of Interest}

The authors declare no conflict of interest.

\section{References}

1. Ron Acierno, Alyssa Rheingold, Heidi Resnick, and Dean Kilpatrick. "Predictors of Fear of Crime in Older Adults." Journal of Anxiety Disorders 18 (2004): 385-96.

2. Tim Newburn, and Elizabeth A. Stanko. "When Men are Victims." In Just Boys Doing Business? Men, Masculinities and Crime. Edited by Tim Newburn and Elizabeth A. Stanko. London: Routledge, 1994.

3. Bonnie Fisher, and David May. "College Students' Crime-Related Fears on Campus: Are Fear-Provoking Cues Gendered?” Journal of Contemporary Criminal Justice 25 (2009): 300-21.

4. Viviana Andreescu. "Fear of Violent Victimization among the Foreign-Born." Journal of Identity and Migration Studies 7 (2013): 69-131.

5. Mark Warr, and Christopher Ellison. "Rethinking Social Reactions to Crime: Personal and Altruistic Fear in Family Households.” American Journal of Sociology 106 (2000): 551-78.

6. Melanie Otis. "Perceptions of Victimization Risk and Fear of Crime among Lesbians and Gay Men.” Journal of Interpersonal Violence 22 (2007): 198-217.

7. Emily Gray, Johnathan Jackson, and Stephen Farrall. "Reassessing the Fear of Crime." European Journal of Criminology 5 (2008): 363-80.

8. Dana. Haynie. "The Gender Gap in Fear of Crime, 1973-1994: A Methodological Approach." Criminal Justice Review 23 (1998): 29-50.

9. Mike Hough, and Patricia Mayhew. British Crime Survey: First Report. London: HMSO, 1983.

10. European Communities. A Review of Scientifically Evaluated Good Practices for Reducing Feelings of Insecurity or Fear of Crime in the EU Member States. London: European Crime Prevention Network, 2004. 
11. Viviana Andreescu, and Deborah Keeling. "Explaining the public distrust of police in the newest European Union Countries.” International Journal of Police Science \& Management 14 (2012): 219-45.

12. Ron Lesthaeghe. "The second demographic transition in western countries: An interpretation." Gender and Family Change in Industrialized Countries 1 (1995): 17-62.

13. Marie Beaulieu, Nancy Leclerc, and Michelene Dubé. "Fear of Crime among the Elderly." Journal of Gerontological Social Work 40 (2004): 121-38.

14. Kenneth Ferraro. Fear of Crime: Interpreting Victimization Risk. Albany: State University of New York Press, 1995.

15. Chris Hale. "Fear of Crime: A Review of the Literature." International Review of Victimology 4 (1996): 79-150.

16. Amber Pearson, and Gregory Breetzke. "The association between fear of crime, and mental and physical wellbeing in New Zealand.” Social Indicators Research 119 (2014): 281-94.

17. Julie Phelan, Diana Sanchez, and Tara Broccoli. "The danger in Sexism: The links among fear of crime, benevolent sexism and well-being." Sex Roles 62 (2010): 35-47.

18. European Social Survey. "ESS Round 6: European Social Survey Round 6 Data (2012)." 2014. Available online: http://www.europeansocialsurvey.org/data/download.html?r=6 (accessed on 3 April 2015).

19. Mark Warr, and Mark Stafford. "Fear of Victimization: A Look at the Proximate Causes." Social Forces 61 (1983): 1033-43.

20. Robbie Sutton, and Stephen Farrall. "Gender, Socially Desirable Responding and the Fear of Crime: Are Women really More Anxious about Crime?” British Journal of Criminology 45 (2005): 212-24.

21. Elizabeth Stanko. "Women, Crime, and Fear." Annals of the American Academy of Political and Social Science 539 (1995): 46-58.

22. Nicole Rader. "Until death do us part? Husband perceptions and responses to fear of crime." Deviant Behavior 31 (2010): 33-59.

23. United Nations, Department of Economic and Social Affairs, Population Division. "World Marriage Data 2012.” 2013. Available online: http://www.un.org/esa/population/publications/ WMD2012/MainFrame.html (accessed on 12 March 2015).

24. William Smith, and Marie Torstensson. "Gender differences in risk perception and neutralising fear of crime: Toward resolving the paradoxes.” British Journal of Criminology 37 (1997): 608-34.

25. Nicole Rader. "Gendered Fear Strategies: Doing Gender and Fear Management Strategies in Married and Divorced Women's Lives.” Sociological Focus 41 (2008): 34-52.

26. Elizabeth Gilchrist, John Bannister, Jason Ditton, and Stephen Farrall. "Women and the 'Fear of Crime': Challenging the Accepted Stereotype." British Journal of Criminology 38 (1998): 283-98.

27. Anke Plagnol, and Richard Easterlin. "Aspirations, attainments, and satisfaction: Life cycle differences between American women and men." Journal of Happiness Studies 9 (2008): 601-19. 
28. Andrew Cherlin. Marriage, Divorce, Remarriage. Cambridge: Harvard University Press, 2009.

29. Jeralynn Cossman, and Nicole Rader. "Fear of crime and personal vulnerability: Examining self-reported health." Sociological Spectrum 31 (2011): 141-62.

30. Mai Stafford, Tarani Chandola, and Michael Marmot. "Association between fear of crime and mental health and physical functioning." American Journal of Public Health 97 (2007): 2076-81.

31. Jonathan Jackson, and Emily Gray. "Functional Fear and Public Insecurities about Crime." British Journal of Criminology 50 (2010): 1-22.

32. Theo Lorenc, Stephen Clayton, David Neary, Margaret Whitehead, Mark Petticrew, Hillary Thomson, Steven Cummins, Amanda Sowden, and Adrian Renton. "Crime, Fear of Crime, Environment and Mental Health and Well-Being: Mapping Review of Theories and Causal Pathways." Health Place 18 (2012): 757-65.

33. Nicole Rader, Jeralynn Cossman, and Jeramy Porter. "Fear of crime and vulnerability: Using a national sample of Americans to examine two competing paradigms." Journal of Criminal Justice 40 (2012): 134-41.

34. Mariel Alper, and Allison T. Chappell. "Untangling fear of crime: A multi-theoretical approach to examining the causes of crime-specific fear." Sociological Spectrum 32 (2012): 346-63.

35. Lesley Reid, and Miriam Konrad. "The gender gap in fear: Assessing the interactive effects of gender and perceived risk on fear of crime." Sociological Spectrum 24 (2004): 399-425.

36. Rachel Pain. "Social geographies of women's fear of crime." Transactions: Institute of British Geography 22 (1997): 231-44.

37. Jonathan Jackson, and Mai Stafford. "Public Health and Fear of Crime: A Prospective Cohort Study." British Journal of Criminology 49 (2009): 832-47.

38. European Social Survey. "ESS 6-2012 Documentation Report." 2014. Available online: http:// www.europeansocialsurvey.org/docs/round6/survey/ESS6_data_documentation_report_e02_1. pdf (accessed on 3 April 2015).

39. Aaron Beck, Norman Epstein, Gary Brown, and Robert Steer. "An inventory for measuring clinical anxiety: Psychometric properties." Journal of Consulting and Clinical Psychology 56 (1988): 893-97.

40. Abdul Khaleque. "Sleep deficiency and quality of life of shift workers." Social Indicators Research 46 (1999): 181-89.

41. Peter Meerlo, Andrea Sgoifo, and Deborah Suchecki. "Restricted and disrupted sleep: Effects on autonomic function, neuroendocrine stress systems and stress responsivity." Sleep Medicine Reviews 12 (2008): 197-210.

42. Shelley Taylor, and Johnathan Brown. "Illusion and well-being: A social psychological perspective on mental health." Psychological Bulletin 103 (1988): 193-210.

43. Leah Ruppanner. "Conflict and housework: Does country context matter?" European Sociological Review 26 (2010): 557-70.

44. Leah Ruppanner. "Cross-national reports of housework: An investigation of the gender empowerment measure.” Social Science Research 39 (2010): 963-75. 


\section{Social Policies in Contemporary Latin America: Families and Poverty in the Social Protection Systems ${ }^{1}$}

\section{Cristina González}

Abstract: This article examines the impact of social policies on the living conditions of poor families - particularly women - in Latin America from the late 1980s to the present. It identifies three distinct trends of familialism in the region's social protection systems. The first social policy trend is characterized by poverty alleviation policies addressing the family in an "elliptical" way, taking for granted the idea of a nuclear family. The distinguishing trait of the second trend is the appearance of social programs aimed at families and stressing the role of women as chief caregivers and administrators. And finally, the third policy trend is defined by an expansion of more universal social programs targeting children and the elderly. Despite the recent emergence of programs with gender specific goals, social policies continue to put a great burden on female workers. For example, many subsidies to poor families deliver money directly to women, improving their intra-family bargaining power, but this translates also into an increase of responsibilities and the ensuing overload of work. Consequently, social policies in Latin America need to aim at encouraging a more egalitarian distribution of housework and care work within the family, especially given how well-established androcentrism is in the region.

Reprinted from Soc. Sci. Cite as: González, C. Social Policies in Contemporary Latin America: Families and Poverty in the Social Protection Systems. Soc. Sci. 2015, 4, 134-147.

\section{Introduction}

In Latin America, the absence of family-specific policies has been linked to the prevalence of the familialization of welfare (even in countries with a relatively strong system of social security). The family component of social policies has only been present in the form of dispersed and uncoordinated measures, including health and education programs, prevention and eradication of domestic violence, or compensatory social programs.

Notwithstanding their emotionally appealing names, social programs such as Bolsa Familia or Familias por la Inclusion Social, are far from being genuine family policies. This situation is not too far from that of Europe. In a report about the European case, Linda Hantrais says,

"Family matters can be considered as a specific area of social policy, but not all governments would claim to have an explicit family policy remit. Within the European context, the term 'family policy' is generally used to characterise policies that identify families as the deliberate target of specific actions, and where the measures initiated are

\footnotetext{
1 This article is an expanded and modified version of the author's presentation "Social policies towards families in the new millennium: Argentina and Latin America" at the International Seminar "Engaging with Families Facing Complex Difficulties", at the University of Birmingham, Birmingham, UK, on 19 June 2013.
} 
designed to have an impact on family resources and, ultimately, on family structure, as is the case for child or family benefits" ([1], p. 2).

Ironically, although the family occupies a central place in most political discourses and policy proposals in Latin America, such significance is out of kilter with actual public policy.

This paradox can be explained by the familialism of welfare systems which rely on families for the tasks of social reproduction. According to Gosta Esping Andersen [2], a welfare regime is "familialist" when it deposits the greatest responsibility for the well-being of family members on the family itself, rather than on the state or the market. For him, the responsibility of families in their own welfare is measured by the time they engage in unpaid domestic duties, or by the extent to which they absorb certain social burdens such as caring for children, the elderly, or the sick.

The consolidation of social welfare systems in Latin America came about after the 1950s with the rise of the developmentalist state $^{2}$, which took measures towards improving the quality of life of the population and growing the economy through industrialization ([3], p. 22). Since then and until the 1980s, we can see the consolidation of three welfare sub-systems, with different variations in each country: (a) social security, associated with benefits for citizens based on fundamental rights to welfare; (b) social insurance, with benefits for occupational groups through a contractual relationship; and (c) social assistance, related to programs and services aimed at vulnerable groups who demonstrate their inability to properly remain on the labor market [4].

The three sub-systems have helped to perpetuate the traditional concept of a nuclear family (father, mother, and children) that is based on the "male breadwinner model". Such a model presupposes that men should provide monetary resources through their inclusion in the labor market, while women should be in charge of domestic work and home care tasks. This model—though challenged both empirically and normatively_-informed social policies over many decades. These policies ranged from health programs, educational curricula and the coverage of family insurance, to other policies whose description is beyond the scope of this work. Due to its direct relationship to formal employment, the implementation of this model has been particularly evident in the field of social insurance policies. As Sunkel notes,

"Social protection systems associated with employment assume that the core of the labor force is male and, consequently, the family depends on a man as its main supplier" ([3], p. 23).

As explained below, despite changes in family structures and the increasing integration of women into the labor market, the traditional gender division of work centered on the "male bread-winner model" still permeates social assistance policies, albeit under different assumptions and strategies.

In highly stratified Latin American societies, the familialist bias in social policies has had a strong impact on family life conditions, particularly on wage earners and informal economy sectors. This

2 Developmentalism (desarrollismo) is a political-economic paradigm related to theories developed by ECLAC (Economic Commission for Latin America and the Caribbean) economists from the 1950s through the early 1970s. Its distinguishing feature is the promotion of inward-oriented development programs to accelerate growth rates, based on import-substitution industrialization, export taxes, and duties on manufactured imports. In this model, the state is regarded as the crucial agent for the strengthening of internal market, and national economic growth. 
article discusses the relationship between social policy and family in Latin America from the late 1980 s to the present, through a characterization of three trends of familialism that have accompanied security systems in the region. The first trend, centered on the privatization of services and assistance policies for fighting poverty, prevailed during the boom years of the Washington Consensus model of the 1980s and 1990s. The second policy trend, aimed at mitigating the effects of rising unemployment levels and poverty, encompassed the years around the turn of the millennium (from the mid-1990s to the mid-2000s). As in the first trend, the new measures were in accord with the recommendations of international agencies of credit and technical assistance whose model was known as "Post-Washington Consensus" ${ }^{3}$. One of its leading exponents-Nobel Prize-winning economist Joseph Stiglitz-explained the main differences between the two models as follows,

"The Washington Consensus advocated use of a small set of instruments (including macroeconomic stability, liberalized trade, and privatization) to achieve a relatively narrow goal (economic growth). The Post-Washington Consensus recognizes both that a broader set of instruments is necessary and that our goals are also much broader. We seek increases in living standards - including improved health and education-not just increases in measured GDP. We seek sustainable development, which includes preserving natural resources and maintaining a healthy environment. We seek equitable development, which ensures that all groups in society, not just those at the top, enjoy the fruits of development. And we seek democratic development, in which citizens participate in a variety of ways in making the decisions that affect their lives" ([5], p. 31).

The third familist trend emerged in the region during the last decade and continues into the present. This new model of social protection restores the state as the provider of goods and services, and reinstates the language of rights, extending benefits to previously excluded social sectors. Social policies aimed at children and the elderly make families the explicit target, giving a central role to women in their function as mothers.

\section{Familist Policies in the 1990s: Economic Liberalism, Assistentialism, and the Fight against Poverty}

In Latin America, the 1980s and 1990s were characterized by the strengthening of the neoliberal model of state administration. The neoliberal model of welfare left behind the economic policies that had promoted full employment with the active support of families. Following the guidelines of the Washington Consensus (also called "first generation reforms"), policy-making focused on the liberalization of trade and financing, the promotion of macroeconomic stability, and the transformation of the role of the state in the economy.

Public policies limited state social intervention to targeted social programs, thus strengthening the residual-liberal component of the state. A key strategy was the transfer of welfare sectors to the

3 The term Washington Consensus is usually associated with the precepts of economic adjustment, administrative shrinking of the state, and social policies targeted at the poor. The Post-Washington Consensus emerged out of criticism towards the former, which led to economic instability, rising unemployment and deepening social inequalities in many countries. 
private market — as in the case of pension systems — and to other state jurisdictions — like health and educational services ${ }^{4}$.

The implementation of poverty alleviation policies was centered on social programs targeted mainly at the unemployed and families with unmet basic needs. Two main characteristics were: first, the provision of means-tested benefits - usually subject to low income verification — and, second, the requirement of work as a condition to remain in the program. Contrary to the universalizing tendency of social policies based on citizenship rights, policies targeted at the poor have stigmatizing effects. Subject to the personal characteristics of those who claim assistance, these policies tend to reinforce discrimination ([6], p. 193). Workfare policies have functioned as the main strategy for managing the reproduction of the "supernumerary" population. Their implementation revealed the magnitude of the decline of social rights in the region, as the notion of rights was replaced by that of obligation, and the right to work was substituted by the duty to work in order to receive assistance $[7,8]$.

A paradigmatic case was the Argentine Jefes y Jefas de Familia (Heads of Household Plan) that was launched in 2002. Its purpose was to counteract the devastating effects of the economic and social crisis of 2001 , which led to the growth of poverty rate from $38.3 \%$ to $53 \%$ in one year (2001-2002). This plan differed from other workfare programs previously implemented in Argentina. One novelty was the creation of local advisory councils as mechanisms of control and supervision by civil society. Additionally, by acknowledging women as heads of household, it helped the inclusion of a large number of females into the program, who accounted for $64 \%$ of participants ${ }^{5}$.

A distinguishing feature of poverty alleviation policies is that they are financially contingent. They are usually based on occasional budgets, unlike social security and social insurance policies that integrate all social public expenditures (such as education, or family allowances). Another characteristic is that they target vulnerable families. This is founded on doctrinal and instrumental assumptions. The doctrinal assumption goes back to the liberal principle of non-state intervention on social matters, unless families prove their incompetence for solving certain problems. In turn, the instrumental value of families is based on empirical evidence about their central role in the material and social reproduction of their members $[9,10]$.

These policies are backed by discourses that take for granted the idea of a nuclear, "conjugal" family, ignoring other family arrangements. Correspondingly, they address the family in an "elliptical" way, overlooking the existence of sexual and generational divisions of power within the household. However, their criteria for eligibility (and other requisites) suppose traditional family roles. By addressing the family as a whole, as an homogeneous group free of hierarchical divisions of labor, these programs end up reinforcing existing gender and generation inequalities.

4 The residual model places in the market the leading role of managing social risks, leaving to the state only "unacceptable" risks, such as extreme poverty.

5 The plan provided a monthly allowance in exchange for work in productive projects or community services. It was aimed at male or female heads of unemployed households with children up to 18 years of age or disabled of any age, and at households where the female spouse — concubine or cohabiting household head — was in a state of pregnancy. It was also meant to secure children's school attendance and health control, and to include beneficiaries into formal education, and/or job training activities that could contribute to their future re-employment. 


\section{Familism and Policies in the Transition to the New Millennium: Towards a New Instrumentalization of Families?}

Contrary to the expectations created by the Washington Consensus (which promoted the idea that economic growth alone would lead to the welfare of the population), by the mid-90s alarming signs of unemployment and poverty emerged in the region. Despite the compensatory nature of policies aimed at diminishing the negative effects of structural adjustment, poverty continued to rise in Latin America, showing the failure of the "trickle-down theory". At the same time, growing public concern about the impact of neoliberal reforms led to a review of the principles of the Washington Consensus.

As a result, multilateral agencies developed new proposals for regional policymaking. "Second generation reforms"- or "Post-Washington Consensus" recommendations - emphasized the integration of economic and social development ${ }^{6}$. They promoted a type of relationship between state and society that combined democracy and the market by focusing on "good governance", "sustainable development", "human development", and "social capital"-concepts which have gained ground in the language of policymaking.

In brief, the recommendations were intended to correct the deficits of previous policies through a set of measures organized around two central axes, whose relative weight varied according to country and political conjuncture: the return to the state as an agent of development-planning and controlling - and the participation of civil society - mainly NGOs - in the execution of social programs. Although they stressed "good governance" through democracy, participation and decentralization, these policies retained some elements from the neoliberal model of state management. An example is the technification of policymaking as seen in the diverse and complex instruments for measuring the rates of poverty that serve as the basis of targeting strategies. "Second generation" policies improved the mechanisms for targeting poor families. For instance, more reliable databases were created in order to avoid the dispersion of resources produced when different programs target the same beneficiaries.

In the context of labor market crisis and lack of public services, the family acquired an instrumental value as "social capital" and as a strategic resource. As Alicia Bárcena, Executive Secretary of the Economic Commission for Latin America and the Caribbean (ECLAC), states:

"Latin American families provide social support and protection against economic crises, unemployment, illness and death of some of its members. As social capital, the family is a resource of great value, since the limited social coverage in some countries of the region regarding work, health and social security, transforms the family in the only institution of social protection against unemployment, disease, migration and other traumatic events" ([11], p. 10).

The transformation of family structures - like the expansion of monoparental and extended families - which increased poverty and other related social problems, encouraged research on family habits and survival strategies. Accordingly, the family was increasingly regarded as a unit of

6 This concept of development took shape in the various summits organized by the United Nations - in particular the Earth Summit in Rio de Janeiro in 1992, and the World Development Summit in Copenhagen in 1995. 
observation and intervention. As a unit of observation, the family helped in the characterization of consumption practices. As a unit of intervention, it was useful for the implementation of community and educational programs, and the inculcation of habits.

This new approach incorporates the gender perspective by stressing the role of women as caretakers, household administrators, and intermediaries between welfare programs, households, and community organizations. As a result, most Conditional Cash Transfer programs (CCT) disseminated in the region in the last fifteen years, are targeted at mothers under the assumption that they are more reliable than men in the use of funds and the care of children. However, several studies show some unexpected side effects, both in intra-family relationships (e.g., gender conflicts) and in the relationship between families and their communities. As Villatoro states,

"In this sense, despite the discursive emphasis on the centrality of the family and the fundamental role assigned to women (in the administration of transfers and the operation of programs), what happens 'within the families', i.e., the displacements of income, negotiations, perverse effects, conflicts and overlaps of power, remains a black box for program design" ([12], p. 275).

Hence, most CCT programs end up overloading the work of women, who apart from being the primary force of domestic work, are also a workforce in the labor market.

For example, a study of the impact of the Mexican Program Oportunidades (Opportunities) on women found that the only element put into practice from the gender perspective is the granting of scholarships to girls and young women. Incidentally, this encouraged female school attendance, thus helping the reduction of the gender gap in schooling. However, the fact that mothers receive money that is spent on food, school uniforms and footwear for children cannot be interpreted as a practice that promotes gender equality but rather as a reinforcement of the traditional role of females as childcare providers. According to this report, the absence of men deserves special attention, as they not only failed to fulfill their role as major providers, but many of them showed an inability to fulfill their role as co-providers. Furthermore, they failed to participate in domestic and care work, which remain a responsibility of women [13].

Yet, as noted below - in reference to the impact of conditional cash transfers - an alternative interpretation suggests that making the payment to women could strengthen the mother's bargaining position, reinforcing her ability to shift priorities in household spending and time allocation, especially in circumstances where her power within the household is limited ([14], p. 59). This issue remains a subject of numerous debates.

Similarly, the program Familias por la Inclusion Social (Family for Social Inclusion Program), implemented in Argentina between 2004 and 2009, provided subsidies to mothers with two or more children under the age of 19 and/or disabled at any age. In exchange, they were obligated to send their children to school and to take them to regular health checkups. This program was also subject to criticism, as it reproduced traditional patterns of division of labor by gender. Although CCTs are an improvement on workfare policies, they displace obligations from the space of waged labor to the space of family work. Combining the short-term goal of alleviating poverty and the long-term goal 
of promoting human development, these programs resort to the traditional value of sacrifice and dedication to motherhood from women ([15], p. 16).

The "generational transmission of poverty", that is, the idea that poverty is transmitted from one generation to the next, has also gained strength in policymaking. Thus, social programs include strategies to stimulate the development of human capital. As a result, current social policies that target poor families focus on their most vulnerable members, such as children.

\section{The Latin American System of Social Protection in the XXI Century: Strengthening Motherhood or Democratizing Families?}

Welfare systems are currently undergoing promising changes that seek to combine economic growth and social development. The objective is to overcome the devastating effects of previous structural adjustment policies through pro-active measures. As Cecchini, Filgueira and Robles, say:

"...over the last 10 years, the region has seen a major transformation of its social protection matrix and in its social policies generally. [...] this transformation have a very different orientation than those of the reform of the 1980s and early 1990s. While that era saw a major retreat from, and downscaling of, State social action (reduction or freezing of social spending, privatization, close targeting, financing of demand, etc.), the new century has seen an expansion of State action in social areas (broader coverages; partial or full re-nationalization; increased social spending; combination of vectors of need, supply and demand to determine investment and fiscal effort)." ([16], p. 31).

In this context, new notions of social protection have been gaining ground, in which the state plays a more active role and regains its place as guarantor of rights and as an actor in the regulation of the labor market. This is in sharp contrast to the paradigm of social protection which focused on "risk management" promoted by the World Bank (WB) in the mid-1990s ${ }^{7}$. While the International Labor Organization (ILO) emphasizes the link between social protection and labor markets, other United Nations (UN) agencies stress the social protection of rights, the promotion of social cohesion and the construction of citizenship [15,17].

Currently, ILO promotes the consolidation of a "Social Protection Floor" (SPF), seeking to guarantee a minimum level of economic security and access to basic services on the basis of citizen rights. The SPF provides the basis for countries to build their own social protection systems, and includes basic security guarantees in various forms: income transfers such as pensions for the elderly or the disabled, benefits for dependent children, income support for the unemployed and poor workers, among others ([18], p. 2). ECLAC also promotes public policy strategies based on a citizen rights approach to overcome productive heterogeneity without compromising social equality. It fosters the construction of a new state-market-society equation, grounded on the capacity of contributory schemes associated with employment and solidarity mechanisms [19].

7 Defining risk as undesirable fluctuations - predictable or not-that might generate welfare losses, the WB proposes a strategy for managing social risk through the use of informal systems (e.g., the self-protection strategies of households), market systems (e.g., financial assets and insurance policies) and public sector systems (e.g., state intervention). 
The efforts of Latin American and Caribbean countries at increasing the coverage of social protection are reflected in four areas of social policy: (a) retirement benefits, pensions and other monetary transfers to the elderly; (b) cash transfers to families with children; (c) access to services and health insurance; and (d) protection to workers in the field of health insurance, unemployment insurance and working conditions. In all four areas some important boundaries are being redefined, like those between contributory and non-contributory, targeting and universality, and subject contributor and recipient of the benefit ([16], p. 32).

Several countries have extended the coverage of retirements and pensions for the elderly. They have expanded non-contributory benefits, though with variations in their specific design and their degree of integration with the broader social security system. Among the benefits with wider coverage are Renta Dignidad (Dignity Income) in Bolivia, Brazil's rural pensions, Pension para Adultos Mayores (Pension for the Elderly) in Ecuador, Pension Basica Solidaria (Basic Solidarity Pension) and Aporte Previsional Solidario (Solidary Pension Contribution) in Chile.

In Argentina, coverage was expanded through a mechanism of flexibilization of contributory requirements, which extends benefits to various categories of informal workers, retaining the centrality of the contributory scheme ([20], p. 11) ${ }^{8}$. The Plan de Inclusion Previsional (Plan for Inclusive Social Insurance), implemented from 2005 to 2007, softened contribution requirements, granting access to the system to those who had been previously excluded. It covered individuals who fulfilled the minimum age to retire but had not met the requirements to enter the system -30 years of contributions and various dimensions of continuity [21]. Currently, a second stage of this plan is being launched, covering those who did not meet the requirements of age or years of service during the first stage.

Another example is the Chilean system of retirements and pensions. The Solidarity Pension System is part of the Pension Reform Act, which came into effect in 2008. It consists of a basic solidarity pension for the elderly and the disabled, which provides (or supplements) coverage to those who did not save enough during their working life, in order to finance a decent benefit. This system comprises the Pension Basica Solidaria de Vejez (Old Age Basic Solidarity Pension) and the Aporte Previsional Solidario de Vejez (Old Age Solidarity Pension Contribution) ([22], p. 436; [23], p. 39).

These reforms have favored women in a significant way. For instance, in Argentina the Prevision Inclusion Plan is popularly known as "retirement for housewives", because $73 \%$ of beneficiaries were women, and the remaining 27\%, male ([21], p. 123). However, this statistic indicates the scale of inequality between men and women in the formal labor market, upon which the Argentine system of retirements and pensions is based.

In terms of children's coverage, there still are few policies besides CCTs. Some countries, like Chile, Uruguay and Argentina, have changed their systems of family allowances through a combination of contributory and non-contributory schemes. Chile has a contributory system of family allowances for formal workers. It also has a non-contributory system called Subsidio Unico Familiar (Single Family Subsidy) for poor people who cannot access the benefits of the Family

8 Since its origins in the 1940 s, the Argentine system of social security has been characterized by the centrality of social insurances that deal with risks related to the activities of workers, such as retirements covering the impossibility to work due to advanced age, health care and family allowances. 
Allowance and Maternal Allowance (Asignación Familiar o Maternal) because they do not work in the formal market and therefore they do not have any benefits thereof ${ }^{9}$. Together with other subsidies, the Single Family Subsidy is part of the program Chile Solidario (Solidary Chile), created in 2002 for "families, individuals and territories that are in situations of vulnerability" [25].

Uruguay also has two family allowance schemes: on the one hand, the regimen for formal wage workers and, on the other, the scheme for low-income households, regardless of the type of employment. In order to expand coverage, the latter was replaced in 2008 by the New Family Allowance Regime (Nuevo Régimen de Asignaciones Familiares). Benefits vary according to the number of children per household, using an equivalence scale which provides a greater amount to children attending secondary levels of education. Family allowances are administered by the Ministry of Social Development (Ministerio de Desarrollo Social) and the Bank of Social Security (Banco de Previsión Social), and have been integrated into the Equity Plan (Plan de Equidad), which consists of a set of programs included in the Assistance Network for Social Integration ([23], p. 31).

In Argentina, the Universal Child Allowance for Social Protection (Asignación Universal por Hijo para la Protección Social) and the Pregnancy Allowance for Social Protection (Asignación por Embarazo para Protección Social) have been designed in direct connection with the contributory system, just like retirements and pensions. The Universal Child Allowance for Social Protection (non-contributive) was added to the existing Law of contributory Family Allowances (Ley de Asignaciones Familiares) in 2009. It expanded family allowances to unemployed workers, informal workers earning an income below the minimum living wage, and domestic employees.

Today, Latin American systems of social protection include other policies that try to improve the living conditions of the poor, such as the expansion of kindergartens and nurseries, and health programs for maternal and child nutrition. As Cecchini, Filgueira and Robles say, "nearly all countries in the region have extended the ages of education coverage towards preschool children (3-6 years), and many have created care facilities for children from birth to two years old." ([16], p. 36).

According to the United Nations Educational, Scientific and Cultural Organization (UNESCO), the gross enrollment ratio of children 3 to 5 years of age rose from $56 \%$ to $65 \%$ from 1999 to 2007 in the region. The Inter-American Development Bank (IDB) reports a similar increase in the enrollment of children from 4 to 5 years, which rose from 55\% to $71 \%$ between 1998 and 2009. It also states that the highest increases were registered in Mexico, Argentina and Chile: while the proportion of children enrolled in Mexico grew by more than 50 percentage points, both Argentina and Chile show a rise of more than 25 percentage points ([26], p. 35; [27], p. 70; [28], p. 35). For example, between 2005 and 2009 Chile - one of the few countries with public coverage data-increased preschool enrollment from $4.3 \%$ to $11.5 \%$ for children between 0 and 2 years, and $17 \%$ to $22 \%$ for those between 2 and 4 years ([29]. But despite improvements in the region, there are profound differences in the access to preschool education according to socioeconomic status. The IDB points out that in El Salvador the percentage of enrolled children who belong to the lowest quintile of the

9 This subsidy gives the right to medical and dental benefits, and is inconsistent with the other benefits of the Sistema Único de Prestaciones Familiares (Single Family Benefit System), the Pensión Básica Solidaria (Basic Solidarity Pension), and the subsidy for mental disability [24]. 
distribution of wealth was about half the children in the highest quintile. In Brazil and Nicaragua the gap between the first and fifth quintile was 27 percentage points ([27], p. 70).

Aside from preschool services, many countries are launching other programs for early childhood. Examples include the centers of child and family care in Uruguay, preschool and nursery services of provincial and municipal programs in Argentina, nurseries and preschool services in Chile, the expansion of nurseries in Brazil, and the subsidies to community care for early childhood in Mexico. Some countries have also created integral systems or subsystems of childcare: Brazil Carinhoso (Affectionate Brazil), Chile Crece Contigo (Chile Grows with You); Colombia's De Cero a Siempre (Zero to Always) and, more recently, Uruguay Crece Contigo (Uruguay Grows with You) ([16], p. 36).

Likewise, maternity leave is undergoing changes that could improve early childhood care, family arrangements, and women's employment opportunities. Traditionally, maternity leave was given to waged women workers, to the detriment of informal, independent, and rural female workers. However, some countries as Brazil, Uruguay, Costa Rica, Chile and Argentina, have recognized the labor rights of domestic service workers, affording them the entitlement to maternity leave. Other reforms include the provision of paternity leave, and the same benefits and rights to adoption as to birth ([30], p. 5).

These policies show a new trend towards a greater re-distribution of resources by the state. But at the same time this poses major challenges to the administration of social policies, particularly regarding the articulation of specific measures into a coordinated system. The integration of policies has long been regarded by many as a remedy for the excessive dispersion of social actions aimed at tackling the numerous problems that affect families, from health and education to intra-family violence.

In summary, the main aspects of the current trend in Latin American social policies are:

(a) The restoration of the state's role in establishing a "social protection floor" that combines a minimum of economic security with access to basic services (universal coverage grounded on citizen's rights);

(b) The tendency to make families the explicit targeting of policies, giving a central role to women in their role as mothers (maternalist tradition);

(c) A gradual increase of services aimed at relieving family care;

(d) A significant reduction in the gap between pensions for men and women, as a result of the reforms of retirements and pensions systems; and,

(e) A weakness or absence of policies reconciling waged labor and the domestic labor of women, as well as policies promoting the democratization of family work.

\section{Conclusions}

Latin American social policies are experiencing transformations that recover two principles that were abandoned in previous decades: the provision of goods and services by the state, and the language of rights. However, despite the changes that are taking place, these policies continue to give families a central role in the care of their members. While previous policies tended to conceal internal inequalities by elliptically targeting the family as an "undifferentiated whole", current policies unveil the female predominance in care work, since they are directed explicitly at women. 
There is a continuity in the familialist tradition of social state interventions in the region, but with a maternalist bias that is not free from tensions: policies acknowledge the role of women as mothers, but they fail to promote the redistribution of housework and caregiving in a more equitable way.

Some studies highlight the positive impact that CCT programs have on income level and stability in vulnerable households. But at the same time, they indicate an adverse effect on women. Although such programs bestow greater autonomy and negotiating power to women, the services required in order to receive cash transfers compromise their time ([31], p. 64).

An expansion of public services for children and the elderly could partially alleviate women from the burden of excessive family responsibilities and contribute to the democratization of households. It could also counteract the profound social stratification of Latin American societies. While upper and upper middle classes can count on private childcare services and paid domestic work, the poor can rely only on informal intra-family and community services, generally supported by the voluntary work of mothers themselves ([32], p. 132). Despite some progress, investment in early childhood services is still deficient in the region. As stated in the Annual Social Report (Panorama Social) of ECLAC for 2009,

"The traditional welfare regime in Latin America is premised on the model of the male breadwinner and the female homemaker caring for children and older persons. Both the empirical evidence and the normative principles seriously challenge this vision today. In other words, there is no way to resolve the care crisis without redistributing the burdens of paid work, unpaid work and care work. It is not enough to lobby for ways to reconcile the paid and unpaid work performed by women. What is needed is for the State and public policy to make simultaneous progress on various fronts." ([33], p. 212).

Combined with the low participation of men in family responsibilities, the chances for poor and middle class women to reconcile paid and domestic work are minimal, which also excludes them from better employment opportunities ([31], p. 58).

Familialism remains a prominent feature of Latin American welfare systems. Recent changes show a tendency towards easing the financial burden on families through policies aimed at improving household income. Some countries are also broadening the coverage of retirement benefits and pensions, the maternity leave system, family allowances and childcare services, thus protecting sectors of the population that were previously neglected. These new policies are gradually replacing the social programs that deepen the discrimination of the poor, restoring the language of social rights. Furthermore, they are conferring more visibility to women in their crucial role as domestic workers and caregivers. Nonetheless, social policies continue to place the greatest responsibility for the well-being of family members on the family, particularly on women. Social policies should play a more active role in the democratization of families.

\section{Acknowledgments}

The author thanks Nathan Hughes, Carolina Muñoz and the anonymous reviewers for their helpful comments on the draft version of this article. The amended version is the sole responsibility of the author. 


\section{Abbreviations}

GDP: $\quad$ Gross Domestic Product;

NGOs: Non-Governmental Organizations;

ECLAC: $\quad$ Economic Commission for Latin America and the Caribbean;

CCT: $\quad$ Conditional Cash Transfer programs;

WB: World Bank;

ILO: International Labour Organization;

UN: $\quad$ United Nations;

SPF: $\quad$ Social Protection Floor;

UNESCO: United Nations Educational, Scientific and Cultural Organization;

IDB: Inter-American Development Bank.

\section{Conflicts of Interest}

The author declares no conflict of interest.

\section{References}

1. Linda Hantrais. "Policy Review of 'Family and Welfare'." Research for the European Commission, October 2003. Available online: http://ftp.cordis.europa.eu/pub/citizens/docs/ hantrais_report_en.pdf (accessed on 6 December 2014).

2. Gosta Esping-Andersen. Los tres Mundos del Estado del Bienestar. Valencia: Edicions Alfons el Magnánim-IVEI, 1993. (In Spanish)

3. Guillermo Sunkel. El Papel de la Familia en la Protección Social en América Latina. Santiago de Chile: ECLAC, 2006. (In Spanish)

4. Sonia Fleury, and Carlos Gerardo Molina. "Modelos de protección social." Available online: http://www.researchgate.net/profile/Sonia_Fleury/publication/242115612_MODELOS_DE_P ROTECCION_SOCIAL/links/543bd2880cf204cab1db3b4d.pdf (accessed on 6 February 2015).

5. Joseph E. Stiglitz. "More instruments and broader goals: Moving toward the post-Washington consensus." Available online: https://inef.uni-due.de/PolitikOn/Stiglitz.pdf (accessed on 9 December 2014).

6. Rubén Lo Vuolo, Alberto Barbeito, Laura Pautassi, and Corina Rodríguez. La Pobreza... de la Política contra la Pobreza. Buenos Aires: Ciepp/Miño y Dávila, 1999. (In Spanish)

7. Nora Britos, and Rubén Caro. "Workfare: Sufrimiento social y disciplinamiento laboral." Paper presented at Congreso Nacional de Políticas Sociales: Estrategias de Articulación de Políticas, Programas y Proyectos Sociales en Argentina, Universidad Nacional de Quilmes, Buenos Aires, Argentina, May 2002.

8. Cristina González, Nora Britos, and Rubén Caro. "Las políticas de combate a la pobreza del Post-Consenso de Washington: ¿Un nuevo rostro para la asistencia?” Paper presented at Primer Foro Universitario de Investigación e Intervención Social, Escuela de Trabajo Social-Escuela de Ciencias de la Información, Universidad Nacional de Córdoba, Córdoba, Argentina, September 2006. 
9. Cristina González. "Familia, ciudadanía y políticas públicas: El caso de las políticas asistenciales." In Familia(s), Estallido, Puente y Diversidad: Una Mirada Transdiciplinaria de Derechos Humanos. Edited by Carlos Eroles. Buenos Aires: Espacio Editorial, 2006, pp. 205-17. (In Spanish)

10. Cristina González, Nelly Nucci, Alicia Soldevilla, Rossana Crosetto, Luis Eduardo Ortolanis, Ana María Miani, and Sabrina Bermúdez. "La familia como objeto de las políticas asistenciales: Los programas de combate a la pobreza y el papel de los organismos multilaterals." In Trabajo Social, Estado y Sociedad. Edited by Nora Aquín. Buenos Aires: Espacio Editorial, 2008, pp. 53-78. (In Spanish)

11. Alicia Bárcena. "Sesión inaugural." In Cambio de las Familias en el Marco de las Transformaciones Globales: Necesidad de Politicas Públicas Eficaces. Edited by Irma Arriagada and Verónica Aranda. Santiago de Chile: CEPAL, 2004, pp. 9-13. (In Spanish)

12. Pablo Villatoro. "Comentarios." In Políticas Hacia las Familias, Protección e Inclusión Sociales. Edited by Irma Arriagada. Santiago de Chile: United Nations Publications, 2005, vol. 46, pp. 275-78. (In Spanish)

13. Mercedes González de la Rocha. "Familia y Política Social en MÉXICO. El Caso de Oportunidades." In Politicas Hacia las Familias, Protección e Inclusión Sociales. Edited by Irma Arriagada. Santiago de Chile: United Nations Publications, 2005, vol. 46, pp. 245-74. (In Spanish)

14. Ariel Fiszbein, Norbert Schady, Francisco H. G. Ferreira, Margaret Grosh, Nial Kelleher, Pedro Olinto, and Emmanuel Skoufias. Conditional Cash Transfers: Reducing Present and Future Poverty. Washington: World Bank Publications, 2009.

15. Victoria Pereyra Iraola. Rendición de Cuentas y Programas Sociales: Los Programas de Transferencias Condicionadas en América Latina, 1st ed. Buenos Aires: Fundación CIPPEC, 2010. (In Spanish)

16. Simone Cecchini, Fernando Filgueira, and Claudia Robles. Social Protection Systems in Latin America and the Caribbean: A Comparative View. Santiago de Chile: ECLAC, 2014.

17. Fabián Repetto. "Protección social en América Latina: La búsqueda de una integralidad con enfoque de derechos." Revista del CLAD 47 (2010): 1-24. Available online: http://old.clad.org/portal/publicaciones-del-clad/revista-clad-reforma-democracia/articulos/047junio-2010 (accessed on 6 February 2015).

18. International Organization of Labor (ILO). "Social Protection Floors for Social Justice and a Fair Globalization." 2012. Available online: http://www.ilo.org/wcmsp5/groups/public/ @ed_norm/@relconf/documents/meetingdocument/wcms_160210.pdf (accessed on 3 February 2015).

19. Economic Commission for Latin America and the Caribbean (ECLAC). "La Hora de la Igualdad. Brechas por Cerrar, Caminos por Abrir. Trigésimo Tercer Período de Sesiones de la CEPAL." Available online: http://www.cepal.org/es/publicaciones/13309-la-hora-de-la-igualdad-brechaspor-cerrar-caminos-por-abrir-trigesimo-tercer (accessed on 6 February 2015). 
20. Camila Arza, and Florencia Chahbenderian. "Pensiones básicas en América Latina. Diseño, cobertura y beneficios comparados en Argentina, Brasil, Bolivia y Chile.” Documentos de Trabajo CIEPP, No. 89, Centro Interdisciplinario para el Estudio de Políticas Públicas, Buenos Aires, Argentina, April 2014.

21. Claudia Danani, and Alejandra Beccaria. "La (contra)reforma previsional argentina 2004-2008: Aspectos institucionales y político-culturales del proceso de transformación de la protección." In Protecciones y Desprotecciones: La Seguridad Social en Argentina 1990-2010. Edited by Claudia Danani and Susana Hintze. Los Polvorines: Universidad Nacional General Sarmiento, 2011, pp. 103-51. (In Spanish)

22. Carmelo Mesa-Lago. "Protección social en Chile: Reformas para Mejorar la Equidad." Revista Internacional del Trabajo 127 (2008): 421-46.

23. Fabio Bertranou, Oscar Centrángolo, Carlos Grushka, and Luis Casanova. Encrucijadas en la Seguridad Social Argentina: Reformas, Cobertura y Desafios para el Sistema de Pensiones, 1st ed. Buenos Aires: CEPAL y Oficina Internacional del Trabajo, 2011. (In Spanish)

24. Chile Atiende. "Subsidio Familiar (SUF)." Available online: http://www.chileatiende.cl/fichas/ ver/33112 (accessed on 3 December 2014).

25. Chile Solidario. “¿Qué es Chile Solidario?” Available online: http://www.chilesolidario.gob.cl/ sist/sist1.php (accessed on 3 December 2014).

26. UNESCO. "Early Childhod Care and Education Latin America and the Caribbean." Report prepared for the World Conference on Early Childhood, Care and Education, Moscow, Russia, September 2010.

27. Marcelo Cabrol, and Miguel Székely, eds. Educación Para la Transformación. Washington: BID, 2012. Available online: http://www10.iadb.org/intal/intalcdi/PE/2013/11771.pdf (accessed on 24 January 2015). (In Spanish)

28. Maria Caridad Araujo, Florencia López-Boo, and Manuela Puyana. Panorama Sobre los Servicios de Desarrollo Infantil en América Latina y el Caribe. Washington: BID, 2013. Available online: http://cippec.org/mapeal/wp-content/uploads/2014/06/BID-Panorama-sobrelos-servicios-de-desarrollo-infantil.pdf (accessed on 24 January 2015). (In Spanish)

29. Andrea Tokman. "Compromisos y resultados en la primera infancia: Progresos y obstáculos." Documentos de Trabajo No 13, Facultad de Economía y Empresas, Universidad Diego Portales, Santiago de Chile, Chile, 2010. (In Spanish)

30. Laura Pautassi, and María Nieves Rico. "Childcare leave: A right of children and parents." Challenges 12 (2011): 4-9. Available online: http://www.unicef.org/lac/challenges_12_eclacunicef.pdf (accessed on 6 February 2015).

31. Economic Commission for Latin America and the Caribbean (ECLAC). “QQué Estado para qué igualdad?" Paper presented at XI Conferencia Regional sobre la Mujer de América Latina y el Caribe, Brasilia, Brazil, July 2010. 
32. Débora Lopreite. “¿Las mujeres y los niños primero? Nuevas estrategias de inversión social en América Latina.” Nueva Sociedad 239 (2012): 122-36. Available online: http://www.nuso.org/ revista.php? $\mathrm{n}=239$ (accessed on 6 February 2015).

33. Economic Commission for Latin America and the Caribbean (ECLAC). Social Panorama of Latin America 2009. Santiago de Chile: United Nations Publication, 2010. 

MDPI AG

Klybeckstrasse 64

4057 Basel, Switzerland

Tel. +41616837734

Fax +41 613028918

http://www.mdpi.com/

Social Sciences Editorial Office

E-mail: socsci@mdpi.com

http://www.mdpi.com/journal/socsci 


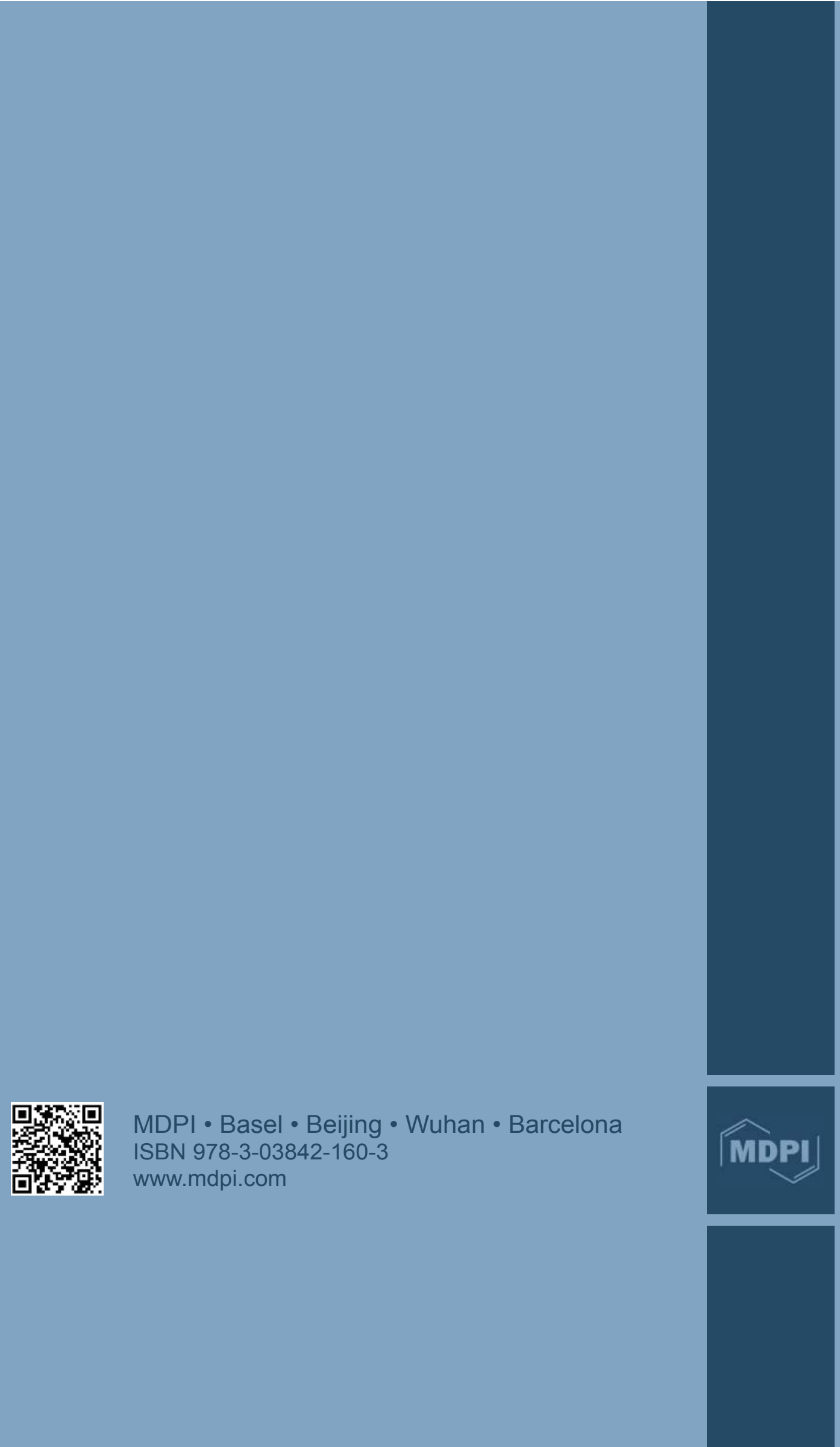